\title{
Examination of Novel Cardiac Mechanisms Influencing Mitochondrial Proteomes during Diabetes Mellitus
}

Walter Baseler

West Virginia University

Follow this and additional works at: https://researchrepository.wvu.edu/etd

\section{Recommended Citation}

Baseler, Walter, "Examination of Novel Cardiac Mechanisms Influencing Mitochondrial Proteomes during Diabetes Mellitus" (2012). Graduate Theses, Dissertations, and Problem Reports. 4830.

https://researchrepository.wvu.edu/etd/4830

This Dissertation is protected by copyright and/or related rights. It has been brought to you by the The Research Repository @ WVU with permission from the rights-holder(s). You are free to use this Dissertation in any way that is permitted by the copyright and related rights legislation that applies to your use. For other uses you must obtain permission from the rights-holder(s) directly, unless additional rights are indicated by a Creative Commons license in the record and/ or on the work itself. This Dissertation has been accepted for inclusion in WVU Graduate Theses, Dissertations, and Problem Reports collection by an authorized administrator of The Research Repository @ WVU.

For more information, please contact researchrepository@mail.wvu.edu. 


\title{
Examination of Novel Cardiac Mechanisms Influencing Mitochondrial Proteomes during Diabetes Mellitus
}

\author{
Walter Baseler
}

Dissertation submitted to the School of Medicine at West Virginia University in partial fulfillment of the requirements for the degree of

Doctor of Philosophy in Exercise Physiology

John M. Hollander, Ph.D., Chair Stephen E. Alway, Ph.D. Emidio E. Pistilli, Ph.D. Robert W. Brock, Ph.D. Kathleen M. Brundage, Ph.D. Division of Exercise Physiology Morgantown, West Virginia 2012

Key Words: Diabetes, Mitochondria, Import, microRNA Copyright 2012 Walter Basler 


\title{
ABSTRACT \\ Examination of Novel Cardiac Mechanisms Influencing Mitochondrial Proteomes during Diabetes Mellitus
}

\author{
Walter A. Baseler
}

Cardiac complications, including diabetic cardiomyopathy, are the leading cause of morbidity and mortality within diabetes mellitus. Mitochondrial dysfunction has been suggested as an underlying factor in the initiation and progression of the pathology. Cardiac mitochondria are characterized as two spatially distinct subpopulations within the myocyte including mitochondria located beneath the sarcolemma, termed subsarcolemmal mitochondria (SSM), and those located between myofibrils, termed interfibrillar mitochondria (IFM). Mitochondrial subpopulations have been shown to respond differently to physiological and pathological stimuli with the IFM being the most impacted in a type 1 diabetic setting. Proteomic evaluations within various models of diabetes have highlighted dynamic alterations of the mitochondrial proteome as a consequence of the pathology. To date, no studies have identified how the proteomes of mitochondrial subpopulations are differentially impacted during a type 1 diabetic insult. Further, the mechanisms involved in diabetes-driven mitochondrial proteomic alterations remain limited. Therefore, the goal of the present studies was to determine whether subpopulation-specific proteomes were altered with type 1 diabetes mellitus. Further, we sought to identify mechanisms involved in mitochondrial proteomic dysregulation prevalent within diabetic cardiomyopathy. Type 1 diabetes mellitus was induced in 8 week old mice with multiple low dose $(50 \mathrm{mg} / \mathrm{kg})$ injections of streptozotocin (STZ) administered for 5 days. Five weeks post hyperglycemic onset, hearts were excised and mitochondrial subpopulations were isolated. Proteomic analyses revealed that the proteome of diabetic IFM was significantly dysregulated compared to control with no changes within diabetic SSM compared to control. Further, nuclear-encoded mitochondrial protein import was significantly decreased in the diabetic IFM, which correlated with decreased abundance of essential protein import constituent mitochondrial heat shock protein 70 (MtHsp70). Because greater than 99\% of proteins are of nuclear encoded origin and must be imported into the mitochondria, decrements to the import process may prove to be a novel mechanism of dysfunction within the diabetic IFM. The inner mitochondrial membrane (IMM), the location of essential mitochondrial complexes including import translocases of the inner membrane (TIM), has been shown to be particularly prone to diabetes induced oxidative damage. Reduction in oxidative damage within various pathologies has been shown to have beneficial effects upon mitochondrial functionality. Therefore, we overexpressed antioxidant mitochondrial phospholipid hydroperoxide glutathione peroxidase (mPHGPx) to assess its impact upon the mitochondrial import process and proteomic makeup during a diabetic insult. 
Remarkably, nuclear-encoded mitochondrial protein import was corrected within the diabetic mPHGPx IFM, which correlated with restitution of a large proportion of mitochondrial proteins negatively impacted by diabetes mellitus including those involved in oxidative phosphorylation, the tricarboxylic acid cycle, fatty acid oxidation, and mitochondrial protein import. MPHGPx is capable of scavenging mitochondrial lipid hydroperoxides specifically in mitochondrial membranes and hydrogen peroxide to a lesser extent. Overexpression of the antioxidant preserved or enhanced the protein content of essential mitochondrial import constituents translocase of the outer membrane 20 (Tom20), Tim23, Tim50, and MtHsp70 in mPHGPX diabetic IFM. Therefore, we believe proteomic correction within mPHGPx diabetic IFM may be a consequence of preservation of mitochondrial protein import machinery. These findings support the rationale for the use of mPHGPx as a mitochondrial-targeted therapeutic capable of protection in the diabetic heart. Additional mechanisms of mitochondrial proteomic dysregulation within diabetes mellitus may exist including alterations to the transcriptional/translational regulators, microRNAs (miRNAs). Therefore, we performed a broad scale miRNA analysis on control and STZ-treated mouse hearts 5 weeks post diabetic onset to determine the effect of diabetes mellitus on miRNA modulation. Twenty nine miRNAs were shown to be dysregulated within the diabetic heart including miRNA-141 (miR-141), which was enhanced by 5 fold. miRNA targeting analyses (targetscan.org) revealed miR-141 likely to regulated Slc25a3, the mitochondrial inorganic phosphate carrier. Slc25a3 is essential for ATP production as it acts as conduit for inorganic phosphate to pass from the cytoplasm into the matrix, providing phosphate to fuel the ATP synthase. IFM Slc25a3 protein content was decreased in the diabetic IFM, which correlated with decreased ATP synthesis rates. Similarly, overexpression of miR-141 decreased Slc25a3 protein content and ATP synthase activity within HEK293 cells. These findings show, for the first time, miRNA modulation within diabetes mellitus has a direct impact upon mitochondrial proteomic makeup as well as mitochondrial functionality. Further, miR-141 ablation may provide a protective benefit to mitochondria and subsequent cardiac function during a type 1 diabetic insult. Taken together, the studies highlighted above prove that mitochondrial proteomic dysregulation prevalent within diabetes mellitus is a complicated process involving spatially distinct mitochondrial subpopulations and multiple mechanisms of action. Targeted therapeutics aimed at the correction of one or more of these mechanisms may provide cardiac benefit from diabetic induced dysfunction via preservation of the mitochondrial proteome. 


\begin{abstract}
AKNOWLEDGEMENTS
First and foremost, I'd like to acknowledge my advisor Dr. John Hollander for his unparalleled support and guidance throughout my tenure at West Virginia University. In what must have been a difficult decision, he decided to take a chance on a struggling graduate student coming from an entirely different department than his own. I distinctly remember that within the first hour of us meeting, I was given a project and a key to the laboratory. I truly believe the trust Dr. Hollander exhibited that day provided me with confidence I needed to be successful within my graduate career. Thank you for being an excellent mentor, colleague, and friend. Additionally, I'd like to thank the members of my committee including Dr. Steve Alway, Dr. Robert Brock, Dr. Michael Morissette, Dr. Kathy Brundage, and Dr. Emidio Pistilli for their critical input and suggestions pertaining to my research.
\end{abstract}

I would also like to thank past and present members of the Hollander lab, including Dr. Erinne Dabkowski, who was the primary catalyst for a fast acclimation to the laboratory by answering literally hundreds of questions I had pertaining to the research. I'd also like to personally thank Courtney Williamson, Tara Croston, Dharendra Thapa, Cody Nichols, Danielle Shepherd, Dr. Rajaganapathi Jagannathan and Sara Lewis for all of their support pertaining to my project. Working with these fellow students and co-workers made coming into work a real pleasure. Further, I would like to thank the Exercise Physiology Department faculty and staff not yet mentioned for their contributions to my research presented in the dissertation.

I would like to acknowledge the Microbiology, Immunology, and Cell Biology Department at West Virginia University. Most specifically, I'd like to thank Dr. John Barnett, Dr. Chris Cuff, and Dr. Rosana Schafer for their guidance, which went far beyond scholastics.

I would like to thank Dr. Jamal Mustafa, Dr. Richard Dey and the entire Cardiovascular and Pulmonary T32 committee. I was truly honored to be selected as a member of this prestigious training grant and I can only hope my future scientific research merits such a selection.

Finally, I'd like to thank my family for their unwavering support throughout my graduate career. I am eternally grateful for these loved ones who always had faith in me, even in times when I didn't have faith in myself. For that, I am truly blessed. 


\section{LIST OF ABBREVIATIONS}

\begin{tabular}{|c|c|}
\hline ADP & Adenosine Diphosphate \\
\hline AGE & Advanced Glycation Endproducts \\
\hline AGO & Argonaute \\
\hline ALDH-2 & Aldehyde Dehydrognase-2 \\
\hline ANT & Adenine Nucleotide Transporter \\
\hline ATP & Adenosine Triphosphate \\
\hline ATP5A1 & ATP Synthase Alpha \\
\hline ATP5B & ATP Synthase Beta \\
\hline BSA & Bovine Serum Albumin \\
\hline CAD & Coronary Artery Disease \\
\hline CuZnSOD & Copper Zinc Superoxide Dismutase \\
\hline DIGE & Difference Gel Electrophoresis \\
\hline $\mathrm{DM}$ & Diabetes Mellitus \\
\hline EDP & End Diastolic Pressure \\
\hline ET-1 & Endothelin-1 \\
\hline ETC & Electron Transport Chain \\
\hline FAO & Fatty Acid Oxidation \\
\hline GFP & Green Fluorescent Protein \\
\hline GPx & Glutathione Peroxidase \\
\hline GSH & Reduced Glutathione \\
\hline HSP & Heat Shock Protein \\
\hline
\end{tabular}




\begin{tabular}{|c|c|}
\hline$I / R$ & Ischemia/Reperfusion \\
\hline IFM & Interfibrillar Mitochondria \\
\hline IMM & Inner Mitochondrial Membrane \\
\hline iTRAQ & Isobaric Tag for Relative and Absolute Quantitation \\
\hline $\mathrm{LC}$ & Liquid Chromatography \\
\hline LV & Left Venticular \\
\hline MALDI & Matrix-assisted Laser desorption/ionization \\
\hline MHC & Myosin Heavy Chain \\
\hline miRNA & Micro-RNA \\
\hline MnSOD & Manganese Superoxide Dismutase \\
\hline MPHGPx & Mitochondrial Phospholipid Hydroperoxide Glutathione Peroxidase \\
\hline MPP & Matrix Processing Peptidase \\
\hline МРТP & Mitochondrial Permeability Transition Pore \\
\hline MS & Mass Spectrometry \\
\hline MSF-L & Mitochondrial Like Stimulating Factor \\
\hline MtHsp70 & Mitochondrial Heat Shock Protein 70 \\
\hline MuDPIT & Multidimensional Protein Identification Technology \\
\hline OMM & Outer Mitochondrial Membrane \\
\hline OX PHOS & Oxidative Phosphorylation \\
\hline OXA1 & Oxidase Assembly 1 \\
\hline PAGE & Polyacrylamide Gel Electrophoresis \\
\hline PAM & Presequence Translocase-associated Motor \\
\hline PCR & Polymerase Chain Reaction \\
\hline
\end{tabular}




$\begin{array}{ll}\text { PTM } & \text { Post Translational Modifications } \\ \text { RISC } & \text { RNA Induced Silencing Complex } \\ \text { ROS } & \text { Reactive Oxygen Specie } \\ \text { SCX } & \text { Strong Cation Exchange } \\ \text { SLC25A3 } & \text { Solute Carrier 25A3 } \\ \text { SOD } & \text { Superoxide Dismutase } \\ \text { SSM } & \text { Subsarcolemmal Mitochondria } \\ \text { STZ } & \text { Streptozotocin } \\ \text { T1DM } & \text { Type 1 Diabetes Mellitus } \\ \text { TCA } & \text { Tricarboxylic Acid Cycle } \\ \text { TG } & \text { Transgenic } \\ \text { TIM } & \text { Translocase of the Inner Membrane } \\ \text { TOF } & \text { Time of Flight } \\ \text { TOM } & \text { Translocase of the Outer Membrane } \\ \text { VDAC } & \text { Voltage Dependent Anion Channel } \\ \text { WT } & \text { Wild Type } \\ \Delta \Psi m & \text { Membrane Potential }\end{array}$




\section{TABLE OF CONTENTS}

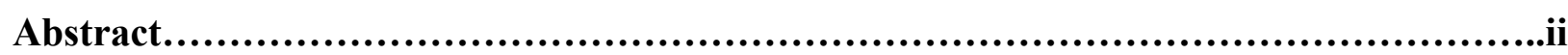

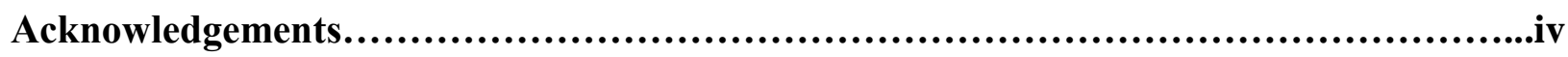

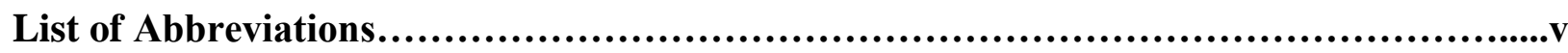

Table of Content .............................................................................iii

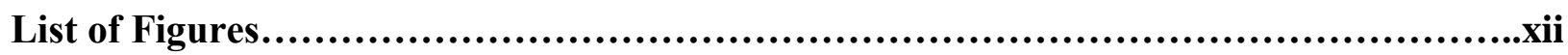

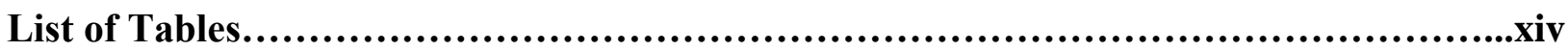

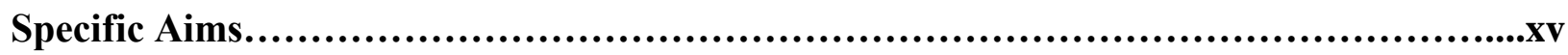

Chapter 1. Background and Significance....................................................1

1.1 Diabetes Mellitus............................................................

a. $\quad$ Type 1 diabetes mellitus ..........................................

b. Significance...............................................................

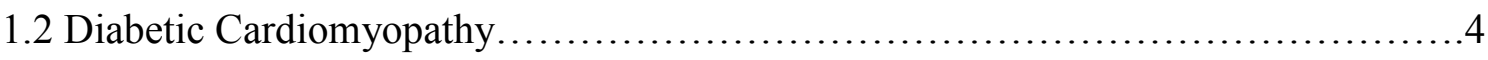

a. Cardiac contractile dysfunction................................... 4

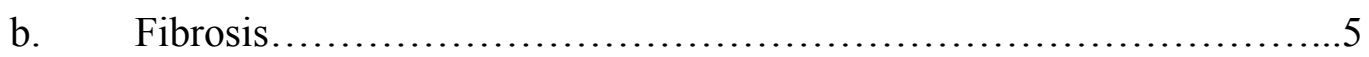

c. Oxidative Stress................................................ 6

1.3 STZ Model of Diabetic Cardiomyopathy....................................6



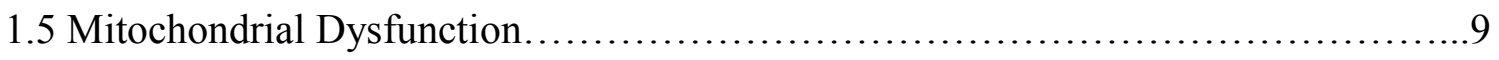

a. Mitochondrial dysfunction and oxidative stress......................9

b. Mitochondrial dysfunction and calcium handling......................10

c. Mitochondrial dysfunction and proteomic remodeling.................11

1.6 Mitochondrial Protein Import............................................... 12 
a. Outer membrane protein import.................................13

b. Inner membrane protein import..................................13

c. Presequence-associated motor complex.........................15

d. Brownian ratchet versus power stroke model........................17

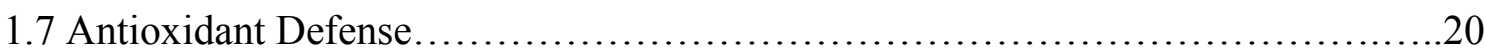

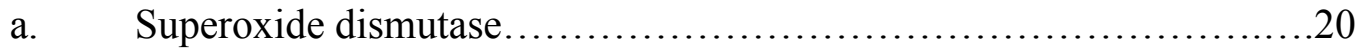

b. Glutathione peroxidase......................................21

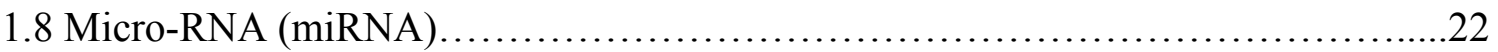

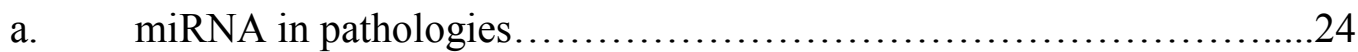

b. Circulating miRNAs......................................... 25

c. miRNA within the heart........................................26

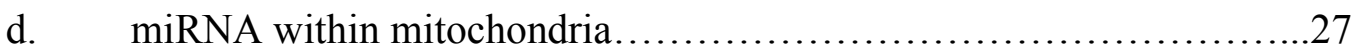

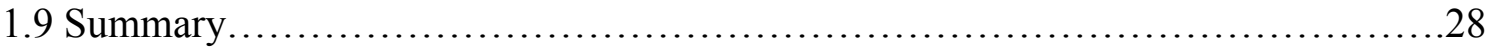

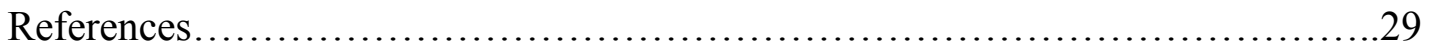

Chapter 2. Proteomic alteration of distinct mitochondrial subpopulations in the type

1 diabetic heart: contribution of protein import dysfunction............................49

2.1 Abstract.................................................................. 50

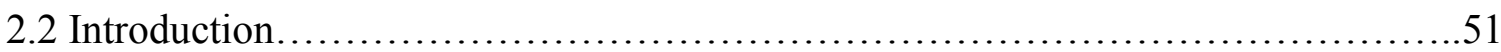

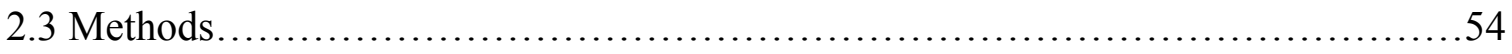

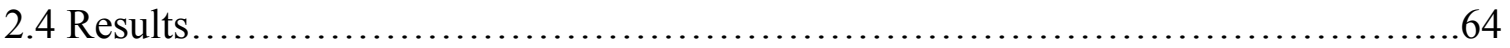

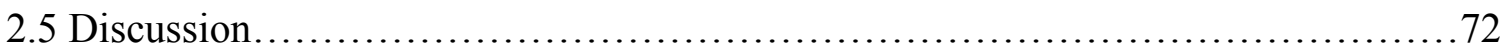

2.6 Perspectives and Significance.......................................... 79 


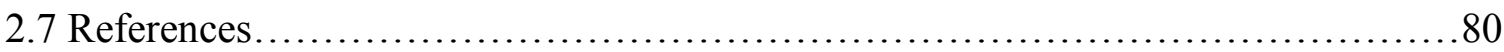

2.8 Figures and figure legends.................................................... 86

2.9 Tables and table legends................................................. 100

Chapter 3. Mitochondria-specific transgenic overexpression of phospholipid hydroperoxide glutathione peroxidase (GPx4) attenuates cardiac mitochondrial proteomic loss and reverses protein import detriments observed with type 1 diabetes mellitus..................113

3.1 Abstract.................................................................. 114



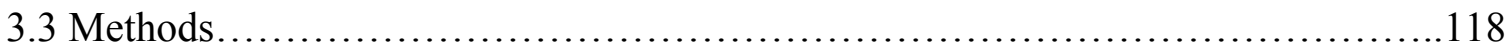

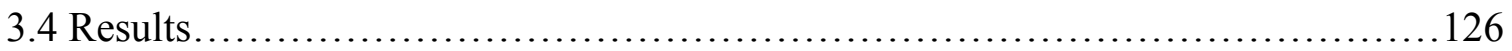

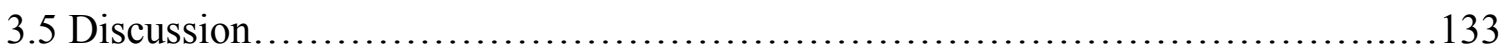

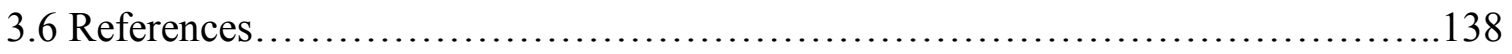

3.7 Figures and figure legends.................................................. 144

3.8 Tables and table legends.................................................. 156

Chapter 4. miRNA-141 is a potential regulator of mitochondrial phosphate carrier

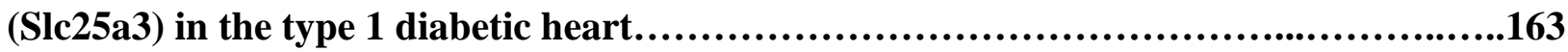

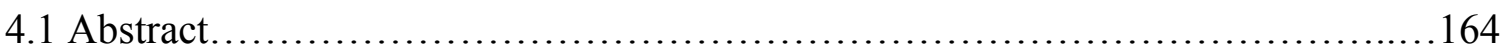

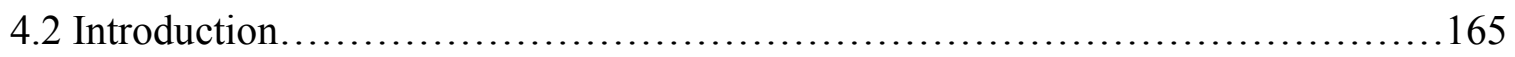



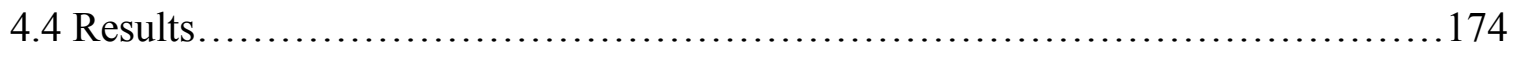

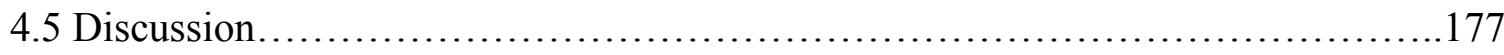


4.6 References........................................................ 181

4.7 Figures and figure legends............................................ 186

Chapter 5. General Discussion.......................................................200

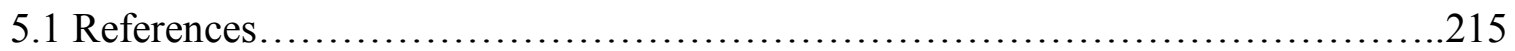

Chapter 6 Future Directions............................................................221

6.1 References........................................................... 230

Chapter 7 Appendix...................................................................231

Permission to reproduce copyrighted materials..............................................240

Curriculum Vitae...................................................................242 


\section{LIST OF FIGURES}

\section{Chapter 1}

1.1 Mitochondrial subpopulations........................................... 8

1.2 Mitochondrial import of matrix-targeted precursor proteins.......................14

1.3 Power stroke verse brownian ratchet models................................. 19

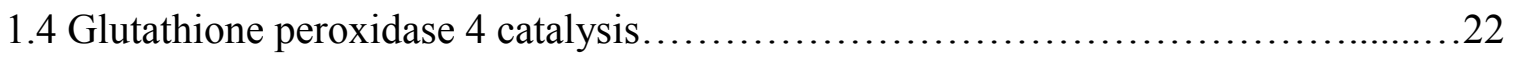

1.5 miRNA biogenesis and function......................................... 24

\section{Chapter 2}

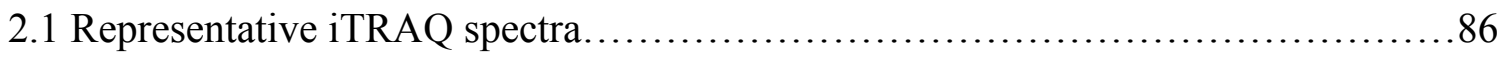

2.2 Representative 2D-DIGE gels........................................ 88

2.3 MITOGFP1 construct.................................................90

2.4 MITOGFP1 protein import............................................92

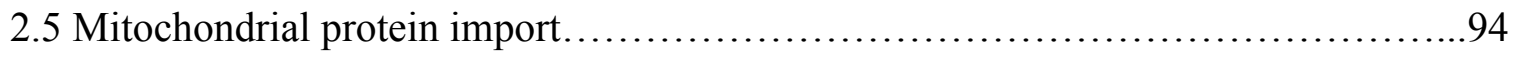

2.6 Western blot analysis of protein import constituents..........................96

2.7 Mitochondrial subpopulation membrane potential...........................98

\section{Chapter 3}

3.1 Proteomic alterations in diabetic and mPHPGx diabetic IFM................... 144

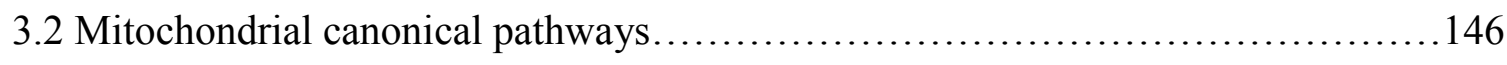

3.3 Mitochondrial protein networks ........................................ 148

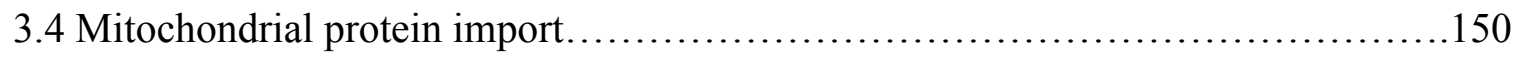

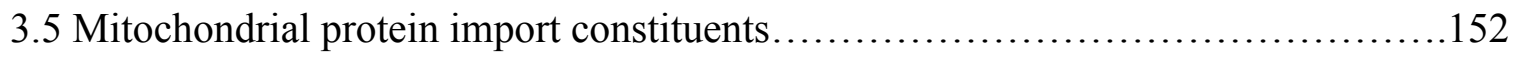




\section{Chapter 4}

4.1 miRNA regulation in type 1 diabetic heart................................... 186

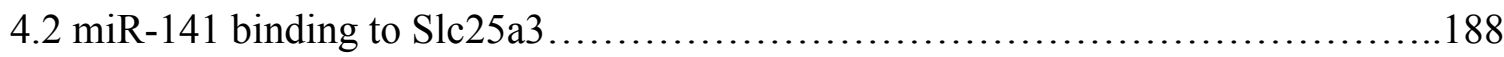

4.3 miR-141 binding to Slc25a3 3' UTR target sequence..............................190

4.4 Slc25a3 expression levels.................................................... 192

4.5 Mitochondrial subpopulation ATP synthase activity.............................194

4.6 miR-141 overexpression..................................................... 196

4.7 miRNA-141 overexpression on ATP synthase activity ...........................198

\section{Chapter 6}

6.1 Mitochondrial protein import into the OMM, IMM, and Matrix...................223

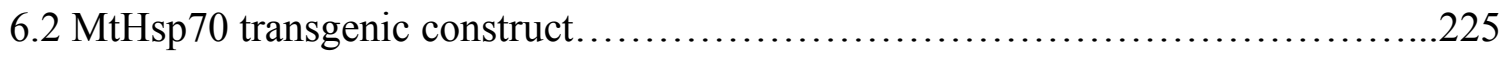

6.3 Mitochondrial miRNAs impacted by diabetes mellitus...........................227

6.4 Mitochondrial miRNAs and their impact on the mitochondrial genome............228

\section{Chapter 7}

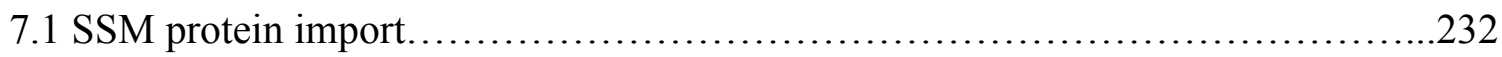

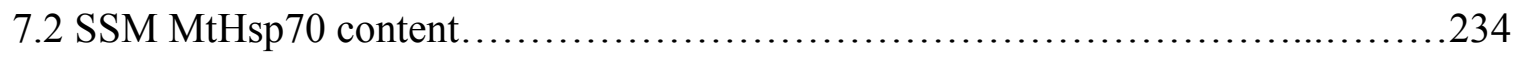








\section{LIST OF TABLES}

\section{Chapter 2}

2.1 iTRAQ proteomic analysis of mitochondrial subpopulations from control and diabetic hearts.

2.2 2D-DIGE proteomic analysis of mitochondrial subpopulations from control and diabetic hearts.

2.3 Post-translational modifications (PTM) in mitochondrial subpopulations from control and diabetic hearts

2.4 Relative gene expression compared to IFM protein expression from control and diabetic hearts.

\section{Chapter 3}

3.1 iTRAQ Proteomic analysis of mitochondrial subpopulations from control, diabetic, and mPHGPx diabetic IFM.

3.2 Posttranslational modifications (PTM) present within diabetic IFM and reversed within mPHGPX diabetic IFM.

\section{Chapter 5}

5.1 Mechanisms involved in IFM proteomic dysregulation in a diabetic setting. 


\section{SPECIFIC AIMS}

Diabetic cardiomyopathy is the primary cause of heart failure in diabetes mellitus occurring independent of vascular pathogenesis. It is characterized by contractile dysfunction leading to an increased risk of heart failure. The hyperglycemic environment resulting from diabetes mellitus has been shown to be associated with mitochondrial dysfunction (2). Mitochondrial examinations are complicated by the fact that there are two mitochondrial subpopulations existing in the cardiomyocyte (3). The mitochondria are spatially distinct with the interfibrillar mitochondria (IFM) residing between myofibrils and the subsarcolemmal mitochondria (SSM) beneath the plasma membrane. Nuclear encoded mitochondrial proteins, which make up $99 \%$ of the organelle's proteome, are translated in the cytoplasm and must be imported into the mitochondria by a complex mechanism involving coordination between the outer and inner mitochondrial membranes $(4,6)$. Recent proteomic analyses indicate decreased abundance of nuclear encoded proteins during a diabetic insult, including those essential for efficient mitochondrial import processes $(1,7)$. Prior to this dissertation, mitochondrial protein import efficiency had not been studied in a pathology such as diabetes mellitus. Specifically, it

was unknown whether diabetes mellitus could cause cardiac mitochondrial protein import decrements and whether this is was mechanism of dysfunction in one or both mitochondrial subpopulations.

Our long term goal is to better understand the mechanisms involved in the pathogenesis of diabetic cardiomyopathy as a prerequisite to the development of therapeutic interventions designed to lessen cardiac complications associated with diabetes mellitus. The objective of this 
dissertation was to: (1) to determine the effect of diabetic insult upon nuclear encoded protein import in mitochondria and identify key structural and functional differences seen in specific mitochondrial subpopulations; (2) to test the therapeutic benefit of overexpressing mitochondrial specific antioxidant mPHGPx on protein translocation into individual mitochondrial subpopulations during a diabetic insult; (3) to evaluate the effect of diabetes induced microRNA (miRNA) modulation upon mitochondrial proteomic make-up.

The central hypothesis of the dissertation was that type 1 diabetic insult would cause dysfunction of the mitochondrial protein import process, leading to a loss of key proteins required for adequate mitochondrial function and structure. These effects being most pronounced in the IFM, influencing cardiac contractile processes. The central hypothesis was based upon preliminary data produced in our laboratory indicating that cardiac mitochondria have decreased efficiency to import proteins following a diabetic insult. Our rationale for the proposed research was based upon the notion that the understanding of mitochondrial subpopulation response and identification of key factors that contribute to mitochondrial dysfunction would aid in the development of therapeutics that can address specific mitochondrial subpopulations at greatest risk from diabetes. We tested our central hypothesis by pursuing the following Specific Aims:

Specific Aim I: Determine the effect of type 1 diabetes insult on the mitochondrial protein import process and the presence of constituents involved in the import process. Further, determine whether these effects are mitochondrial subpopulation-specific in response. 
To address Specific Aim I, we utilized a novel methodology in which a mitochondrial targeted protein was used to assess potential import deficiencies during a diabetic insult. Additionally, constituents involved in the mitochondrial protein import process as well as functional and structural parameters were analyzed. Our working hypothesis was that type 1 diabetic insult would be associated with dysfunction of the mitochondrial protein import process, as evidence by a decreased efficiency of mitochondrial protein import, and loss of key import process constituents. Further these effects were most pronounced in the IFM.

\section{Specific Aim II: Evaluate the therapeutic potential of enhanced mPHGPx on the mitochondrial protein import process and mitochondrial proteome, following type 1 diabetic insult. Further, determine whether the effects of mPHGPx enhancement are mitochondrial subpopulation-specific in nature.}

mPHGPX is a unique antioxidant that has the ability to reduce peroxidized acyl groups in phospholipids, fatty acid hydroperoxides, and cholesterol peroxides within subcellular membranes $(5,8)$. Previous work from our laboratory has shown overexpression of mPHGPx to preserve mitochondrial inner membrane structure, decrease lipid peroxidations, and enhance ATP production in diabetic IFM subpopulation. Overexpression of mPHGPx was employed to assess proteomic dysregulation, post translational modifications, and protein import efficiency during diabetic insult. Our working hypothesis was that enhanced mPHGPx content would lead to restitution of the mitochondrial protein import process and prevention of mitochondrial dysfunction associated with diabetic cardiomyopathy by reversing changes in proteomic loss including proteins essential for mitochondrial structure and function. Further, these effects were shown to be most pronounced in the IFM. 


\section{Specific Aim III: Determine the effect of type 1 diabetes insult on miRNA regulation within the diabetic heart. Further, evaluate how alterations in miRNA presence influences essential proteins involved in mitochondrial function and structure.}

To address aim III we performed a broad scale miRNA screening within the heart following type 1 diabetic insult to elucidate the effect of the pathology on miRNA modulation. The most relevant miRNAs, specifically miR-141, were further examined to determine their impact on essential mitochondrial processes. Our working hypothesis was that miRNAs governing critical mitochondrial processes, such as ATP production, would be upregulated in the diabetic heart. Further, these miRNAs negatively impacted mitochondrial functionality in a type 1 diabetic setting.

The research generated from this dissertation was innovative because it examined previously unexplored mechanisms of mitochondrial dysfunction associated with diabetes mellitus and employed the use of novel molecular techniques developed in our laboratory. At the completion of these studies, we were able to determine protein import dysregulation in mitochondrial subpopulations, highlight specific areas at risk, and evaluate the role of miRNAs during a diabetic insult. Our research concerning mPHGPx highlighted the potential therapeutic value of this critical antioxidant to the import process. Further, the outcomes enhanced our understanding of pathogenic mechanisms involved with diabetic cardiomyopathy as well as provided insight into potential therapeutic interventions that will aid in the treatment of type 1 diabetes mellitus. 


\section{REFERENCES}

1. Dabkowski ER. Quantitative proteomic analysis of distinct mitochondrial subpopulations in diabetic myocardium. FASEB J 22, 2008.

2. Flarsheim CE, Grupp IL, and Matlib MA. Mitochondrial dysfunction accompanies diastolic dysfunction in diabetic rat heart. Am J Physiol 271: H192-202, 1996.

3. Palmer JW, Tandler B, and Hoppel CL. Biochemical properties of subsarcolemmal and interfibrillar mitochondria isolated from rat cardiac muscle. J Biol Chem 252: 8731-8739, 1977.

4. Pfanner $\mathbf{N}$ and Geissler A. Versatility of the mitochondrial protein import machinery. Nat Rev Mol Cell Biol 2: 339-349, 2001.

5. Schnurr K, Belkner J, Ursini F, Schewe T, and Kuhn H. The selenoenzyme phospholipid hydroperoxide glutathione peroxidase controls the activity of the 15-lipoxygenase with complex substrates and preserves the specificity of the oxygenation products. J Biol Chem 271: 4653-4658, 1996.

6. Stojanovski D, Johnston AJ, Streimann I, Hoogenraad NJ, and Ryan MT. Import of nuclear-encoded proteins into mitochondria. Exp Physiol 88: 57-64, 2003.

7. Turko IV and Murad F. Quantitative protein profiling in heart mitochondria from diabetic rats. J Biol Chem 278: 35844-35849, 2003.

8. Ursini F, Heim S, Kiess M, Maiorino M, Roveri A, Wissing J, and Flohe L. Dual function of the selenoprotein PHGPx during sperm maturation. Science 285: 1393-1396, 1999. 


\section{Chapter 1:}

\section{Literature Review}




\section{BACKGROUND AND SIGNIFICANCE}

\subsection{Diabetes Mellitus}

Diabetes mellitus (DM) is a pathological condition that is generally classified as two forms. Type 1 diabetes, which constitutes $10 \%$ of total cases and Type 2 diabetes, which comprises $90 \%$ of cases (121). Both type 1 and type 2 diabetes, when left untreated, will lead to a hyperglycemic environment. Two lesser known types of diabetes exist including gestational diabetes, which is a complication that arises in $2-10 \%$ of all pregnancies (20). DM can also manifest from certain genetic conditions, surgeries, medications, infections, and pancreatic diseases as well, but these diagnoses account for less than $1 \%$ of total cases. Generally, DM is diagnosed when fasting blood glucose levels are above $126 \mathrm{mg}^{-\mathrm{dl}^{-1}}$ and insulin levels are less than $0.50 \mathrm{ng} / \mathrm{ml}$ (type $1 \mathrm{DM})(132)$.

\section{1a Type 1 diabetes mellitus}

Type 1 diabetes mellitus (T1DM) is characterized by the autoimmune destruction of pancreatic $\beta$-cells, severely depleting insulin levels in the body. Briefly, there are several known autoantigens present within pancreatic islet cells, which promote their destruction through a $\beta$ cell mediated mechanism including islet cell antigen, insulin and pro insulin, glutamic acid decarboxylase, and protein tyrosine phosphatase (94). T1DM is also referred to as juvenile-onset diabetes due to the majority of diagnoses occurring in children, adolescents, and young adults. The primary treatment for T1DM is regimented subcutaneous insulin injections prior to eating, allowing for proper cellular glucose transport and utilization. Severe insulin deficiency, as seen in T1DM, increases ketone body production in the liver, causing lowered blood $\mathrm{pH}$, which results in diabetic ketoacidosis, a condition known to be fatal if left untreated (29). 
Uncontrolled T1DM can cause a multitude of other ailments including heart disease, retinal detachment, renal failure due to diabetic nephropathy, nervous system damage, lower limb amputations, and periodontal disease (20). Ultimately, these effects are directly associated with the hyperglycemic environment produced by DM.

\section{1b Significance}

Cardiac failure and heart disease is the leading cause of mortality among diabetic patients in the United States (52). Currently, over 171 million people worldwide are afflicted with DM with an estimate of 366 million by $2030(113,153)$. In the United States alone, there are at least 16 million diabetics, of which over 1 million are afflicted with T1DM (30). DM is characterized as a hyperglycemic environment resulting from defects in insulin secretion or function. Chronic hyperglycemia will lead to damage, dysfunction and ultimately failure of specific organs including the kidneys, eyes, nerves, blood vessels, and heart (156). Increased oxidative damage, due to an imbalance between reactive oxygen species (ROS) and antioxidant defense, has been implicated with the onset and progression of diabetes-associated cardiac dysfunction such as diabetic cardiomyopathy. Diabetic cardiomyopathy occurs independently of vascular dysfunctions such as atherosclerosis, coronary artery disease, or hypertension and is becoming an increasingly prevalent diagnosis in heart failure (6). Diabetic cardiomyopathy affects the myocardium leading to changes in heart structure and function with symptoms ranging from cardiac hypertrophy, diastolic and systolic dysfunction, increased cardiac fibrosis, and elevated ROS levels due to increased glucose exposure $(54,69,150)$. Specifically, our laboratory and others have also shown mitochondrial dysfunction to be a component in diabetic cardiomyopathy, due to its role in ATP production for cardiac contractile function. 


\subsection{Diabetic Cardiomyopathy}

Vascular complications from diabetes such as atherosclerosis, coronary artery disease (CAD) and hypertension have been well studied (5, 57). However, cardiac dysfunction independent of vascular pathogenesis, such as diabetic cardiomyopathy, is becoming an increasingly prevalent diagnosis in heart failure (6). Clinically, Rubler at al. were the first to diagnose patients with cardiomyopathies existing in the absence of the previously mentioned vascular abnormalities (46) In a similar study, diabetic patients lacking CAD had increased left ventricular (LV) end diastolic pressure (EDP), decreased LV compliance, and decreased ejection fraction (108). Characterizing the mechanistic properties of diabetic cardiomyopathy, researchers have generally shown cardiac contractile dysfunction, enhanced fibrosis, and enhanced oxidative stress as primary causative agents ultimately leading to the dysfunction seen within the pathology (44).

\section{2 a Cardiac contractile dysfunction}

Diastolic dysfunction is the most common defect manifesting in diabetic cardiomyopathy, characterized by prolongation of relaxation and considerable slowing in relaxation velocity $(12,134)$. Thirty diabetic male rats were analyzed and compared to controls in which the diabetics showed significant decreases in early to late diastolic mitral inflow velocity ratio and isovolumic relaxation time (39). Based on the results, the group concluded diastolic dysfunction in the diabetic hearts may be related to uncoupling of the contractile apparatus without increases in chamber thickness. Further, a similar study of young T1DM subjects without known CAD demonstrated reduced early peak mitral velocity, increased late peak mitral velocity, and prolonged deceleration time and isovolumic relaxation time compared to controls (116). 
Animal studies have shown diabetic cardiomyopathy to be associated with systolic dysfunction including decreases in heart rate, systolic left ventricular blood pressure, and fractional shortening $(61,66,157)$. However, evidence of systolic dysfunction has not been uniformly reported in the literature $(87,109)$. Those who report normal LV systolic function within diabetics have also shown abnormalities during supine exercise, indicating systolic reserves may be reduced (142). It should be noted that technical limitations may be the primary cause for no alterations seen pertaining to systolic dysfunction. Advancements in technology have allowed for more sensitive assessments of strain, strain rate, and myocardial tissue Doppler velocities $(44,45)$.

\section{2b Fibrosis}

Structural changes to the diabetic myocardium have been reported, focusing on the understanding of enhanced fibrosis in the absence of CAD (10). In a study of 9 diabetic hearts post mortem in which 6 died from heart failure, Regan et al. discovered elevated levels of interstitial fibrosis within the cardiac tissue (109). Similarly, patients with mild diabetes and no symptoms of CAD showed significant increases in right ventricular myocardial cell volume and an increased percentage of interstitial fibrosis compared to controls (100). The mechanisms involved in fibrosis accumulation within the diabetic heart are not entirely understood. Widyantoro et al. found elevated levels of plasma endothelin-1 (ET-1) within the vascular endothelium of mice, which is associated with the accumulation of cardiac fibroblasts in the diabetic hearts (151). Further, increased fibrosis has been observed within the streptozotocin (STZ)-diabetic mouse heart in which it shares an association with enhanced protein kinase C beta-1 activation and decreased heart function (149). Although the mechanisms involved remain 
to be resolved, it is clear that fibrosis plays a critical role in diabetic induced cardiac dysfunction in animal and human.

\section{2c Oxidative stress}

Hyperglycemia is the primary causative agent for diabetic cardiomyopathy. ROS, such as superoxide, are major contributors to hyperglycemic induced cellular damage to the heart primarily through the increased activity of four metabolic pathways. Overproduction of superoxide causes increases in polyl pathway flux, advanced glycation end product (AGE) formation, hexosamine pathway flux and activation of protein kinase C leading to an imbalance between ROS and antioxidant defense known as oxidative stress $(13,41,99)$. Oxidative stress has been shown to alter myocyte morphology, function, protein content, and ion action leading to diabetic cardiomyopathy (13). Hyperglycemia has been suggested to decrease cellular antioxidant levels within the heart increasing the susceptibility of ROS-induced damage (114). Mitochondria are the main source of ROS generation in cardiomyocyte. Previous work from our laboratory shows STZ induced T1DM presents significantly increased levels of ROS produced from cardiac mitochondria (35).

\subsection{STZ Model of Diabetic Cardiomyopathy}

STZ, a nitrosourea derivative, was first used clinically to aid in the destruction of cancerous pancreatic $\beta$-cells in the early 1980's (1). Given the antibiotics unique propensity to target insulin-secreting islet cells, it was also successfully utilized as a method for type 1 diabetic induction within rodent models (1). Structurally, STZ mimics glucose and is able to be transported into cells specifically through transport protein GLUT2. STZ build up occurs within the pancreas because GLUT2 exists predominantly within pancreatic $\beta$-cells (148). 
Mechanistically, STZ acts as an alkylating agent capable of causing DNA damage, which in turn leads to activation of ADP-ribosylation, depleting cellular NAD+ and ATP (119). Further, STZ elicits enhanced ATP dephosphorylation leading to increased xanthine oxidase activity and elevated levels of superoxide production. Finally, increased ROS accumulation within the pancreas will inevitably cause enhanced necrosis of $\beta$-cells and decreased insulin production within the organ (119). Our laboratory performs multiple low dose intraperitoneal injections $(50 \mathrm{mg} / \mathrm{kg})$ of STZ in FVB mice, which is the recommended protocol by the Animal Models of Diabetic Complications Consortium (AMDCC). Typically, mice will develop fasting hyperglycemia $(<250 \mathrm{mg} / \mathrm{dl})$ and low levels of insulin $(0.5 \mathrm{ng} / \mathrm{ml}) 7-14$ days post STZ injection (15). Our laboratory and others have shown STZ treatment will lead to diabetic cardiomyopathy, including alterations to diastolic and systolic function $(35,97,134)$. Specifically, we have shown significant decreases in rate of relaxation and contraction as well as enhanced developed pressure within 5 week diabetic STZ-treated mice (35). A major advantage of STZ treatment is that it can be administered at any time point during rodent's lifespan and can be used on any type of genetic background including transgenic animals. Because of these aforementioned reasons, STZ is the most frequently used model of type 1 diabetes within rodent models (15).

\subsection{Mitochondrial Subpopulations}

Mitochondrial analyses are complicated primarily because two spatially distinct mitochondrial subpopulations exist in cardiac tissue, the subsarcolemmal mitochondria (SSM) and interfibrillar mitochondria (IFM). As shown in figure 1.1, SSM are located directly below the sarcolemma, have rod like morphology, are larger, and more variable in shape with sizes reaching up to $4 \mu \mathrm{m}$ (124). It has been suggested that they function to create ATP which is utilized in active transport of electrolytes and metabolites through the sarcolemma $(112,124)$. 
IFM are arranged in longitudinal rows tightly packed between myofibrils, are smaller than SSM, and elongated in size ranging up to $2 \mu \mathrm{m}$ (124). It has been suggested that IFM create ATP chiefly for the fueling of muscle contraction (112). Internal structure differs between subpopulations with lamelliform cristae in SSM and mainly tubular or mixed tubular/lamelliform in IFM (112). Tubular cristae structure decreases intracristal space leading to a higher concentration of protons within the IFM, increasing adenosine triphosphate (ATP) synthase activity, and enhancing oxidative phosphorylation. It is well established that IFM also display increased oxidative rates (1.5 fold), ATP production ( 3 fold), and nuclear encoded protein import (3 fold) when compared with the SSM $(16,104,112,131)$.

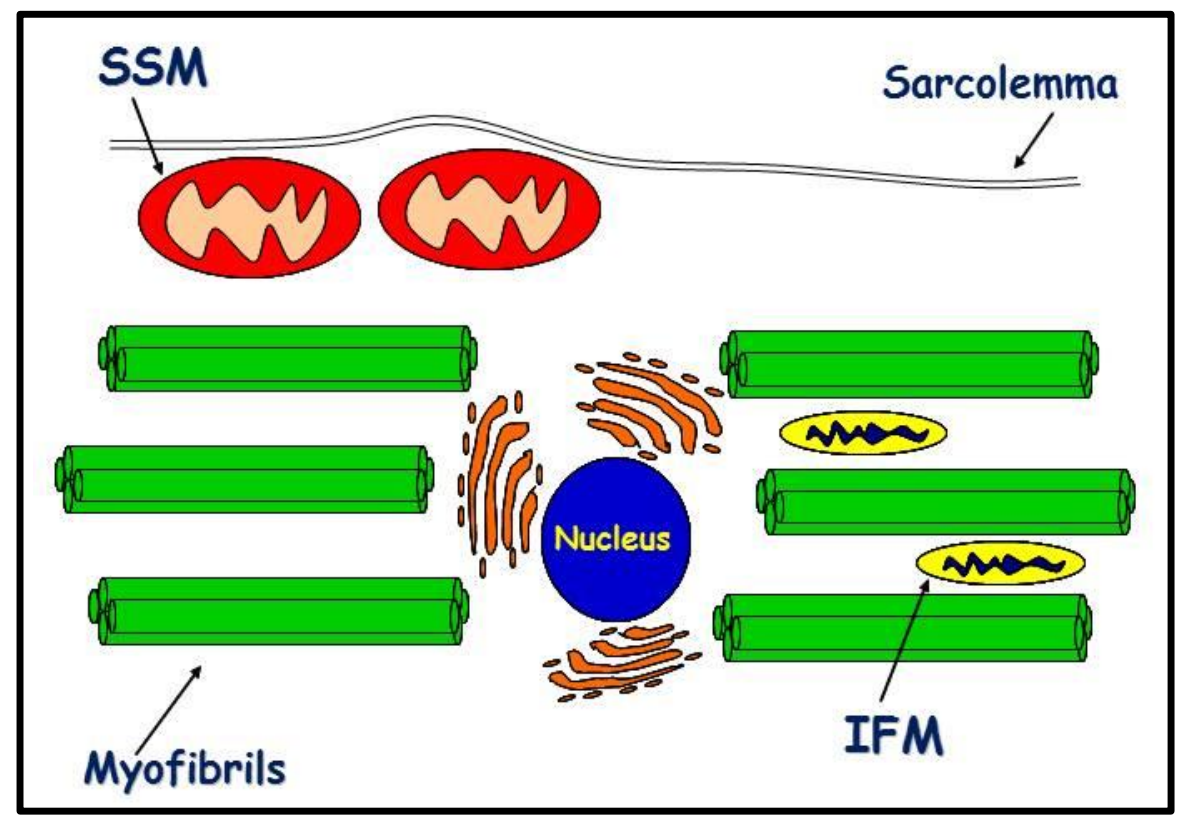

Fig 1.1 Mitochondrial Subpopulations

Investigators has shown mitochondrial subpopulations can have differing responses to physiological or pathological stimuli including aging, Ischemia/Reperfusion (I/R), and diabetes mellitus $(35,67,77,111)$. Pathological aging causes significant increases in oxidative stress levels, with elevations in manganese superoxide dismutase (MnSOD, SOD2), glutathione 
peroxidase 1 (GPX1) as well as superoxide and hydrogen peroxide, exclusively in the IFM subpopulation (67). IFM mitochondria isolated from diabetic mouse hearts have decreased respiratory function, elevated levels of superoxide, nitrotyrosine, and increased lipid peroxidation (35). Interestingly, research evaluating skeletal muscle from type 2 diabetic patients demonstrated a decreased mitochondrial respiratory function with no change evident in the IFM subpopulation (111). These results indicate that mitochondrial subpopulations respond differently to various pathological insults and locations highlighting the importance of examining the subpopulations in different muscles and pathologies.

\subsection{Mitochondrial Dysfunction}

The pathological mechanisms involving heart failure are multifactorial, however there is a multitude of data linking cardiac contractile abnormalities, as seen in diabetic cardiomyopathy to mitochondrial dysfunction $(56,133,159)$. Specifically, oxidative stress, mitochondrial calcium $\left(\mathrm{Ca}^{2+}\right)$ handling, and mitochondrial proteomic remodeling are all factors involved in mitochondrial dysfunction within the diabetic heart.

\section{5a Mitochondrial dysfunction and oxidative stress}

ROS, such as superoxide and hydroxyl anions, are known to be heavily produced from the mitochondrial respiratory chain. Mitochondrial driven ROS generation is thought to be a consequence of enhanced electron leakage, primarily from complex I and III of the electron transport chain (ETC) due to an increased flux of substrate fueling the mitochondria $(11,128)$. ROS will damage mitochondria and cellular components through several mechanisms including direct oxidation of DNA and proteins, lipid peroxidations, and protein nitrations (14, 147). Enhanced ROS production from cardiac mitochondria has been shown within several different 
T1DM animal models $(35,126)$. Alloxane-treated T1DM rats display enhanced tyrosine nitration of energy metabolism including CoA:oxoacid CoA transferase and creatine kinase (136). Further, overexpression of mitochondrial antioxidants such as catalase and MnSOD have shown to protect cardiac contractility and mitochondrial ETC function within the T1DM OVE26 mouse model $(123,159)$. In the STZ-T1DM mouse model, our laboratory utilized electron paramagnetic resonance spectroscopy, which demonstrated enhanced superoxide within the diabetic IFM isolated from the heart compared to control (35). Further, the diabetic IFM also displayed enhanced nitrotyrosine content and lipid peroxidation byproducts malondialdehyde and 4-hydroxyalkenal implicating elevated levels of both reactive nitrogen species and hydroxyl anions (35).

\section{5b Mitochondrial dysfunction and calcium handling}

Mitochondria are known to aid in the sequestering and emission of $\mathrm{Ca}^{2+}$ to help regulate excitation-contraction coupling within the heart (65). $\mathrm{Ca}^{2+}$ also has additional functional roles within mitochondria including regulation of oxidative phosphorylation and activation of apoptosis through induction of the mitochondrial permeability transition pore (mPTP) (58). Indeed, decreased mitochondrial $\mathrm{Ca}^{2+}$ concentrations are shown in cardiomyocytes derived from T1DM hearts $(75,161)$. Further, Oliveira et al. performed exogenous calcium administration experiments within isolated mitochondria from STZ-induced T1DM rats, which yielded decreases in $\mathrm{Ca}^{2+}$ retention as well as enhanced mPTP opening compared to control group (102). Similarly, our laboratory has shown enhanced rates of mPTP formation and cytochrome c release in IFM subpopulations isolated from STZ treated mice (154). Taken together, the data suggests T1DM will lead to cardiac contractile dysfunction, in part, through a mechanism of mitochondrial $\mathrm{Ca}^{2+}$ mishandling and enhanced mitochondrial driven cellular apoptosis. 


\section{5c Mitochondrial dysfunction and proteomic remodeling}

Broad scale proteomic analyses are becoming increasingly prevalent within various type 1 diabetic models and are paramount to understanding mitochondrial dysfunction within the heart $(4,17,60,123,136)$. Isolated mitochondria from STZ induced T1DM rats were subjected to two dimensional polyacrylamide gel electrophoreseis (2D-PAGE) coupled with matrixassisted laser desorption/ionization time of flight mass spectrometry (MALDI-TOF-MS). The results indicate 30 proteins were altered including increases in fatty acid oxidation (FAO) proteins, decreases in oxidative phosphorylation (OXPHOS) complex I subunits, and reductions in mitochondrial heat shock proteins (Hsp60 and MtHsp70) within the diabetic group (136). In a similar study model, Hamblin et al. analyzed cardiac tissue from eight week STZ-diabetic rats and found elevated FAO proteins as well as decreases in aldehyde dehydrogenase (ALDH-2) and 3-mercaptopyruvate sulfurtransferase, proteins involved in antioxidant defense (60). Utilizing iTRAQ proteomic labeling coupled with multidimensional protein identification technology

mass spectrometry (MuDPIT MS/MS), Jüllig et al. examined STZ-treated rat cardiac mitochondria four months post-diabetes mellitus onset in which long chain fatty acid proteins were elevated in conjunction with reductions in catabolic short chain fatty acid enzymes, which could potentially explain enhanced lipotoxicity within type 1 diabetes mellitus (68). In recent studies, Bugger et al. employed a label free approach in conjunction with selective mitochondrial sub compartment enrichment techniques to examine mitochondria in 12 week old type diabetic Akita mice from the kidney, liver, brain, and heart (17). The results indicated increases in FAO proteins, with subsequent decreases in tricaboxylic acid proteins. OXPHOS proteins were differentially regulated with an increase in ATP synthase subunit and decreases in Complex I and IV subunits (17). 
Additionally, our laboratory examined proteomic differences in spatially distinct subpopulations of mitochondria within the STZ-induced diabetic heart through two separate methodologies, 2D-DIGE and iTRAQ coupled with MALDI-TOF-MS (4). Interestingly, the protein alterations within the two mitochondrial subpopulations were vastly different with the IFM being the most adversely affected in the diabetic heart. Specifically, proteins involved in FAO, OXPHOS subunits (complex I, IV, and V), TCA cycle intermediates, mitochondrial structure (mitofilin), and mitochondrial protein import (MtHsp70) were significantly decreased in the diabetic IFM compared to control with no change in the SSM. Further, multidimensional protein identification technology (MudPIT) was used to identify post translational modifications (PTM) of proteins within the mitochondrial subpopulations from control and diabetic mouse hearts. Diabetic IFM displayed the highest number of oxidations and deamidations to proteins including MtHsp70 and mitofilin, both proteins that were also reduced in abundance (4).

\subsection{Mitochondrial Protein Import}

Currently, there are an estimated 1500 proteins in the human mitochondrion, with only 13 transcribed and translated in the organelle itself $(2,19,105)$. The vast majority of proteins $(>99 \%)$ are nuclear-encoded and imported into the mitochondrion through a complex mechanism of translocation (21). Protein import into the matrix is a process involving direct interaction between the imported protein, the outer mitochondrial membrane (OMM), inner mitochondrial membrane (IMM), and the presequence translocase-associated motor (PAM) creating a "supercomplex", which generates a singular avenue for translocation once the protein is

delivered to the mitochondrion (23). Proteins destined for the mitochondria are known as preproteins (48) and have specific targeting signals with cleavable $\mathrm{N}$-terminal presequences being the most prevalent $(48,103)$. 


\section{6a Outer membrane protein import}

Nuclear-encoded preproteins are transported via cytosolic chaperones hsc70, hsp90, and mitochondrial import stimulation factor (MSF-L) to the translocase of the outer membrane (TOM) complex, which has multiple receptors that help recognize and guide preproteins to and through the OMM for entrance into the mitochondrion $(43,62,158,160)$. Tom20 is the main receptor for $\mathrm{N}$-terminal presequence recognition and subsequent binding to the cytosolic side of the OMM. This protein has a binding groove for the hydrophobic face of the polypeptide presequence allowing for proper attachment to the mitochondrion. Tom22 is negatively charged and cooperates with Tom 20 to help keep the incoming protein unfolded by attaching itself to the positively charged presequence. Finally, $\beta$-barrel protein Tom40, along with its three subunits Tom5, Tom6, and Tom7 (small Toms) form the import pore of the TOM complex through which translocating polypeptides are guided into the inner membrane space (Figure 1.2).

\section{$1.6 b$ Inner membrane protein import}

Once through the OMM, preproteins bind simultaneously to the inner membrane space domain of Tom22 and Tim50, as well as IMM protein Tim21, allowing for preproteins to be guided to the translocase of the inner membrane 23 (TIM23) complex. The TIM23 complex is the main mitochondrial import pore that allows entrance into and through the $\operatorname{IMM}(22,96)$. Tim23 has a direct role in the translocation of preproteins into different areas of the mitochondrion including the inner membrane space, IMM, and matrix $(22,40)$. The majority of preproteins that travel through the TIM23 complex are dependent upon mitochondrial membrane potential $(\Delta \Psi \mathrm{m})$ and the PAM complex. MtHsp70 is an essential import protein and the central subunit of the PAM complex. In a well-studied mechanism, MtHsp70 anchors to Tim44 on the 
matrix side of the IMM binding itself to a translocating preprotein, "trapping" and "pulling" it through the IMM in an ATP-dependent manner (144). Once into the mitochondrial matrix, the $\mathrm{N}$-terminal presequence is subsequently cleaved by matrix processing peptidase (MPP) and the unfolded translocating protein is refolded into its native confirmation by co-chaperones hsp60 and hsp10 $(59,125)$. Below is a detailed schematic of matrix-targeted nuclear encoded protein import as described in the text.

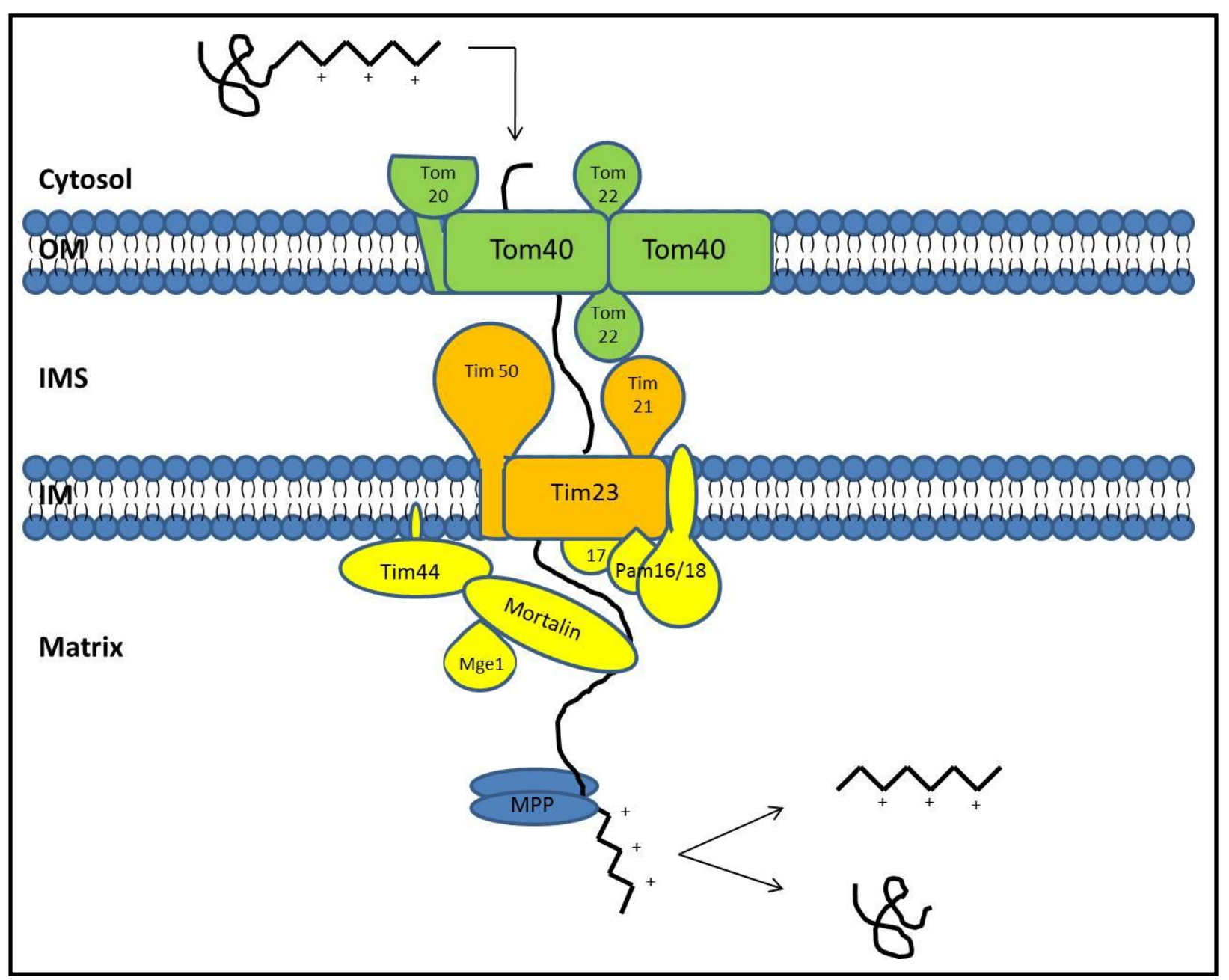

Fig 1.2 Mitochondrial Import of Matrix-Targeted Precursor Proteins

Studies have shown that many matrix-targeted preproteins are not dependent on cytosolic molecular chaperones for import and it is believed MtHsp70 provides the force for unfolding of 
preproteins for protein import. This requires that import occurs at contact sites where the inner and outer membrane come in close association to allow the protein to span both membranes being simultaneously inserted into the TOM complex and TIM23 complex (106). MtHsp70 has been reported to be responsive to cellular insults including thyroid hormone treatment, glucose deprivation, and myocardial $\mathrm{I} / \mathrm{R}(60,71,83,155)$. Research from our laboratory using rat neonatal cardiac myocytes infected with an adenoviral vector expressing MtHsp70 has shown protection from simulated $\mathrm{I} / \mathrm{R}$ injury which were associated with increased import of nuclear encoded antioxidant proteins (MnSOD) (155).

\section{6c Presequence translocase-associated motor complex}

MtHsp70 contains three key regions that include an ATPase domain, peptide binding domain, and a carboxy-terminal segment, all of which are essential for proper import functionality (74). Mutations to MtHsp70 in multiple species have proven to have detrimental effects upon matrix-associated import. As an example, a mutation to the Tim44 binding domain of MtHsp70 reduced mitochondrial translocation activity significantly (79). Additionally, inactivation of ssc1 (MtHsp70 yeast equivalent) by temperature-sensitive mutation inhibited the unfolding, translocation, and subsequent folding of imported preproteins in vitro (51, 70). Interestingly, yeast cells containing low intrinsic ATP production from their mitochondria are still viable, however a deletion of Ssc1 causes complete death of the cell denoting the vast importance of this critical protein for not only the mitochondrial import process, but overall cellular viability (33).

MtHsp70 driven protein import is regulated by the four other essential members of the

PAM complex which include Tim44, Pam16 (Tim14), Pam18 (Tim16), GrpE (Mge1) and the 
non-essential protein Tim17. Tim44 is an adaptor protein that anchors itself to the IMM side of the mitochondrial matrix, serving as a pedestal for MtHsp70 (137). Recent studies have highlighted Tim44 as a translocon with multiple functions including recruitment and coordination of PAM complex constituents, allowing for efficient protein translocation (118). A mutation of the J-related segment of Tim44 in Saccharomyces cerevisiae significantly decreased mitochondrial protein import viability, presumably through dysfunctional Tim44-MtHsp70 interaction (89).

Matrix protein GrpE is the nucleotide exchange factor that promotes the release of ADP from MtHsp70. Liberation of ADP disassociates the preprotein from MtHsp70 and allows for rapid binding of new ATP to further drive mitochondrial protein translocation (38). Examination of a conditional mutant allele of Mge1 (eukaryotic GrpE homolog) demonstrated decreased MtHsp70 binding efficiency to translocating preproteins and enhanced binding of fully imported preproteins highlighting the importance of GrpE regulatory effect upon MtHsp70 (76).

MtHsp70 is also regulated by j-like protein Pam16 and j-protein Pam18, which function collectively to regulate protein import activity. Pam18 uses its j-domain to stimulate the ATPase activity of MtHsp70 and is critical for proper PAM complex function. Additionally, Pam16 acts as a negative regulator of Pam18 by forming a heterodimer which controls its ability to interact with the presequence translocase and is known to affect the formation of the MtHsp70-Tim44 complex $(34,49)$. Further, the destabilization of the Pam16-Pam18 complex not only exhibited a decrease in mitochondrial protein import, but also had lethal effects upon yeast cell viability (34, 92). Finally, although not essential for cell viability, a sixth member of the complex has been identified as Pam17. Genetic and biochemical analyses indicated that Pam17 interacts with Tim44 in a complementary manner to assist in protein import $(64,117)$. Also, Pam17 has been 
shown to interact with several other PAM complex proteins, including Tim23, prior to preprotein translocation and its interaction is required for proper Pam16-Pam18 complex formation (139). Interestingly, mitochondria lacking Pam 17 has shown impaired mitochondrial protein import and PAM complex formation, although import itself was not completely abolished (139). With multiple proteins comprising the PAM complex, some with multiple regulatory functions, MtHsp70 driven mitochondrial protein import is one of the more complicated processes that occur inside the mitochondrion.

\section{6d Brownian ratchet versus power stroke models}

Functionally, MtHsp70 is characterized as the primary motor subunit which aids in the unfolding, transport, and refolding of mitochondrially-targeted proteins containing $\mathrm{N}$-terminal presequences through the mitochondrial IMM to target destinations. The vast majority of mitochondrial matrix proteins are imported through a MtHsp70-dependent mechanism. However, the motor subunit has also been shown to aid in the import of mitochondrial IMM and IMS proteins as well. Oxidase assembly 1 (oxa1), a mitochondrial IMM translocase, was proven to be imported into the matrix via MtHsp70 and subsequently reinserted back into the mitochondrial IMM (8). Likewise, IMS space proteins containing bipartite signaling sequences (matrix and IMS), such as cytochrome $b_{2}$, are partially pulled into the matrix while being actively unfolded by MtHsp70. The bipartite signaling sequences are subsequently cleaved allowing the functional portion of the protein to stay in the IMS where it is actively folded into its native confirmation (53).

Although MtHsp70 is widely accepted as an essential constituent for mitochondrial protein import, how it exerts its effect upon translocating proteins is still unclear. There are two 
different models proposed for MtHsp70 mechanism of action; the Brownian ratchet model and the power stroke model (Figure 1.3) (95). Specifically, the Brownian ratchet mechanism proposes the N-terminal preprotein of the polypeptide is translocated into the matrix initially by the pulling force of $\Delta \Psi \mathrm{m}$. Once through the IMM, the preprotein binds to MtHsp70, ATP hydrolysis occurs, and MtHsp70 is released from the import docking subunit Tim44. MtHsp70 acts to "trap" the translocating protein by preventing its retrograde movement back into the IMM (82, 101). Additional MtHsp70/Tim44 complexes bind to deeper segments of the incoming polypeptide further assisting in the movement of the protein into the matrix. Nucleotide exchange factor GrpE, catalyzes the release of adenosine diphosphate (ADP) from MtHsp70, facilitating the disassociation of the motor subunit from the protein $(82,101)$. This mechanism alleviates the dependence upon $\Delta \Psi \mathrm{m}$ for mitochondrial protein import (129).

The power stroke model begins in a similar fashion with MtHsp70 attached to the docking subunit Tim44. However, MtHsp70 does not dissociate from Tim44, rather it undergoes a conformational change fueled by binding to the incoming polypeptide followed by ATP hydrolysis, which actively propels the protein through the IMM and into the matrix. GrpE again functions as a nucleotide exchange factor, facilitating the release of MtHsp70 from the translocating protein. This method indicates that multiple molecules of MtHsp70 would be needed to thrust the protein into the mitochondrial matrix (24). Indeed, blue native complex analyses of arrested TIM-TOM-PAM supercomplexes estimate 6-7 MtHsp70 molecules are available per imported protein at any given time (37). Below is a diagram depicting the predicted differences between the Brownian ratchet and power stroke model. 


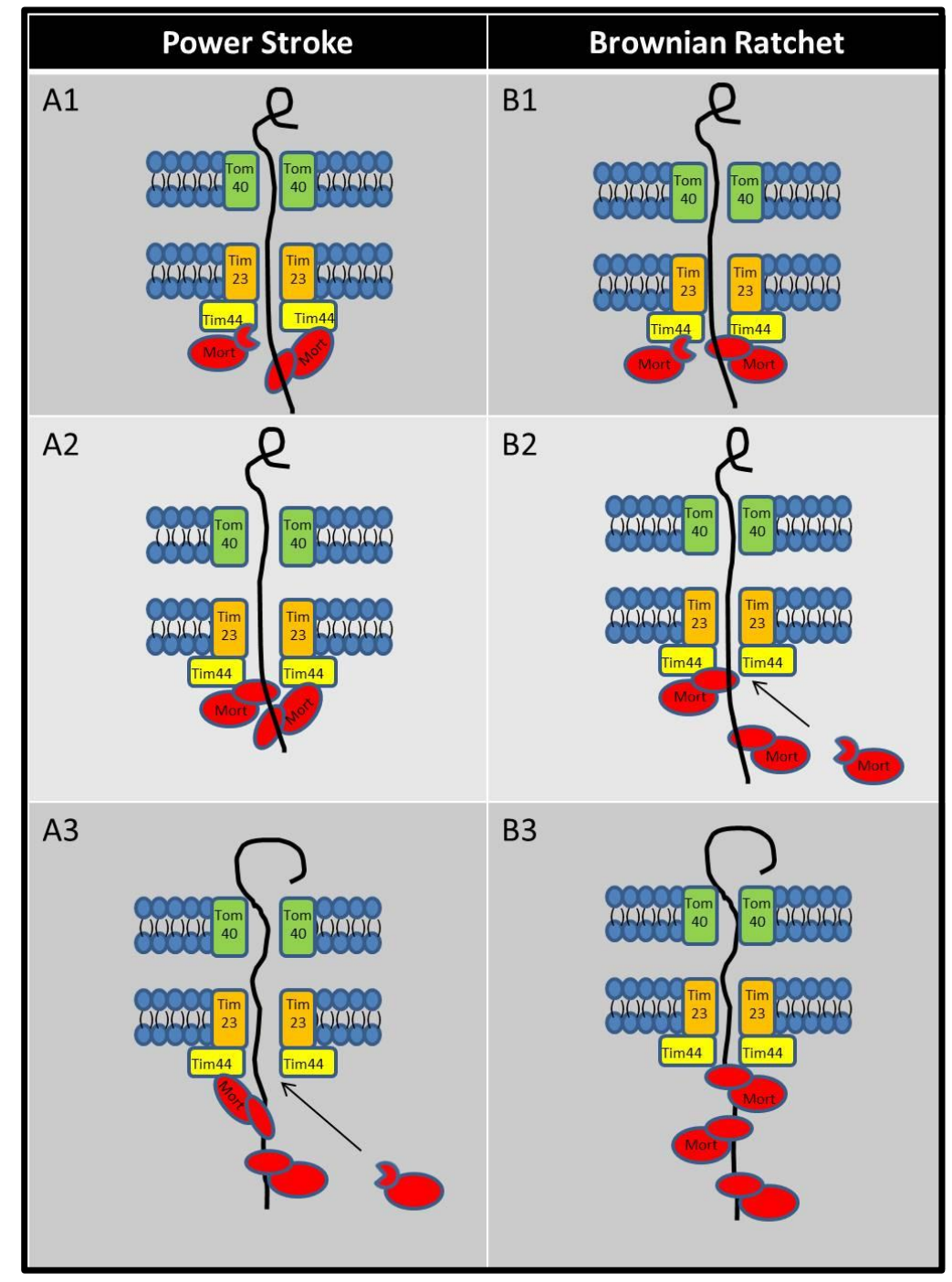

Fig 1.3 Power Stroke verse Brownian Ratchet Models

Recent literature supports the notion that there is not a singular mechanism of action pertaining to the motor function of MtHsp70. It is likely both models are employed in conjunction depending on what protein in being imported (72). As an example, preproteins must be in an unfolded confirmation to fit through the pores of the OMM and IMM. MtHsp70 will exert the necessary amount of force needed to push the N-terminal portion of the imported protein into the matrix. This motion actively unfolds C-terminal hydrophobic domains at the OMM pore during the import process allowing for linear movement into the target destination 
(143). MtHsp70 is the likely driving force for the linearization of proteins due to the absence of unfolding enzymes present at the OMM (145). Additionally, the unfolding of proteins during mitochondrial import is accelerated when the presequence is long enough to span the IMM and OMM, thereby contacting MtHsp70 for expedited entry into the matrix (86). In this scenario, the power stroke model is the most logical mechanism of import for tightly folded proteins due to a large amount of force needed to linearize the protein prior to translocation. However, proteins lacking tightly folded domains do not need to be forcefully straightened. Therefore, the Brownian ratchet model would seem to be the most efficient mechanism of action (152). Thus, the mechanism by which MtHsp70 exerts itself upon mitochondrial protein import likely depends upon the composition of the translocating protein itself.

\subsection{Antioxidant Defense}

Increased oxidative damage, due to an imbalance between reactive oxygen species (ROS) and antioxidant defense, has been implicated with the onset and progression of multiple disease states including $\mathrm{I} / \mathrm{R}$, aging, and diabetes-associated cardiac dysfunction such as diabetic cardiomyopathy. ROS production is regulated by multiple antioxidant enzyme families including the superoxide dismutases (SOD) and glutathione peroxidases (GPx).

\section{7a Superoxide dismutase}

Superoxide dismutases are a family of enzymes that catalyze the dismutation of superoxide into oxygen and hydrogen peroxide $(50,88)$. There are multiple isoforms of SOD, however, the most prominent are the cytoplasmic copper zinc SOD (CuZnSOD, SOD1) and mitochondrial specific MnSOD $(9,130)$. Due to the high quantity of superoxide produced within mitochondria, MnSOD remains a key factor in oxidant regulation. Overexpression of MnSOD 
within the type 1 diabetic heart elicits reduced oxidative damage, improved ETC functionality, and protects against diabetic induced decreases in mitochondrial mass (122). Further, a genetic knockout of MnSOD within mice caused severe dilated cardiomyopathy and was lethal within days of birth, presumably through a mechanism of enhanced oxidative stress (78).

\section{$1.7 b$ Glutathione peroxidase}

The GPx's are a selenoprotein dependent family of enzymes that use reduced glutathione (GSH) to catalyze the reduction of hydrogen peroxide and lipid peroxides. GPx1, the most characterized enzyme of the family, is ubiquitously expressed within almost all tissues (25-27). T1DM, induced through STZ injection in male Wistar rats show increased abundance of GPx1 within the liver that coincided with increased oxidative stress present within the organ (115). Other members of the family exist predominantly in specific areas of the body including GPx2 (gastrointestinal tract) and GPx3 (kidney) $(31,131)$.

The GPx4 family exists in three different isoforms, which target the enzyme to different locations within the cell including the nucleus (nGPx4), cytoplasm (GPx4), and mitochondria (mPHGPx). GPx4 is unique to other GPx family members in that it exists as a monomeric

structure and has the ability to reduce peroxidized acyl groups in phospholipids, fatty acid hydroperoxides, and cholesterol peroxides within subcellular membranes (93). Functionally, the selenoanalate anion is oxidized by a hydroperoxide to selenic acid and subsequently reduced in its active state with two molecules of GSH (Fig 1.4A) (138). Further, in the absence of GSH, GPx4 is able to turn into a thiol peroxidase and oxidize thiol groups within proteins (Fig 1.4B). A detailed schematic below highlights mPHGPx mechanism of action. 


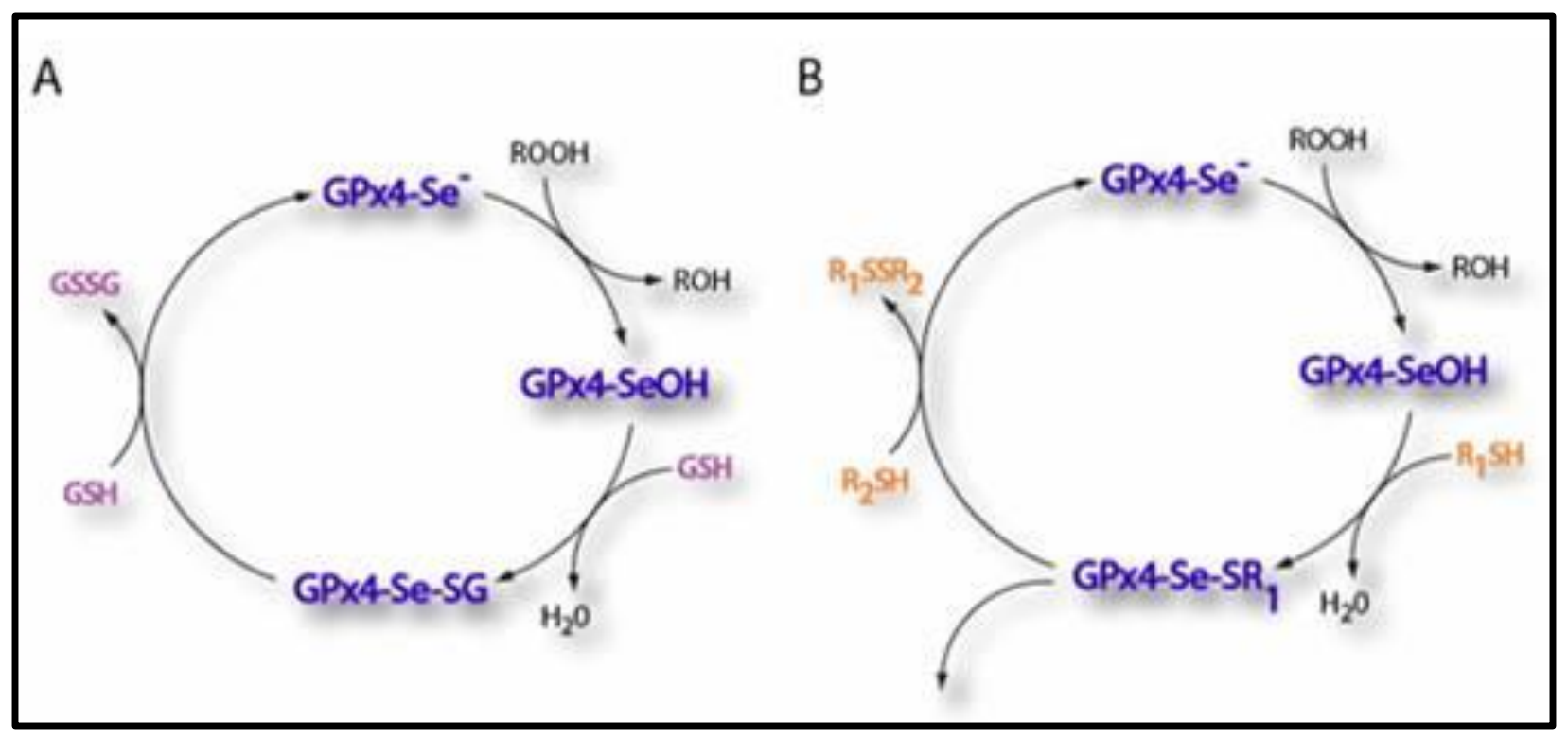

Fig. 1.4 Glutathione Peroxidase 4 Catalysis (32)

MPHGPx, primarily located within and around the mitochondrial inner membrane (IMM), has been shown to be protective against apoptosis, oxidants, DNA-damaging agents, and glucose deficiency (84). Additionally, our laboratory has shown mPHGPx overexpression to be protective of cardiac contractile function through a mechanism of reduced lipid peroxidations and preservation of the mitochondrial ETC complex following I/R injury (36). Further, we have also shown overexpression of mPHGPx to preserve mitochondrial inner membrane structure, decrease lipid peroxidations, and enhance ATP production in diabetic IFM subpopulation through a mechanism of cardiolipin preservation.

\subsection{Micro-RNA (miRNA)}

miRNAs are novel post transcriptional regulators discovered in the early 1990's. Originally described in the nematode $C$. elegans, miRNAs are ubiquitous among many species including all vertebrates (146). To date, there are over 677 known human miRNAs located primarily around intergenic regions, introns, and to a lesser extent, exons of protein coding 
genes. In the nucleus, RNA Polymerase II is chiefly used to transcribe miRNAs producing a "pri-miRNA" transcript that has a hairpin loop, capped 5' end and polyadenylated tail all of which can be thousands of basepairs in length. Nuclear located RNase III enzyme, Drosha, will then cut the pri-miRNA into the intermediate form "pre-miRNA", which still contains the hairpin loop but is significantly smaller in size (approximately 70 basepairs in length). Pre-miRNA are exported out of the nucleus into the cytoplasm by nuclear membrane protein exportin-5 with the help of ran-guanosine triphosphate. Once into the cytoplasm, pre-miRNA are cut again by another RNase III enzyme, Dicer, resulting in the mature double stranded miRNA, ranging from 20-25 base pairs (85). The final stage of processing involves the formation of the RNA Induced Silencing Complex (RISC). Briefly, Dicer is able to unravel the miRNA from its complementary sequence leaving only the single stranded functional miRNA present. Dicer, along with cofactors transactivating response RNA binding protein and protein activator of interferon induced protein kinase help to bring the miRNA to a member of the argonaute family (AGO1-4) forming the RISC (107). AGO proteins function in miRNA repression by inhibiting protein synthesis when artificially tethered to the mRNA 3' UTR (47). The miRNA will then target the RISC, AGO in particular, to a specific mRNA for binding and subsequent inhibition. miRNA have a 2-7 base pair "seeding region" which binds directly to the target mRNA. Once bound, the complex will cause translational repression, deadenylation, or endonucleolytic cleavage causing mRNA degradation (80). Below is a diagram depicting the general mechanism of miRNA biogenesis and function. 


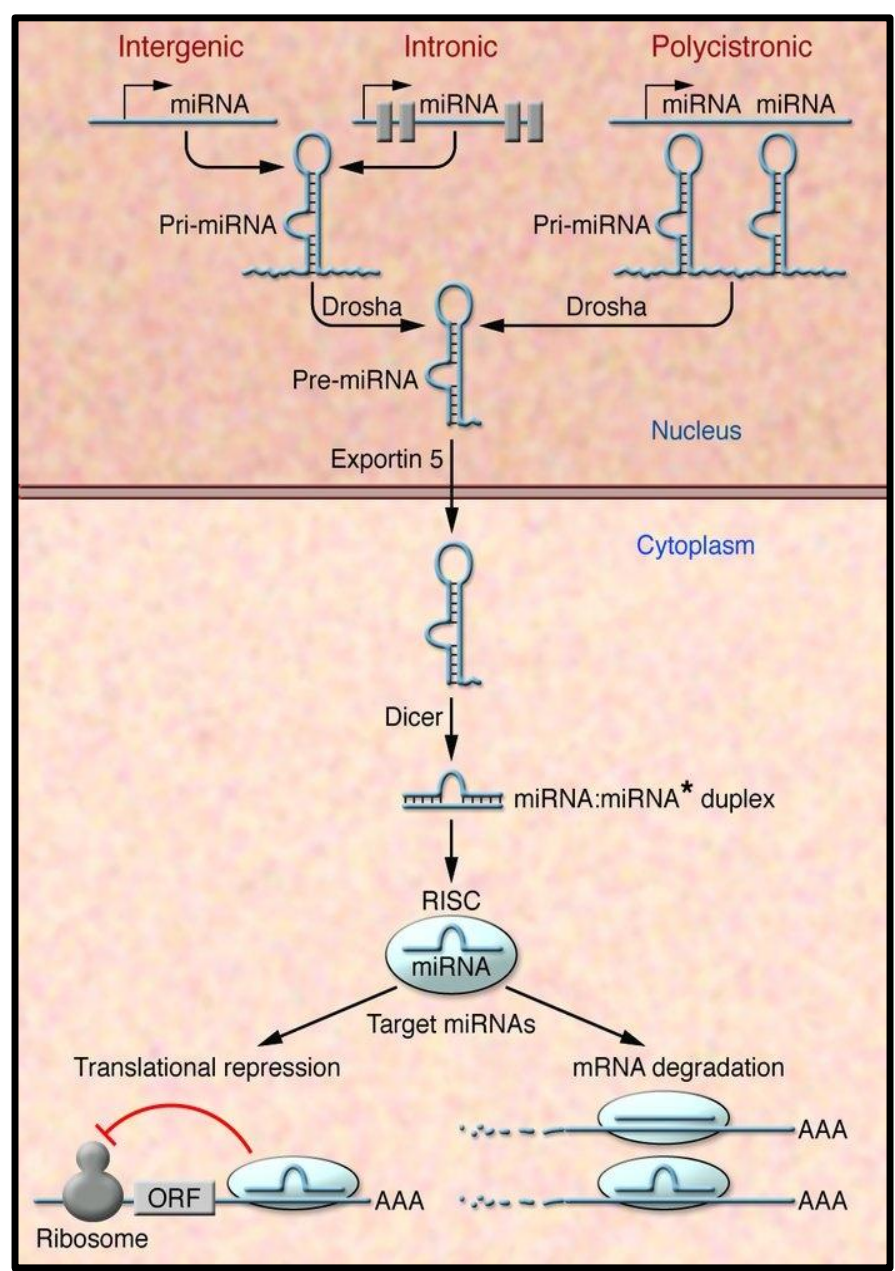

Fig 1.5 miRNA Biogenesis and Function (140)

\section{8a miRNAs in pathologies}

miRNAs have been researched most extensively to determine their role in regulating basic cell function and oncogenesis in studies including colorectal neoplasia, chronic lymphocytic leukemia, and human B cell lymphomas $(18,42,90)$. However, the effect of miRNA dysregulation upon a multitude of other pathophysiological states is becoming a topic of interest. Broad scale miRNA array analyses upon I/R injury in mouse hearts post insult had a significant increase in 33 miRNA compared to control (135). In a similar study, closer examination of miR-320 dysregulation affected targeting to Hsp20, denoting its potential 
importance as a therapeutic target for ischemic heart disease (110). Genetic overexpression of miR-375 lead to reduced pancreatic $\beta$-cell number and viability highlighting this miRNA as an important modulator of $\beta$-cell function (146). Finally, Nishi et al. identified miR-15b as a regulator of mitochondrial ATP production in cardiomyocytes through its inhibition of ADPribosylation factor-like 2, a protein essential for adenine nucleotide transporter function (98).

\section{8b Circulating miRNAs}

miRNAs exist in all parts of the body and seem to be implicated in virtually all cellular processes currently known (120). Further, miRNAs seem to be completely stable as well as resistant to nuclease digestion within the blood stream and can circulate to target areas of the body given the proper physiological or pathophysiological stimulus. Due to this discovery, scientists are now pursuing miRNAs within the circulation as clinical biomarkers for multiple diseases and disease states (55). Hung et al. examined cell-free circulating fetal nucleic acids, such as placental miRNAs, which could be examined for non-invasive prenatal diagnoses (63). Additionally, many laboratories have explored the regulation of miRNAs within different types

of cancer. As an example, miR-141, known to be highly upregulated within epithelial cells in prostate cancer, was also shown to be significantly increased concurrently within blood serum. Therefore, Mitchell et al. believe miR-141 can potentially be used as a viable circulating biomarker for blood-based detection of human prostate cancer (91). Similar to cancers, miRNA expression levels within the blood are starting to be utilized as potential biomarkers in heart disease. miR-1 is traditionally known as the most abundant miRNA within the heart. However, acute myocardial infarction induced in rats through a coronary ligation exhibited increases in miR-1 isolated from blood serum (28). Elevated serum levels of miR-1 was further confirmed in patients with acute myocardial infarctions as well yielding similar results across species (28). To 
date, there have been no published studies on the influence of circulating miRNAs in T1DM and their impact as biomarkers for the disease.

\section{$1.8 \mathrm{c}$ miRNAs within the heart}

miRNA regulation within the heart has been extensively characterized in the last decade playing an intricate role in essential cardiac functions including cardiomyocyte differentiation, cardiac development, and ventricular hypertrophy (3). miR-1 has been shown to regulate essential helix-loop-helix transcription factor HAND2, which controls cardiomyocyte growth specifically within the right ventricle (127). Pertaining to ventricular development, it has been shown that miR-133a has a critical role. Indeed, deletion of miR-133a is lethal in over $50 \%$ of mice after 1 day of birth, which is associated with ventricular septal defects (81). Further, mice that survive to adulthood display severe systolic dysfunction, enhanced cardiomyocyte proliferation, and apoptosis, demonstrating the critical regulatory effect miR-133a has upon cardiac development (81).

Perhaps the most effort put forth within the field has been in the understanding of miRNA dysregulation within ventricular hypertrophy and congestive heart failure. Multiple miRNAs have been identified as key regulators including let-7c, miR-23a, miR-100, miR-103, miR-1, miR-133, miR-208, and miR-29 (3). As an example, ligations of the left anterior descending coronary artery of mice revealed significant decreases in miR-29 expression within the heart (141). Further, knockdown of miR-29 enhanced cardiac fibrosis, suggesting miR-29 has an essential role in collagen gene expression following a myocardial infarction. In a fascinating study, van Rooij et al. examined miR-208 and its regulation upon myosin heavy chain (MHC) expression (140). Pathological hypertrophic growth in the heart will lead to 
downregulation of $\alpha-\mathrm{MHC}$ and an upregulation of $\beta-\mathrm{MHC}$. It was determined that miR-208 is encoded within an intron of $\alpha-\mathrm{MHC}$ and is a regulator of $\beta-\mathrm{MHC}$. Therefore, in stress conditions such as heart failure, $\alpha-\mathrm{MHC}$ and miR208 expression are both decreased, allowing for elevated $\beta$-MHC expression altering contractility within the heart. Taken together, it is clear miRNAs have critical roles in the development and function of the heart within physiological and pathophysiological conditions.

\section{8d miRNAs within mitochondria}

Most recently, researchers have begun identifying miRNAs within organelles, including mitochondria, in which their functional role at this point remains undefined. Influential research by Kren et al. identified 15 miRNAs residing within rat liver mitochondria (73). Utilizing bioinformatics approaches such as MiRanda and TargetScan algorithms, they determined mitochondrial miRNAs are likely involved in regulation of apoptosis, cell proliferation, and differentiation. Further, this group inferred miRNAs may serve as reservoirs that can release miRNA given certain stimulus to aid in the regulation of various cellular processes. In a similar study to determine whether unique subpopulations of miRNAs exist within mitochondria, Bian et al. isolated highly purified RNA from liver tissue and liver mitochondria followed by miRNA microarray analysis (7). Interestingly, the highest expressed miRNAs within mitochondria, such as miR-451, miR7b, and mir-26a, were not present within liver fractions. Further, another group of mice were treated with STZ to induce TIDM in which the STZ treated liver mitochondria miRNAs were compared to control mitochondria miRNA. The results show increased levels of miR-494, miR-202-5p, and miR-134 within the STZ mitochondria. Bioinformatics analyses highlighted several mitochondrial-specific gene targets including tryptophanyl-tRNA synthetase 
and transcription factor A. Taken together, both studied show the distinct possibility of unique miRNA subpopulations within mitochondria.

\subsection{Summary}

As of 2011, 25.8 million people ( $8.3 \%$ of the population) within the United States alone have diagnosed or undiagnosed diabetes mellitus. It also appears that this number will only increase in the years ahead. Understanding the mechanisms involved within the etiology is absolutely essential for better diagnoses and therapeutic treatment programs. Dysregulation of the mitochondrial proteome seems to be a critical factor within the pathology of diabetic cardiomyopathy. Therefore, the goal of the studies presented was to determine whether nuclear encoded mitochondrial protein import is a potential mechanism for proteomic dysregulation within the diabetic IFM and to evaluate whether overexpression of a targeted antioxidant (mPHGPx) will preserve import function. Further, we assessed how miRNAs are regulated within the heart in context to T1DM and determined how specific miRNAs can influence the mitochondrial proteome. 


\section{REFERENCES}

1. Al-Achi A and Greenwood R. A brief report on some physiological parameters of streptozocin-diabetic rat. Drug Dev Ind Pharm 27: 465-468, 2001.

2. Anderson S, Bankier AT, Barrell BG, de Bruijn MH, Coulson AR, Drouin J, Eperon IC, Nierlich DP, Roe BA, Sanger F, Schreier PH, Smith AJ, Staden R, and Young IG. Sequence and organization of the human mitochondrial genome. Nature 290: 457-465, 1981.

3. Barringhaus KG and Zamore PD. MicroRNAs: regulating a change of heart. Circulation 119: 2217-2224, 2009.

4. Baseler WA, Dabkowski ER, Williamson CL, Croston TL, Thapa D, Powell MJ, Razunguzwa TT, and Hollander JM. Proteomic alterations of distinct mitochondrial subpopulations in the type 1 diabetic heart: contribution of protein import dysfunction. Am J Physiol Regul Integr Comp Physiol 300: R186-200.

5. Beckman JA, Creager MA, and Libby P. Diabetes and atherosclerosis: epidemiology, pathophysiology, and management. JAMA 287: 2570-2581, 2002.

6. Bell DS. Diabetic cardiomyopathy. Diabetes Care 26: 2949-2951, 2003.

7. Bian Z, Li LM, Tang R, Hou DX, Chen X, Zhang CY, and Zen K. Identification of mouse liver mitochondria-associated miRNAs and their potential biological functions. Cell Res 20: 1076-1078.

8. Bohnert M, Rehling P, Guiard B, Herrmann JM, Pfanner N, and van der Laan M. Cooperation of stop-transfer and conservative sorting mechanisms in mitochondrial protein transport. Curr Biol 20: 1227-1232. 
9. Borgstahl GE, Parge HE, Hickey MJ, Beyer WF, Jr., Hallewell RA, and Tainer JA. The structure of human mitochondrial manganese superoxide dismutase reveals a novel tetrameric interface of two 4-helix bundles. Cell 71: 107-118, 1992.

10. Boudina S and Abel ED. Diabetic cardiomyopathy, causes and effects. Rev Endocr Metab Disord 11: 31-39.

11. Brand MD, Affourtit C, Esteves TC, Green K, Lambert AJ, Miwa S, Pakay JL, and Parker N. Mitochondrial superoxide: production, biological effects, and activation of uncoupling proteins. Free Radic Biol Med 37: 755-767, 2004.

12. Brown RA, Filipovich P, Walsh MF, and Sowers JR. Influence of sex, diabetes and ethanol on intrinsic contractile performance of isolated rat myocardium. Basic Res Cardiol 91: 353-360, 1996.

13. Brownlee M. Biochemistry and molecular cell biology of diabetic complications. Nature 414: 813-820, 2001.

14. Bugger H and Abel ED. Mitochondria in the diabetic heart. Cardiovasc Res 88: 229240.

15. Bugger H and Abel ED. Rodent models of diabetic cardiomyopathy. Dis Model Mech 2: 454-466, 2009.

16. Bugger H, Chemnitius JM, and Doenst T. Differential changes in respiratory capacity and ischemia tolerance of isolated mitochondria from atrophied and hypertrophied hearts. Metabolism 55: 1097-1106, 2006.

\section{Bugger H, Chen D, Riehle C, Soto J, Theobald HA, Hu XX, Ganesan B, Weimer}

BC, and Abel ED. Tissue-specific remodeling of the mitochondrial proteome in type 1 diabetic akita mice. Diabetes 58: 1986-1997, 2009. 
18. Calin GA, Dumitru CD, Shimizu M, Bichi R, Zupo S, Noch E, Aldler H, Rattan S, Keating M, Rai K, Rassenti L, Kipps T, Negrini M, Bullrich F, and Croce CM. Frequent deletions and down-regulation of micro- RNA genes miR15 and miR16 at 13q14 in chronic lymphocytic leukemia. Proc Natl Acad Sci U S A 99: 15524-15529, 2002.

19. Calvo S, Jain M, Xie X, Sheth SA, Chang B, Goldberger OA, Spinazzola A, Zeviani M, Carr SA, and Mootha VK. Systematic identification of human mitochondrial disease genes through integrative genomics. Nat Genet 38: 576-582, 2006.

20. CDC. Centers for Disease Control and Prevention. National diabetes fact sheet: national estimates and general information on diabetes and prediabetes in the United States, 2011. Atlanta, GA: U.S. Department of Health and Human Services, Centers for Disease Control and Prevention, 2011., 2011.

21. Chacinska A, Koehler CM, Milenkovic D, Lithgow T, and Pfanner N. Importing mitochondrial proteins: machineries and mechanisms. Cell 138: 628-644, 2009.

22. Chacinska A, Lind M, Frazier AE, Dudek J, Meisinger C, Geissler A, Sickmann A, Meyer HE, Truscott KN, Guiard B, Pfanner N, and Rehling P. Mitochondrial presequence translocase: switching between TOM tethering and motor recruitment involves Tim21 and Tim17. Cell 120: 817-829, 2005.

23. Chacinska A, Rehling P, Guiard B, Frazier AE, Schulze-Specking A, Pfanner N, Voos W, and Meisinger C. Mitochondrial translocation contact sites: separation of dynamic and stabilizing elements in formation of a TOM-TIM-preprotein supercomplex. Embo J 22: 5370$5381,2003$.

24. Chauwin JF, Oster G, and Glick BS. Strong precursor-pore interactions constrain models for mitochondrial protein import. Biophys J 74: 1732-1743, 1998. 
25. Cheng WH, Combs GF, Jr., and Lei XG. Knockout of cellular glutathione peroxidase affects selenium-dependent parameters similarly in mice fed adequate and excessive dietary selenium. Biofactors 7: 311-321, 1998.

26. Cheng WH, Ho YS, Ross DA, Han Y, Combs GF, Jr., and Lei XG. Overexpression of cellular glutathione peroxidase does not affect expression of plasma glutathione peroxidase or phospholipid hydroperoxide glutathione peroxidase in mice offered diets adequate or deficient in selenium. J Nutr 127: 675-680, 1997.

27. Cheng WH, Ho YS, Ross DA, Valentine BA, Combs GF, and Lei XG. Cellular glutathione peroxidase knockout mice express normal levels of selenium-dependent plasma and phospholipid hydroperoxide glutathione peroxidases in various tissues. J Nutr 127: 1445-1450, 1997.

28. Cheng Y, Tan N, Yang J, Liu X, Cao X, He P, Dong X, Qin S, and Zhang C. A translational study of circulating cell-free microRNA-1 in acute myocardial infarction. Clin Sci (Lond) 119: 87-95.

29. Chiasson JL, Aris-Jilwan N, Belanger R, Bertrand S, Beauregard H, Ekoe JM, Fournier H, and Havrankova J. Diagnosis and treatment of diabetic ketoacidosis and the hyperglycemic hyperosmolar state. CMAJ 168: 859-866, 2003.

30. Choi KM, Zhong Y, Hoit BD, Grupp IL, Hahn H, Dilly KW, Guatimosim S, Lederer WJ, and Matlib MA. Defective intracellular $\mathrm{Ca}(2+)$ signaling contributes to cardiomyopathy in Type 1 diabetic rats. Am J Physiol Heart Circ Physiol 283: H1398-1408, 2002. 
31. Chu FF, Esworthy RS, Ho YS, Bermeister M, Swiderek K, and Elliott RW. Expression and chromosomal mapping of mouse Gpx2 gene encoding the gastrointestinal form of glutathione peroxidase, GPX-GI. Biomed Environ Sci 10: 156-162, 1997.

32. Conrad M. Redox balance and reactive oxygen species in physiology and disease. 2011.

33. Craig EA, Kramer J, and Kosic-Smithers J. SSC1, a member of the 70-kDa heat shock protein multigene family of Saccharomyces cerevisiae, is essential for growth. Proc Natl Acad Sci U S A 84: 4156-4160, 1987.

34. D'Silva PR, Schilke B, Walter W, and Craig EA. Role of Pam16's degenerate J domain in protein import across the mitochondrial inner membrane. Proc Natl Acad Sci U S A 102: 12419-12424, 2005.

35. Dabkowski ER, Williamson CL, Bukowski VC, Chapman RS, Leonard SS, Peer CJ, Callery PS, and Hollander JM. Diabetic cardiomyopathy-associated dysfunction in spatially distinct mitochondrial subpopulations. Am J Physiol Heart Circ Physiol 296: H359-369, 2009.

36. Dabkowski ER, Williamson CL, and Hollander JM. Mitochondria-specific transgenic overexpression of phospholipid hydroperoxide glutathione peroxidase (GPx4) attenuates ischemia/reperfusion-associated cardiac dysfunction. Free Radic Biol Med 45: 855-865, 2008.

37. Dekker PJ, Martin F, Maarse AC, Bomer U, Muller H, Guiard B, Meijer M, Rassow J, and Pfanner N. The Tim core complex defines the number of mitochondrial translocation contact sites and can hold arrested preproteins in the absence of matrix Hsp70Tim44. EMBO J 16: 5408-5419, 1997.

38. Dekker PJ and Pfanner N. Role of mitochondrial GrpE and phosphate in the ATPase cycle of matrix Hsp70. J Mol Biol 270: 321-327, 1997. 
39. Dent CL, Bowman AW, Scott MJ, Allen JS, Lisauskas JB, Janif M, Wickline SA, and Kovacs SJ. Echocardiographic characterization of fundamental mechanisms of abnormal diastolic filling in diabetic rats with a parameterized diastolic filling formalism. J Am Soc Echocardiogr 14: 1166-1172, 2001.

40. Distler AM, Kerner J, and Hoppel CL. Proteomics of mitochondrial inner and outer membranes. Proteomics 8: 4066-4082, 2008.

41. Du XL, Edelstein D, Rossetti L, Fantus IG, Goldberg H, Ziyadeh F, Wu J, and Brownlee M. Hyperglycemia-induced mitochondrial superoxide overproduction activates the hexosamine pathway and induces plasminogen activator inhibitor-1 expression by increasing Sp1 glycosylation. Proc Natl Acad Sci U S A 97: 12222-12226, 2000.

42. Eis PS, Tam W, Sun L, Chadburn A, Li Z, Gomez MF, Lund E, and Dahlberg JE. Accumulation of miR-155 and BIC RNA in human B cell lymphomas. Proc Natl Acad Sci U S A 102: 3627-3632, 2005.

43. Emr SD, Vassarotti A, Garrett J, Geller BL, Takeda M, and Douglas MG. The amino terminus of the yeast F1-ATPase beta-subunit precursor functions as a mitochondrial import signal. J Cell Biol 102: 523-533, 1986.

44. Fang ZY, Prins JB, and Marwick TH. Diabetic cardiomyopathy: evidence, mechanisms, and therapeutic implications. Endocr Rev 25: 543-567, 2004.

45. Fang ZY, Yuda S, Anderson V, Short L, Case C, and Marwick TH. Echocardiographic detection of early diabetic myocardial disease. J Am Coll Cardiol 41: 611$617,2003$.

46. Fein FS and Sonnenblick EH. Diabetic cardiomyopathy. Cardiovasc Drugs Ther 8: 6573, 1994. 
47. Filipowicz W, Bhattacharyya SN, and Sonenberg N. Mechanisms of posttranscriptional regulation by microRNAs: are the answers in sight? Nat Rev Genet 9: 102-114, 2008.

48. Folsch H, Guiard B, Neupert W, and Stuart RA. Internal targeting signal of the BCS1 protein: a novel mechanism of import into mitochondria. EMBO J 15: 479-487, 1996.

49. Frazier AE, Dudek J, Guiard B, Voos W, Li Y, Lind M, Meisinger C, Geissler A, Sickmann A, Meyer HE, Bilanchone V, Cumsky MG, Truscott KN, Pfanner N, and Rehling P. Pam16 has an essential role in the mitochondrial protein import motor. Nat Struct Mol Biol 11: 226-233, 2004.

50. Fukai T, Folz RJ, Landmesser U, and Harrison DG. Extracellular superoxide dismutase and cardiovascular disease. Cardiovasc Res 55: 239-249, 2002.

51. Gambill BD, Voos W, Kang PJ, Miao B, Langer T, Craig EA, and Pfanner N. A dual role for mitochondrial heat shock protein 70 in membrane translocation of preproteins. J Cell Biol 123: 109-117, 1993.

52. Garcia MJ, McNamara PM, Gordon T, and Kannel WB. Morbidity and mortality in diabetics in the Framingham population. Sixteen year follow-up study. Diabetes 23: 105-111, 1974.

53. Gartner F, Bomer U, Guiard B, and Pfanner N. The sorting signal of cytochrome b2 promotes early divergence from the general mitochondrial import pathway and restricts the unfoldase activity of matrix Hsp70. EMBO J 14: 6043-6057, 1995.

54. Ghosh S, Ting S, Lau H, Pulinilkunnil T, An D, Qi D, Abrahani MA, and Rodrigues B. Increased efflux of glutathione conjugate in acutely diabetic cardiomyocytes. Can J Physiol Pharmacol 82: 879-887, 2004. 
55. Gilad S, Meiri E, Yogev Y, Benjamin S, Lebanony D, Yerushalmi N, Benjamin H, Kushnir M, Cholakh H, Melamed N, Bentwich Z, Hod M, Goren Y, and Chajut A. Serum microRNAs are promising novel biomarkers. PLoS One 3: e3148, 2008.

56. Green K, Brand MD, and Murphy MP. Prevention of mitochondrial oxidative damage as a therapeutic strategy in diabetes. Diabetes 53 Suppl 1: S110-118, 2004.

57. Grundy SM, Benjamin IJ, Burke GL, Chait A, Eckel RH, Howard BV, Mitch W, Smith SC, Jr., and Sowers JR. Diabetes and cardiovascular disease: a statement for healthcare professionals from the American Heart Association. Circulation 100: 1134-1146, 1999.

58. Gunter TE, Yule DI, Gunter KK, Eliseev RA, and Salter JD. Calcium and mitochondria. FEBS Lett 567: 96-102, 2004.

59. Gupta RS. Evolution of the chaperonin families (Hsp60, Hsp10 and Tcp-1) of proteins and the origin of eukaryotic cells. Mol Microbiol 15: 1-11, 1995.

60. Hamblin M, Friedman DB, Hill S, Caprioli RM, Smith HM, and Hill MF. Alterations in the diabetic myocardial proteome coupled with increased myocardial oxidative stress underlies diabetic cardiomyopathy. J Mol Cell Cardiol 42: 884-895, 2007.

61. Hayashi K, Okumura K, Matsui H, Murase K, Kamiya H, Saburi Y, Numaguchi Y, Toki Y, and Hayakawa T. Involvement of 1,2-diacylglycerol in improvement of heart function by etomoxir in diabetic rats. Life Sci 68: 1515-1526, 2001.

62. Hill K, Model K, Ryan MT, Dietmeier K, Martin F, Wagner R, and Pfanner N. Tom40 forms the hydrophilic channel of the mitochondrial import pore for preproteins [see comment]. Nature 395: 516-521, 1998.

63. Hung EC, Chiu RW, and Lo YM. Detection of circulating fetal nucleic acids: a review of methods and applications. J Clin Pathol 62: 308-313, 2009. 
64. Hutu DP, Guiard B, Chacinska A, Becker D, Pfanner N, Rehling P, and van der Laan M. Mitochondrial protein import motor: differential role of Tim44 in the recruitment of Pam17 and J-complex to the presequence translocase. Mol Biol Cell 19: 2642-2649, 2008.

65. Isenberg G, Han S, Schiefer A, and Wendt-Gallitelli MF. Changes in mitochondrial calcium concentration during the cardiac contraction cycle. Cardiovasc Res 27: 1800-1809, 1993.

66. Joffe, II, Travers KE, Perreault-Micale CL, Hampton T, Katz SE, Morgan JP, and Douglas PS. Abnormal cardiac function in the streptozotocin-induced non-insulin-dependent diabetic rat: noninvasive assessment with doppler echocardiography and contribution of the nitric oxide pathway. J Am Coll Cardiol 34: 2111-2119, 1999.

67. Judge S, Jang YM, Smith A, Hagen T, and Leeuwenburgh C. Age-associated increases in oxidative stress and antioxidant enzyme activities in cardiac interfibrillar mitochondria: implications for the mitochondrial theory of aging. FASEB J 19: 419-421, 2005.

68. Jullig M, Hickey AJ, Middleditch MJ, Crossman DJ, Lee SC, and Cooper GJ. Characterization of proteomic changes in cardiac mitochondria in streptozotocin-diabetic rats using iTRAQ isobaric tags. Proteomics Clin Appl 1: 565-576, 2007.

69. Kajstura J, Fiordaliso F, Andreoli AM, Li B, Chimenti S, Medow MS, Limana F, Nadal-Ginard B, Leri A, and Anversa P. IGF-1 overexpression inhibits the development of diabetic cardiomyopathy and angiotensin II-mediated oxidative stress. Diabetes 50: 1414-1424, 2001.

70. Kang PJ, Ostermann J, Shilling J, Neupert W, Craig EA, and Pfanner N. Requirement for hsp70 in the mitochondrial matrix for translocation and folding of precursor proteins. Nature 348: 137-143, 1990. 
71. Kilgore JL, Musch TI, and Ross CR. Regional distribution of HSP70 proteins after myocardial infarction. Basic Res Cardiol 91: 283-288, 1996.

72. Krayl M, Lim JH, Martin F, Guiard B, and Voos W. A cooperative action of the ATP-dependent import motor complex and the inner membrane potential drives mitochondrial preprotein import. Mol Cell Biol 27: 411-425, 2007.

73. Kren BT, Wong PY, Sarver A, Zhang X, Zeng Y, and Steer CJ. MicroRNAs identified in highly purified liver-derived mitochondria may play a role in apoptosis. RNA Biol 6: 65-72, 2009 .

74. Krimmer T, Rassow J, Kunau WH, Voos W, and Pfanner N. Mitochondrial protein import motor: the ATPase domain of matrix Hsp70 is crucial for binding to Tim44, while the peptide binding domain and the carboxy-terminal segment play a stimulatory role. Mol Cell Biol 20: 5879-5887, 2000.

75. Lagadic-Gossmann D, Buckler KJ, Le Prigent K, and Feuvray D. Altered Ca2+ handling in ventricular myocytes isolated from diabetic rats. Am J Physiol 270: H1529-1537, 1996.

76. Laloraya S, Dekker PJ, Voos W, Craig EA, and Pfanner N. Mitochondrial GrpE modulates the function of matrix Hsp70 in translocation and maturation of preproteins. Mol Cell Biol 15: 7098-7105, 1995.

77. Lesnefsky EJ, Chen Q, Slabe TJ, Stoll MS, Minkler PE, Hassan MO, Tandler B, and Hoppel CL. Ischemia, rather than reperfusion, inhibits respiration through cytochrome oxidase in the isolated, perfused rabbit heart: role of cardiolipin. Am J Physiol Heart Circ Physiol 287: H258-267, 2004. 
78. Li Y, Huang TT, Carlson EJ, Melov S, Ursell PC, Olson JL, Noble LJ, Yoshimura MP, Berger C, Chan PH, Wallace DC, and Epstein CJ. Dilated cardiomyopathy and neonatal lethality in mutant mice lacking manganese superoxide dismutase. Nat Genet 11: 376-381, 1995.

79. Lim JH, Martin F, Guiard B, Pfanner N, and Voos W. The mitochondrial Hsp70dependent import system actively unfolds preproteins and shortens the lag phase of translocation. EMBO J 20: 941-950, 2001.

80. Lim LP, Lau NC, Garrett-Engele P, Grimson A, Schelter JM, Castle J, Bartel DP, Linsley PS, and Johnson JM. Microarray analysis shows that some microRNAs downregulate large numbers of target mRNAs. Nature 433: 769-773, 2005.

81. Liu N, Bezprozvannaya S, Williams AH, Qi X, Richardson JA, Bassel-Duby R, and Olson EN. microRNA-133a regulates cardiomyocyte proliferation and suppresses smooth muscle gene expression in the heart. Genes Dev 22: 3242-3254, 2008.

82. Liu Q, D'Silva P, Walter W, Marszalek J, and Craig EA. Regulated cycling of mitochondrial Hsp70 at the protein import channel. Science 300: 139-141, 2003.

83. Liu Y, Liu W, Song XD, and Zuo J. Effect of GRP75/mthsp70/PBP74/mortalin overexpression on intracellular ATP level, mitochondrial membrane potential and ROS accumulation following glucose deprivation in PC12 cells. Mol Cell Biochem 268: 45-51, 2005.

84. Lu J and Holmgren A. Selenoproteins. J Biol Chem 284: 723-727, 2009.

85. Lund E and Dahlberg JE. Substrate selectivity of exportin 5 and Dicer in the biogenesis of microRNAs. Cold Spring Harb Symp Quant Biol 71: 59-66, 2006.

86. Matouschek A, Azem A, Ratliff K, Glick BS, Schmid K, and Schatz G. Active unfolding of precursor proteins during mitochondrial protein import. EMBO J 16: 6727-6736, 1997. 
87. Mbanya JC, Sobngwi E, Mbanya DS, and Ngu KB. Left ventricular mass and systolic function in African diabetic patients: association with microalbuminuria. Diabetes Metab 27: 378-382, 2001.

88. McCord JM and Fridovich I. Superoxide dismutase: the first twenty years (1968-1988). Free Radic Biol Med 5: 363-369, 1988.

89. Merlin A, Voos W, Maarse AC, Meijer M, Pfanner N, and Rassow J. The J-related segment of tim44 is essential for cell viability: a mutant Tim44 remains in the mitochondrial import site, but inefficiently recruits mtHsp70 and impairs protein translocation. J Cell Biol 145: 961-972, 1999.

90. Michael MZ, SM OC, van Holst Pellekaan NG, Young GP, and James RJ. Reduced accumulation of specific microRNAs in colorectal neoplasia. Mol Cancer Res 1: 882-891, 2003.

91. Mitchell PS, Parkin RK, Kroh EM, Fritz BR, Wyman SK, Pogosova-Agadjanyan EL, Peterson A, Noteboom J, O'Briant KC, Allen A, Lin DW, Urban N, Drescher CW, Knudsen BS, Stirewalt DL, Gentleman R, Vessella RL, Nelson PS, Martin DB, and Tewari M. Circulating microRNAs as stable blood-based markers for cancer detection. Proc Natl Acad Sci U S A 105: 10513-10518, 2008.

92. Mokranjac D, Bourenkov G, Hell K, Neupert W, and Groll M. Structure and function of Tim14 and Tim16, the J and J-like components of the mitochondrial protein import motor. EMBO J 25: 4675-4685, 2006.

93. Nam S, Nakamuta N, Kurohmaru M, and Hayashi Y. Cloning and sequencing of the mouse cDNA encoding a phospholipid hydroperoxide glutathione peroxidase. Gene 198: 245249, 1997. 
94. Narendran P, Estella E, and Fourlanos S. Immunology of type 1 diabetes. QJM 98: 547-556, 2005.

95. Neupert W and Brunner M. The protein import motor of mitochondria. Nat Rev Mol Cell Biol 3: 555-565, 2002.

96. Neupert W and Herrmann JM. Translocation of proteins into mitochondria. Annu Rev Biochem 76: 723-749, 2007.

97. Nielsen LB, Bartels ED, and Bollano E. Overexpression of apolipoprotein B in the heart impedes cardiac triglyceride accumulation and development of cardiac dysfunction in diabetic mice. J Biol Chem 277: 27014-27020, 2002.

98. Nishi H, Ono K, Iwanaga Y, Horie T, Nagao K, Takemura G, Kinoshita M, Kuwabara Y, Mori RT, Hasegawa K, Kita T, and Kimura T. MicroRNA-15b modulates cellular ATP levels and degenerates mitochondria via Arl2 in neonatal rat cardiac myocytes. J Biol Chem 285: 4920-4930.

99. Nishikawa T, Edelstein D, and Brownlee M. The missing link: a single unifying mechanism for diabetic complications. Kidney Int Suppl 77: S26-30, 2000.

100. Nunoda S, Genda A, Sugihara N, Nakayama A, Mizuno S, and Takeda R. Quantitative approach to the histopathology of the biopsied right ventricular myocardium in patients with diabetes mellitus. Heart Vessels 1: 43-47, 1985.

101. Okamoto K, Brinker A, Paschen SA, Moarefi I, Hayer-Hartl M, Neupert W, and Brunner M. The protein import motor of mitochondria: a targeted molecular ratchet driving unfolding and translocation. EMBO J 21: 3659-3671, 2002. 
102. Oliveira PJ, Seica R, Coxito PM, Rolo AP, Palmeira CM, Santos MS, and Moreno AJ. Enhanced permeability transition explains the reduced calcium uptake in cardiac mitochondria from streptozotocin-induced diabetic rats. FEBS Lett 554: 511-514, 2003.

103. Otera H, Taira Y, Horie C, Suzuki Y, Suzuki H, Setoguchi K, Kato H, Oka T, and

Mihara K. A novel insertion pathway of mitochondrial outer membrane proteins with multiple transmembrane segments. J Cell Biol 179: 1355-1363, 2007.

104. Palmer JW, Tandler B, and Hoppel CL. Biochemical properties of subsarcolemmal and interfibrillar mitochondria isolated from rat cardiac muscle. J Biol Chem 252: 8731-8739, 1977.

105. Perocchi F, Jensen LJ, Gagneur J, Ahting U, von Mering C, Bork P, Prokisch H, and Steinmetz LM. Assessing systems properties of yeast mitochondria through an interaction map of the organelle. PLoS Genet 2: e170, 2006.

106. Pfanner $\mathbf{N}$ and Geissler A. Versatility of the mitochondrial protein import machinery. Nat Rev Mol Cell Biol 2: 339-349, 2001.

107. Rana TM. Illuminating the silence: understanding the structure and function of small RNAs. Nat Rev Mol Cell Biol 8: 23-36, 2007.

108. Regan TJ and Lyons MM. Diabetic cardiomyopathy. Circulation 83: 1830, 1991.

109. Regan TJ, Lyons MM, Ahmed SS, Levinson GE, Oldewurtel HA, Ahmad MR, and Haider B. Evidence for cardiomyopathy in familial diabetes mellitus. J Clin Invest 60: 884-899, 1977.

110. Ren XP, Wu J, Wang X, Sartor MA, Qian J, Jones K, Nicolaou P, Pritchard TJ, and Fan GC. MicroRNA-320 is involved in the regulation of cardiac ischemia/reperfusion injury by targeting heat-shock protein 20. Circulation 119: 2357-2366, 2009. 
111. Ritov VB, Menshikova EV, He J, Ferrell RE, Goodpaster BH, and Kelley DE. Deficiency of subsarcolemmal mitochondria in obesity and type 2 diabetes. Diabetes 54: 8-14, 2005.

112. Riva A, Tandler B, Loffredo F, Vazquez E, and Hoppel C. Structural differences in two biochemically defined populations of cardiac mitochondria. Am J Physiol Heart Circ Physiol 289: H868-872, 2005.

113. Roglic G, Unwin N, Bennett PH, Mathers C, Tuomilehto J, Nag S, Connolly V, and

King H. The burden of mortality attributable to diabetes: realistic estimates for the year 2000. Diabetes Care 28: 2130-2135, 2005.

114. Rolo AP and Palmeira CM. Diabetes and mitochondrial function: role of hyperglycemia and oxidative stress. Toxicol Appl Pharmacol 212: 167-178, 2006.

115. Sadi G and Guray T. Gene expressions of Mn-SOD and GPx-1 in streptozotocininduced diabetes: effect of antioxidants. Mol Cell Biochem 327: 127-134, 2009.

116. Schannwell CM, Schneppenheim M, Perings S, Plehn G, and Strauer BE. Left ventricular diastolic dysfunction as an early manifestation of diabetic cardiomyopathy. Cardiology 98: 33-39, 2002.

117. Schiller D. Pam17 and Tim44 act sequentially in protein import into the mitochondrial matrix. Int J Biochem Cell Biol 41: 2343-2349, 2009.

118. Schiller D, Cheng YC, Liu Q, Walter W, and Craig EA. Residues of Tim44 involved in both association with the translocon of the inner mitochondrial membrane and regulation of mitochondrial Hsp70 tethering. Mol Cell Biol 28: 4424-4433, 2008.

119. Schnedl WJ, Ferber S, Johnson JH, and Newgard CB. STZ transport and cytotoxicity. Specific enhancement in GLUT2-expressing cells. Diabetes 43: 1326-1333, 1994. 
120. Sen CK. MicroRNAs as new maestro conducting the expanding symphony orchestra of regenerative and reparative medicine. Physiol Genomics 43: 517-520.

121. Severson DL. Diabetic cardiomyopathy: recent evidence from mouse models of type 1 and type 2 diabetes. Can J Physiol Pharmacol 82: 813-823, 2004.

122. Shen X, Zheng S, Metreveli NS, and Epstein PN. Protection of cardiac mitochondria by overexpression of MnSOD reduces diabetic cardiomyopathy. Diabetes 55: 798-805, 2006.

\section{Shen X, Zheng S, Thongboonkerd V, Xu M, Pierce WM, Jr., Klein JB, and Epstein}

PN. Cardiac mitochondrial damage and biogenesis in a chronic model of type 1 diabetes. Am J Physiol Endocrinol Metab 287: E896-905, 2004.

124. Shimada T, Horita K, Murakami M, and Ogura R. Morphological studies of different mitochondrial populations in monkey myocardial cells. Cell Tissue Res 238: 577-582, 1984.

125. Singh B, Patel HV, Ridley RG, Freeman KB, and Gupta RS. Mitochondrial import of the human chaperonin (HSP60) protein. Biochem Biophys Res Commun 169: 391-396, 1990.

126. Song Y, Du Y, Prabhu SD, and Epstein PN. Diabetic Cardiomyopathy in OVE26 Mice Shows Mitochondrial ROS Production and Divergence Between In Vivo and In Vitro Contractility. Rev Diabet Stud 4: 159-168, 2007.

127. Srivastava D and Olson EN. A genetic blueprint for cardiac development. Nature 407: 221-226, 2000.

128. St-Pierre J, Buckingham JA, Roebuck SJ, and Brand MD. Topology of superoxide production from different sites in the mitochondrial electron transport chain. J Biol Chem 277: 44784-44790, 2002.

129. Strub A, Lim JH, Pfanner N, and Voos W. The mitochondrial protein import motor. Biol Chem 381: 943-949, 2000. 
130. Tainer JA, Getzoff ED, Richardson JS, and Richardson DC. Structure and mechanism of copper, zinc superoxide dismutase. Nature 306: 284-287, 1983.

131. Takahashi M and Hood DA. Protein import into subsarcolemmal and intermyofibrillar skeletal muscle mitochondria. Differential import regulation in distinct subcellular regions. J Biol Chem 271: 27285-27291, 1996.

132. Tominaga M. [Diagnostic criteria for diabetes mellitus]. Rinsho Byori 47: 901-908, 1999.

133. Tomita M, Mukae S, Geshi E, Umetsu K, Nakatani M, and Katagiri T. Mitochondrial respiratory impairment in streptozotocin-induced diabetic rat heart. Jpn Circ J 60: 673-682, 1996.

134. Trost SU, Belke DD, Bluhm WF, Meyer M, Swanson E, and Dillmann WH. Overexpression of the sarcoplasmic reticulum $\mathrm{Ca}(2+)$-ATPase improves myocardial contractility in diabetic cardiomyopathy. Diabetes 51: 1166-1171, 2002.

135. Tsutsumi YM. Ischemia Reperfusion-Induced microRNAs are Blunted by Ischemic Preconditioning. FASEB J, 2008.

136. Turko IV and Murad F. Quantitative protein profiling in heart mitochondria from diabetic rats. J Biol Chem 278: 35844-35849, 2003.

137. Ungermann C, Guiard B, Neupert W, and Cyr DM. The delta psi- and Hsp70/MIM44-dependent reaction cycle driving early steps of protein import into mitochondria. EMBO J 15: 735-744, 1996.

138. Ursini F, Heim S, Kiess M, Maiorino M, Roveri A, Wissing J, and Flohe L. Dual function of the selenoprotein PHGPx during sperm maturation. Science 285: 1393-1396, 1999. 
139. van der Laan M, Chacinska A, Lind M, Perschil I, Sickmann A, Meyer HE, Guiard B, Meisinger C, Pfanner N, and Rehling P. Pam17 is required for architecture and translocation activity of the mitochondrial protein import motor. Mol Cell Biol 25: 7449-7458, 2005.

140. van Rooij E, Sutherland LB, Qi X, Richardson JA, Hill J, and Olson EN. Control of stress-dependent cardiac growth and gene expression by a microRNA. Science 316: 575-579, 2007.

141. van Rooij E, Sutherland LB, Thatcher JE, DiMaio JM, Naseem RH, Marshall WS, Hill JA, and Olson EN. Dysregulation of microRNAs after myocardial infarction reveals a role of miR-29 in cardiac fibrosis. Proc Natl Acad Sci U S A 105: 13027-13032, 2008.

142. Vered A, Battler A, Segal P, Liberman D, Yerushalmi Y, Berezin M, and Neufeld HN. Exercise-induced left ventricular dysfunction in young men with asymptomatic diabetes mellitus (diabetic cardiomyopathy). Am J Cardiol 54: 633-637, 1984.

143. Voisine C, Craig EA, Zufall N, von Ahsen O, Pfanner N, and Voos W. The protein import motor of mitochondria: unfolding and trapping of preproteins are distinct and separable functions of matrix Hsp70. Cell 97: 565-574, 1999.

144. Voos W, Martin H, Krimmer T, and Pfanner N. Mechanisms of protein translocation into mitochondria. Biochim Biophys Acta 1422: 235-254, 1999.

145. Voos W and Rottgers K. Molecular chaperones as essential mediators of mitochondrial biogenesis. Biochim Biophys Acta 1592: 51-62, 2002.

146. Walker MD. Role of MicroRNA in pancreatic beta-cells: where more is less. Diabetes 57: 2567-2568, 2008. 
147. Wallace DC. Mitochondrial genetics: a paradigm for aging and degenerative diseases? Science 256: 628-632, 1992.

148. Wang $\mathbf{Z}$ and Gleichmann H. GLUT2 in pancreatic islets: crucial target molecule in diabetes induced with multiple low doses of streptozotocin in mice. Diabetes 47: 50-56, 1998.

149. Way KJ, Isshiki K, Suzuma K, Yokota T, Zvagelsky D, Schoen FJ, Sandusky GE,

Pechous PA, Vlahos CJ, Wakasaki H, and King GL. Expression of connective tissue growth factor is increased in injured myocardium associated with protein kinase $\mathrm{C}$ beta2 activation and diabetes. Diabetes 51: 2709-2718, 2002.

150. Westermann D, Rutschow S, Jager S, Linderer A, Anker S, Riad A, Unger T, Schultheiss HP, Pauschinger M, and Tschope C. Contributions of inflammation and cardiac matrix metalloproteinase activity to cardiac failure in diabetic cardiomyopathy: the role of angiotensin type 1 receptor antagonism. Diabetes 56: 641-646, 2007.

151. Widyantoro B, Emoto N, Nakayama K, Anggrahini DW, Adiarto S, Iwasa N, Yagi K, Miyagawa K, Rikitake Y, Suzuki T, Kisanuki YY, Yanagisawa M, and Hirata K. Endothelial cell-derived endothelin-1 promotes cardiac fibrosis in diabetic hearts through stimulation of endothelial-to-mesenchymal transition. Circulation 121: 2407-2418.

152. Wilcox AJ, Choy J, Bustamante C, and Matouschek A. Effect of protein structure on mitochondrial import. Proc Natl Acad Sci U S A 102: 15435-15440, 2005.

153. Wild S, Roglic G, Green A, Sicree R, and King H. Global prevalence of diabetes: estimates for the year 2000 and projections for 2030. Diabetes Care 27: 1047-1053, 2004.

154. Williamson CL, Dabkowski ER, Baseler WA, Croston TL, Alway SE, and Hollander JM. Enhanced apoptotic propensity in diabetic cardiac mitochondria: influence of subcellular spatial location. Am J Physiol Heart Circ Physiol 298: H633-642. 
155. Williamson CL, Dabkowski ER, Dillmann WH, and Hollander JM. Mitochondria protection from hypoxia/reoxygenation injury with mitochondria heat shock protein 70 overexpression. Am J Physiol Heart Circ Physiol 294: H249-256, 2008.

156. Wold LE, Ceylan-Isik AF, and Ren J. Oxidative stress and stress signaling: menace of diabetic cardiomyopathy. Acta Pharmacol Sin 26: 908-917, 2005.

157. Wold LE, Relling DP, Colligan PB, Scott GI, Hintz KK, Ren BH, Epstein PN, and Ren J. Characterization of contractile function in diabetic hypertensive cardiomyopathy in adult rat ventricular myocytes. J Mol Cell Cardiol 33: 1719-1726, 2001.

158. Yano M, Terada K, and Mori M. Mitochondrial import receptors Tom 20 and Tom 22 have chaperone-like activity. J Biol Chem 279: 10808-10813, 2004.

159. Ye G, Metreveli NS, Donthi RV, Xia S, Xu M, Carlson EC, and Epstein PN. Catalase protects cardiomyocyte function in models of type 1 and type 2 diabetes. Diabetes 53: 13361343, 2004.

160. Young JC, Hoogenraad NJ, and Hartl FU. Molecular chaperones Hsp90 and Hsp70 deliver preproteins to the mitochondrial import receptor Tom70. Cell 112: 41-50, 2003.

161. Yu Z, Quamme GA, and McNeill JH. Depressed [Ca2+]i responses to isoproterenol and cAMP in isolated cardiomyocytes from experimental diabetic rats. Am J Physiol 266: H2334-2342, 1994. 


\section{Chapter 2:}

\section{Proteomic Alterations of Distinct Mitochondrial Subpopulations in the Type 1 Diabetic Heart: Contribution of Protein Import Dysfunction}

As published in Am J Physiol Regul Integr Comp Physiol. 2011 Feb;300(2):R186-200.

*Walter A. Baseler ${ }^{1,2}$, Erinne R. Dabkowki ${ }^{1,2}$,Courtney L. Williamson ${ }^{1,2}$, Tara L. Croston ${ }^{1,2}$, Dharendra Thapa $^{1,2}$, Matthew J. Powell ${ }^{3}$, Trust T. Razunguzwa ${ }^{3}$, and John M. Hollander ${ }^{1,2}$

*These authors contributed equally

${ }^{1}$ West Virginia University School of Medicine, Division of Exercise Physiology; ${ }^{2}$ Center for Cardiovascular and Respiratory Sciences; Morgantown, WV 26506; ${ }^{3}$ Protea Biosciences Inc.; Morgantown, WV 26507

Running Title: Mitochondrial Subpopulation Proteomics and the Type 1 Diabetic Heart 


\begin{abstract}
Diabetic cardiomyopathy is associated with increased risk of heart failure in type 1 diabetic patients. Mitochondrial dysfunction is suggested as an underlying contributor to diabetic cardiomyopathy. Cardiac mitochondria are characterized by their subcellular spatial locale including mitochondria located beneath the sarcolemma, subsarcolemmal mitochondria (SSM), and mitochondria situated between the myofibrils, interfibrillar mitochondria (IFM). The goal of this study was to determine whether type 1 diabetic insult in the heart influences proteomic make-up of spatially-distinct mitochondrial subpopulations and to evaluate the role of nuclearencoded mitochondrial protein import. Utilizing multiple proteomic approaches (iTRAQ, and 2D-DIGE), IFM proteomic make-up was impacted by type 1 diabetes mellitus to a greater extent than SSM as evidenced by decreased abundance of fatty acid oxidation and electron transport chain proteins. Mitochondrial phosphate carrier and adenine nucleotide translocator, inner membrane translocases, were decreased in the diabetic IFM ( $p<0.05$ for both). Mitofilin, a protein involved in cristae morphology, was diminished in the diabetic IFM $(p<0.05)$. Posttranslational modifications, including oxidations and deamidations, were most prevalent in the diabetic IFM. Mitochondrial heat shock protein $70(\mathrm{mtHsp} 70)$ was significantly decreased in diabetic IFM $(p<0.05)$. Mitochondrial protein import was decreased in the diabetic IFM with no change in the diabetic SSM $(p<0.05)$. Taken together, these results indicate that mitochondrial proteomic alterations in the type 1 diabetic heart are more pronounced in the IFM. Further, proteomic alterations are associated with nuclear-encoded mitochondrial protein import dysfunction and loss of an essential mitochondrial protein import constituent, mtHsp70, implicating this process in the pathogenesis of the diabetic heart.
\end{abstract}




\section{INTRODUCTION}

Cardiovascular complications, including diabetic cardiomyopathy, are the leading cause of mortality among type 1 diabetic patients. A number of studies have indicated that mitochondrial dysfunction underlies and is a central contributor to the dysfunction seen in the type 1 diabetic heart $(11,13,36,39)$. An increasing amount of evidence suggests that mitochondrial subcellular location influences the pathogenesis of dysfunctional mitochondria in the type 1 diabetic heart $(11,24)$. Cardiac mitochondria are characterized by different spatial location within the cell including mitochondria located at the sarcolemma, subsarcolemmal mitochondria (SSM), and mitochondria situated between the myofibrils, interfibrillar mitochondria (IFM). We and others have shown that these two spatially distinct subpopulations of mitochondria are differentially affected with various pathological insults $(11,24,26,27,32,37,43)$. Specifically, we have demonstrated that the IFM display greater dysfunctional profiles with type 1 diabetic insult, as evidenced by enhanced oxidative stress, diminished ETC function and decreased cardiolipin content (11).

Proteomic evaluations have played an important role in furthering our understanding of mitochondrial dysfunction in the diabetic heart. Several proteomic studies have been undertaken in various diabetic models in an effort to clarify the nature of the proteomic changes associated with the diabetic heart $(5,15,21,39,41)$. Turko et al. identified 30 altered mitochondrial proteins in isolated mitochondria from STZ-induced type 1 diabetic rat hearts (41). In particular, they observed enhanced fatty acid oxidation (FAO) proteins and reduction of several oxidative phosphorylation (OXPHOS) protein subunits. Utilizing an iTRAQ ${ }^{\mathrm{TM}}$ labeling method, Jullig et

al. identified 65 proteins significantly changing in the STZ-induced type 1 diabetic rat heart as compared to control (21). The most significant changes were increased levels of FAO enzymes 
and decreased proteins involved in OXPHOS. In a recent study using label free proteome expression analyses, Bugger et al. examined mitochondrial proteomes of several tissues from the Akita mouse (kidney, liver, brain and heart) (5). Their results indicate that FAO proteins were less abundant in liver mitochondria, whereas FAO protein content was induced in mitochondria from all other tissues. In addition, levels of OXPHOS subunits were coordinately increased in liver mitochondria, whereas mitochondria from other tissues were unaffected (5). Taken together, these data suggest that the cardiac mitochondrial proteome is impacted during type 1 diabetes mellitus, though a number of variables may contribute to conflicting results. To date no one has examined proteomic differences in spatially distinct subpopulations of mitochondria in the type 1 diabetic heart which may offer further insight into the nature of this dynamic process in the type 1 diabetic heart.

Studies examining mechanisms underlying or contributing to the proteomic alterations in the diabetic heart are limited (16). Potential mechanisms of proteomic dysregulation may include pathological alterations in gene expression, increases in post-translational modifications (PTMs) of proteins, or upregulation of post-translational regulators such as microRNAs (miRNAs). Alternatively, dysfunctional nuclear-encoded mitochondrial protein import could also disturb the proteomic composition of the mitochondrion. Currently, there are approximately 1200 known proteins in the human mitochondrion (38), and an estimated 1500 proteins (6). Of this number only 13 proteins are transcribed and translated inside the organelle itself. As a result, the vast majority of proteins ( $\sim 99 \%)$ must be imported into mitochondrion through a complex mechanism of translocation involving interaction between protein targeting signals and mitochondrial translocases (7). To date, no study has examined the impact of type 1 diabetes mellitus on spatially distinct mitochondrial proteomes in the diabetic heart or offered insight into the 
mechanisms influencing specific proteomic profiles. The goal of this study was to determine whether proteomic differences exist in subpopulations of mitochondria as well as to evaluate the role of nuclear-encoded mitochondrial protein import in the type 1 diabetic heart. 


\section{MATERIALS AND METHODS}

\section{Experimental Animals and Diabetes Induction}

The animal experiments in this study conformed to National Institutes of Health (NIH) Guidelines for the Care and Use of Laboratory Animals and were approved by the West Virginia University Animal Care and Use Committee. Male FVB mice (Charles River Laboratories, Wilmington, MA) were housed in the West Virginia University Health Sciences Center animal facility. Mice were given unlimited access to a rodent diet and water. Type 1 diabetes mellitus was induced in 8-wk-old mice following the protocol of the Animal Models of Diabetic Complications Consortium using multiple low-dose streptozotocin (STZ; Sigma, St. Louis, MO) injections. Injections of $50 \mathrm{mg} / \mathrm{kg}$ body weight STZ dissolved in sodium citrate buffer (pH 4.5) were performed daily for 5 consecutive days after 6 hours of fasting. Mice that served as vehicle controls were given the same volume per body weight of sodium citrate buffer. One week postinjections, hyperglycemia was confirmed by measuring urinary glucose levels (Chemstrip 2GP Urine test strips, Roche Diagnostics, Indianapolis, IN). Five weeks post hyperglycemia onset, animals were sacrificed for further experimentation. To characterize the diabetic phenotype, blood glucose (Bayer, Mishawaka, IN) and plasma insulin (ALPCO, Salem, NH) levels were determined using commercially available kits.

\section{Preparation of Individual Mitochondrial Subpopulations}

At 5 weeks post hyperglycemia onset, FVB mice and their littermate controls were sacrificed, and the hearts were excised. Hearts were rinsed in phosphate buffered saline (PBS, pH 7.4), then blotted dry. SSM and IFM were isolated as previously described following the methods of 
Palmer et al. (31) with minor modifications $(11,12,43)$. Protein concentrations were determined using the Bradford method with bovine serum albumin (BSA) as a standard (3).

\section{iTRAQ Labeling}

Pooled SSM and IFM subpopulations $(\mathrm{N}=4)$ from diabetic and control hearts were lysed and precipitated overnight in acetone at $-20^{\circ} \mathrm{C}$ and pellets were resuspended in $20 \mu \mathrm{L}$ of $0.5 \mathrm{M}$ triethylammonium bicarbonate (TEAB; $\mathrm{pH} 8.5$ ) as previously described (10). Protein contents were determined using a 2-D Quant Kit (Amersham, Piscataway, NJ) and $100 \mu \mathrm{g}$ of each pooled sample was than denatured with $0.1 \%$ SDS and reduced with $5 \mathrm{mM}$ tris-(2-carboxyethyl) phosphine (TCEP). After incubation for 1 hour at $60^{\circ} \mathrm{C}$, cysteines were blocked with $10 \mathrm{mM}$ methyl methane thiosulfonate (MMTS) in isopropanol, and the samples were incubated at room temperature for 10 minutes. Addition of $10 \mu \mathrm{L}$ of sequencing grade trypsin (Applied Biosystems, Foster City, CA) was added in a trypsin/protein ratio of 1:20, and the samples incubated at $37^{\circ} \mathrm{C}$ overnight. Digested samples were labeled with the iTRAQ ${ }^{\mathrm{TM}}$ reagents following the protocol provided by the vendor (Applied Biosystems, Foster City, CA).

After digestion and iTRAQ labeling, the ultra-complex protein digests were combined to create a $400 \mu \mathrm{g}$ pooled protein digest sample that contained equal fractions of each of the four labeled samples for subsequent Multi Dimensional Protein Identification Technology (MudPIT) analysis (28). After lyophilization, the digest mixture was reconstituted in strong cation exchange (SCX) loading buffer ( $5 \mathrm{mM}$ ammonium formate in $20 \%$ acetonitrile; $\mathrm{pH} 3.0$ ) to be fractionated with SCX SpinTips (Protea Biosciences, Morgantown, WV) per the manufacturer's protocol. Briefly, the sample solution was loaded centrifugally onto the SCX SpinTip. The non-adsorbing solution 
that passed through the SCX SpinTip was collected. Eight different elution solutions were used to fractionate the peptides $(20,60,100,150,200,250,400$, and $500 \mathrm{mM}$ ammonium formate in $10 \%$ acetonitrile) in a step-wise manner, for a total of nine sample fractions. The collected fractions were cleaned by repeated lyophilization and reconstituted in a $0.1 \mathrm{M}$ acetic acid solution, and then lyophilized to dryness. The fractions were then submitted for LC-MALDI TOF/TOF mass spectral analysis for protein identification, characterization, and differential expression analysis.

\section{Mass Spectrometry (MS) Analyses with iTRAQ ${ }^{\mathrm{TM}}$ Labeling}

The LC-MALDI mass spectrometry system utilized was an ABI Tempo LC MALDI spotter with Tempo LC MALDI v.2.00.09 data acquisition and processing software. Lyophilized SCX sample fractions were reconstituted in LC aqueous run buffer $(0.1 \%$ trifluoroacetic acid, $2 \%$ acetonitrile) and injected onto a Zorbax $\mathrm{C}_{18}$ chromatographic column, 150 x $0.3 \mathrm{~mm}$ (Agilent Technologies, Wilmington, DE). The peptides were eluted from the column using an acetonitrile/trifluoroacetic acid gradient (2-72\% acetonitrile in 35 minutes) and spotted directly onto a MALDI plate in 6 second spot fractions. The MALDI spots were analyzed using an ABI 4800 MALDI TOF/TOF analyzer operated with 4000 Series Explorer software. The MS acquisition was in positive ion reflector mode with 400 laser shots per spectrum performed. The 15 strongest precursors per spot were chosen for MS/MS and the MALDI spot was interrogated until at least 4 peaks in the MS/MS, spectra achieved a $\mathrm{S} / \mathrm{N} \geq 70$.

The resulting MS/MS spectra were analyzed using ABI Protein ProteinPilot software 2.0 (Applied Biosystems, Foster City, CA). The spectral data was searched against the mouse 
protein database (NCBI nr.fasta database customized to select for all mouse proteins) for identification of the peptides and corresponding proteins. In ProteinPilot, the sample type was selected as iTRAQ 4Plex for retrieval of the isotopic tag information from the mass spectra. After database correlation analysis, the proteins were grouped, scored, and normalized against one of four isotope correction factors. The Pro Group algorithm of ProteinPilot generated a protein score (ProtScore) that is a cumulative score from each of the peptides used by the algorithm in the protein identification. ProtScores above 2.0, 1.0, and 0.47 expressed the percent confidence levels of $>99,>90$, and $>66 \%$, respectively. Each peptide match showed the iTRAQ isotopic labels, MMTS labeled cysteines, and other PTMs present as mass spectral shifts identified during the database correlation analysis. Each protein identified also showed the differential protein expression compared against the other iTRAQ labeled samples for relative quantitation.

\section{D-Differential In-Gel Electrophoresis (2D-DIGE)}

\section{Sample Preparation}

Isolated mitochondrial subpopulations were placed in lysis buffer $(7 \mathrm{M}$ urea, $2 \mathrm{M}$ thiourea, $30 \mathrm{mM}$ Tris, $5 \mathrm{mM}$ magnesium acetate, $4 \%$ CHAPS, and $58 \mathrm{mM}$ DTT) in a 1:10 ratio. Protein concentration of the samples was determined using a 2-D Quant Kit (Amersham Biosciences, Piscataway, NJ).

2D-DIGE and Differential-display Proteome Analyses 
$100 \mu \mathrm{g}$ of each mitochondria subpopulation from both diabetic and control was lysed with labeling buffer ( $7 \mathrm{M}$ urea, $2 \mathrm{M}$ thiourea, 4\% CHAPS, $30 \mathrm{mM}$ Tris, $5 \mathrm{mM}$ magnesium acetate). One third of each sample was removed and combined into a separate tube to serve as an internal standard. $50 \mu \mathrm{g}$ of the remaining samples were labeled separately with $400 \mathrm{pmol}$ of Cy3 or Cy5 NHS-ester minimal labeling reagents for 30 minutes on ice and in the dark. The samples were then quenched with $2 \mu \mathrm{l}$ of $10 \mathrm{mM}$ lysine for 10 minutes on ice in the dark. $50 \mu \mathrm{g}$ of the combined sample was also labeled with $400 \mathrm{pmol}$ of $\mathrm{Cy} 2$ and than quenched with $10 \mu \mathrm{l}$ of 10 $\mathrm{mM}$ lysine. Individual Cy3- and Cy5-labeled samples were combined with the same amount of the Cy2-labeled internal standard. Each gel contained one control and one diabetic sample from individual mitochondrial subpopulations, and the $\mathrm{Cy} 3$ and $\mathrm{Cy} 5$ dyes were alternated to account for dye labeling variability. The samples were separated by standard 2D gel electrophoresis utilizing a manifold-equipped IPGphor first dimension isoelectric focusing unit and $24 \mathrm{~cm} \mathrm{3-10}$ immobilized $\mathrm{pH}$ gradient (IPG) strips. The initial separation was followed by a seconddimension 12\% SDS-PAGE homogenous on hand-cast gels. The Cy2 (mixed standard), Cy3 and Cy5 components of each gel were visualized separately at $100 \mu \mathrm{m}$ resolution with mutuallyexclusive excitation/emission wavelengths using a Typhoon 9400 Variable Mode Fluorescence Imager (GE Healthcare, Piscataway, NJ). A Sypro Ruby protein post-stain (Invitrogen, Carlsbad, CA) was used to extract protein from the gels. Gel images were submitted to Ludesi 2D Analysis (Ludesi, Malmo, Sweden, http://www.ludesi.com) for spot detection, matching, and analysis. Control:standard and diabetic:standard normalized volume ratios were calculated for each protein on every gel, and the internal standards were used to normalize and compare these ratios across the 10 2D-DIGE gels. This method allowed for the calculation of average 
abundance changes and Student's T-test p-values for the variance of these ratios for each proteinpair across all 10 individual gels.

Mass Spectrometry and Database Analysis

Proteins that were changing were excised and digested in gel with trypsin protease and the resulting peptides analyzed using a Micromass MALDI micro MX TOF Spectrometer (Waters, Milford, MA). The resulting peptide mass maps were compared to sequences present in the SWISS-PROT and NCBInr databases to generate statistically significant identifications of proteins using GPS Explorer software (Applied Biosystems, Foster City, CA) running the MASCOT search algorithm. Searches were performed without constraining protein molecular weight or isoelectric point, with complete carbamidomethylation of cysteine, partial oxidation of methionine residues, and one missed cleavage also allowed in the search parameters. Molecular Weight Search (MOWSE) scores from database interrogation above $58(p<0.05)$, number of matched ions, number of matching sequence coverage, and correlation of gel region with predicted MW and $\mathrm{pI}$ were considered for each protein identification.

\section{Protein Import}

\section{Plasmid Construction}

The fusion protein construct pAcGFP1-Mito (Clontech Laboratories, Mountain View, CA) containing the precursor subunit VIII of human cytochrome $\mathrm{C}$ oxidase and the green fluorescent protein from Aequorea coerulescens (AcGFP1) was cloned into pIVEX2.3d (Roche Applied Science, Indianapolis, IN) at restriction sites Not I and blunted Nco I/Nhe I creating pMITOGFP1 (Supplemental Figure 1S). The correct sequence was confirmed by 
dideoxynucleotide sequencing. pMITOGFP1 was grown to a concentration of $500 \mathrm{ng} / \mu \mathrm{l}$ and isolated using mini prep plasmid DNA isolation (Qiagen, Valencia, CA).

\section{In Vitro Synthesis of Mitochondrial Protein}

In vitro transcription and translation of MitoGFP1 was performed using the S30 T7 protein expression system (Promega, Madison, WI) as per the manufacturer's protocol. Additionally, fluorescent labeling of MitoGFP1 was performed using the FluoroTect Green ${ }_{\text {Lys }}$ tRNA in vitro labeling system (Promega, Madison, WI) as per the manufacturer's protocol. MitoGFP1 and fluorescent MitoGFP1 lysates were subsequently used as substrates for the in vitro protein import process.

\section{Mitochondrial Protein Import}

The mitochondrial protein import procedure was performed following the protocol from Stojanovski et al. (40) with modifications. Briefly, $40 \mu \mathrm{g}$ of mitochondria was resuspended in $100 \mu \mathrm{l}$ of import buffer ( $250 \mathrm{mM}$ Sucrose, $80 \mathrm{mM} \mathrm{KCl}, 5 \mathrm{mM} \mathrm{MgCl} 2,2 \mathrm{mM} \mathrm{KH}_{2} \mathrm{PO}_{4}, 10 \mathrm{mM}$ MOP-KOH, $\mathrm{pH}$ 7.2) with addition of $2 \mathrm{mM} \mathrm{ATP}$ and $10 \mathrm{mM} \mathrm{Na-Succinate.} 1-5 \mu 1$ of bacterial lysate containing MitoGFP1 protein was added and protein import performed at increasing time intervals of 2,5 , and 10 minutes at $25^{\circ} \mathrm{C} .2 \mu \mathrm{M}$ valinomycin was added to stop the import reaction, and samples were centrifuged at $12,000 \times g$ for 5 minutes at $4{ }^{\circ} \mathrm{C}$. The supernatant was discarded and the pellet resuspended in SEM buffer (250 mM Sucrose, $1 \mathrm{mM}$ EDTA, $10 \mathrm{mM}$ MOP-KOH, $\mathrm{pH} 7.2$ ) containing $25 \mu \mathrm{g} / \mathrm{ml}$ trypsin, on ice. Trypsin was subsequently inhibited by protease inhibitor cocktail (BioVision, Mountain View, CA). Samples were centrifuged again at $12,000 \mathrm{x} g$ for $5 \mathrm{~min}$ at $4^{\circ} \mathrm{C}$. Pellets were then resuspended in lysis buffer (BioVision, Mountain View, California), subjected to SDS-PAGE, and subsequent Western blot analyses performed. 
Quantification of blots was performed using Pierce ECL Western Blotting Substrate (Pierce Biotech, Rockford, IL). The primary antibody was an anti-GFP monoclonal antibody raised in a mouse host (Clontech Laboratories, Mountain View, CA). The secondary antibody was an antimouse IgG horseradish peroxidase conjugate (Sigma, St. Louis, MO). Quantification of chemiluminescent signals were detected using a G:BOX (Syngene, Frederick, MD), and data expressed as arbitrary optical density units. Additionally, visualization of imported fluorescent MitoGFP1 was performed using a Typhoon 9400 Variable Mode Fluorescence Imager (GE Healthcare, Piscataway, NJ) with a 532nm excitation. Control for protein loading was confirmed using Ponceau staining.

\section{Western Blot Analyses}

SDS polyacrylamide gel electrophoresis (SDS-PAGE) was run on 4-12\% gradient gels as previously described $(25,43)$ with equal amounts of protein loaded for each study treatment. Relative amounts of subpopulation-specific mitochondrial heat shock protein 70 (mtHsp70), translocases of the outer membrane 40 and 20 (Tom40 and Tom20), translocases of the inner membrane 23 and 44 (Tim23 and Tim44), were analyzed using the following primary antibodies; anti-mtHsp70 mouse antibody (Product\# SPA-825; Stressgen, Ann Arbor, MI ), anti-Tom40 goat antibody (Product\# sc-11025; Santa Cruz Biotech, Santa Cruz, CA), anti-Tom20 mouse antibody (Product \# 612278; BD Biosciences, San Jose, CA), anti-Tim23 mouse antibody (Product \# 611222; BD Biosciences, San Jose, CA), and anti-Tim44 mouse antibody (Product \# 612582, BD Biosciences, San Jose, CA). The secondary antibodies used in the analyses were donkey anti-goat IgG HRP conjugate (Product \#sc-2020; Santa Cruz Biotech, Santa Cruz, CA) for Tom40, and goat-anti mouse conjugate (Product\# 31430; Pierce Biotech, Rockford, IL) for 
mtHsp70, Tom20, Tim23 and Tim44. Detection of signal was performed according to the manufacturer's instructions as above. Quantification of chemiluminescent signals and data analysis were performed as above. Control for protein loading was confirmed using Ponceau staining.

\section{mRNA Analyses}

$30 \mathrm{mg}$ of tissue was excised from control and diabetic hearts for mRNA extraction using an RNeasy mini kit per manufacturer's protocol (Qiagen, Valencia, CA) and reverse transcribed. Equal amounts of cDNA from the hearts of control and diabetic mice were subjected to real-time PCR. Custom primers were designed for target genes adenine nucleotide translocator 4 (ANT4), ATP synthase subunit alpha (ATP5A1), and ATP synthase subunit beta (ATP5B). SYBR Green I was used for quantification of respective cDNA replicates (Qiagen, Valencia, CA). Data were normalized by gene expression relative to the levels of GAPDH.

\section{Mitochondrial Membrane Potential ( $\Delta \Psi \mathrm{m})$}

Mitochondrial membrane potential $(\Delta \Psi \mathrm{m})$ was measured by flow cytometry using the ratiometric dye 5,5',6,6'-tetrachloro-1,1',3,3'-tetraethylbenzimidazol carbocyanine iodide (JC-1) (Molecular Probes, Carlsbad, CA), which is a lipophilic cation that enters selectively into mitochondria, as previously described (43). Values are expressed as the mean orange fluorescence divided by the mean green fluorescence of 20,000 mitochondrial events per individual mitochondrial sample. 


\section{Statistics}

Means and standard errors (SEM) were calculated for all data sets. Data were analyzed with a one-way analysis of variance (ANOVA) method to evaluate the main treatment effect, diabetes induction (GraphPad Software Inc., La Jolla, CA). Fisher's Least Significant Difference (LSD) post hoc tests were performed to determine the significant differences among means. When appropriate a Student's T-test was employed. $p<0.05$ was considered significant. 


\section{RESULTS}

\section{Diabetes Mellitus Phenotype}

The diabetes mellitus phenotype was characterized five weeks following STZ treatment by assessing blood glucose and plasma insulin levels. Blood glucose levels were significantly elevated in diabetic mice as compared to control (Control, $140 \pm 5 \mathrm{mg} / \mathrm{dL}$ vs. Diabetic, $548 \pm 22$ $\mathrm{mg} / \mathrm{dL} ; P<0.05)$. Further, plasma insulin levels were significantly reduced in diabetic mice as compared to control (Control, $1.92 \pm 0.17 \mathrm{ng} / \mathrm{mL}$ vs. Diabetic, $0.47 \pm 0.06 \mathrm{ng} / \mathrm{mL}$ ).

\section{Proteomic Analyses}

To determine whether type 1 diabetes mellitus differentially impacts spatially distinct mitochondrial subpopulation proteomes, we utilized both iTRAQ and 2D-DIGE approaches. iTRAQ enables simultaneous identification and relative quantification of mitochondrial proteins through isobaric peptide tagging, while 2D-DIGE analysis is a quantitative technique that enables multiple protein samples to be separated on the same 2-D gel, thereby greatly reducing the introduction of potential artifacts due to gel-to-gel variations. Figure 2.1 is an example of an MS/MS fragment ion (spectra) for a peptide that was used to identify a protein, mtHsp70. Located below the spectra is an example of an iTRAQ tag mass spectral signature $(\mathrm{m} / \mathrm{z}, 114,115$, 116, and 117) used to make a relative quantification of mtHsp70 within the four labeled sample groups (see Figure 2.1 legend for groups). Figures 2.2A-D are representative 2D gels from four mitochondrial samples, (A) control IFM, (B) diabetic IFM, (C) control SSM, and (D) diabetic SSM, labeled with different Cy dyes. In this example, an individual spot, identified as mtHsp70, is indicated by the red arrows, and the quantitative differences assessed by examination of peak 
densities which are shown in each individual representative gel image (Figures 2.2A-D). MtHsp70 peak density was significantly decreased $(p<0.02)$ in the diabetic IFM as compared to control IFM, with no changes in diabetic SSM as compared to control SSM.

Proteins of Fatty Acid Oxidation (FAO). FAO proteins were significantly altered in both diabetic SSM and diabetic IFM as compared to control using both iTRAQ and 2D-DIGE methods. In contrast to our previous study in a type 2 diabetes mellitus model (10), iTRAQ analysis revealed 8 of 10 proteins involved in FAO which were decreased in the diabetic IFM, while 4 of 10 were decreased in the diabetic SSM (Table 2.1). Interestingly, carnitine palmitoyltransferase-1 (CPT-1), an outer mitochondrial membrane protein that mediates transport of long-chain fatty acids across the membrane, was significantly increased in the diabetic SSM while diminished in the diabetic IFM (Table 2.1). Further, 2D-DIGE analysis identified 6 FAO proteins that were also significantly decreased in the diabetic IFM, while 2 of 6 were decreased in the diabetic SSM (Table 2.2). Taken together, both proteomic analyses suggest that FAO proteins are impaired in both diabetic SSM and IFM, with the effect being greatest in the IFM.

Proteins of the Mitochondrial Respiratory Chain. Utilizing both iTRAQ and 2D-DIGE, a number of proteins of the mitochondrial respiratory chain were significantly altered in both diabetic SSM and diabetic IFM as compared to control. With iTRAQ, 9 of 23 respiratory chain proteins identified were significantly decreased in the diabetic IFM as compared to control, while 1 of 23 respiratory chain proteins identified were decreased in expression in the diabetic SSM as compared to control (Table 2.1). Interestingly, 5 of 23 respiratory chain proteins identified were increased in the SSM as compared to control. In the diabetic IFM, all 4 proteins identified from complex V (ATP synthase) were decreased, while 2 of 6 proteins from complex I, and 1 of 4 
were from complex IV were decreased (Table 2.1). In the diabetic SSM, one protein each from complexes I, III, IV and V, respectively, were significantly increased as compared to control SSM (Table 2.1). Similar to the iTRAQ analysis, 2D-DIGE analysis revealed 16 proteins of the respiratory chain decreased in the diabetic IFM, with 3 proteins increased in the diabetic SSM (Tables 2.1 and 2.2). Proteins that were decreased in the diabetic IFM were from all respiratory complexes including complexes I, II, III, IV and V with the greatest number of decreased proteins occurring at complex I. Similar to the iTRAQ analysis, several respiratory proteins were increased in the diabetic SSM suggesting a possible compensatory mechanism to prevent dysfunction.

Proteins of the Citric Acid Cycle (TCA). ITRAQ and 2D-DIGE analyses of proteins involved in the TCA revealed significant changes in both the diabetic SSM and IFM as compared to control. In the diabetic IFM, 2 of 5 TCA proteins were decreased, while 3 of 5 proteins were increased in the diabetic SSM (Table 2.1). Of particular interest was the observation that isocitrate dehydrogenase $2(\mathrm{NADP}+)$ displayed increased content in the diabetic SSM yet decreased content in the diabetic IFM (Table 2.1). Similar to the iTRAQ analysis, 2D-DIGE analysis reported 6 TCA proteins decreased in the diabetic IFM, and 3 proteins increased in the diabetic SSM (Table 2.2). These data suggest again that TCA proteins and other proteins necessary for energy production are increased in the diabetic SSM, yet decreased in the diabetic IFM.

Transport Proteins. Proteins involved in transport of proteins and or substrates across the inner mitochondrial membrane (IMM) were preferentially decreased in the diabetic IFM as compared to control IFM as evidenced by a decreased content in 3 of 4 proteins, with no changes in the SSM (Table 2.1). Mitochondrial phosphate carrier, a protein that is involved in transport of phosphate groups from the cytosol to the mitochondrial matrix, was significantly decreased in 
diabetic IFM as compared to control (Table 2.1). Another translocase required for exchange of ADP and ATP across the IMM, adenine nucleotide translocator 1 (ANT1), was also significantly decreased in the diabetic IFM as compared to control (Table 2.1). Interestingly, mtHsp70 (a.k.a glucose-regulated protein 75; Grp75), a heat shock protein and a constituent of the mitochondrial import process essential for import of proteins into mitochondria, was also significantly decreased only in diabetic IFM as compared to control (Tables 2.1 and 2.2). Western blot analyses of mtHsp70 (Figure 2.5C), provided confirmation of both the iTRAQ and 2D-DIGE results observed. Another heat shock protein involved in folding and protein import into the mitochondrion, Hsp60, was also significantly decreased only in the diabetic IFM as revealed by 2D-DIGE analysis (Table 2.2).

Structural Proteins. With both iTRAQ and 2D-DIGE analyses, alterations to proteins involved in mitochondrial structure were apparent in only the diabetic IFM as compared to control with no changes in diabetic SSM. In particular, mitofilin, a transmembrane IMM protein that regulates mitochondrial cristae morphology (cristae density) (19), was significantly decreased only in diabetic IFM as indicated by both iTRAQ and 2D-DIGE analysis (Tables 2.1 and 2.2). Further, prohibitin-2, a protein involved in mitochondrial chaperone functions which may impact mitochondrial morphology as well as maintenance of mitochondrial DNA (1), was significantly decreased in the diabetic IFM with 2D-DIGE analysis (Table 2.2). These data are consistent with our previously published data suggesting that mitochondrial internal complexity is decreased in the diabetic IFM (11).

\section{Post-translational Modifications (PTM)}


Utilizing MudPIT technology to assess PTM, 42 proteins were identified as having a PTM in the diabetic IFM while 23 proteins were identified in the diabetic SSM (Table 2.3). Interestingly, 11 of the 42 proteins in the diabetic IFM contained oxidations on various amino acid residues. In particular, 3 proteins of complex III, 2 proteins of complex V and 1 protein of complex I were oxidized in the diabetic IFM. Further, mtHsp70 and mitofilin were also only oxidized in the diabetic IFM. Additionally, 13 proteins in the diabetic IFM and 8 proteins in the diabetic SSM involved in the ETC presented with some sort of PTM including acetylations, deamidations and methylations. Of greatest interest was that the majority of the modified proteins were IMM proteins, suggesting that this locus may be specifically impacted and as a result, play a key role in the pathogenesis of cardiac dysfunction associated with type 1 diabetes mellitus.

\section{Mitochondrial Protein Import Construct}

The MITOGFP1 cDNA was inserted as a Not I, Nhe I blunt fragment into the PIVEX2.3d plasmid (Figure 2.3). PIVEX2.3d has all necessary components for efficient protein production in a cell free bacterial protein expression lysate system including a T7 promoter, ribosomal binding site, and poly A tail. The MITOGFP1 gene consists of an N-terminal mitochondrial targeting sequence derived from cytochrome $\mathrm{C}$ oxidase subunit VIII (targeted to the matrix) fused with AcGFP. Translated MitoGFP1 protein was incubated with isolated mitochondria to allow for proper import. Mitochondria were subsequently cleaned of non-imported protein, lysed, and a Western blot analysis was performed probing for AcGFP. Isolated cardiac mitochondria alone does not produce a signal on the blot, (Figure 2.4, lane 1) whereas pure protein lysate from the bacterial expression system does produce the full length $31 \mathrm{kDa}$ band 
containing the N-terminal presequence (Figure 2.4, lane 2). Addition of total mitochondria and lysate together produce a similar $31 \mathrm{kDa}$ band, which is the precursor protein in transit through the mitochondrial outer and inner membrane yet to be completely imported into the mitochondrial matrix. Additionally, there is a $27 \mathrm{kDa}$ band representing the mature MitoGFP1 protein in which the precursor sequence has been cleaved and properly imported into the mitochondrial matrix (Figure 2.4, lane 3). Presequence cleavage of our target protein by mitochondrial processing peptidase will not occur until the protein is pulled into the matrix. Therefore, the smaller mature sequence was quantified for import analysis.

\section{Mitochondrial Protein Import}

Utilizing Western blot analysis, Figures $2.5 \mathrm{~A}$ and $\mathrm{C}$ show increasing amounts of protein abundance at 2, 5, and 10 minutes, respectively, of the mature $27 \mathrm{kDa}$ MitoGFP1 in the control SSM and diabetic SSM subpopulations with no statistical difference between the samples. Conversely, a significant decrease (40\%) in the amount of MitoGFP1 imported into the diabetic IFM compared to control IFM is shown at all three time points (Fig 2.5B and D). Additionally, fluorescent labeling and subsequent import of MitoGFP1 was performed to confirm our Western blot findings (Figures $2.5 \mathrm{~A}$ and $\mathrm{B}$ ). The $31 \mathrm{kDa}$ band is also decreased in the diabetic IFM compared to control denoting lesser amounts of precursor proteins in transit to the matrix.

\section{Protein Import Machinery}


Several outer and inner mitochondrial membrane translocases essential for proper mitochondrial protein import were also analyzed by Western blot analysis. There were no significant differences observed in the protein expression of Tom20, Tom40, Tim23, or Tim44 in either the diabetic SSM or diabetic IFM as compared to control (Figure 2.6A). It should be noted that Tim44 protein content showed a trend for decrease in the diabetic IFM, but the difference was not significant $(p=0.07)$. In contrast, the essential mitochondrial protein import motor, $\mathrm{mtHsp} 70$, was significantly decreased in only the diabetic IFM subpopulation compared to control (Figure 2.6C) with no change in the diabetic SSM compared to control (Figure 2.6B). These results indicate that of the several mitochondrial protein import constituents examined, only mtHsp70 is significantly decreased in abundance during type 1 diabetic insult and this phenomenon is specific to the IFM subpopulation.

\section{mRNA Analyses}

Expression of mitochondrial IMM (ANT4) and matrix (ATP5B and ATP5A1) transcripts were evaluated to determine if proteomic alterations (Tables 2.1 and 2.2) were preceded by transcriptional dysregulation in the diabetic heart. Our results indicated in Table 2.4, show no significant decreases in the gene expression of diabetic vs. control for these three specific proteins (ANT4, ATP5A1, and ATP5B), suggesting that diabetes induced proteomic decreases to IFM proteins were not a consequence of decreased mRNA presence for these particular proteins.

\section{Mitochondrial Membrane Potential ( $\Delta \Psi \mathrm{m})$}


$\Delta \Psi \mathrm{m}$ is essential for protein translocation across the IMM. Therefore, $\Delta \Psi \mathrm{m}$ was analyzed in freshly isolated mitochondrial subpopulations by flow cytometry using JC-1. No significant differences in $\Delta \Psi \mathrm{m}$ were observed in SSM control vs. diabetic (Figure 2.7A). However, there was a $19 \%$ reduction in diabetic IFM $\Delta \Psi \mathrm{m}$ as compared to control (Figure 2.7B). Additionally, baseline $\Delta \Psi \mathrm{m}$ was higher in IFM compared with SSM, which is in agreement with previous reports $(34,43)$. These data suggest that IFM $\Delta \Psi \mathrm{m}$ is decreased relative to control during diabetic insult, whereas SSM $\Delta \Psi$ m remains unaffected. 


\section{DISCUSSION}

A significant amount of data supports the notion that mitochondrial dysfunction plays a critical role in the pathogenesis of diabetic cardiomyopathy. Despite the growing evidence for mitochondrial abnormalities underlying diabetic cardiomyopathy, the mechanisms involved in this dysfunction are not entirely clear. Evidence suggests that mitochondrial dysfunction varies depending on subcellular location, with those mitochondria located between the myofibrils being affected to a greater extent in the type 1 diabetic heart $(11,43)$. Data also suggests that dysfunction manifests via disturbance to the IMM as evidenced by diminished ETC complex activities, an enhanced oxidative environment and depletion of cardiolipin, an essential phospholipid required for proper mitochondrial function $(11,33)$. The goal of this study was to build upon our previous findings and determine whether mitochondrial subpopulation-specific proteomes are altered with type 1 diabetes mellitus in the heart. In an effort to elucidate mechanism, we examined whether mitochondrial import of nuclear-encoded proteins is decreased resulting in mitochondrial proteome dysregulation.

Proteomic analyses have played an integral role in furthering our understanding of mitochondrial dysfunction in the diabetic heart. Several proteomic studies, in a variety of diabetic models, have been employed to assess proteomic changes associated with the diabetic heart $(5,10,15,21,39$, 41). However, to date no examination of subpopulation-specific proteomic make-up has been performed in a type 1 diabetic model. Proteomic profile comparisons of mitochondrial subpopulations from diabetic and control mouse hearts revealed that the majority of proteins changing were in the IFM and that almost all of these changes were decreases in protein abundances. Utilizing iTRAQ and 2D-DIGE methodologies afforded a number of advantages over the use of a single proteomic methodology including the ability to confirm experimental 
results and accuracy by essentially comparing results from each method. By using MudPIT analysis combined with iTRAQ labeling, the limitations associated with 2D-DIGE, such as solubility and separation, were bypassed. Further, the iTRAQ approach enabled comparison of total protein levels, which can be more difficult using 2D-DIGE separation, where PTMs such as phosphorylation can alter pIs and hence gel migration (21). Utilizing 2D-DIGE allowed us to examine proteins that may be in less abundance and as a result, less likely to show up with iTRAQ analyses. Because each method has its own unique set of advantages, the combined use of both techniques enhanced our level of confidence in the reported findings.

The majority of proteins identified as changing with both 2D-DIGE and iTRAQ approaches in the diabetic IFM were FAO and ETC proteins. In contrast to previous studies $(21,41)$, proteins involved in FAO (transport and/or utilization of fatty acids) were decreased in abundance in the diabetic IFM to a greater extent than in diabetic SSM. It is not entirely clear why the disparity in findings was observed. One could speculate that differences in animal models employed (mouse vs. rat), timing of examinations, STZ protocols utilized (single dose vs. multiple dose), mitochondria examined (total vs. subpopulations), or a combination of these variations in study designs may have contributed to the dissimilarity in findings. It is important to point out that in the current study, both proteomic platforms seemed to yield similar results. Nevertheless, the findings are interesting and warrant further investigation. In addition, though only a few fatty acid utilization enzymes were decreased in diabetic SSM, CPT-1 a transporter of fatty acids into the mitochondrion, was upregulated which is consistent with other proteomic studies utilizing an STZ-induced diabetic model (21). One could hypothesize that the diminished ability to utilize fatty acids within the diabetic IFM may have hampered its ability to produce ATP which in turn, contributed to an overall decrease in cardiac contractile function as reported previously $(11,42)$. 
Additionally, ETC complexes and translocases within the IMM act as key contributors to overall oxidative phosphorylation and energy production within the mitochondrion. In total, we identified 9 ETC proteins from iTRAQ analyses and 16 ETC proteins from 2D-DIGE analyses as being decreased in the diabetic IFM. Jullig et al. reported decreases in ETC constituents that are involved in oxidative phosphorylation in total mitochondria (21), which is somewhat different from our current study examining mitochondrial subpopulations. Further, translocases located within the IMM that are essential for energy production through synthesis (mitochondrial phosphate carrier) and transport of ATP (ANT1) were also significantly decreased only in the diabetic IFM. Interestingly, Jullig et al. did not report changes in ANT1 or the mitochondrial phosphate carrier which may have resulted from their analyses being performed on total mitochondria as opposed to our study examining subpopulations of mitochondria. Our proteomic data are consistent with previous reports of decreased respiratory capacity in the diabetic heart as well as functional data indicating down-regulation of ETC activities, specifically in the IFM $(11,24,39)$. Down-regulation of multiple components of the oxidative phosphorylation machinery and FAO proteins suggests that mitochondria in the type 1 diabetic mouse heart, specifically IFM, may be less efficient in producing ATP required for contraction and calcium homeostasis.

Mitochondrial morphological abnormalities have been reported with both type 1 and type 2 diabetes mellitus $(4,23,39)$. Previous reports suggest that IFM morphology is specifically impacted by diabetes mellitus $(11,23)$. We reported previously that IFM were smaller and less complex in the type 1 diabetic heart with no changes in the SSM (11). Both 2D-DIGE and iTRAQ analyses indentified mitofilin, a protein critical for proper cristae morphology (19), as being decreased only in the diabetic IFM. It is conceivable that diminished mitofilin, along with 
our previous reports of depleted cardiolipin may have been a contributing factor to the altered IFM morphology reported previously (11).

To date, no attempts have been made to define the mechanisms accounting for mitochondrial proteomic dysregulation in the diabetic heart. Many potential mechanisms of proteomic dysregulation exist, including alterations in gene expression, enhanced PTMs, or upregulation of regulators such as miRNAs $(22,30)$. To start to dissect some of these potential mechanisms we examined a small subset of mRNAs encoding for nuclear-encoded mitochondrial proteins whose contents were decreased in diabetic IFM. Our results indicate that despite significant decreases in the IFM protein contents for these proteins (ANT4, ATP5A1, and ATP5B), no significant decreases in mRNAs encoding for these proteins was observed. Though the subset is small, our results suggest that decreased mRNA abundance does not necessarily account for the decreased IFM protein contents observed, and suggest that other mechanisms may be involved such as protein import deficiencies and/or enhanced PTMs. In the present study, PTMs identified included oxidations, deamidations, deacetylations and methylations, with oxidations and deamidations being the most prevalent. Interestingly, the diabetic IFM displayed the greatest number of oxidatively-modified proteins. These findings complement previous studies suggesting that enhanced mitochondrial ROS formation during type 1 diabetic insult may precipitate oxidative damage to mitochondrial constituents $(2,11,39)$. Also in agreement are the results from our previous study reporting increased superoxide formation in the type 1 diabetic IFM and the associated enhancement of protein oxidation (nitrotyrosine) within the mitochondrion (11). Another PTM that was prevalent in the diabetic IFM was deamidation. It has been suggested that deamidation of asparaginyl and glutaminyl residues within proteins causes structural and biological alterations to peptide and protein structure (35). Though the 
contribution of deamidation and oxidation to protein dysfunction is somewhat unclear, these PTMs may alter protein structure/function making the protein more susceptible for degradation by the proteasome system $(17,35)$. In addition, several proteins that were decreased in the diabetic IFM also contained oxidations and deamidations within their structure. Interestingly, mtHsp70, mitofilin and several components of complex $\mathrm{V}$ were decreased in abundance with both proteomic technologies and contained oxidations and deamidations within their structures. It is plausible that these modifications may have contributed to altered functionality and subsequent proteasomal degradation, all of which may have contributed to the morphological and oxidative phosphorylation deficiencies present in the type 1 diabetic heart.

Given that the majority of mitochondrial proteins are nuclear-encoded and must be imported into the mitochondrion, it is possible that defects in this complicated process may underlie proteomic dysregulation in the diabetic heart. Nuclear-encoded mitochondrial proteins constitute $99 \%$ of the organelle's proteome (7). These proteins are translated outside the mitochondrion and must be imported into the mitochondrion via an intricate mechanism involving coordination between the outer and inner mitochondrial membranes (8). The two membranes come together to form a "supercomplex", which creates a singular avenue for translocation of the imported protein into the IMM and matrix (8). Given the considerable importance of this process, protein import decrements resulting from pathological conditions could represent a mechanism for mitochondrial dysfunction in the diabetic heart. Hence, a major goal of this study was to gain insight into whether diabetes mellitus causes protein import deficiencies in the mitochondrion and determine whether this phenomenon manifests differently in mitochondrial subpopulations. Utilizing a novel mitochondrial protein import methodology that eliminated the use of protein radiolabeling, we observed dysfunction of the IFM protein import process without effect to the 
SSM. Previous literature examining mitochondrial protein import in the skeletal muscle of aging mice revealed enhanced cytoplasmic protein degradation, as opposed to protein import decrements as the contributing source of the mitochondrial dysfunction (16). It is unclear why the differences were observed but they may be due in part to the different pathologies and tissue types examined. In addition, movement of preproteins into the IMM is aided by $\Delta \Psi \mathrm{m}$. Our results indicate that a 5 week diabetic insult caused a modest decrease (19\%) in IFM $\Delta \Psi \mathrm{m}$ suggesting that mitochondrial protein import deficiencies in diabetic IFM could be at least partially due to mitochondrial $\Delta \Psi \mathrm{m}$ deficiencies. However, previous studies examining aged skeletal muscle have indicated that as much as a $50 \%$ decrease in $\Delta \Psi \mathrm{m}$ had no impact on mitochondrial protein import mechanics (16). Therefore, it's possible that reduced $\Delta \Psi \mathrm{m}$, as reported in our study, may still be sufficient to allow for proper mitochondrial protein import.

Mitochondrial protein import dysfunction has been attributed in part to cardiolipin loss (20). Cardiolipin is known to surround and stabilize protein import complexes including Tim23, the major pore forming unit essential for protein translocation. Studies examining a mutation of cardiolipin that leads to loss of the phospholipid, caused reduced $\Delta \Psi \mathrm{m}$ and decreased mitochondrial protein import (18). Another potential mechanism of mitochondrial import dysfunction is PTMs to proteins essential for protein translocation. As indicated above, we observed multiple modifications to mtHsp70 in the diabetic IFM subpopulation. MtHsp70 is a heat shock protein and the central subunit of the presequence translocase-associated motor complex (PAM) that binds to a translocating polypeptide chain and drives its movement through the IMM into the matrix by a reaction cycle that requires hydrolysis of ATP (7). Previous literature examining inactivation of yeast mtHsp70 revealed a near complete inhibition of oxidase assembly 1 protein translocation through the IMM (14). Additionally, cardiac 
mitochondria in senescent mice were shown to have elevated $\mathrm{mtHsp} 70$ protein content as well as increased protein import of a mitochondrial matrix protein, malate dehydrogenase (9). In our study, we show a marked decrease in $\mathrm{mtHsp} 70$ protein content coinciding with decreased protein import in the diabetic IFM subpopulation, suggesting that mtHsp70 protein content is associated with protein import capacity. Our examination of several other key translocases that play a major role in mitochondrial protein import including translocase of the outer membrane Tom20, outer membrane pore Tom40, inner membrane pore Tim23, and docking subunit Tim44 indicated that none of these mitochondrial protein import constituents were significantly decreased in the diabetic heart. It should be noted that our examination of Tim44 protein content revealed a trend for decrease in the diabetic IFM $(p=0.07)$. This result is of interest in that previous studies have suggested a protective role for Tim44 overexpression in multiple tissue types following diabetic insult $(29,44)$. Additional experimentation regarding Tim44 and the diabetic heart are warranted.

\section{Perspectives and Significance}

With the dramatic increase in diabetes mellitus incidence elucidation of the mechanisms contributing to the pathogenesis of diabetic cardiomyopathy are critical. An increasing amount of evidence suggests that mitochondrial dysfunction in the diabetic heart does not manifest in a homogeneous fashion. Rather, mitochondrial dysfunction occurs in a heterogeneous fashion with specific impact on mitochondria located in distinct subcellular locales and dependent upon the pathology (type 1 diabetes mellitus vs. type 2 diabetes mellitus). In the current study, we observed that type 1 diabetic insult differentially influenced spatially distinct cardiac 
mitochondrial proteomes, with the greatest impact occurring to those mitochondria located between the myofibrils (IFM). Further, changes in IFM proteomic make-up were associated with dysfunction to the nuclear-encoded mitochondrial protein import process, which may account in part, for the more pronounced loss of proteins in this specific mitochondrial subpopulation. Finally, loss of key mitochondrial protein import constituents in the IFM may underlie protein import deficiencies during type 1 diabetic insult in the heart. The results support a paradigm in which changes in mitochondrial subpopulation-specific proteomic make-up underlie mitochondrial dysfunction, necessitating the study of the underpinnings of the complex and coordinated process of nuclear-encoded mitochondrial protein import during diabetes mellitus. In addition, these findings continue to emphasize the importance of incorporating subcellular spatial locale into the study of diabetic mitochondria which may be of particular relevance for the future development of diagnostics and therapeutic interventions. 


\section{REFERENCES}

1. Artal-Sanz M and Tavernarakis N. Prohibitin and mitochondrial biology. Trends Endocrinol Metab 20, 394-401, 2009.

2. Baynes JW. Role of oxidative stress in development of complications in diabetes. Diabetes 40: 405-412, 1991.

3. Bradford MM. A rapid and sensitive method for the quantitation of microgram quantities of protein utilizing the principle of protein-dye binding. Anal Biochem 72: 248-254, 1976.

4. Bugger H, Boudina S, Hu XX, Tuinei J, Zaha VG, Theobald HA, Yun UJ, McQueen AP, Wayment B, Litwin SE, and Abel ED. Type 1 diabetic akita mouse hearts are insulin sensitive but manifest structurally abnormal mitochondria that remain coupled despite increased uncoupling protein 3. Diabetes 57: 2924-2932, 2008.

\section{Bugger H, Chen D, Riehle C, Soto J, Theobald HA, Hu XX, Ganesan B, Weimer} BC, and Abel ED. Tissue-specific remodeling of the mitochondrial proteome in type 1 diabetic akita mice. Diabetes 58: 1986-1997, 2009.

6. Calvo S, Jain M, Xie X, Sheth SA, Chang B, Goldberger OA, Spinazzola A, Zeviani M, Carr SA, and Mootha VK. Systematic identification of human mitochondrial disease genes through integrative genomics. Nat Genet 38: 576-582, 2006.

7. Chacinska A, Koehler CM, Milenkovic D, Lithgow T, and Pfanner N. Importing mitochondrial proteins: machineries and mechanisms. Cell 138: 628-644, 2009.

8. Chacinska A, Rehling P, Guiard B, Frazier AE, Schulze-Specking A, Pfanner N, Voos W, and Meisinger C. Mitochondrial translocation contact sites: separation of dynamic and 
stabilizing elements in formation of a TOM-TIM-preprotein supercomplex. EMBO J 22: 53705381, 2003.

9. Craig EE and Hood DA. Influence of aging on protein import into cardiac mitochondria. Am J Physiol 272: H2983-2988, 1997.

10. Dabkowski ER, Baseler WA, Williamson CL, Powell M, Razunguzwa TT, Frisbee

JC, and Hollander JM. Mitochondrial Dysfunction in the Type 2 Diabetic Heart is Associated with Alterations in Spatially-Distinct Mitochondrial Proteomes. Am J Physiol Heart Circ Physiol: ajpheart.00267.02010, 2010.

11. Dabkowski ER, Williamson CL, Bukowski VC, Chapman RS, Leonard SS, Peer CJ, Callery PS, and Hollander JM. Diabetic cardiomyopathy-associated dysfunction in spatially distinct mitochondrial subpopulations. Am J Physiol Heart Circ Physiol 296: H359-369, 2009.

12. Dabkowski ER, Williamson CL, and Hollander JM. Mitochondria-specific transgenic overexpression of phospholipid hydroperoxide glutathione peroxidase (GPx4) attenuates ischemia/reperfusion-associated cardiac dysfunction. Free Radic Biol Med 45: 855-865, 2008.

13. Flarsheim CE, Grupp IL, and Matlib MA. Mitochondrial dysfunction accompanies diastolic dysfunction in diabetic rat heart. Am J Physiol 271: H192-202, 1996.

14. Frazier AE, Chacinska A, Truscott KN, Guiard B, Pfanner N, and Rehling P. Mitochondria use different mechanisms for transport of multispanning membrane proteins through the intermembrane space. Mol Cell Biol 23: 7818-7828, 2003.

15. Hamblin M, Friedman DB, Hill S, Caprioli RM, Smith HM, and Hill MF. Alterations in the diabetic myocardial proteome coupled with increased myocardial oxidative stress underlies diabetic cardiomyopathy. J Mol Cell Cardiol 42: 884-895, 2007. 
16. Huang JH, Joseph AM, Ljubicic V, Iqbal S, and Hood DA. Effect of age on the processing and import of matrix-destined mitochondrial proteins in skeletal muscle. J Gerontol A Biol Sci Med Sci 65: 138-146, 2010.

17. Iwai K, Drake SK, Wehr NB, Weissman AM, LaVaute T, Minato N, Klausner RD, Levine RL, and Rouault TA. Iron-dependent oxidation, ubiquitination, and degradation of iron regulatory protein 2: implications for degradation of oxidized proteins. Proc Natl Acad Sci U S A 95: 4924-4928, 1998.

18. Jiang F, Ryan MT, Schlame M, Zhao M, Gu Z, Klingenberg M, Pfanner N, and Greenberg ML. Absence of cardiolipin in the crd1 null mutant results in decreased mitochondrial membrane potential and reduced mitochondrial function. J Biol Chem 275: 22387$22394,2000$.

19. John GB, Shang Y, Li L, Renken C, Mannella CA, Selker JM, Rangell L, Bennett MJ, and Zha J. The mitochondrial inner membrane protein mitofilin controls cristae morphology. Mol Biol Cell 16: 1543-1554, 2005.

20. Joshi AS, Zhou J, Gohil VM, Chen S, and Greenberg ML. Cellular functions of cardiolipin in yeast. Biochim Biophys Acta 1793: 212-218, 2009.

21. Jüllig M, Hickey AJ, Middleditch MJ, Crossman DJ, Lee SC, and Cooper GJS. Characterization of proteomic changes in cardiac mitochondria in streptozotocin-diabetic rats using iTRAQ ${ }^{\mathrm{TM}}$ isobaric tags. Poteomics Clin Appl 1: 565-576, 2007.

22. Kane LA and Van Eyk JE. Post-translational modifications of ATP synthase in the heart: biology and function. J Bioenerg Biomembr 41: 145-150, 2009.

23. Kelley DE, He J, Menshikova EV, and Ritov VB. Dysfunction of mitochondria in human skeletal muscle in type 2 diabetes. Diabetes 51: 2944-2950, 2002. 
24. King KL, Young ME, Kerner J, Huang H, O'Shea KM, Alexson SE, Hoppel CL, and Stanley WC. Diabetes or peroxisome proliferator-activated receptor alpha agonist increases mitochondrial thioesterase I activity in heart. J Lipid Res 48: 1511-1517, 2007.

25. Laemmli UK. Cleavage of structural proteins during the assembly of the head of bacteriophage T4. Nature 227: 680-685, 1970.

26. Lesnefsky EJ, Gudz TI, Moghaddas S, Migita CT, Ikeda-Saito M, Turkaly PJ, and Hoppel CL. Aging decreases electron transport complex III activity in heart interfibrillar mitochondria by alteration of the cytochrome c binding site. J Mol Cell Cardiol 33: 37-47, 2001.

27. Lesnefsky EJ, Slabe TJ, Stoll MS, Minkler PE, and Hoppel CL. Myocardial ischemia selectively depletes cardiolipin in rabbit heart subsarcolemmal mitochondria. Am J Physiol Heart Circ Physiol 280: H2770-2778, 2001.

28. Lin D. Multidimensional Protein Identification Technology as an Effective Tool for Proteomics. American Genomic/Proteomic Technology 1: 38-46, 2001.

29. Matsuoka T, Wada J, Hashimoto I, Zhang Y, Eguchi J, Ogawa N, Shikata K, Kanwar YS, and Makino H. Gene delivery of Tim44 reduces mitochondrial superoxide production and ameliorates neointimal proliferation of injured carotid artery in diabetic rats. Diabetes 54: 2882-2890, 2005.

30. Nishi H, Ono K, Iwanaga Y, Horie T, Nagao K, Takemura G, Kinoshita M, Kuwabara Y, Mori RT, Hasegawa K, Kita T, and Kimura T. MicroRNA-15b modulates cellular ATP levels and degenerates mitochondria via Arl2 in neonatal rat cardiac myocytes. $J$ Biol Chem 285: 4920-4930, 2010. 
31. Palmer JW, Tandler B, and Hoppel CL. Biochemical properties of subsarcolemmal and interfibrillar mitochondria isolated from rat cardiac muscle. J Biol Chem 252: 8731-8739, 1977.

32. Palmer JW, Tandler B, and Hoppel CL. Heterogeneous response of subsarcolemmal heart mitochondria to calcium. Am J Physiol 250: H741-748, 1986.

33. Paradies G, Petrosillo G, Paradies V, and Ruggiero FM. Role of cardiolipin peroxidation and $\mathrm{Ca} 2+$ in mitochondrial dysfunction and disease. Cell Calcium 45: 643-650, 2009.

34. Riva A, Tandler B, Loffredo F, Vazquez E, and Hoppel C. Structural differences in two biochemically defined populations of cardiac mitochondria. Am J Physiol Heart Circ Physiol 289: H868-872, 2005.

35. Robinson AB and Rudd CJ. Deamidation of glutaminyl and asparaginyl residues in peptides and proteins. Curr Top Cell Regul 8: 247-295, 1974.

36. Rolo AP and Palmeira CM. Diabetes and mitochondrial function: role of hyperglycemia and oxidative stress. Toxicol Appl Pharmacol 212: 167-178, 2006.

37. Rosca MG, Vazquez EJ, Kerner J, Parland W, Chandler MP, Stanley W, Sabbah HN, and Hoppel CL. Cardiac mitochondria in heart failure: decrease in respirasomes and oxidative phosphorylation. Cardiovasc Res 80: 30-39, 2008.

38. Scharfe C, Lu HH, Neuenburg JK, Allen EA, Li GC, Klopstock T, Cowan TM, Enns GM, and Davis RW. Mapping gene associations in human mitochondria using clinical disease phenotypes. PLoS Comput Biol 5: e1000374, 2009. 
39. Shen X, Zheng S, Thongboonkerd V, Xu M, Pierce WM, Jr., Klein JB, and Epstein

PN. Cardiac mitochondrial damage and biogenesis in a chronic model of type 1 diabetes. Am $J$ Physiol Endocrinol Metab 287: E896-905, 2004.

40. Stojanovski D, Pfanner N, and Wiedemann N. Import of proteins into mitochondria. Methods Cell Biol 80: 783-806, 2007.

41. Turko IV and Murad F. Quantitative protein profiling in heart mitochondria from diabetic rats. J Biol Chem 278: 35844-35849, 2003.

42. Weytjens C, Cosyns B, D'Hooge J, Droogmans S, Lahoutte T, Garbar C, Roossens

B, and Van Camp G. Evaluation of contractile function and inotropic reserve with tissue velocity, strain and strain rate imaging in streptozotocin-induced diabetes. Eur J Echocardiogr, 2010.

43. Williamson CL, Dabkowski ER, Baseler WA, Croston TL, Alway SE, and Hollander JM. Enhanced apoptotic propensity in diabetic cardiac mitochondria: influence of subcellular spatial location. Am J Physiol Heart Circ Physiol 298: H633-642, 2010.

44. Zhang Y, Wada J, Hashimoto I, Eguchi J, Yasuhara A, Kanwar YS, Shikata K, and Makino H. Therapeutic approach for diabetic nephropathy using gene delivery of translocase of inner mitochondrial membrane 44 by reducing mitochondrial superoxide production. $J$ Am Soc Nephrol 17: 1090-1101, 2006. 


\section{Fig 2.1}

A EGSGSSGTGEOK, $\mathrm{m} / \mathrm{z}=1411.69$




Figure 2.1. Representative iTRAQ spectra. Isolated mitochondrial subpopulations from control and diabetic hearts were labeled with iTRAQ reagents 114 (diabetic SSM), 115 (diabetic IFM), 116 (control SSM), 117 (control IFM) and combined for analysis with mass spectrometry. (A) Representative spectra of simultaneous quantitation of a $\mathrm{mtHsp70}$ peptide in control and diabetic mitochondrial subpopulations. (B) MS/MS spectra for the reporter groups of the iTRAQ reagents $(114,115,116$ and 117$)$ from a mtHsp70 peptide. These spectra were used along with other peptides to simultaneously quantify mtHsp70 control and diabetic mitochondrial subpopulations. 
Fig 2.2
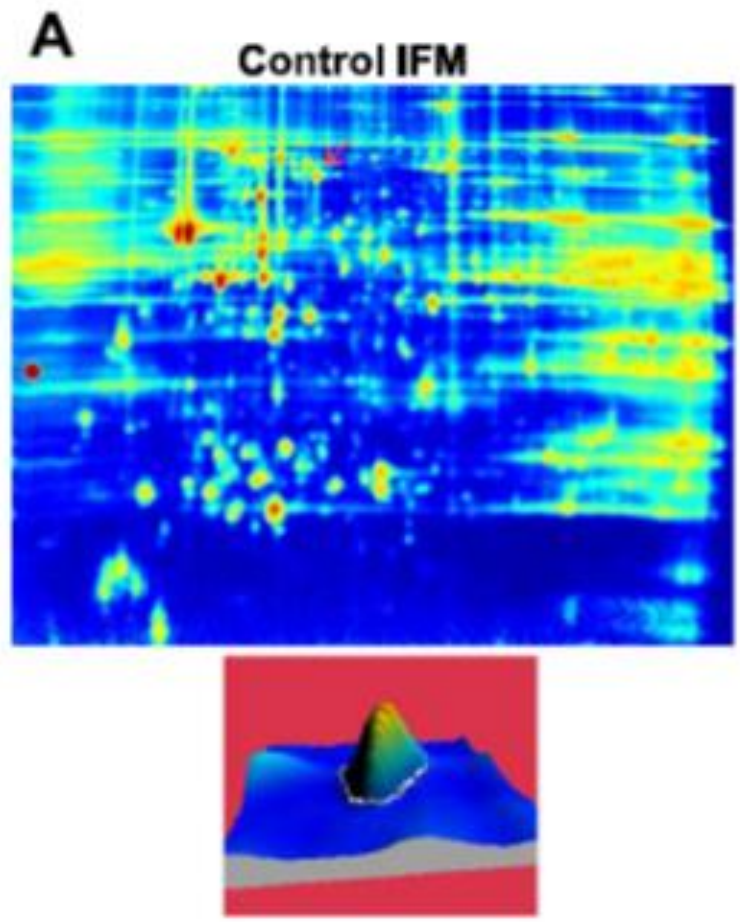

C


B


\section{Diabetic SSM}
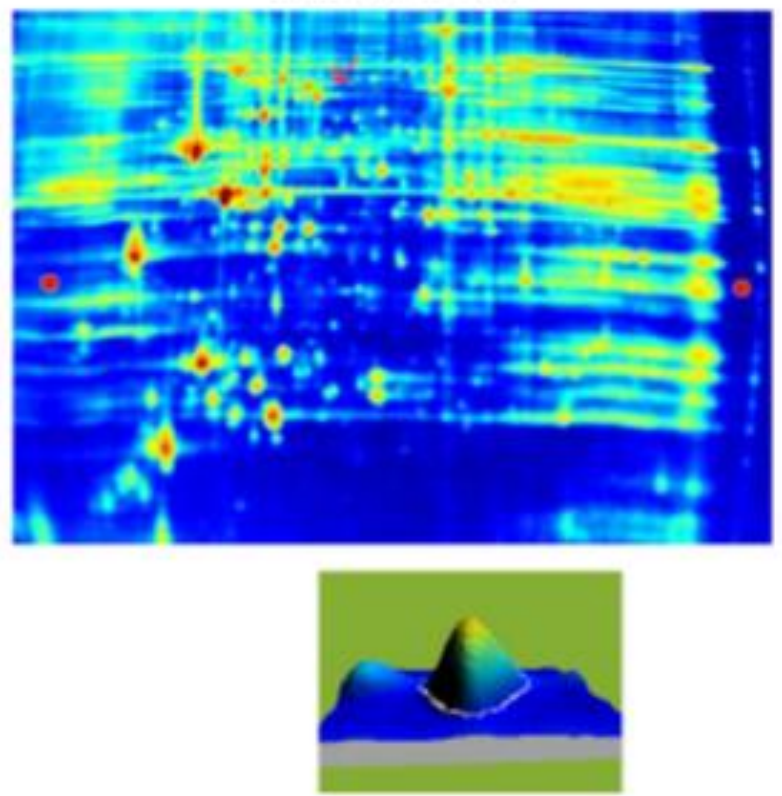
Figure 2.2. Representative 2D-DIGE gels. Samples were labeled with either Cy3 or Cy5 alternating between control and diabetic SSM and IFM. A control and treated were run on the same gel and an internal standard was labeled with $\mathrm{Cy} 2$ and run on every gel for gel to gel comparisons. (A) A representative gel showing Cy3 labeled control IFM and (B) is the same gel showing Cy5 labeled diabetic IFM. (C) A representative gel showing Cy3 labeled control SSM and (D) is the same gel showing Cy5 labeled control SSM. Below the gel images are individual spots that were identified as mtHsp70, (indicated by the red arrow) and quantitative differences were assessed by examination of peak density. 
Fig 2.3

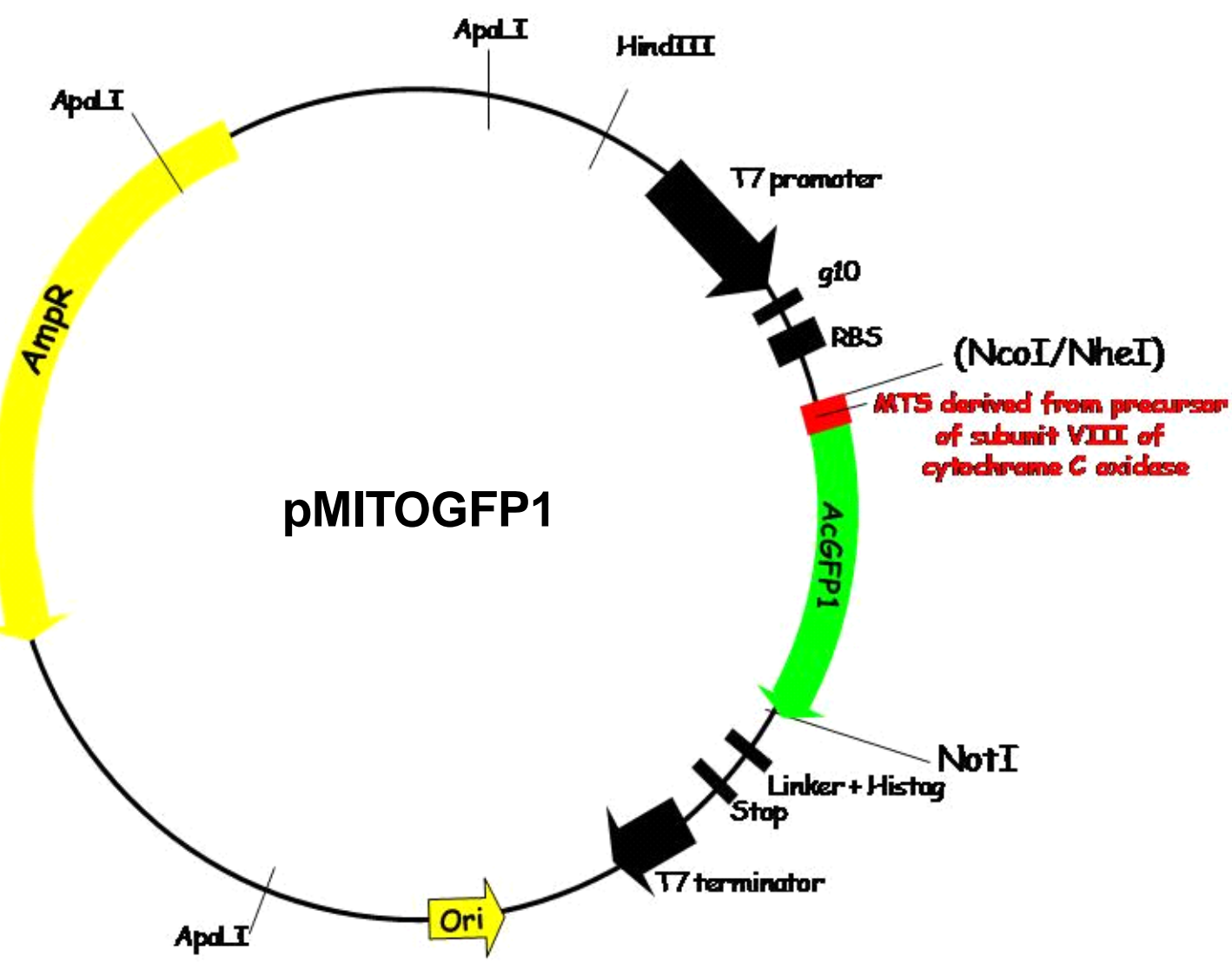


Figure 2.3. pMITOGFP1 construct. The pMITOGFP1 plasmid was generated and inserted into a bacterial cell free protein expression system to produce MitoGFP1 protein. The MITOGFP1 gene consists of an N-terminal mitochondrial targeting sequence derived from cytochrome C oxidase subunit VIII (red) fused with AcGFP1 (green). The MITOGFP1 gene was cloned into pIVEX2.3d at restriction sites Not I and blunted Nco I/Nhe I sites. The correct sequence was confirmed by dideoxynucleotide sequencing. 
Fig 2.4

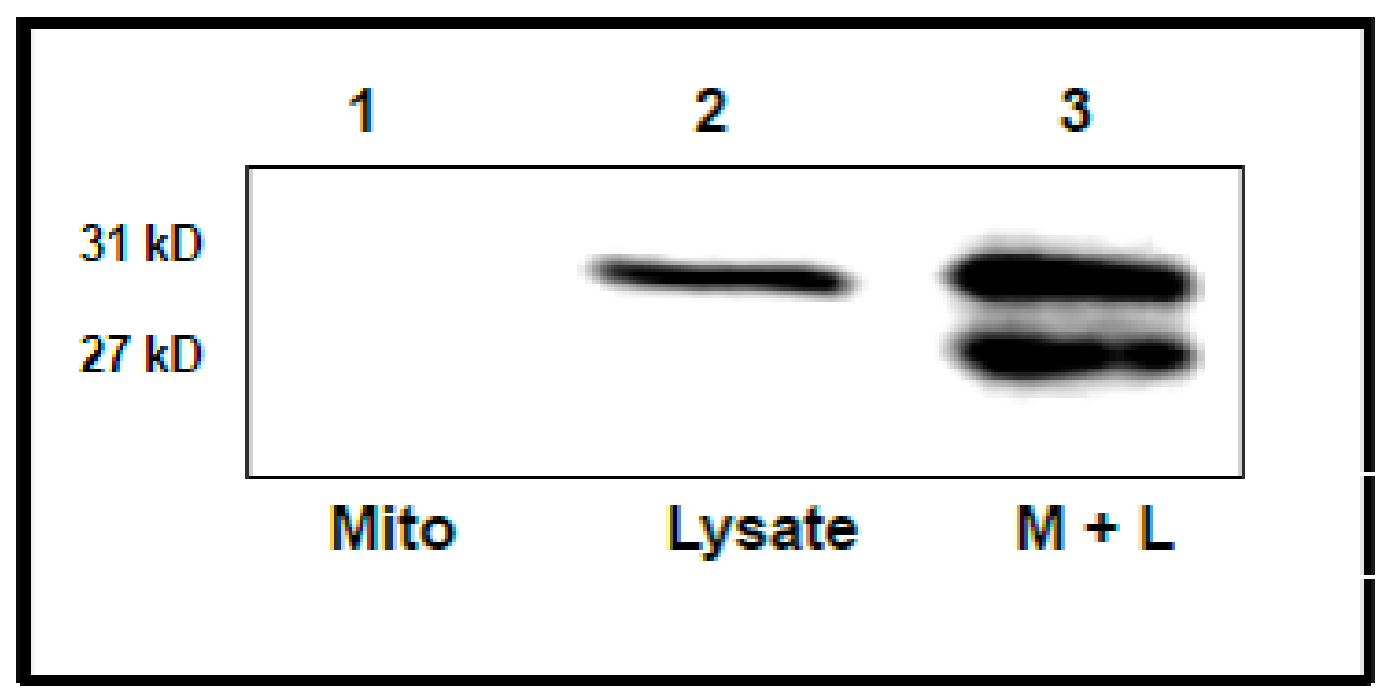


Figure 2.4. MITOGFP1 protein import. Western blot analysis of MitoGFP1 protein import into isolated cardiac mitochondria probed for AcGFP in samples containing $40 \mu \mathrm{g}$ of mitochondria only (lane 1), $0.05 \mu 1$ of MitoGFP1 protein lysate (lane 2), or combined mitochondria and lysate $(3 \mu \mathrm{l})$ (lane 3$)$. The upper $31 \mathrm{kDa}$ band represents the full length precursor MitoGFP1 in transit and yet to be processed while the lower $27 \mathrm{kDa}$ band represents a mature cleaved MitoGFP1 protein residing within the mitochondrial matrix. 
Fig 2.5

A

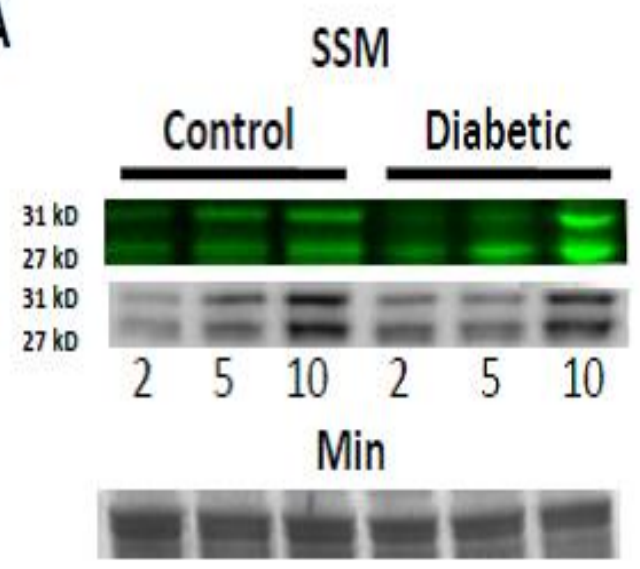

C



B

IFM

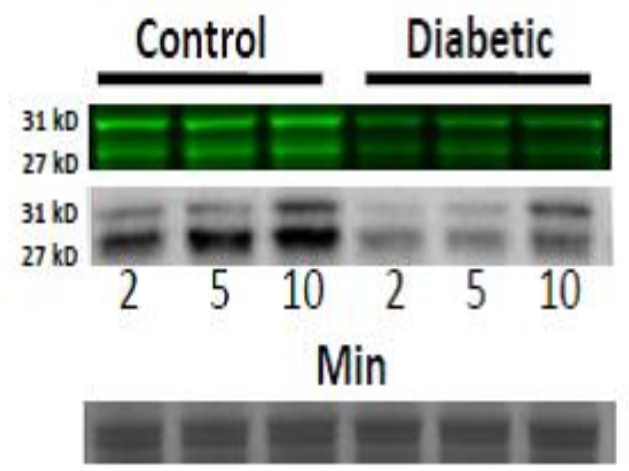

D

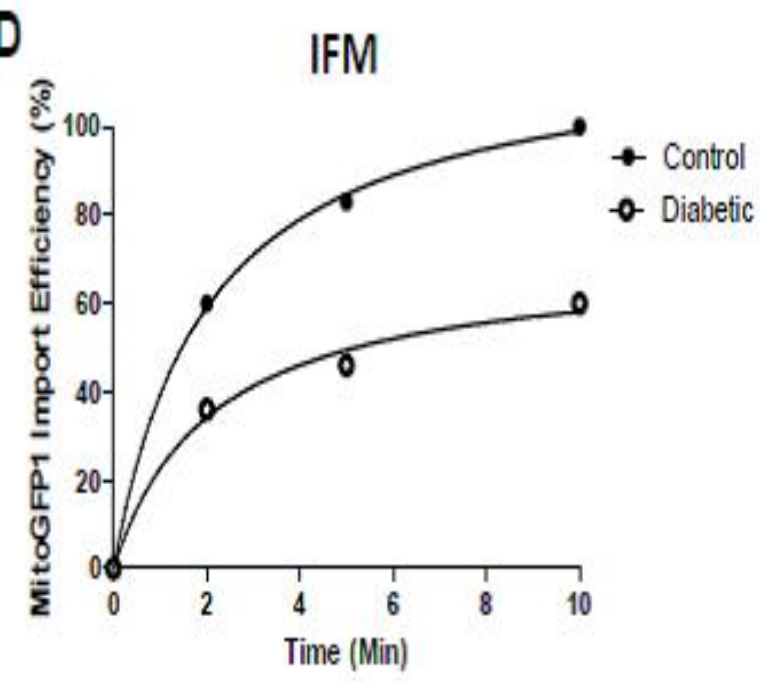


Figure 2.5. Mitochondrial protein import. Effect of type 1 diabetes mellitus on MitoGFP1 import in SSM and IFM subpopulations. Cardiac mitochondrial subpopulations from control and diabetic mice were isolated and incubated with $3 \mu 1$ of MitoGFP1 protein lysate at 2, 5, and 10 minute time points. Representative Western blots and fluorescent images from (A) SSM and (B) IFM protein import assay. Graphical representation of mitochondrial protein import performed in (C) SSM and (D) IFM control and diabetic subpopulations. The relative amount of imported MitoGFP1 was determined by densitometry. The highest value was set to $100 \%$ to determine percent import at each time point (Control $10 \mathrm{~min}$ ). Control for protein loading was confirmed by Ponceau staining. $\mathrm{N}=8$ per group. 
Fig 2.6

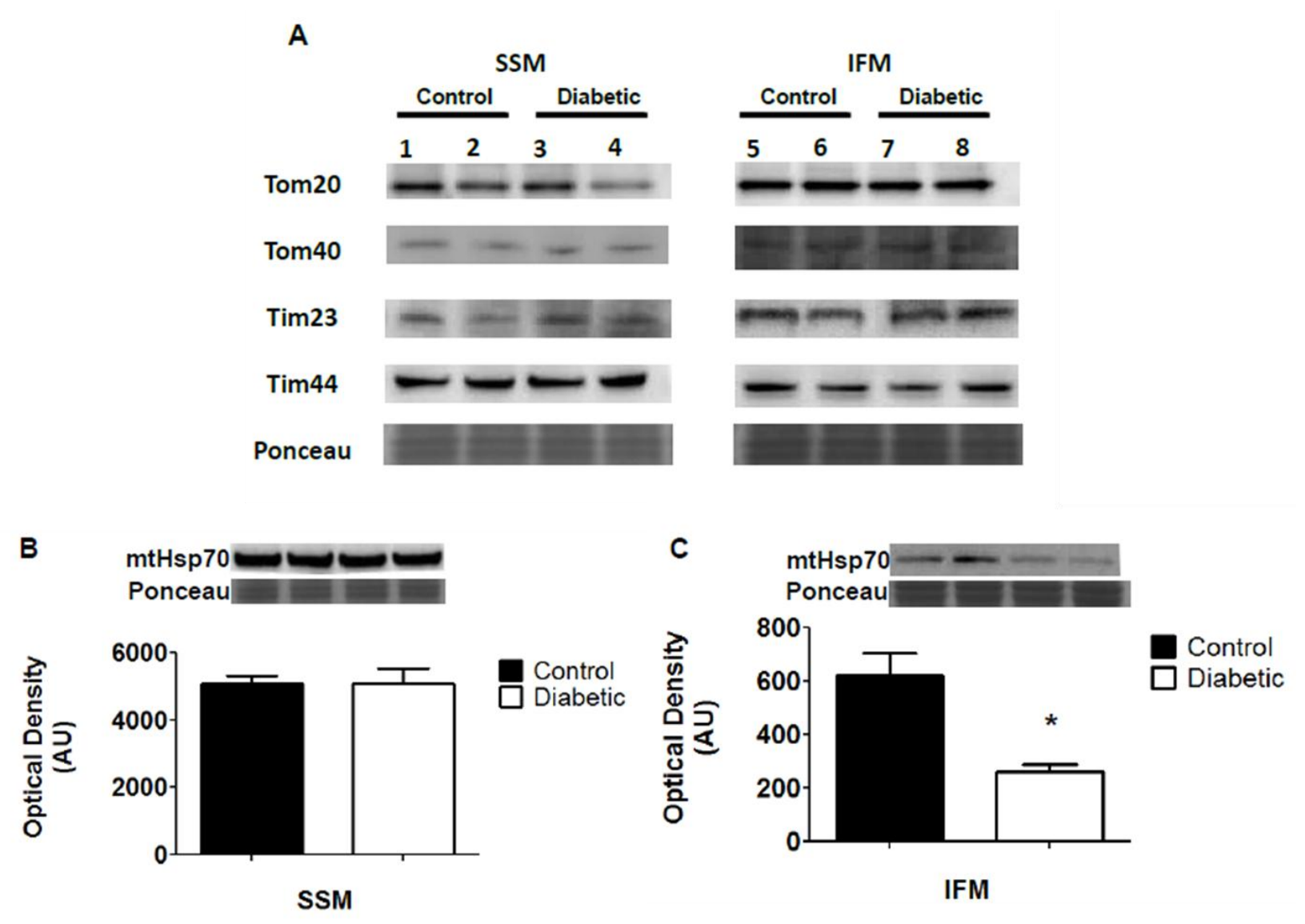


Figure 2.6. Western blot analysis of protein import constituents. Key proteins involved in mitochondrial protein import were assessed using Western Blot analyses. (A) Control SSM (lanes 1-2), Diabetic SSM (lanes 3-4), Control IFM (lanes 5-6), Diabetic IFM (lanes 7-8); translocases of the outer mitochondrial membrane Tom20, Tom40 and inner mitochondrial membrane Tim23, Tim44 protein expression. Representative Western blots and densitometry analysis for mtHsp70 protein expression in (B) SSM, and (C) IFM from control and diabetic hearts. Values are represented as mean \pm SEM. All values presented indicate a significant difference of at least $* p<0.05$ for control vs. diabetic groups. Control for protein loading was confirmed with Ponceau staining. $\mathrm{N}=5$ for each group. 


\section{Fig 2.7}

A

SSM



B

IFM




Figure 2.7. Mitochondrial subpopulation membrane potential. Isolated mitochondrial subpopulations were incubated with JC-1, and 20,000 gated events were analyzed per sample. Control and diabetic SSM (A) and IFM (B) samples were analyzed. Values are represented as mean \pm SEM. All values presented indicate a significant difference of at least $* p<0.05$ for control vs. diabetic groups. $\mathrm{N}=4$ for each group. 


\section{Table 2.1}

\begin{tabular}{|c|c|c|}
\hline Protein Name & $\begin{array}{l}\text { SSM Diabetic/ } \\
\text { SSM Control }\end{array}$ & $\begin{array}{l}\text { IFM Diabeticl } \\
\text { IFM Control }\end{array}$ \\
\hline \multicolumn{3}{|l|}{ Mitochondrial Fatty Acids Beta-oxidation } \\
\hline Hydroxyacyl-coenzyme A dehydrogenase 3 ketoacyl coenzyme A & .69 & 59 \\
\hline Mitochondrial trifunctional protein, beta subunit & .61 & .72 \\
\hline Acetyl-coenzyme A acyl transferase 2 & NS & .85 \\
\hline Acyl coenzyme A dehydrogenase, medium chain & NS & .87 \\
\hline Acyl Coenzyme A dehydrogenase, very long chain & .76 & .77 \\
\hline 2,4-dienoyl COA reductase 1 & .76 & .71 \\
\hline Enoyl coenzyme hydratase 1 & NS & .79 \\
\hline Carnitine palmitoyltransferase 1 & 1.37 & .57 \\
\hline \multicolumn{3}{|l|}{ Mitochondrial Respiratory Chain } \\
\hline ATP synthase, $\mathrm{H}+$ transporting. mitochondrial F1 complex, Beta subunit & NS & .66 \\
\hline ATP synthase, $\mathrm{H}+$ transporting. FO complex subunit F & 1.36 & .60 \\
\hline ATP synthase, $\mathrm{H}+$ transporting. mitochondrial F1 complex, O subunit & NS & .88 \\
\hline ATP synthase, $\mathrm{H}+$ transporting. mitochondrial FO, subunit $b$, isoform 1 & NS & .80 \\
\hline NADH dehydrogenase ubiquinone navoprotein 1 & NS & .83 \\
\hline NADH dehydrogenase ubiquinone 1 alpha subcomplex 8 & 1.21 & NS \\
\hline NADH dehydrogenase (ubiquinone) 1 alpha subcomplex 12 & NS & .71 \\
\hline Ubiquinol cytochrome c reductase, Rieske iron sulfur unit polypeptide 1 & NS & 1.20 \\
\hline Cytochrome C-1 & 1.36 & NS \\
\hline Cytochrome Coxidase subunit IV isoform 1 & 1.18 & NS \\
\hline Cytochrome C oxidase subunit VIb polypeptide 1 & NS & .70 \\
\hline Electron transfer flavoprotein-ubiquinone oxidoreductase & NS & .87 \\
\hline Electron transfer flavoprotein subunit alpha & NS & .74 \\
\hline Electron transfer flavoprotein beta polypeptide & 1.19 & .85 \\
\hline \multicolumn{3}{|l|}{ TCA Cycle } \\
\hline Aconitase 2 & NS & .91 \\
\hline Malate dehydrogenase 2, NAD & NS & 1.07 \\
\hline Isocitrate dehydrogenase 2 (NADP + ) & 1.16 & .75 \\
\hline Pyruvate dehydrogenase (lipoamide) beta & 1.28 & NS \\
\hline Creatine Kinase & 1.46 & NS \\
\hline \multicolumn{3}{|l|}{ Transport Proteins } \\
\hline Adenine nucleotide translocator, member 4 & NS & .70 \\
\hline Vdac (Vdac-1) & NS & 1.15 \\
\hline Solute carrier family 25, member 3 phosphate carrier & NS & .67 \\
\hline mtHsp70 (Grp75) & NS & .80 \\
\hline \multicolumn{3}{|l|}{ Structural } \\
\hline Inner membrane protein immt, mitofilin & NS & .64 \\
\hline \multicolumn{3}{|l|}{ Miscellaneous } \\
\hline Myoglobin & NS & 1.51 \\
\hline Es 1 protein & NS & .80 \\
\hline Multimerin 2 & NS & .88 \\
\hline Hydroxysteroid dehydrogenase like 2 , isoform CRA_c & .60 & .79 \\
\hline Mirq-like protein & NS & .66 \\
\hline
\end{tabular}


Table 2.1. iTRAQ Proteomic analysis of mitochondrial subpopulations from control and diabetic hearts. iTRAQ analysis of proteins identified and significantly changing, categorized into groups consisting of fatty acid oxidation (FAO), mitochondrial respiratory chain, citric acid cycle (TCA), transport proteins, structural and miscellaneous proteins in isolated SSM and IFM from control and diabetic hearts. Cells highlighted in red represent decreased protein expression in the diabetic mitochondria compared to control, while cells highlighted in green are increased in diabetic vs. control. All values presented indicate a significant difference of at least $p<0.05$ for control vs. diabetic groups, while NS represents no significant differences between any groups. $\mathrm{N}=4$ for each group. 


\section{Table 2.2}

\begin{tabular}{|c|c|c|}
\hline Protein Name & $\begin{array}{l}\text { SSM Diabeticl } \\
\text { SSM Control }\end{array}$ & $\begin{array}{l}\text { IFM Diabeticl } \\
\text { IFM Control }\end{array}$ \\
\hline \multicolumn{3}{|l|}{ Mitochondrial Fatty Acids Beta-oxidation } \\
\hline Very long-chain specific Acyl-COA Dehydrogenase & .87 & .80 \\
\hline Long-Chain specific Acyl-COA Dehydrogenase & NS & .82 \\
\hline Isoform 2 of 2-oxoglutarate dehydrogenase E1 Complex & NS & .78 \\
\hline Medium-chain specific acyl-coA dehydrogenase & .69 & .76 \\
\hline mitochondrial acyl-COA thicesterase 1 & NS & .91 \\
\hline Delta(3,5)-Delta(2,4)-Dienoyl-COA ISOMERASE & 2.02 & .90 \\
\hline \multicolumn{3}{|l|}{ Mitochondrial Respiratory Chain } \\
\hline Isoform 1 of NADH Dehydrogenase (Ubiquinone) Flavoprotein2 & 1.25 & .84 \\
\hline NADH dehydrogenase iron-sulfur protein 2 & NS & .86 \\
\hline NADH-Ubiquinone Oxidoreductase $75 \mathrm{kda}$ subunit & -1.54 & .76 \\
\hline NADH Dehydrogenase Ubiquinone 1 Alpha subcomplex subunit 10 & NS & .81 \\
\hline NADH Dehydrogenase Ubiquinone Iron-sulfur Protein 8 & NS & .86 \\
\hline NADH dehydrogenase (ubiquinone) iron-sulfur protein 3 & NS & .85 \\
\hline NADH dehydrogenase (ubiquinone) iron-sulfur protein 4 & NS & .91 \\
\hline Electron Transfer Flavoprotein-ubiquinone oxidoreductase & 2.83 & .85 \\
\hline Ubquinol cytochrome c redcutase core protein 1 & NS & .86 \\
\hline Cytochrome b-cl complex c & NS & .85 \\
\hline Cytochrome b-c1 complex subunit Rieske & NS & .75 \\
\hline Ubiquinone biosynthesis protein COQ9 & .95 & .81 \\
\hline Succinate dehydrogenase (ubiquinone) iron-sulfur unit & NS & .59 \\
\hline ATP synthase subunit beta & NS & .80 \\
\hline ATP synthase subunit $O$ & 1.13 & .60 \\
\hline ATP5a1 ATP synthase subunit alpha & NS & .82 \\
\hline \multicolumn{3}{|l|}{ TCA Cycle } \\
\hline Aldehyde dehydrogenase & 1.15 & .87 \\
\hline Pyruvate dehydrogenase E1 component subunit Beta & NS & .77 \\
\hline Dihydrolipoyllysine-residue acetyltrasnferase & 1.50 & .80 \\
\hline Malate dehydrogenase & 2.30 & .75 \\
\hline Isocitrate dehydrogenase NAD subunit alpha & NS & .68 \\
\hline Aconitase hydratase & NS & .71 \\
\hline \multicolumn{3}{|l|}{ Amino Acid Metabolism } \\
\hline Aspartate aminotransferase & NS & 1.96 \\
\hline ubiquitin protein ligase $\mathrm{E} 3 \mathrm{C}$ & 1.34 & .43 \\
\hline \multicolumn{3}{|l|}{ Oxidative Stress Related } \\
\hline Prd $\times 3$ & NS & .81 \\
\hline \multicolumn{3}{|l|}{ Transport Proteins } \\
\hline Heat Shock Protein 60 & .71 & .66 \\
\hline mtHsp70 (Grp75) & NS & .73 \\
\hline Prohibitin-2 & NS & .72 \\
\hline \multicolumn{3}{|l|}{ Structural } \\
\hline IMMT Mitofilin & NS & .75 \\
\hline
\end{tabular}


Table 2.2. 2D-DIGE proteomic analysis of mitochondrial subpopulations from control and diabetic hearts. 2D-DIGE analysis of proteins identified and significantly changing, categorized into groups consisting of fatty acid oxidation (FAO), mitochondrial respiratory chain, citric acid cycle (TCA), amino acid metabolism, oxidative stress related, transport proteins, and structural proteins in isolated SSM and IFM from control and diabetic hearts. Cells highlighted in red represent decreased protein expression in the diabetic mitochondria compared to control, while cells highlighted in green are increased in diabetic vs. control. All values presented indicate a significant difference of at least $* p<0.05$ for control vs. diabetic groups, while NS represents no significant differences between any groups. $\mathrm{N}=4$ for each group. 


\section{Table 2.3}

\begin{tabular}{|c|c|c|}
\hline Protein Diabetic IFM & $\begin{array}{c}\text { Peptide Sequence } \\
\text { Diabetic IFM }\end{array}$ & $\begin{array}{c}\text { Post Translational Modification } \\
\text { Diabetic IFM } \\
\end{array}$ \\
\hline $\begin{array}{l}\text { ATP synthase, } \mathrm{H}+\text { transpouting mitochondrial } \mathrm{Fl} \\
\text { complex, beta subunit }\end{array}$ & ALVYGQMNEPPGAR & 0xidation(M)@7; Cation: $\mathrm{K}(\mathrm{E}) @ 9$ \\
\hline Ubiquinol cytochrome c reductase core protein 2 & NALANPLYCPDYR & $\begin{array}{l}\text { Carbamidomethyl(C)@9; } \\
\text { Dioxidation(Y)@12; Arg }: G l u S A(R) @ 13\end{array}$ \\
\hline $\begin{array}{l}\text { solute canier family } 25 \text { (mitochondrial canier, } \\
\text { adenine nucleotide translocator), member } 4 \text { [Mus } \\
\text { musculus] }\end{array}$ & GADIMYTGTLDCWR & $\begin{array}{l}\text { Carbamidomethyl(C)@12; } \\
\text { Dioxidation(W)@13; Arg.:GluSA(R)@14 }\end{array}$ \\
\hline ubiquinol-cytochrome c reductase core protein l & VYEEDAVPGLTPCR & $\begin{array}{l}\text { Oxidation(P)@8;0xidation(P)@12; } \\
\text { Carbamidomethyl(C)@13; Arg- } \\
\text { >GluSA(R)@14 }\end{array}$ \\
\hline ubiquinol-cytochrome c reductase core protein l & NALVSHLDGTTPVCEDIGR & $\begin{array}{l}\text { Dioxidation(P)@12; } \\
\text { Carbamidomethyl(C)@14; Arg- } \\
\text { >GluSA(R)@19 }\end{array}$ \\
\hline acetyl-Coenzyme A acetyltransferase 1 & $\begin{array}{l}\text { ENGTITAANASTLNDGAAALVLMTAE } \\
\text { AAQR }\end{array}$ & Oxidation(N)@2; Deamidated(N)@9 \\
\hline mtHsp70 (Glucose regulated protein 75) & MKETAENYLGHTAK & Oxidation(M)@1 \\
\hline $\begin{array}{l}\text { ATP synthase, } \mathrm{H}+\text { transpouting, mitochondrial F0 } \\
\text { complex, subunit b, isoform l }\end{array}$ & QIQDAIDMEK & Oxidation(M)@8 \\
\hline
\end{tabular}




\section{Table 2.3}

\begin{tabular}{|c|c|c|}
\hline Protein Diabetic IFM & $\begin{array}{c}\text { Peptide Sequence } \\
\text { Diabetic IFM }\end{array}$ & $\begin{array}{c}\text { Post Translational Modification } \\
\text { Diabetic IFM } \\
\end{array}$ \\
\hline Titin (Connectin) & KMEAPPPKAPKKR & Dioxidation(P)@s \\
\hline $\begin{array}{l}\text { NADH dehydrogenase (ubiquinone) } 1 \text { beta } \\
\text { subcomplex } 8\end{array}$ & VEDYEPYPDDGMGYGDYPMLPNR & 0xidation(D)@3 \\
\hline inner membrane protein, mitochondrial(Mitofilin) & RVAQDWLKEAR & Deamidated(Q)@4; 0xidation(W)@6 \\
\hline dodecenoyl-Coenzyme A delta isomerase & SLHMYLEK & Oxidation(M)@4 \\
\hline $\begin{array}{l}\text { ATP synthase, } \mathrm{H}+\text { transporting mitochondrial } \mathrm{F} 1 \\
\text { complex, beta subunit }\end{array}$ & TREGNDLYHEMIESGVINLK & Deamidated(N)@5 \\
\hline $\begin{array}{l}\text { ATP synthase, } \mathrm{H}+\text { transporting mitochondrial } \mathrm{F} 1 \\
\text { complex, beta subunit }\end{array}$ & $\begin{array}{l}\text { GSITSVQAIYVPADDLTDPAPATTFAH } \\
\text { LDATTVLSR }\end{array}$ & $\begin{array}{l}\text { Acetyl@N-term; Deamidated(Q)@7; } \\
\text { Carbamidomethyl(D)@14 }\end{array}$ \\
\hline $\begin{array}{l}\text { ATP synthase, } \mathrm{H}+\text { transporting, mitochondrial } \mathrm{F} 1 \\
\text { complex, alpha subunit, isoform } 1\end{array}$ & VVDALGNAIDGK & Deamidated(N)@7 \\
\hline $\begin{array}{l}\text { 3-ketoacyl-CoA thiolase, mitochondrial (Beta- } \\
\text { ketothiolase) }\end{array}$ & $\begin{array}{l}\text { AALSAGKVPPETIDSVIVGNVMQSSSD } \\
\text { AAYLAR }\end{array}$ & Deamidated(N)@20 \\
\hline mitochondrial trifunctional protein, beta & DNGIRPSSLEQMAK & Deamidated(N)@2 \\
\hline
\end{tabular}




\section{Table 2.3}

\begin{tabular}{|c|c|c|}
\hline Protein Diabetic IFM & $\begin{array}{l}\text { Peptide Sequence } \\
\text { Diabetic IFM }\end{array}$ & $\begin{array}{c}\text { Post Translational Modification } \\
\text { Diabetic IFM }\end{array}$ \\
\hline mitochondrial trifunctional protein, beta & $\begin{array}{l}\text { LKPAFIKPYGTVTAANSSFLTDGASA } \\
\text { MLIMSEDR }\end{array}$ & Deamidated(N)@16 \\
\hline $\begin{array}{l}\text { glutamate oxaloacetate transaminase 2, } \\
\text { mitochondrial [Mus musculus] }\end{array}$ & DDNGKPYVLPSVR & Deamidated(N)@3 \\
\hline $\begin{array}{l}\text { glutamate oxaloacetate transaminase 2, } \\
\text { mitochondrial [Mus musculus] }\end{array}$ & KMNLGVGAYRDDNGKPYVLPSVR & Deamidated(N)@13 \\
\hline $\begin{array}{l}\text { succinate dehydrogenase Fp subunit [Mus } \\
\text { musculus] }\end{array}$ & NTVIATGGYGR & Deamidated(N)@1 \\
\hline $\begin{array}{l}\text { solute carrier family } 25 \text { (mitochondrial carrier, } \\
\text { adenine nucleotide translocator) }\end{array}$ & GDQALSFLKDFLAGGIAAAVSK & Protein Terminal Acetyl@N-term \\
\hline $\begin{array}{l}\text { solute carrier family } 25 \text { (mitochondrial carrier, } \\
\text { adenine nucleotide translocator) }\end{array}$ & GDQALSFLK & Protein Terminal Acetyl@N-term \\
\hline ubiquinol-cytochrome c reductase core protein 1 & TATFAQALQSVPETQVSILDNGLR & Deamidated(N)@21 \\
\hline ubiquinol-cytochrome c reductase core protein 1 & EVESIGAHLNAYSTR & Deamidated(N)@10 \\
\hline cytochrome $\mathrm{c}$ oxidase, subunit $\mathrm{Va}$ & LNDFASAVR & Deamidated(N)@2 \\
\hline cytochrome c oxidase, subunit $\mathrm{Va}$ & RLNDFASAVR & Deamidated(N)@3; Dehydrated(D)@4 \\
\hline
\end{tabular}




\section{Table 2.3}

\begin{tabular}{|c|c|c|}
\hline Protein Diabetic IFM & $\begin{array}{c}\text { Peptide Sequence } \\
\text { Diabetic IFM } \\
\end{array}$ & $\begin{array}{c}\text { Post Translational Modification } \\
\text { Diabetic IFM } \\
\end{array}$ \\
\hline $\begin{array}{l}\text { acyl-Coenzyme A dehydrogenase, long-chain } \\
\text { [Mus musculus] }\end{array}$ & SPAHGISLFLVENGMK & Deamidated(N)@13 \\
\hline mtHsp70 (Glucose regulated protein 75) & ASNGDAWVEAHGK & Deamidated(N)@3 \\
\hline mtHsp70 (Glucose regulated protein 75) & STNGDTFLGGEDFDQALLR & Deamidated(N)@3 \\
\hline Fumarate hydratase 1 & YPIEHGIITNWDDMEK & Methyl(H)@5 \\
\hline Fumarate hydratase 1 & $\begin{array}{l}\text { LNDHFPLVVWQTGSGTQTNMNVNEV } \\
\text { ISNR }\end{array}$ & Deamidated(Q)@17 \\
\hline $\begin{array}{l}\text { ATP synthase, } \mathrm{H}+\text { transporting, mitochondrial } \mathrm{F} 0 \\
\text { complex, subunit } \mathrm{F}\end{array}$ & RQASGGPVDIGPEYQQDLDRELYK & Deamidated(Q)@2; Dehydrated(S)@4 \\
\hline $\begin{array}{l}\text { pynuvate dehydrogenase E1 alpha } 1 \text { [Mus } \\
\text { musculus] }\end{array}$ & TREEIQEVRSKSDPIMLLK & Deamidated(R)@9 \\
\hline $\begin{array}{l}\text { superoxide dismutase 2, mitochondrial [Mus } \\
\text { musculus]; Sod2 protein [Mus musculus] }\end{array}$ & FNGGGHINHTIFWTNLSPK & Deamidated(N)@2 \\
\hline $\begin{array}{l}\text { Camitine 0-acetyltransferase (Camitine } \\
\text { acetylase) (CAT) }\end{array}$ & IWNSSLQSNKEPVGILTSNHR & Deamidated(N)@3 \\
\hline $\begin{array}{l}\text { NADH dehydrogenase (ubiquinone) } 1 \text { beta } \\
\text { subcomplex, } 9 \text { [Mus musculus] }\end{array}$ & $\begin{array}{l}\text { EAEEEFWQNQHPQPYIFPDSPGGTSFE } \\
\mathrm{R}\end{array}$ & Deamidated(N)@9 \\
\hline
\end{tabular}




\section{Table 2.3}

\begin{tabular}{|c|c|c|}
\hline Protein Diabetic IFM & $\begin{array}{c}\text { Peptide Sequence } \\
\text { Diabetic IFM }\end{array}$ & $\begin{array}{c}\text { Post Translational Modification } \\
\text { Diabetic IFM }\end{array}$ \\
\hline 3-hydroxyacyl $\mathrm{CoA}$ dehydrogenase & $\begin{array}{l}\text { LDKFAAEHTIFASNTSSLQITNIANATT } \\
\mathrm{R}\end{array}$ & Deamidated(N)@14 \\
\hline Aldehyde dehydrogenase family 6 , subfamily A1 & $\begin{array}{l}\text { NHGVVMPDANKENTLNQLVGAAFGA } \\
\text { AGQR }\end{array}$ & Deamidated(N)@10 \\
\hline Aldehyde dehydrogenase family 6 , subfamily Al & IVNDNPYGNGTAIFTTNGATAR & Deamidated(N)@9; Deamidated(N)@17 \\
\hline dihydrolipoamide S-succinyltransferase & NDVITVQTPAFAESVTEGDVR & Deamidated(N)@1 \\
\hline $\begin{array}{l}\text { NADH dehydrogenase (ubiquinone) 1, } \\
\text { subcomplex unknown, } 2 \text { [Mus musculus] }\end{array}$ & MMNGRPGHEPLK & $\begin{array}{l}\text { Protein Terminal Acetyl@N-term; } \\
\text { Deamidated(N)@3 }\end{array}$ \\
\hline isocitrate dehydrogenase $3(\mathrm{NAD}+)$, gamma & $\begin{array}{l}\text { KAVLASMDNENMHTPDIGGQGTTSQ } \\
\text { AIQDII }\end{array}$ & Deamidated(N)@9 \\
\hline Protein Diabetic SSM & $\begin{array}{l}\text { Peptide Sequence } \\
\text { Diabetic SSM }\end{array}$ & $\begin{array}{l}\text { Post Translational Modification } \\
\text { Diabetic SSMI }\end{array}$ \\
\hline $\begin{array}{l}\text { ATP synthase, } \mathrm{H}+\text { transporting mitochondrial } \mathrm{F} 1 \\
\text { complex, beta subunit }\end{array}$ & IPSAVGYQPTLATDMGTMQER & Oxidation(P)@2 \\
\hline acetyl-Coenzyme $A$ acyltransferase 2 & VPPETIDSVIVGNVMQSSSDAAYLAR & Oxidation(P)@2 \\
\hline ubiquinol-cytochrome c reductase core protein 1 & VYEEDAVPGLTPCR & $\begin{array}{l}\text { Dioxidation(P)@12; } \\
\text { Carbamidomethyl(C)@13; Arg- } \\
\text { >GluSA(R)@14 }\end{array}$ \\
\hline
\end{tabular}




\section{Table 2.3}

\begin{tabular}{|c|c|c|}
\hline Protein Diabetic SSMI & $\begin{array}{l}\text { Peptide Sequence } \\
\text { Diabetic SSMI }\end{array}$ & $\begin{array}{l}\text { Post Translational Modification } \\
\text { Diabetic SSMI }\end{array}$ \\
\hline ubiquinol-cytochrome c reductase core protein 1 & TATFAQALQSVPETQVSILDNGLR & $\begin{array}{l}\text { Oxidation(F)@4; Deamidated(Q)@6; } \\
\text { Deamidated(N)@21 }\end{array}$ \\
\hline $\begin{array}{l}\text { NADH dehydrogenase (ubiquinone) } 1 \text { beta } \\
\text { subcomplex } 8 \text { [Mus musculus] }\end{array}$ & VEDYEPYPDDGMGYGDYPMLPNR & Oxidation(D)@3 \\
\hline $\begin{array}{l}\text { ATP synthase, } \mathrm{H}+\text { transporting, mitochondrial } \mathrm{F} 1 \\
\text { complex, alpha subunit, isoform } 1\end{array}$ & VVDALGNAIDGK & Deamidated(N)@7 \\
\hline $\begin{array}{l}\text { enoyl-Coenzyme A hydratase (trifunctional } \\
\text { protein), alpha subunit }\end{array}$ & $\begin{array}{l}\text { SLNSEMDNILANLRLPAKPEVSSDEDV } \\
\text { QYR }\end{array}$ & Deamidated(N)@3 \\
\hline $\begin{array}{l}\text { glutamate oxaloacetate transaminase } 2 \text {, } \\
\text { mitochondrial [Mus musculus]; }\end{array}$ & ILIRPLYSNPPLNGAR & Deamidated(N)@13 \\
\hline $\begin{array}{l}\text { glutamate oxaloacetate transaminase } 2 \text {, } \\
\text { mitochondrial [Mus musculus]; }\end{array}$ & MNLGVGAYRDDNGKPYVLPSVR & Deamidated(N)@12 \\
\hline $\begin{array}{l}\text { ATP synthase, } \mathrm{H}+\text { transporting, mitochondrial } \mathrm{F} 0 \\
\text { complex, subunit d }\end{array}$ & NIIPFDQMTIDDLNEIFPETKLDKK & Deamidated(N)@1 \\
\hline $\begin{array}{l}\text { Electron transfer flavoprotein-ubiquinone } \\
\text { oxidoreductase }\end{array}$ & IPVPILPGLPMNNHGNYIVR & Deamidated(N)@12 \\
\hline oxoglutarate dehydrogenase (lipoamide) & $\begin{array}{l}\text { SSLATMAHAQSLVEAQPNVDKLVED } \\
\text { HLAVQSLIR }\end{array}$ & Deamidated(Q)@10 \\
\hline $\begin{array}{l}\text { ubiquinol cytochrome c reductase core protein } 2 \\
\text { [Mus musculus] }\end{array}$ & LPNGLVIASLENYAPLSR & Deamidated(N)@3 \\
\hline
\end{tabular}


Table 2.3. Post-translational modifications (PTM) in mitochondrial subpopulations from control and diabetic hearts. Multidimensional protein identification technology (MudPIT) was used to identify post-translational modifications (PTM) of proteins from SSM and IFM from control and diabetic mitochondria. Peptides presented represent only those peptides that have PTMs in the diabetic SSM or diabetic IFM and not present in the control group. 


\section{Table 2.4}

\begin{tabular}{|l|c|c|}
\hline \multicolumn{1}{|c|}{ Gene/Protein } & $\begin{array}{c}\text { mRNA } \\
\text { (Diabetic/Control) }\end{array}$ & $\begin{array}{c}\text { Protein } \\
\text { (IFM Diabetic//FM Control) }\end{array}$ \\
\hline $\begin{array}{l}\text { Adenine nucleotide } \\
\text { translocator, member 4 }\end{array}$ & 1.27 & .70 \\
\hline $\begin{array}{l}\text { ATP5B ATP synthase F1 } \\
\text { subunit beta }\end{array}$ & .94 & .66 \\
\hline $\begin{array}{l}\text { ATP5a1 ATP synthase } \\
\text { subunit alpha }\end{array}$ & 1.03 & .82 \\
\hline
\end{tabular}


Table 2.4. Relative gene expression compared to IFM protein expression from control and diabetic hearts. Myocardial gene expression of ANT4, ATP5B and ATP5A1 in control and diabetic mice as compared to respective protein expression levels in IFM. Values represent cellular mRNA transcript levels and IFM protein expression in diabetic compared to control. mRNA expression was normalized to GAPDH. All protein values presented indicate a significant difference of at least $* p<0.05$ for control vs. diabetic groups. $\mathrm{N}=4$ for each group. 


\section{Chapter 3:}

\section{Overexpression of Phospholipid Hydroperoxide Glutathione Peroxidase (mPHGPx) Attenuates Cardiac Mitochondrial Proteomic Loss and Reverses Protein Import Detriments Observed with Type 1 Diabetes Mellitus}

Walter A. Baseler, Erinne R. Dabkowski, Rajaganapathi Jagannathan, Dharendra Thapa, Cody E. Nichols, Danielle L. Shepherd, Tara L. Croston, David M. Schnell, John M. Hollander.

West Virginia University School of Medicine, Division of Exercise Physiology; Center for Cardiovascular and Respiratory Sciences; Morgantown, WV 26506

Running Title: MPHGPx and the Type 1 Diabetic Heart 


\begin{abstract}
Mitochondrial dysfunction is a contributor to diabetic cardiomyopathy. Previously, we observed proteomic decrements within the mitochondrial inner membrane (IMM) and matrix of diabetic cardiac interfibrillar mitochondria (IFM) correlating with dysfunctional mitochondrial import. The goal of this study was to determine whether overexpression of mPHGPx, an antioxidant capable of scavenging membrane-associated lipid peroxides, could preserve the mitochondrial proteome and import process. mPHGPx transgenic mice and controls were made diabetic by multiple low-dose streptozotocin. Proteomic analyses revealed mPHGPx overexpression preserved proteins decreased within the diabetic IFM. Posttranslational modifications, including oxidations and deamidations, were reversed within mPHGPx diabetic IFM. Ingenuity Pathway Analyses indicated that OXPHOS, TCA, and FAO processes most influenced in diabetic IFM were preserved by mPHGPx overexpression $(\mathrm{P}<0.05)$. IMM proteins were the most highly preserved (63\%) followed by matrix proteins (34\%). Specific mitochondrial protein networks were preserved including those of Complex I and II, structure (mitofilin), and mitochondrial import. Mitochondrial protein import was also preserved in the mPHGPx diabetic IFM $(\mathrm{P}<0.05)$ which correlated with increases in protein import constituents. Mitochondrial import translocases Tom20, Tim23, Tim50, and MtHsp70 were all preserved within mPHGPx diabetic IFM $(\mathrm{P}<0.05)$. The results indicate overexpression of mPHGPx can protect the mitochondrial proteome and may provide cardioprotective benefits to the diabetic heart.
\end{abstract}




\section{INTRODUCTION}

Cardiac failure and heart disease are the leading cause of morbidity and mortality among type 1 diabetic patients (15). Multiple studies have specifically implicated mitochondrial dysfunction as an underlying mechanism for cardiac dysfunction seen in the type 1 diabetic heart $(12,15,46)$. Mitochondrial analyses are complicated primarily because two spatially distinct mitochondrial subpopulations exist in cardiac tissue, subsarcolemmal (SSM) and interfibrillar mitochondria (IFM). Literature suggests mitochondrial subpopulations are differentially affected within various pathological insults $(2,12,23,29,36)$. Specifically, we have shown cardiac IFM exhibit the greatest dysfunctional profile within the type 1 diabetic insult including enhanced oxidative stress, decreased OXPHOS, and diminished nuclear-encoded mitochondrial import (2, 12).

Broad scale proteomic analyses are becoming increasingly prevalent within various type 1 diabetic models and are paramount to understanding mitochondrial dysfunction within the heart $(2,6,18,38,41)$. In general, diabetes mellitus leads to significant alterations to proteins directly involved in mitochondrial energy production, including processes such as fatty acid oxidation (FAO), oxidative phosphorylation (OXPHOS), and the tricarboxylic acid cycle (TCA). Further, proteins involved in mitochondrial antioxidant defense, nuclear-encoded mitochondrial import, and protein folding were also highlighted as key loci affected by diabetes mellitus $(2,24$, 41). Specifically, our laboratory examined proteomic differences in spatially distinct subpopulations of mitochondria in which cardiac IFM displayed decrements to proteins involved in FAO, OXPHOS, the TCA cycle, mitochondrial structure (mitofilin) and nuclear-encoded 
mitochondrial protein import. Post translational modifications (PTM), such as oxidations and deamidations, were also elevated within the diabetic IFM (2).

Potential mechanisms as to why mitochondrial proteomic dysregulation occurs within the diabetic heart remain limited. Mitochondrial dysfunction has been shown to be directly correlative with enhanced mitochondrial derived reactive oxygen species (ROS) generation and oxidative damage within the organelle. Multiple proteins and lipids within the inner mitochondrial membrane (IMM) are known targets of reactive oxygen species damage, which may potentially elucidate a mechanism of proteomic dysregulation. Phospholipid hydroperoxide glutathione peroxidase (PHGPx; GPx4) is an antioxidant that exists as a monomeric structure and has the ability to reduce peroxidized acyl groups in phospholipids, fatty acid hydroperoxides, and cholesterol peroxides within subcellular membranes (32). The mitochondrial specific isoform, mPHGPx, is primarily located within the inner membrane space (IMS) and has been shown to be protective against apoptosis, oxidants, DNA-damaging agents, and glucose deficiency (31). mPHGPx overexpression was shown to be protective of cardiac contractile function through a mechanism of reduced lipid peroxidations preservation of essential mitochondrial phospholipid cardiolipin, and protection of the mitochondrial ETC complex following Ischemia/Reperfusion (I/R) injury (13). Cardiolipin is known to surround essential mitochondrial complexes such at the ETC and Tim23 protein import complex $(16,22,35)$. To date, no study has examined how antioxidant overexpression within the diabetic heart influences mitochondrial proteomic makeup and essential processes within the organelle.

Currently, there are an estimated 1500 proteins residing within the human mitochondrion, with only 13 proteins transcribed and translated in the organelle itself $(1,7,34)$. The vast majority of proteins ( $>99 \%)$ are nuclear-encoded and must be imported into the mitochondrion 
through a complex mechanism of translocation (8). Mutations or deletions to essential protein import constituents, specifically mitochondrial heat shock protein 70 (MtHsp70), have been shown to drastically reduce nuclear encoded mitochondrial import into the mitochondrial matrix and has been proven lethal within yeast cells $(10,14,25)$. Our laboratory has previously shown decreased nuclear-encoded mitochondrial protein import correlated with the loss of MtHsp70 within the diabetic IFM (2).

It is known type 1 diabetes mellitus will cause widespread proteomics irregularities within cardiac mitochondria, however the mechanism of action as well as targeted therapeutics to preserve proteomic integrity remain limited. The goal of this manuscript was to assess the influence mPHGPx overexpression has on mitochondrial proteomic integrity and evaluate its impact on essential processes such as nuclear-encoded mitochondrial protein import in a diabetic setting. We hypothesize mPHGPx overexpression will preserve essential constituents of the protein import process, which will lead to restoration of nuclear-encoded mitochondrial import and potentially elucidate a mechanism of mitochondrial proteomic protection within the mPHGPx diabetic mouse model. 


\section{METHODS}

\section{Experimental Animals and Diabetes Induction}

The animal experiments in this study conformed to National Institutes of Health (NIH) Guidelines for the Care and Use of Laboratory Animals and were approved by the West Virginia University Animal Care and Use Committee. Mixed sex FVB mice were housed in the West Virginia University Health Sciences Center animal facility. Mice were given unlimited access to a rodent diet and water. MPHGPx transgenic mouse lines were generated as previously described $(13,19,20)$. Briefly, the pCAGGS vector places the mPHGPx gene under the control of the human cytomegalovirus (CMV). All littermante control and transgenic mice were generated using an FVB background, and experimental procedures were performed on animals of approximately 8 weeks of age. Type 1 diabetes was induced in 8 -wk-old mice following the protocol of the Animal Models of Diabetic Complications Consortium using multiple low-dose streptozotocin (STZ; Sigma, St. Louis, MO) injections. A multiple low-dose STZ protocol was chosen because previous reports (21) have indicated that this model limits the body weight losses associated with diabetic protocols. Injections of $50 \mathrm{mg} / \mathrm{kg}$ body wt STZ dissolved in sodium citrate buffer ( $\mathrm{pH} 4.5$ ) were performed daily for 5 consecutive days after $6 \mathrm{~h}$ of fasting. Mice that served as vehicle controls were given the same volume per body weight of sodium citrate buffer.

One week postinjection, hyperglycemia was confirmed by measuring urinary glucose (Chemstrip 2GP Urine test strips, Roche Diagnostics, Indianapolis, IN), where $>250 \mathrm{mg} / \mathrm{dl}$ was considered diabetic. Five weeks after the onset of hyperglycemia, animals were sacrificed for further experimentation. 


\section{Preparation of Individual Mitochondrial Subpopulations}

At 5 wk post hyperglycemia onset, FVB control, diabetic, MPHGPx, and MPHGPx diabetic mice were killed, and their hearts excised. Hearts were rinsed in PBS (pH 7.4), then blotted dry. IFM were isolated as previously described following the methods of Palmer et al. (33) with minor modifications $(2,11,12)$. Protein concentrations were determined using the Bradford method with BSA as a standard (5).

\section{iTRAQ $Q^{\mathrm{TM}}$ Labeling}

Pooled IFM $(n=4)$ from control, diabetic, mPHGPx, and mPHGPx diabetic mice were lysed and precipitated overnight in acetone at $-20^{\circ} \mathrm{C}$ and pellets were resuspended in $20 \mu \mathrm{L}$ of 0.5 M triethylammonium bicarbonate (TEAB; $\mathrm{pH} 8.5$ ). Protein contents were determined using a 2-D Quant Kit (Amersham, Piscataway, NJ) and $100 \mu \mathrm{g}$ of each pooled sample was than denatured with $0.1 \%$ SDS and reduced with $5 \mathrm{mM}$ tris-(2-carboxyethyl) phosphine (TCEP). After incubation for 1 hour at $60^{\circ} \mathrm{C}$, cysteines were blocked with $10 \mathrm{mM}$ methyl methane thiosulfonate (MMTS) in isopropanol, and the samples were incubated at room temperature for 10 minutes. Addition of $10 \mu \mathrm{L}$ of sequencing grade trypsin (Applied Biosystems, Foster City, CA) was added in a trypsin/protein ratio of $1: 20$, and the samples incubated at $37^{\circ} \mathrm{C}$ overnight. Digested samples were labeled with the iTRAQ ${ }^{\mathrm{TM}}$ reagents following the protocol provided by the vendor (Applied Biosystems, Foster City, CA).

After digestion and $\mathrm{iTRAQ}{ }^{\mathrm{TM}}$ labeling, the ultra-complex protein digests were combined to create a $400 \mu \mathrm{g}$ pooled protein digest sample that contained equal fractions of each of the four 
labeled samples for subsequent Multi Dimensional Protein Identificiation Technology (MudPIT) analysis (30). After lyophilization, the digest mixture was reconstituted in strong cation exchange (SCX) loading buffer ( $5 \mathrm{mM}$ ammonium formate in $20 \%$ acetonitrile; $\mathrm{pH} 3.0$ ) to be fractionated with SCX SpinTips (Protea Biosciences, Morgantown, WV) per the manufacturer's protocol. Briefly, the sample solution was loaded centrifugally onto the SCX SpinTip. The nonadsorbing solution that passed through the SCX SpinTip was collected. Eight different elution solutions were used to fractionate the peptides $(20,60,100,150,200,250,400$, and $500 \mathrm{mM}$ ammonium formate in $10 \%$ acetonitrile) in a step-wise manner, for a total of nine sample fractions. The collected fractions were cleaned by repeated lyophilization and reconstituted in a $0.1 \mathrm{M}$ acetic acid solution, and then lyophilized to dryness. The fractions were then submitted for LC-MALDI TOF/TOF mass spectral analysis for protein identification, characterization, and differential expression analysis.

\section{Mass Spectrometry (MS) Analyses with iTRAQ ${ }^{\mathrm{TM}}$ Labeling}

The LC-MALDI mass spectrometry system utilized was an ABI Tempo LC MALDI spotter with Tempo LC MALDI v.2.00.09 data acquisition and processing software. Lyophilized SCX sample fractions were reconstituted in LC aqueous run buffer $(0.1 \%$ trifluoroacetic acid, $2 \%$ acetonitrile) and was injected onto a Zorbax $\mathrm{C}_{18}$ chromatographic column, $150 \times 0.3 \mathrm{~mm}$ (Agilent Technologies, Wilmington, DE). The peptides were eluted from the column using an acetonitrile/trifluoroacetic acid gradient (2-72\% acetonitrile in 35 minutes) and spotted directly onto a MALDI plate in 6 second spot fractions. The MALDI spots were analyzed using an ABI 4800 MALDI TOF/TOF analyzer operated with 4000 Series Explorer software. The MS 
acquisition was in positive ion reflector mode with 400 laser shots per spectrum performed. The 15 strongest precursors per spot were chosen for MS/MS and the MALDI spot was interrogated until at least 4 peaks in the MS/MS, spectra achieved a $\mathrm{S} / \mathrm{N} \geq 70$.

The resulting MS/MS spectra were analyzed using ABI Protein ProteinPilot software 2.0 (Applied Biosystems, Foster City, CA). The spectral data was searched against the mouse protein database (NCBI nr.fasta database customized to select for all mouse proteins) for identification of the peptides and corresponding proteins. In ProteinPilot, the sample type was selected as iTRAQ 4Plex for retrieval of the isotopic tag information from the mass spectra. After database correlation analysis, the proteins were grouped, scored, and normalized against one to four isotope correction factors. The Pro Group algorithm of ProteinPilot generated a ProtScore that is a cumulative score from each of the peptides used by the algorithm in the protein identification. Protein scores (ProtScore) above 2.0, 1.0, and 0.47 expressed the percent confidence levels of $>99,>90$, and $>66 \%$, respectively. Each peptide match showed the iTRAQ $^{\mathrm{TM}}$ isotopic labels, carbamidomethylated cysteines, and other post-translational modifications present as mass spectral shifts identified during the database correlation analysis. Each protein identified also showed the differential protein expression compared against the other iTRAQ ${ }^{\mathrm{TM}}$ labeled samples for relative quantitation.

\section{Canonical Pathways and Molecular Network Analysis}

After protein identification/quantification of diabetic IFM and mPHGPx diabetic IFM proteomes through iTRAQ proteomic analyses, the accession numbers and fold changes of the differentially expressed proteins were tabulated in Microsoft Excel and imported into IPA 
(Ingenuity Systems, www.ingenuity.com) for canonical pathway analyses. The statistical significance of each pathway was determined by IPA using a Fisher Exact test $p<0.05$ and visualized as a bar graph. IPA was also used to construct interacting protein networks identified within diabetic IFM and mPHGPx diabetic IFM groups obtained through iTRAQ proteomic analyses. IPA contains a database that uses the most current knowledge available on genes, proteins, disease processes, signaling and metabolic pathways needed for protein network construction.

\section{Protein Import}

\section{Plasmid Construction}

The fusion protein pAcGFP1-Mito (Clontech Laboratories, Mountain View, CA) containing the precursor subunit VIII of human cytochrome C oxidase and the green fluorescent protein from Aequorea coerulescens (AcGFP1) was cloned into pIVEX2.3d (Roche Applied Science, Indianapolis, IN) at restriction sites NotI and blunted NcoI/NheI creating pMitoGFP1. The correct sequence was confirmed by dideoxynucleotide sequencing. pMitoGFP1 was grown to a concentration of $500 \mathrm{ng} / \mu 1$ and isolated using mini prep plasmid DNA isolations (Qiagen, Valencia, CA).

\section{In Vitro Synthesis of Mitochondrial Protein}

In Vitro transcription/ translation of mitoGFP1 was performed using the S30 T7 protein expression system (Promega, Madison, WI) per manufacturer's protocol. MitoGFP1 lysate was subsequently used as substrates for the in Vitro protein import process.

\section{Mitochondrial Protein Import}


The mitochondrial protein import procedure was performed following the protocol from Stojanovski et al. (40) with modifications. Briefly, $40 \mu \mathrm{g}$ of mitochondria was resuspended in $100 \mu 1$ of import buffer (250 mM Sucrose, $80 \mathrm{mM} \mathrm{KCl} 5 \mathrm{mM} \mathrm{MgCl} 2,2 \mathrm{mM} \mathrm{KH_{2 }} \mathrm{PO}_{4} 10 \mathrm{mM}$ MOP-KOH, $\mathrm{pH}$ 7.2) with addition of $2 \mathrm{mM}$ ATP and $10 \mathrm{mM}$ Na-Succinate. 1-5 $\mu 1$ lysate containing MitoGFP1 protein was added, and protein import was performed at increasing time intervals of 1 and 2 minutes at $25^{\circ} \mathrm{C}$. Valinomycin $(2 \mu \mathrm{M})$ was added to stop the import reaction, and samples were centrifuged at $12,000 \times \mathrm{g}$ for $5 \mathrm{~min}$ at $4^{\circ} \mathrm{C}$. The supernatant was discarded, and the pellet resuspended in SEM buffer (250 mM Sucrose, $1 \mathrm{mM}$ EDTA, $10 \mathrm{mM}$ MOP-KOH, $\mathrm{pH}$ 7.2) containing trypsin, on ice. Trypsin was subsequently inhibited by protease inhibitor cocktail (BioVision, Mountain View, CA). Samples were centrifuged again at 12,000 x $g$ for 5 min at $4^{\circ} \mathrm{C}$. Pellets were then resuspended in lysis buffer (Biovision, Mountain View, California), subjected to SDS-PAGE, and subsequent Western blot analyses. Quantification of blots was performed using Pierce ECL Western Blotting Substrate (Pierce Biotech, Rockford, IL). The primary antibody was an anti-GFP monoclonal antibody raised in a mouse host (Clontech Laboratories, Mountain View, CA). The secondary antibody was an anti-mouse IgG horseradish peroxidase conjugate (Sigma, St. Louis, MO). Quantification of chemiluminescent signals were detected using a G:BOX (Syngene, Frederick, MD), and data expressed as arbitrary optical density units.

\section{Western Blot Analyses}

SDS polyacrylamide gel electrophoresis (SDS-PAGE) was run on 4-12\% gradient gels as previously described $(28,44)$ with equal amounts of protein loaded for each study treatment. Relative amounts of subpopulation-specific mitochondrial MtHsp70 (MtHsp70), translocase of 
the outer membrane 20 (Tom20), translocases of the inner membrane 23 (Tim23) and 50 (Tim50) were analyzed using the following primary antibodies; anti-MtHsp70 mouse antibody (Product \# SPA-825; Stressgen, Ann Arbor, MI), anti-TOM20 mouse antibody (Product \# 612278; BD Biosciences, San Jose, CA), anti-Tim23 mouse antibody (Product \# 611222; BD Biosciences, San Jose, CA) . The secondary antibodies used in the analyses were donkey antigoat IgG HRP conjugate (Product \# sc-2020; Santa Cruz Biotech, Santa Cruz, CA) for TIM50, goat-anti mouse conjugate (Product \# 31430; Pierce Biotech, Rockford, IL) for TOM20, TIM23, and MtHsp70. Detection of signal was performed according to the manufacturer's instructions, using Pierce ECL Western Blotting Substrate (Pierce Biotech, Rockford, IL). Autoradiographic signals were assessed using a G:Box Bioimaging System (Syngene, Frederick, MD), and the data captured and analyzed using GeneSnap/GeneTools software (Syngene, Frederick, MD).

\section{Blue Native Gel}

To assess MtHsp70 abundance within the PAM complex, Native Polyacrylamide Gel Electrophoresis (NativePAGE) was performed in control, diabetic, mPHGPx, and diabetic mPHGPx IFM according to manufacturer's protocol (Invitrogen, Carlsbad, CA). Briefly, $20 \mu \mathrm{g}$ of isolated mitochondria was solubilized with $1 \%$ digitonin for 15 minutes on ice. After addition of $1.25 \mu \mathrm{l}$ of Coomassie G-250, samples were run in 4-16\% NativePAGE gels at $120 \mathrm{~V}$ for 90 minutes in room temperature. Gels were transferred to PDVF membranes and subsequently probed with mtHSP70 antibody previously described. 


\section{Statistics}

Means and standard errors (SEM) were calculated for all data sets. Data were analyzed with a one-way analysis of variance (ANOVA) method to evaluate the main treatment effect, diabetes induction and mPHGPx transgene presence (GraphPad Software Inc., La Jolla, CA). Fisher's Least Significant Difference (LSD) post hoc tests were performed to determine the significant differences among means. When appropriate a Student's T-test was employed. $P<0.05$ was considered significant. 


\section{RESULTS}

\section{Proteomic Analyses}

To determine how mPHGPx overexpression impacts the proteomic makeup of IFM during a type 1 diabetic insult, iTRAQ labeling followed by MALDI-TOF/TOF mass spectrometry was performed. iTRAQ allows for identification and quantification of unique polypeptide sequences through isobaric tagging. Only proteins that were statistically significant as a result of diabetes mellitus in control or mPHGPx overexpressed animals were reported.

\section{Proteins of the Mitochondrial Respiratory Chain.}

As previously reported, multiple mitochondrial respiratory chains proteins were significantly decreased in the IFM by diabetes mellitus (2). The greatest influence was upon the NADH dehydrogenase complex (complex I) with 5 proteins significantly decreased. To a lesser extent, the other respiratory chain complexes were also decreased including 2 proteins from complex II, 3 proteins from complex III, 1 protein from complex IV, and 2 proteins from the ATP synthase itself (TABLE 3.1). Interestingly, overexpression of mPHGPx within the diabetic IFM lead to the preservation of 9 OXPHOS proteins significantly decreased in the diabetic IFM group including those from complex I, II, III, and V (Table 3.1). Further, mPHGPx diabetic IFM displayed enhanced protein content of 9 OXPHOS proteins that weren't decreased in the diabetic IFM (Table 3.1). The results indicate that mPHGPx has the specific ability to protect the mitochondrial respiratory chain during a type 1 diabetic insult.

\section{Proteins of Lipid Metabolism}


Because of the inability to utilize glucose within the diabetic heart, preservation of lipid metabolism is paramount for proper energy production and utilization. Three mitochondrial proteins involved in lipid metabolism, acyl carrier protein, hydroxyacyl-coenzyme A dehydrogenase, and short-chain specific acyl-CoA dehydrogenase were significantly decreased when comparing control and diabetic IFM (Table 3.1). Interestingly, 2 of these proteins as well as other lipid metabolism constituents including enoyl-CoA hydratase were significantly increased in the mPHGPx diabetic transgenic IFM compared to diabetic counterpart (Table 3.1).

Proteins of the Citric Acid Cycle (TCA).

Two proteins of the TCA cycle were significantly decreased in the IFM of the diabetic animals compared to control including isocitrate dehydrogenase 3 (IDH3) (Table 3.1). Conversely, mPHGPx diabetic IFM show highly significant increases in IDH3 (3.5 fold) when compared to the diabetic phenotype. Interestingly, mPHGPx was able to preserve or elevate 4 additional TCA cycle proteins that were not influenced by diabetes mellitus. These proteins include aconitate hydratase, citrate synthase, and malate dehydrogenase (Table 3.1). Because mPHGPx is thought to predominantly exist within the inner membrane space, we did not anticipate its effects upon the mitochondrial matrix.

\section{Transport Proteins}

Multiple mitochondrial transport proteins were decreased including mtHsp70, the key constituent of the presequence translocase-associated motor (PAM) complex essential for all mitochondrial matrix import and to a lesser extent, IMM transport. Following trend, mtHsp70 protein content was preserved in the IFM mPHGPx diabetic group compared to the diabetic group (Table 3.1). The IMM transporter essential for phosphate transport into the mitochondrial 
matrix, Phosphate carrier protein, was also decreased in the diabetic IFM and rescued in the MPHGPx transgenic animal. ADP/ATP translocase 1 was also preserved within the mPHGPx diabetic IFM (Table 3.1). Outer mitochondrial membrane (OMM) channel, voltage dependent anion selective channel 1 was also enhanced within the mPHGPx diabetic IFM, highlighting the ability of mPHGPx to preserve proteins within the OMM as well.

\section{Miscellaneous}

D-beta-hydroxybutyrate dehydrogenase was significantly decreased in the diabetic IFM compared to control and increased by 2.45 fold in the mPHGPx transgenic compared to diabetic (Table 3.1). Antioxidant peroxiredoxin-5, which is capable of reducing hydrogen peroxide and alkyl hydroperoxides was significantly decreased within the diabetic IFM compare to control. mPHGPx diabetic mice show a trending increase in peroxiredoxin-5 when compared with diabetic IFM, however not statistically significant (Table 3.1). MPHGPx diabetic IFM show increases in amino acid metabolism protein aspartate aminotransferase as well as ketone metabolism protein succinyl-CoA:3-ketoacid-coenzyme A transferase 1 when compared to diabetic IFM (Table 3.1).

\section{Diabetic mPHGPx IFM vs mPHGPx IFM}

Analyses were conducted analyzing diabetic mPHGPx IFM and control mPHGPx IFM, which are shown in Table 3.1. Interestingly, the majority of proteins (34 out of 46) were not significantly changed between mPHGPx diabetic IFM and mPHGPx IFM indicating a preservation of these proteins within a diabetic setting (Table 3.1). Further, diabetic mPHGPx IFM displayed enhanced protein content in 12 out of 46 proteins identified when compared to 
mPHGPx IFM, including MtHsp70 (Table 3.1). Western blot data confirms elevated levels of MtHsp70 protein content in diabetic mPHGPx IFM compared to mPHGPx IFM (Fig 3.5C).

\section{Posttranslational Modifications (PTM)}

Utilizing MudPIT technology to examine PTM, we identified 68 peptide sequences of 44 different protein that were modified through oxidations, acetylations or deamidations, within the diabetic IFM, which were reversed in the diabetic mPHGPx transgenic (Table 3.2). All proteins analyzed were within the IMM or matrix. Nine proteins were no longer oxidized in the diabetic mPHGPx IFM including 3 from the ETC, 2 from the TCA cycle, and 2 FAO proteins (Table 3.2). Interestingly, $16 \mathrm{IMM}$ proteins and 21 matrix protein identified no longer displayed deamidations within the mPHGPx diabetic IFM group including essential mitochondrial import protein MtHsp70 (Table 3.2).

\section{Proteomic Analyses}

To begin to understand the impact of mPHGPx overexpression upon diabetic IFM, we evaluated proteins in three categories; unique proteins decreased only in the diabetic IFM, unique protein only upregulated within the diabetic mPHGPx IFM, or common proteins (decreased in diabetic IFM, restored in mPHGPx diabetic IFM). Analyses revealed a total of 25 proteins statistically decreased within the diabetic IFM compared to control. Of those, 9/24 mitochondrial proteins were uniquely decreased in the diabetic IFM alone without correction in the mPHGPx diabetic group (Fig. 3.1B). Conversely, the remaining 15/24 proteins (62.5\%) were shown to be significantly decreased in the diabetic IFM and subsequently preserved within the diabetic mPHGPx IFM group. Interestingly, there are an additional 20 unique proteins that were not changed in the diabetic verse control IFM but were significantly increased within the diabetic 
mPHGPx group (Fig. 3.1B). These results indicate that the majority of proteins negatively impacted by type 1 diabetes mellitus are preserved with mPHGPx overexpression.

\section{Mitochondrial Subcompartment Targeting}

Because mitochondria are double membrane organelles, they contain various sub compartments including the OMM, IMS, IMM, and matrix. To determine the sub-mitochondrial location most targeted by mPHGPx overexpression within diabetic IFM, we analyzed the percentage of proteins preserved within the various compartments. As shown in Fig. 3.1A, proteomic protection via mPHGPx overexpression predominantly occurred within the mitochondrial IM (61\%), followed by the mitochondrial matrix (36\%), and then OMM (3\%).

\section{Canonical Pathways}

We utilized Ingenuity based software (IPA) in conjunction with iTRAQ proteomics to predict canonical pathways within mitochondria that were most negatively impacted by a diabetic insult and subsequently preserved through mPHGPx overexpression. As expected, Fig. 3.2 demonstrates OXPHOS, FAO, the TCA cycle and fatty acid elongation pathways were the most negatively affected (green) by diabetes mellitus within IFM. Interestingly, mPHGPx overexpression within diabetic IFM not only corrected but enhanced (red) proteins involved within all four of these major pathways within the diabetic IFM (Fig. 3.2). Further, mPHGPx was also shown to influence proteins involved in pyruvate metabolism within the diabetic mPHGPx IFM. The results suggest that mPHGPx overexpression is able to preserve and even potentially bolster essential mitochondrial processes negatively influenced by diabetes mellitus.

\section{Common Molecular Networks}


IPA software was able to identify essential mitochondrial molecular networks that were damaged within diabetic IFM and preserved within the mPHGPx diabetic IFM. Of the 6 networks identified, 5 were of IMM origin including ETC complexes I and II networks, ATPsensitive $\mathrm{K}+$ channel network, structural protein mitofilin network, and mitochondrial protein import network (Fig 3.3). Finally, a hydrogen peroxide $\left(\mathrm{H}_{2} \mathrm{O}_{2}\right)$ network was also identified and shown to be preserved within the diabetic mPHGPx (Fig 3.3). mPHGPx is capable of directly scavenging $\mathrm{H}_{2} \mathrm{O}_{2}$.

\section{Mitochondrial Protein Import}

In vitro mitochondrial protein import was evaluated by quantifying the amount of mature MitoGFP1 protein within mitochondrial subpopulations of control, mPHGPx, diabetic, and mPHGPx diabetic hearts as previously described (2). Western blot analyses highlighted increasing amount of MitoGFP1 at 1 and 2 minutes, respectively, of the mature 27-kDA band in all IFM groups. MitoGFP1 protein import was significantly decreased in the diabetic IFM when compared to control, which is in agreement with previous findings from our laboratory (2) (Fig. 3.4, A and B). Further, MitoGFP1 import was restored back to control levels in the mPHGPx

diabetic group indicating mPHGPx overexpression is protective against diabetes induced mitochondrial import decrements within the IFM (Fig. 3.4, A and B). SSM protein import was not significantly altered in any of the groups examined (Appendix 7.1).

\section{Protein Import Machinery}

To determine the impact of mPHGPx overexpression upon key mitochondrial import constituents, we evaluated the protein abundance of OMM translocase Tom20, IMM translocases Tim23 and Tim50, and essential PAM complex constituent MtHsp70 in control, mPHGPx, 
diabetic, and mPHGPx diabetic IFM (Table 3.1, Fig. 3.5). MtHsp70 protein content was significantly decreased in the diabetic IFM group and significantly increased in the mPHGPx diabetic group, which is in agreement with our iTRAQ data (Fig. 3.5C). Further, Tom20, Tim23, and Tim50 were all significantly increased in the diabetic mPHGPx IFM compared to diabetic IFM (Fig. 3.5, A, B and D). MtHsp70 also had a trending increase $(\mathrm{P}<0.07)$ in the $\mathrm{mPHGPx}$ diabetic SSM group compared to all other SSM groups (Appendix 7.2). The results indicate mPHGPx has a direct ability to protect and enhance nuclear-encoded mitochondrial protein import constituents.

\section{MtHsp70 Complexing}

During moments of import into the mitochondrial matrix, MtHsp70 will complex with inner membrane anchor protein Tim44 to form the functional element of the PAM complex. To examine the ability of MtHsp70 to complex with Tim44, we performed BN-PAGE analyses on isolated IFM in control, diabetic, MPHGPx, and diabetic MPHGPx mouse hearts (Fig. 3.6, A and B). Similar to the Western blot results, diabetic IFM displayed a significant decrease in MtHsp70-Timm44 protein complexing compared to all other groups and diabetic mPHGPx IFM was restored to control levels (Fig. 3.6, A and B). The results indicate that diabetic mPHGPx IFM are able to adequately form the functional PAM complex, which was decreased in the diabetic IFM. 


\section{DISCUSSION}

Mitochondrial dysfunction plays a critical role in the progression and pathogenesis of type 1 diabetes mellitus and diabetic cardiomyopathy. Although multiple studies highlight mitochondrial abnormalities within the pathology, the underlying mechanisms involved with dysfunction remain limited. Further complicating studies of this nature are that mitochondria exist in two spatially distinct subpopulations within the heart, the SSM and IFM. Interestingly, literature suggests the two subpopulations respond differently to pathological insults. As an example, our laboratory has shown type 1 diabetic IFM to produce elevated levels of ROS, have enhanced oxidative damage and decreased cardiolipin content compared to IFM control (12). Further, we found that the proteomic makeup of IFM was significantly altered, presumably through a mechanism of enhanced post translational modifications and altered nuclear-encoded mitochondrial protein import mechanism (2). Mitochondrial proteomic decrements predominantly occur within the IMM locale. Because so many critical complexes exist within the IMM such as the ETC, the ATP synthase, and mitochondrial protein import TIM complex, preservation of this critical locale is essential for correction of the dysfunction present within mitochondria during a type 1 diabetic insult. MPHGPx is a unique antioxidant capable of scavenging phospholipid hydroperoxides, and is critical for the preservation of the IMM. Therefore, the goal of the study was to determine whether overexpression of mPHGPx will lead to protection of the IFM proteome and preservation of essential mitochondrial processes such as nuclear-encoded mitochondrial import during a diabetic insult.

Proteomic analyses are excellent tools for furthering our understanding of how mitochondrial proteins are influenced globally within the diabetic heart. Utilizing iTRAQ methodologies, we confirmed previous research from our laboratory highlighting decreases in 
essential mitochondrial proteins governing processes such as OXPHOS, TCA cycle, FAO, and transport proteins of the diabetic IFM (2). A rather compelling finding from the proteomic analysis was that mPHGPx was able to preserve a significant portion of the proteins decreased in the diabetic IFM (62.5\%) from all the mitochondrial processes highlighted above (Table 3.1). Further, the majority of proteins preserved or elevated within the diabetic mPHGPx IFM resided within the IMM. The results seem logical because mPHGPx resides predominantly within the mitochondrial IMS allowing for proximal scavenging membrane lipid hydroperoxides of the $\operatorname{IMM}(31,32)$. However, it is important to point out that nearly one third of proteins protected or elevated within the diabetic mPHGPx IFM resided within the matrix. Because mPHGPx is not endogenous to this submitochondrial region, this data was unexpected. ETC Complexes I and III, the principle sites for electron leakage, were highly preserved within the mPHGPx diabetic IFM potentially decreasing total ROS production and subsequent damage of matrix proteins (9). Our PTM data supports this notion by highlighting decreases in oxidations and deamidations in IMM and matrix proteins from mPHGPx diabetic IFM (Table 3.2). Further, mPHGPx is capable of scavenging ROS hydrogen peroxide, potentially further decreasing the oxidative environment seen within the mitochondria and highlighting another possible mechanism for proteomic protection seen within the matrix of mPHGPX diabetic IFM (42). However, further studies elucidating exact mechanisms of mPHGPx protection of mitochondrial matrix proteins is warranted.

Ingenuity Pathways Analysis (IPA) software is critical for the identification of key IFM canonical pathways and networks that are directly influenced by diabetes mellitus and preserved within mPHGPx diabetic IFM. From our results, we were able to validate the major processes negatively impacted by diabetes mellitus are OXPHOS, TCA, and FAO (Fig. 3.2). Interestingly, 
mPHGPx overexpression preserved all three of these canonical pathways highlighting the antioxidants ability to protect the exact areas of dysfunction within the diabetic IFM. Delving further into IPA's capabilities, we analyzed molecular networks directly influenced by enhanced mPHGPx in diabetic IFM. MPHGPx overexpression preserved biological networks originating within the IMM that are involved in OXPHOS (Complex I and II), ATP-sensitive K+ channel function, mitochondrial structure (mitofilin), and nuclear-encoded mitochondrial protein import. Some of the networks analyzed validate previous results from our laboratory and others as areas of dysfunction within diabetic IFM such as complex I and II of the ETC $(12,26,27)$. Interestingly, mPHGPx overexpression was able to correct networks relatively unexplored within a diabetic setting, including structural networks through the preservation of known mitochondrial scaffolding protein mitofilin. Deeper analysis into how the mitofilin network is influenced by diabetes mellitus may lead to novel mechanisms of dysfunction within the pathology.

Most importantly, IPA was able to identify a central linkage, connecting all other common networks displayed, the mitochondrial protein import network. Currently, there are an estimated 1500 proteins in the human mitochondrion, with only 13 transcribed and translated in the organelle itself $(1,7,34)$. The vast majority of proteins $(>99 \%)$ are nuclear-encoded and imported into the mitochondrion through a complex mechanism of translocation (8). Mitochondrial import of proteins into the matrix involved a coordinated effort between the translocases of the OMM (TOM), IMM (TIM), and the PAM complex, which create a "supercomplex", generating a singular avenue for translocation once the protein is targeted to the mitochondria. Because mitochondrial protein import is absolutely essential for mitochondrial morphology and structure, preservation of this process may be paramount within pathologies involving mitochondrial dysfunction, such as diabetes mellitus. 
Interestingly, key mitochondrial import protein and main component of the PAM complex, MtHsp70, was decreased in the diabetic IFM and preserved within the diabetic mPHGPx IFM in our proteomic analysis, which also was confirmed through Western blot analysis (Fig. 3.5C). Further, BN-PAGE was utilized to determine the level of MtHsp70 within the PAM complex. Similar to Western blot results, MtHsp70 content within the complex was decreased in the diabetic IFM and preserved within the mPHGPx diabetic group (Fig. 3.6B). Functionally MtHsp70 assists in the import of preproteins into various mitochondrial subcompartments including the inner membrane space, IMM, and matrix $(4,37,43)$. Previously, we have shown decreased MtHsp70 content within the diabetic IFM, which correlated with decreased ability of the mitochondria to import preproteins into the mitochondrial matrix (2). Therefore, we hypothesized that MtHsp70 preservation through mPHGPx overexpression could lead to correction of import decrements seem within the diabetic IFM and potentially elucidate a mechanism of proteomic protection within the diabetic mouse. Confirming previous experimentation, in vitro import of mitochondrial matrix targeted mitoGFP1 was significantly decreased in the diabetic IFM compared to control IFM. Further, mitoGFP1 import into the diabetic mPHGPx IFM was significantly higher (back to control level) when compared to diabetic IFM import, indicating restoration of matrix import within the diabetic mPHGPx IFM (Fig. 3.4). Further highlighting the positive effects upon nuclear-encoded mitochondrial protein import, key import constituents Tom20, Tim23, and Tim50 were all significantly increased within diabetic mPHGPx IFM compared to diabetic IFM (Fig 3.5 A, B, D). A number of reports have recently identified mitochondrial import decrements when one or more of these essential translocases are disturbed. Mutations to or inactivation of MtHsp70 was shown to inhibit unfolding, translocation, and subsequent folding of mitochondrial preproteins imported into yeast 
mitochondria $(3,14,25)$ Singh et al. examined mitochondrial protein import in a model of skeletal muscle disuse through unilateral peroneal nerve denervation (39). Interestingly, in vitro import of TCA cycle protein malate dehydrogenase 2 was decreased coinciding with significant decreases to MtHsp70, Tim23, and Tom20 protein content (39). Further, research from our laboratory using rat neonatal cardiac myocytes infected with an adenoviral vector overexpressing MtHsp70 enhanced protein content of Tom20 and antioxidant MnSOD compared to control myocytes (45). Recently, Gevorkyan-Airepetov et al. mutated the binding region of Tim23 and Tim50, destabilizing the interaction between the translocases (17). In vitro import of both IMM and matrix bound proteins were inhibited in the mutant yeast indicating the importance of Tim50 for the transport of numerous proteins within these mitochondrial locales. Overall, mPHGPx overexpression was able to preserve key translocases of the mitochondrial import process, which lead to restoration of mitochondrial protein import within the diabetic IFM subpopulation.

In conclusion, the data presented indicates for the first time that enhanced antioxidant defense via mPHGPx overexpression lead to protection of the IFM proteome within the diabetic heart. IPA analysis was utilized to highlight specific areas of dysfunction and preservation within diabetic and mPHGPx diabetic IFM respectively. Further, nuclear-encoded mitochondrial protein import function was corrected within the mPHGPx diabetic mice and may provide a mechanism for proteomic protection seen within the transgenic animal. These finding provide further rationale for the use of mPHGPx as a therapeutic protectant against type 1 diabeticinduced cardiac injury. 


\section{REFERENCES}

1. Anderson S, Bankier AT, Barrell BG, de Bruijn MH, Coulson AR, Drouin J, Eperon IC, Nierlich DP, Roe BA, Sanger F, Schreier PH, Smith AJ, Staden R, and Young IG. Sequence and organization of the human mitochondrial genome. Nature 290: 457-465, 1981.

2. Baseler WA, Dabkowski ER, Williamson CL, Croston TL, Thapa D, Powell MJ, Razunguzwa TT, and Hollander JM. Proteomic alterations of distinct mitochondrial subpopulations in the type 1 diabetic heart: contribution of protein import dysfunction. Am $J$ Physiol Regul Integr Comp Physiol 300: R186-200.

3. Becker D, Krayl M, Strub A, Li Y, Mayer MP, and Voos W. Impaired interdomain communication in mitochondrial Hsp70 results in the loss of inward-directed translocation force. J Biol Chem 284: 2934-2946, 2009.

4. Bohnert M, Rehling P, Guiard B, Herrmann JM, Pfanner N, and van der Laan M. Cooperation of stop-transfer and conservative sorting mechanisms in mitochondrial protein transport. Curr Biol 20: 1227-1232.

5. Bradford MM. A rapid and sensitive method for the quantitation of microgram quantities of protein utilizing the principle of protein-dye binding. Anal Biochem 72: 248-254, 1976.

6. Bugger H, Chen D, Riehle C, Soto J, Theobald HA, Hu XX, Ganesan B, Weimer BC, and Abel ED. Tissue-specific remodeling of the mitochondrial proteome in type 1 diabetic akita mice. Diabetes 58: 1986-1997, 2009.

7. Calvo S, Jain M, Xie X, Sheth SA, Chang B, Goldberger OA, Spinazzola A, Zeviani M, Carr SA, and Mootha VK. Systematic identification of human mitochondrial disease genes through integrative genomics. Nat Genet 38: 576-582, 2006. 
8. Chacinska A, Koehler CM, Milenkovic D, Lithgow T, and Pfanner N. Importing mitochondrial proteins: machineries and mechanisms. Cell 138: 628-644, 2009.

9. Chen Q, Vazquez EJ, Moghaddas S, Hoppel CL, and Lesnefsky EJ. Production of reactive oxygen species by mitochondria: central role of complex III. J Biol Chem 278: 3602736031, 2003.

10. Craig EA, Kramer J, and Kosic-Smithers J. SSC1, a member of the 70-kDa heat shock protein multigene family of Saccharomyces cerevisiae, is essential for growth. Proc Natl Acad Sci U S A 84: 4156-4160, 1987.

11. Dabkowski ER. Quantitative proteomic analysis of distinct mitochondrial subpopulations in diabetic myocardium. FASEB J 22, 2008.

12. Dabkowski ER, Williamson CL, Bukowski VC, Chapman RS, Leonard SS, Peer CJ, Callery PS, and Hollander JM. Diabetic cardiomyopathy-associated dysfunction in spatially distinct mitochondrial subpopulations. Am J Physiol Heart Circ Physiol 296: H359-369, 2009.

13. Dabkowski ER, Williamson CL, and Hollander JM. Mitochondria-specific transgenic overexpression of phospholipid hydroperoxide glutathione peroxidase (GPx4) attenuates ischemia/reperfusion-associated cardiac dysfunction. Free Radic Biol Med 45: 855-865, 2008.

14. Gambill BD, Voos W, Kang PJ, Miao B, Langer T, Craig EA, and Pfanner N. A dual role for mitochondrial heat shock protein 70 in membrane translocation of preproteins. $J$ Cell Biol 123: 109-117, 1993.

15. Garcia MJ, McNamara PM, Gordon T, and Kannel WB. Morbidity and mortality in diabetics in the Framingham population. Sixteen year follow-up study. Diabetes 23: 105-111, 1974. 
16. Gebert N, Joshi AS, Kutik S, Becker T, McKenzie M, Guan XL, Mooga VP, Stroud DA, Kulkarni G, Wenk MR, Rehling P, Meisinger C, Ryan MT, Wiedemann N, Greenberg ML, and Pfanner N. Mitochondrial cardiolipin involved in outer-membrane protein biogenesis: implications for Barth syndrome. Curr Biol 19: 2133-2139, 2009.

17. Gevorkyan-Airapetov L, Zohary K, Popov-Celeketic D, Mapa K, Hell K, Neupert W, Azem A, and Mokranjac D. Interaction of Tim23 with Tim50 Is essential for protein translocation by the mitochondrial TIM23 complex. J Biol Chem 284: 4865-4872, 2009.

18. Hamblin M, Friedman DB, Hill S, Caprioli RM, Smith HM, and Hill MF. Alterations in the diabetic myocardial proteome coupled with increased myocardial oxidative stress underlies diabetic cardiomyopathy. J Mol Cell Cardiol 42: 884-895, 2007.

19. He H, Giordano FJ, Hilal-Dandan R, Choi DJ, Rockman HA, McDonough PM, Bluhm WF, Meyer M, Sayen MR, Swanson E, and Dillmann WH. Overexpression of the rat sarcoplasmic reticulum $\mathrm{Ca} 2+$ ATPase gene in the heart of transgenic mice accelerates calcium transients and cardiac relaxation. J Clin Invest 100: 380-389, 1997.

20. Hollander JM, Martin JL, Belke DD, Scott BT, Swanson E, Krishnamoorthy V, and Dillmann WH. Overexpression of wild-type heat shock protein 27 and a nonphosphorylatable heat shock protein 27 mutant protects against ischemia/reperfusion injury in a transgenic mouse model. Circulation 110: 3544-3552, 2004.

21. Howarth FC, Qureshi A, Shahin A, and Lukic ML. Effects of single high-dose and multiple low-dose streptozotocin on contraction and intracellular $\mathrm{Ca} 2+$ in ventricular myocytes from diabetes resistant and susceptible rats. Mol Cell Biochem 269: 103-108, 2005.

22. Jiang F, Ryan MT, Schlame M, Zhao M, Gu Z, Klingenberg M, Pfanner N, and Greenberg ML. Absence of cardiolipin in the crd1 null mutant results in decreased 
mitochondrial membrane potential and reduced mitochondrial function. J Biol Chem 275: 2238722394, 2000.

23. Judge S, Jang YM, Smith A, Hagen T, and Leeuwenburgh C. Age-associated increases in oxidative stress and antioxidant enzyme activities in cardiac interfibrillar mitochondria: implications for the mitochondrial theory of aging. FASEB J 19: 419-421, 2005.

24. Jullig M, Hickey AJ, Middleditch MJ, Crossman DJ, Lee SC, and Cooper GJ. Characterization of proteomic changes in cardiac mitochondria in streptozotocin-diabetic rats using iTRAQ isobaric tags. Proteomics Clin Appl 1: 565-576, 2007.

25. Kang PJ, Ostermann J, Shilling J, Neupert W, Craig EA, and Pfanner N. Requirement for hsp70 in the mitochondrial matrix for translocation and folding of precursor proteins. Nature 348: 137-143, 1990.

26. Kelley DE, He J, Menshikova EV, and Ritov VB. Dysfunction of mitochondria in human skeletal muscle in type 2 diabetes. Diabetes 51: 2944-2950, 2002.

27. King KL, Young ME, Kerner J, Huang H, O'Shea KM, Alexson SE, Hoppel CL, and Stanley WC. Diabetes or peroxisome proliferator-activated receptor alpha agonist increases mitochondrial thioesterase I activity in heart. J Lipid Res 48: 1511-1517, 2007.

28. Laemmli UK. Cleavage of structural proteins during the assembly of the head of bacteriophage T4. Nature 227: 680-685, 1970.

29. Lesnefsky EJ, Chen Q, Slabe TJ, Stoll MS, Minkler PE, Hassan MO, Tandler B, and Hoppel CL. Ischemia, rather than reperfusion, inhibits respiration through cytochrome oxidase in the isolated, perfused rabbit heart: role of cardiolipin. Am J Physiol Heart Circ Physiol 287: H258-267, 2004. 
30. Lin D. Multidimensional Protein Identification Technology as an Effective Tool for Proteomics. American Genomic/Proteomic Technology 1: 38-46, 2001.

31. Lu J and Holmgren A. Selenoproteins. J Biol Chem 284: 723-727, 2009.

32. Nam S, Nakamuta N, Kurohmaru M, and Hayashi Y. Cloning and sequencing of the mouse cDNA encoding a phospholipid hydroperoxide glutathione peroxidase. Gene 198: 245249, 1997.

33. Palmer JW, Tandler B, and Hoppel CL. Biochemical properties of subsarcolemmal and interfibrillar mitochondria isolated from rat cardiac muscle. J Biol Chem 252: 8731-8739, 1977.

34. Perocchi F, Jensen LJ, Gagneur J, Ahting U, von Mering C, Bork P, Prokisch H, and Steinmetz LM. Assessing systems properties of yeast mitochondria through an interaction map of the organelle. PLoS Genet 2: e170, 2006.

35. Pfeiffer K, Gohil V, Stuart RA, Hunte C, Brandt U, Greenberg ML, and Schagger H. Cardiolipin stabilizes respiratory chain supercomplexes. J Biol Chem 278: 52873-52880, 2003.

36. Ritov VB, Menshikova EV, He J, Ferrell RE, Goodpaster BH, and Kelley DE. Deficiency of subsarcolemmal mitochondria in obesity and type 2 diabetes. Diabetes 54: 8-14, 2005.

37. Schwarz E, Seytter T, Guiard B, and Neupert W. Targeting of cytochrome b2 into the mitochondrial intermembrane space: specific recognition of the sorting signal. EMBO $J 12$ : 2295-2302, 1993. 
38. Shen X, Zheng S, Thongboonkerd V, Xu M, Pierce WM, Jr., Klein JB, and Epstein PN. Cardiac mitochondrial damage and biogenesis in a chronic model of type 1 diabetes. Am $J$ Physiol Endocrinol Metab 287: E896-905, 2004.

39. Singh K and Hood DA. Effect of denervation-induced muscle disuse on mitochondrial protein import. Am J Physiol Cell Physiol 300: C138-145.

40. Stojanovski D, Pfanner N, and Wiedemann N. Import of proteins into mitochondria. Methods Cell Biol 80: 783-806, 2007.

41. Turko IV and Murad F. Quantitative protein profiling in heart mitochondria from diabetic rats. J Biol Chem 278: 35844-35849, 2003.

42. Ursini F, Maiorino M, Brigelius-Flohe R, Aumann KD, Roveri A, Schomburg D, and Flohe L. Diversity of glutathione peroxidases. Methods Enzymol 252: 38-53, 1995.

43. Voos W, Martin H, Krimmer T, and Pfanner N. Mechanisms of protein translocation into mitochondria. Biochim Biophys Acta 1422: 235-254, 1999.

44. Williamson CL, Dabkowski ER, Baseler WA, Croston TL, Alway SE, and Hollander JM. Enhanced apoptotic propensity in diabetic cardiac mitochondria: influence of subcellular spatial location. Am J Physiol Heart Circ Physiol 298: H633-642.

45. Williamson CL, Dabkowski ER, Dillmann WH, and Hollander JM. Mitochondria protection from hypoxia/reoxygenation injury with mitochondria heat shock protein 70 overexpression. Am J Physiol Heart Circ Physiol 294: H249-256, 2008.

46. Ye G, Metreveli NS, Donthi RV, Xia S, Xu M, Carlson EC, and Epstein PN. Catalase protects cardiomyocyte function in models of type 1 and type 2 diabetes. Diabetes 53: 1336$1343,2004$. 


\section{Fig 3.1}

A

\section{\% Protein Change in mPHGPX Diabetic IFM} омм

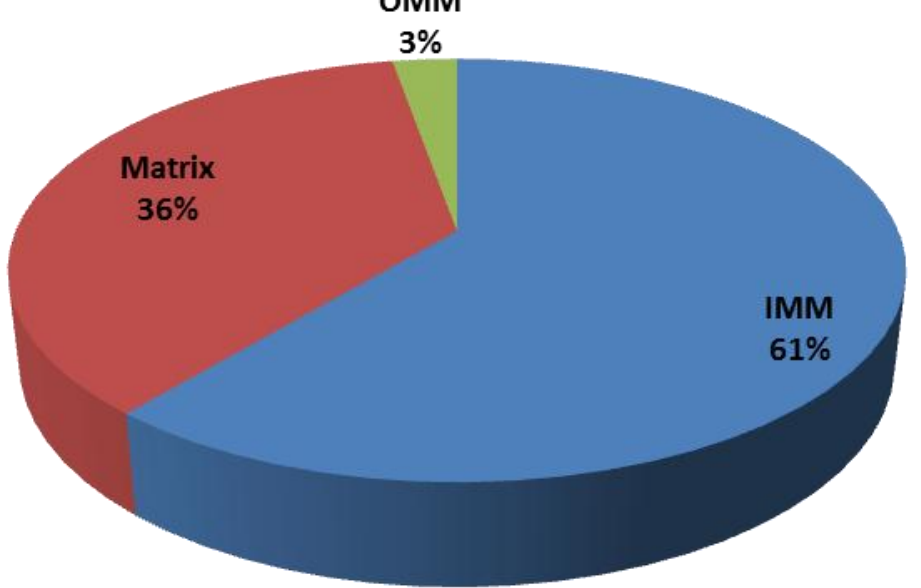

B

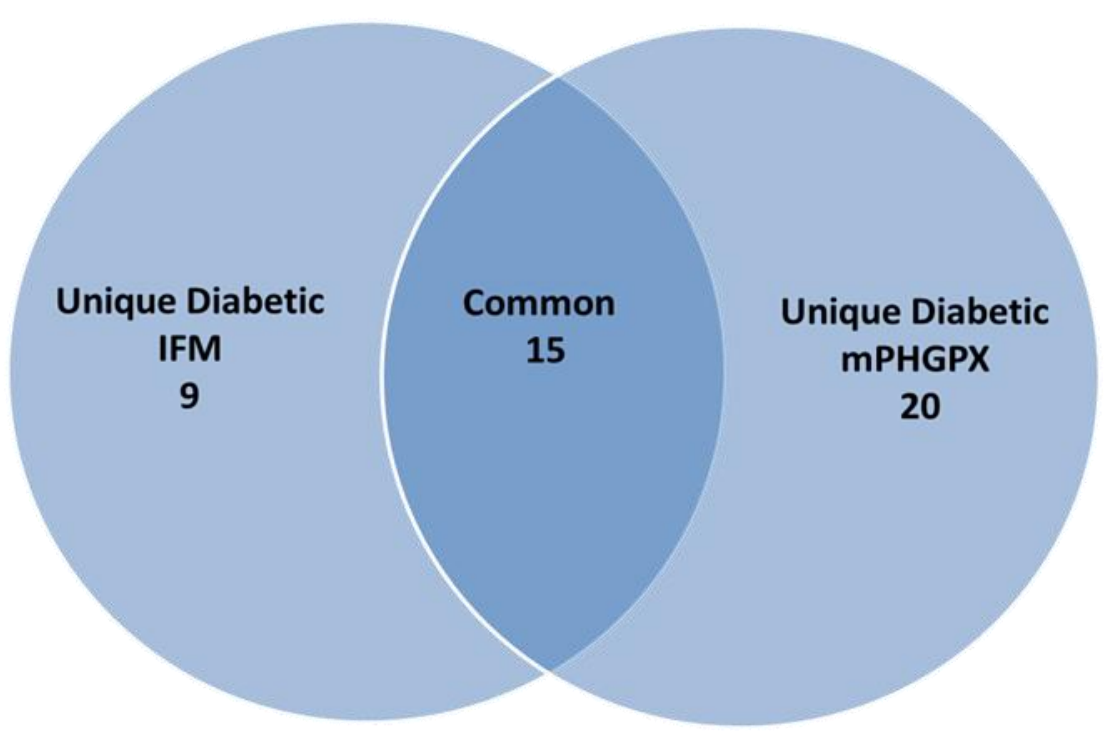


Figure 3.1. Proteomic alterations in diabetic and mPHPGx diabetic IFM. (A) Breakdown in approximate percentages of protein contents preserved in the mPHGPx diabetic heart IFM. (B) total amount of proteins decreased solely in the diabetic IFM (left), common proteins decreased in diabetic IFM and preserved within mPHGPx diabetic IFM (middle), and proteins increased solely within the mPHGPx diabetic IFM. OMM, outer mitochondrial membrane; IMM, inner mitochondrial membrane. 
Fig 3.2

\section{Canonical Pathways in IFM of diabetic and mPHGPX rescued hearts}




Figure 3.2. Mitochondrial canonical pathways. Identification of essential mitochondrial canonical pathways negatively influenced in diabetic IFM and preserved within mPHGPx diabetic IFM. Oxidative phosphorylation, Citrate cycle, fatty acid metabolism, and fatty acid elongation were negatively affected (green) by diabetes mellitus. Conversely, these pathways as well as pyruvate metabolism were preserved (red) within the mPHGPx diabetic IFM. 


\section{Fig 3.3}

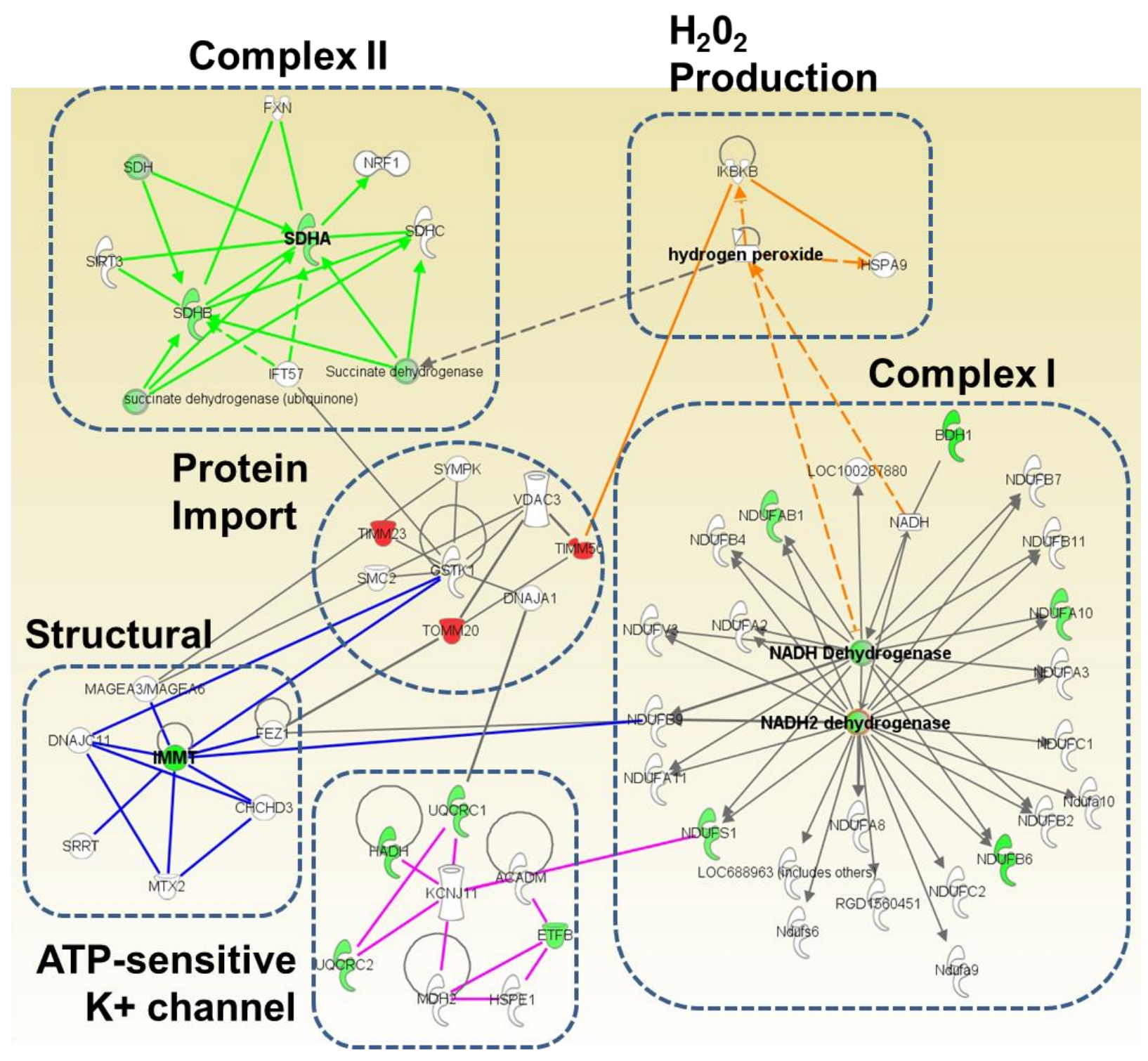


Figure 3.3. Mitochondrial protein networks. Identification of mitochondrial proteomic networks negatively influenced in diabetic IFM and preserved within mPHGPx diabetic IFM. Six networks including ETC complexes I and II, $\mathrm{H}_{2} \mathrm{O}_{2}$ production, Structure, ATP-sensitive K+ channel, and mitochondrial protein import were identified. Mitochondrial protein import network is the central node linking all other networks. Green indicates proteins preserved within mPHGPx diabetic IFM. Red indicates proteins positively enhanced in mPHGPx diabetic IFM. White indicates proteins unchanged by diabetes mellitus but are part of their respective networks. 
Fig 3.4

A

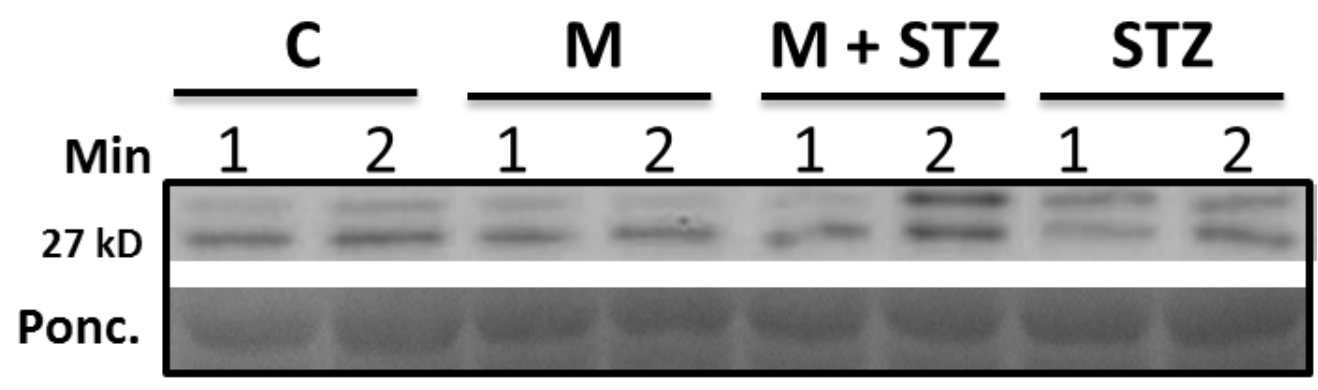

B

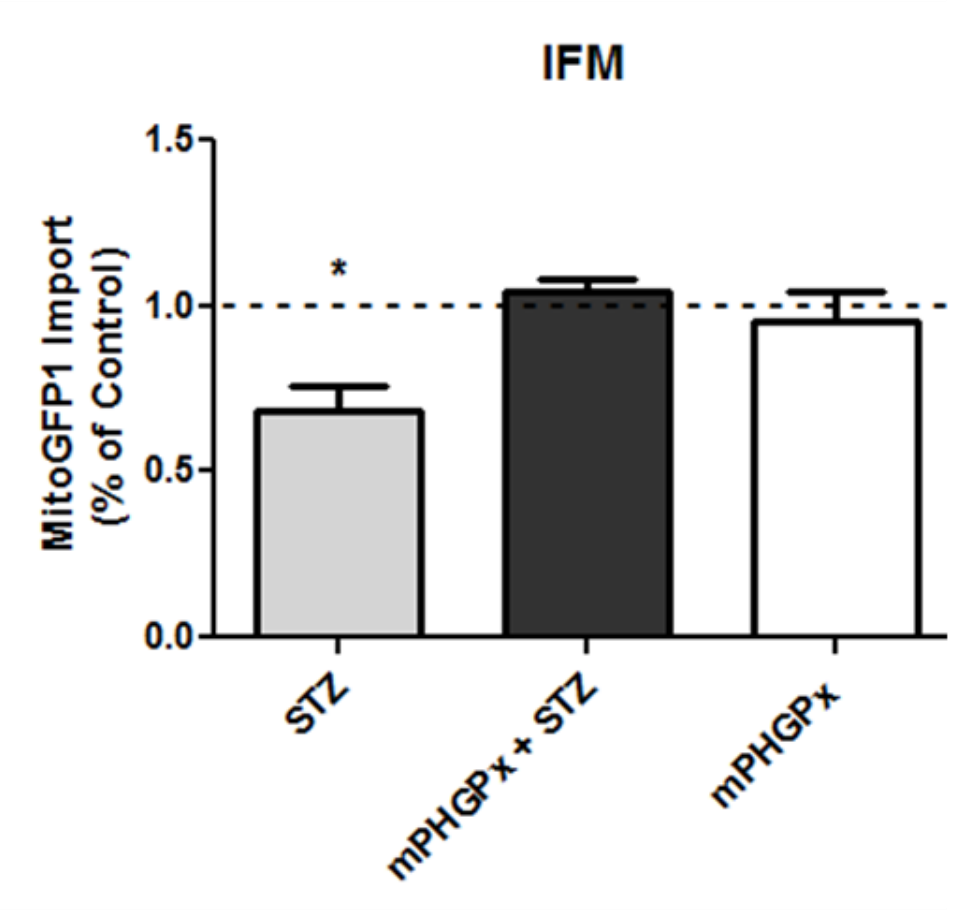


Figure 3.4. Mitochondrial protein import. Effect of type 1 diabetes mellitus and mPHGPx overexpression on MitoGFP1 import in IFM. Cardiac mitochondrial subpopulations from control, diabetic, mPHGPx, and diabetic mPHGPx mice were isolated and incubated with $2 \mu 1$ of MitoGFP1 protein lysate at 1 and 2 minute time points. Representative Western blots from IFM (A) protein import assay. Graphical representation of mitochondrial protein import performed in control (C), diabetic (STZ), mPHGPx (M), and diabetic mPHGPx IFM (M + STZ) (B). The relative amount of imported MitoGFP1 was determined by densitometry. Dashed line denotes control levels. Import efficiency was based off of percent control at the 1 and 2 minute time points. Both time point percentages were then averaged to show total import efficiency. Control for protein loading was confirmed by Ponceau staining. Values are presented as means $\pm \mathrm{SE}$; $\mathrm{P}$ $<0.05$ for IFM STZ vs. all IFM groups. $\mathrm{N}=5$ per group. 


\section{Fig 3.5}

A

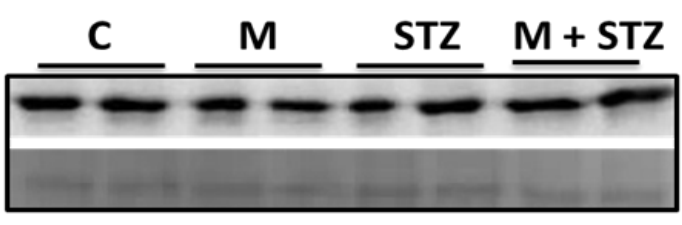

IFM Tom20

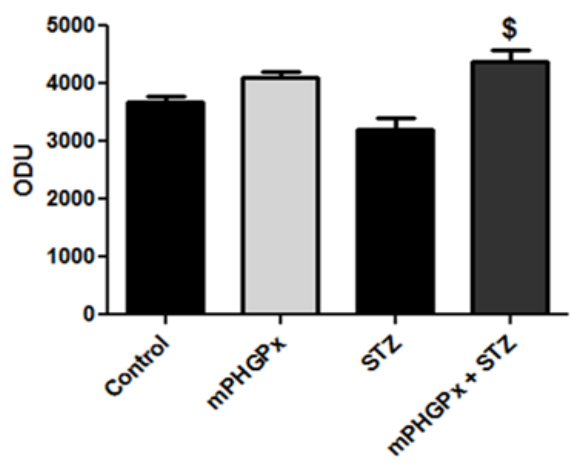

B



IFM Timm50



C

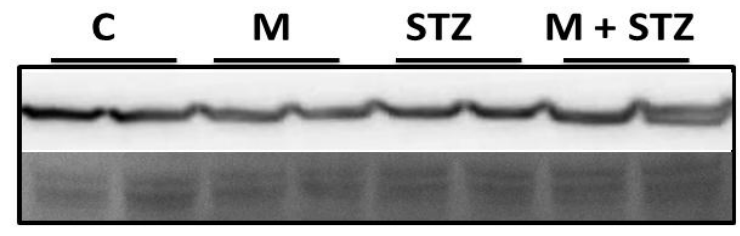

IFM MtHsp70

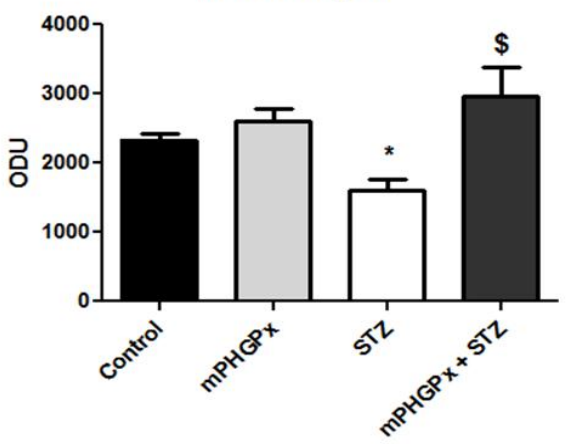

IFM TIM23

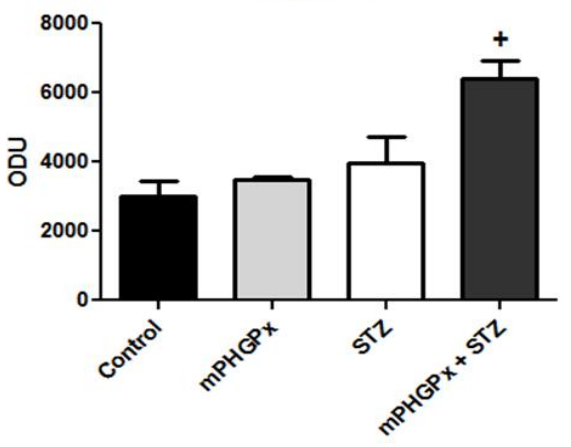


Figure 3.5. Mitochondrial protein import constituents. Western blot analysis of protein import constituents. Key proteins involved in mitochondrial protein import were assessed using Western blot analysis. Representative Western blot and densitometry analysis for Tom20 (A), Tim50 (B), MtHsp70 (C), and Tim23 (D) from control, mPHGPx, diabetic and diabetic MPHGPx IFM. Control for protein loading was confirmed by Ponceau staining. Values are presented as means $\pm \mathrm{SE} ; * \mathrm{P}$ $<0.05$ for IFM STZ vs. all groups; $+\mathrm{P}<0.05$ for IFM mPHGPX diabetic vs. all groups; \$P $<0.05$ for IFM MPHGPx STZ vs. IFM diabetic. $\mathrm{N}=4$ per group. 


\section{Fig 3.6}

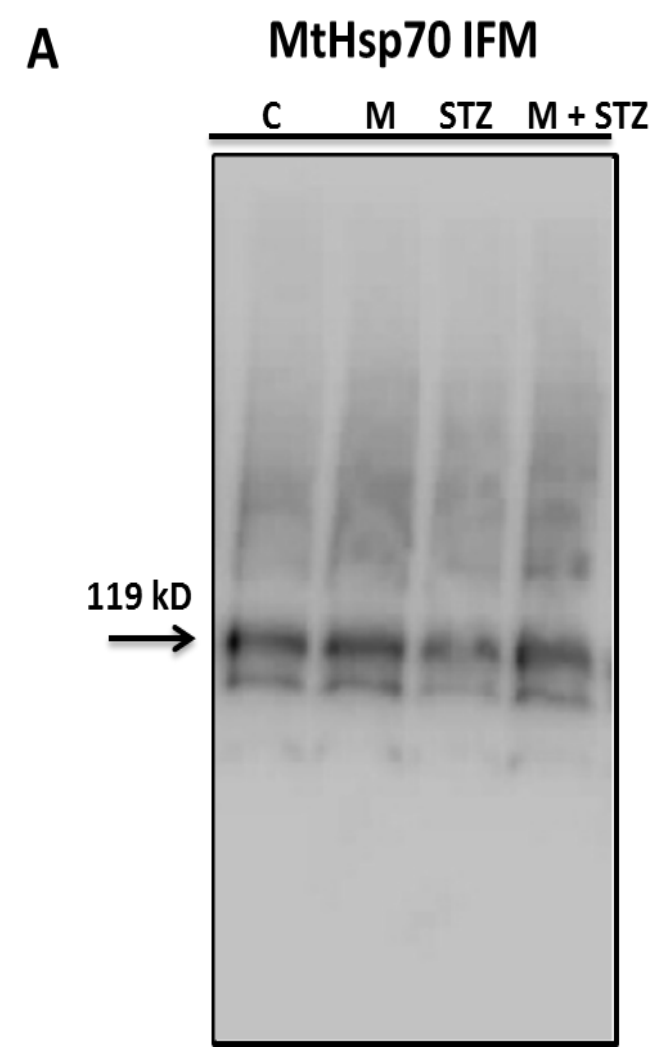

B

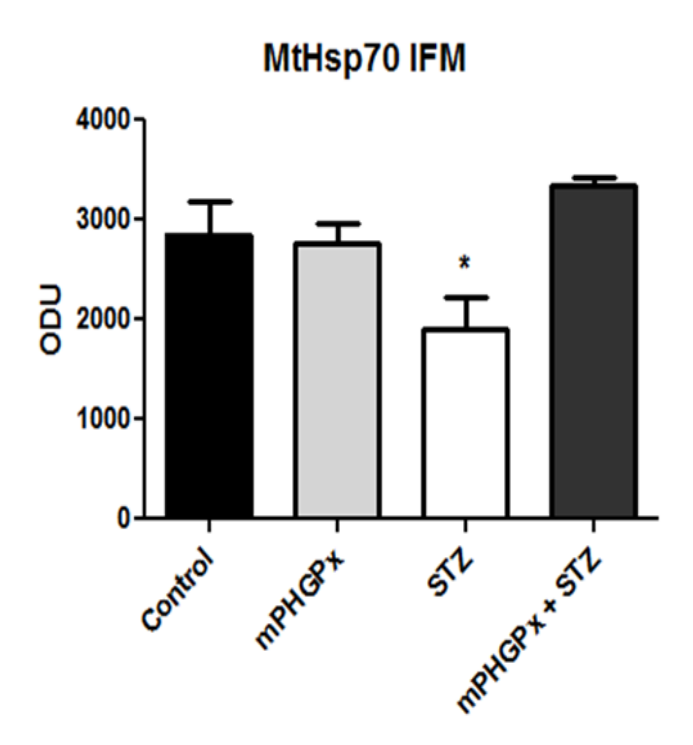


Figure 3.6. MtHsp70 protein complexing. Isolated mitochondrial subpopulations from control, diabetic, mPHGPx, and diabetic mPHGPx hearts were partially lysed in digitonin buffer and subjected to BN-PAGE. Protein complexes were transferred to nitrocellulose membrane and probed for MtHSP70. A complex of MtHsp70 and Timm44 exists at $119 \mathrm{kD}$ (A). MtHsp70 content was analyzed through densitometric analysis (B). ${ }^{*} \mathrm{P}<0.05$ for IFM STZ vs. all IFM groups. $\mathrm{N}=4$ per group. 


\section{Table 3.1}

\begin{tabular}{|c|c|c|c|}
\hline Protein & IFM Diab/IFM Control & IFM MPHGPx Diabetic/IFM Diabetic & IFM MPHGPx Diabetic/IFM MPHGPX \\
\hline \multicolumn{4}{|l|}{ Oxidative Phosphorylation } \\
\hline NADH dehydrogenase [ubiquinone] 1 alpha subcomplex subunit 10 & 0.77 & 1.53 & $\mathrm{NC}$ \\
\hline NADH dehydrogenase [ubiquinone] 1 alpha subcomplex subunit 6 & NC & 1.63 & NC \\
\hline NADH dehydrogenase [ubiquinone] 1 alpha subcomplex subunit 7 & 0.77 & $\mathrm{NC}$ & $\mathrm{NC}$ \\
\hline NADH dehydrogenase [ubiquinone] 1 alpha subcomplex subunit 8 & $\mathrm{NC}$ & 1.57 & 1.3 \\
\hline NADH dehydrogenase [ubiquinone] 1 beta subcomplex subunit 10 & 0.63 & NC & NC \\
\hline NADH dehydrogenase [ubiquinone] 1 beta subcomplex subunit 6 & 0.61 & 1.6 & NC \\
\hline NADH dehydrogenase [ubiquinone] 1 beta subcomplex subunit 7 & $\mathrm{NC}$ & 2.28 & $\mathrm{NC}$ \\
\hline NADH dehydrogenase [ubiquinone] iron-sulfur protein 2 & $\mathrm{NC}$ & 1.75 & 1.46 \\
\hline NADH dehydrogenase [ubiquinone] iron-sulfur protein 3 & NC & 1.41 & 1.32 \\
\hline NADH-ubiquinone oxidoreductase $75 \mathrm{kDa}$ subunit & 0.83 & 1.42 & NC \\
\hline Succinate dehydrogenase [ubiquinone] flavoprotein subunit & 0.86 & 1.37 & 1.21 \\
\hline Succinate dehydrogenase [ubiquinone] iron-sulfur subunit & 0.84 & 1.25 & NC \\
\hline Cytochrome b-c1 complex subunit 1 & 0.79 & 1.31 & NC \\
\hline Cytochrome b-c1 complex subunit 2 & 0.82 & 1.56 & $\mathrm{NC}$ \\
\hline Cytochrome b-c1 complex subunit 8 & 0.73 & NC & NC \\
\hline Cytochrome b-c1 complex subunit Rieske & NC & 1.42 & $\mathrm{NC}$ \\
\hline Cytochrome c oxidase subunit 6 & 0.88 & NC & NC \\
\hline Cytochrome c1, heme protein & NC & 1.37 & $\mathrm{NC}$ \\
\hline ATP synthase protein 8 & 0.55 & 1.95 & $\mathrm{NC}$ \\
\hline ATP synthase subunit alpha & $\mathrm{NC}$ & 1.57 & $\mathrm{NC}$ \\
\hline ATP synthase subunit epsilon & NC & 1.92 & 1.74 \\
\hline ATP synthase subunit 0 & 0.76 & NS & $\mathrm{NC}$ \\
\hline Electron transfer flavoprotein subunit beta & 0.80 & 1.62 & NC \\
\hline \multicolumn{4}{|l|}{ Lipid Metabolism } \\
\hline Acyl carrier protein & 0.82 & 1.87 & NC \\
\hline Enoyl-CoA hydratase & NC & 1.91 & \\
\hline Hydroxyacyl-coenzyme A dehydrogenase & 0.71 & 2.06 & \\
\hline Short-chain specific acyl-CoA dehydrogenase & 0.69 & $\mathrm{NC}$ & \\
\hline 3-ketoacyl-CoA thiolase & NC & 1.31 & 1.46 \\
\hline \multicolumn{4}{|l|}{ TCA cycle } \\
\hline Dihydrolipoyllysine-residue succinyltransferase component of 2-oxoglutarate deh & 0.75 & NC & NC \\
\hline Aconitate hydratase & $\mathrm{NC}$ & 1.80 & 1.37 \\
\hline Citrate synthase & NC & 2.07 & NC \\
\hline Isocitrate dehydrogenase $3(\mathrm{NAD}+)$ & 0.74 & 3.5 & 2.43 \\
\hline Malate dehydrogenase & $\mathrm{NC}$ & 1.39 & NC \\
\hline $\mathrm{NAD}(\mathrm{P})$ transhydrogenase & NC & 1.47 & 1.25 \\
\hline \multicolumn{4}{|l|}{ Transport } \\
\hline $60 \mathrm{kDa}$ heat shock protein & NC & 1.39 & NC \\
\hline ADP/ATP translocase & $\mathrm{NC}$ & 1.59 & NC \\
\hline Mitochondrial heat shock protein 75 & 0.69 & 1.77 & 1.21 \\
\hline Mitochondrial inner membrane protein & 0.55 & 1.7 & NC \\
\hline Phosphate carrier protein & 0.81 & 1.66 & NC \\
\hline Voltage-dependent anion-selective channel 1 & NC & 1.58 & $\mathrm{NC}$ \\
\hline Prohibitin-2 & 0.59 & $\mathrm{NC}$ & NC \\
\hline \multicolumn{4}{|l|}{ Amino Acid Metabolism } \\
\hline Aspartate aminotransferase & NC & 1.98 & 1.29 \\
\hline \multicolumn{4}{|l|}{ Oxidation/Reduction } \\
\hline D-beta-hydroxybutyrate dehydrogenase & 0.57 & 2.45 & 1.99 \\
\hline \multicolumn{4}{|l|}{ Ketone Metabolism } \\
\hline Succinyl-CoA:3-ketoacid-coenzyme A transferase 1 & NC & 2.05 & NC \\
\hline \multicolumn{4}{|l|}{ Oxidative stress related } \\
\hline Peroxiredoxin-5 & 0.73 & NC & NC \\
\hline
\end{tabular}


Table 3.1. iTRAQ Proteomic analysis of mitochondrial subpopulations from control, diabetic, and mPHGPx diabetic IFM. iTRAQ analysis of proteins identified and significantly changing, categorized into groups consisting of oxidative phosphorylation, citric acid cycle (TCA), structural, glycolysis, lipid metabolism, and transport proteins isolated form isolated IFM from control, diabetic, and diabetic mPHGPx hearts. Cells greater than 1.0 denote increased protein expression (green) and cells less than 1.0 denote decreased protein expression (red) in the control vs diabetic, diabetic mPHGPx vs diabetic groups, and diabetic mPHGPx vs mPHGPx group. All values presented indicate a significant difference of at least $p<0.05$ for control vs diabetic and diabetic mPHGPx vs diabetic groups, while NS represents no significant differences between any groups. $\mathrm{N}=4$ for each group. 


\section{Table 3.2}

\begin{tabular}{|c|c|c|}
\hline Protein & Peptide sequence & Modification \\
\hline \multicolumn{3}{|l|}{ Outer Mitochondrial Membrane } \\
\hline $\begin{array}{l}\text { Voltage-dependent anion-selective } \\
\text { channel protein } 2\end{array}$ & VNNSSLIGVGYTQTLRPGVK & Deamidated(N)@3 \\
\hline $\begin{array}{l}\text { Voltage-dependent anion-selective } \\
\text { channel protein } 2\end{array}$ & LTFDTTFSPNTGK & Deamidated(N)@10 \\
\hline Mitochondrial fission 1 protein & MEAVLNELVSVEDLK & $\begin{array}{l}\text { Protein Terminal Acetyl@N- } \\
\text { term }\end{array}$ \\
\hline \multicolumn{3}{|l|}{ Inner Mitochondrial Membrane } \\
\hline ATP synthase subunit alpha & ELLGRVVDALGNAIDGK & $\begin{array}{l}\text { Oxidation(R)@5: } \\
\text { Deamidated(N)@12 }\end{array}$ \\
\hline $\begin{array}{l}\text { ATP synthase, } \mathrm{H}+\text { transporting.F1 } \\
\text { complex, alpha subunit }\end{array}$ & VVDALGNAIDGKGPVGSK & $\begin{array}{l}\text { Deamidated(N)@7: } \\
\text { Oxidation }(\mathrm{P}) @ 14 \\
\end{array}$ \\
\hline ATP synthase subunit beta & IMDPNIVGNEHYDVAR & Deamidated(N)@9 \\
\hline ATP synthase subunit alpha & VVDALGNAIDGK & Deamidated(N)@7 \\
\hline ATP synthase subunit gamma & QMKNEVAALTAAGK & $\begin{array}{l}\text { Gin->pyro-Glu@N-term; } \\
\text { Deamidated(N)@4 }\end{array}$ \\
\hline Cytochrome b-c1 complex subunit 2 & RGNNTTSLLSQSVAK & Deamidated(N)@3 \\
\hline Cytochrome b-c 1 complex subunit 1 & $\begin{array}{l}\text { TATFAQALQSVPETQVSILD } \\
\text { NGLR }\end{array}$ & Deamidated(N)@21 \\
\hline Cytochrome b-c1 complex subunit 1 & $\begin{array}{l}\text { EMQENDASMQNVNFDYLHA } \\
\text { TAFQGTPLAQAVEGPSENV } \\
\mathrm{R}\end{array}$ & Deamidated(Q)@29 \\
\hline $\begin{array}{l}\text { Cytochrome b-c1 complex subunit } \\
\text { Rieske }\end{array}$ & MLSVAAR & $\begin{array}{l}\text { Protein Terminal Acetyl@N- } \\
\text { term }\end{array}$ \\
\hline Cytochrome $c 1$, heme protein & $\begin{array}{l}\text { ALAEEVEVQDGPNDDGEMF } \\
\text { MRPGK }\end{array}$ & Deamidated(N)@13 \\
\hline Cytochrome coxidase subunit 5A & $\begin{array}{l}\text { AWELRKGMNTLVGYDLVPE } \\
\text { PK }\end{array}$ & $\begin{array}{l}\text { Dioxidation }(\mathrm{M}) @ 8 ; \\
\text { Deamidated(N)@9 }\end{array}$ \\
\hline Cytochrome coxidase subunit 5A & LNDFASAVR & $\begin{array}{l}\text { Deamidated(N)@2; } \\
\text { Dehydrated(D)@3 }\end{array}$ \\
\hline Cytochrome coxidase subunit 5A & RLNDFASAVR & Deamidated(N)@3 \\
\hline Cytochrome coxidase subunit 5A & YEDSNNLGTSHLLR & Deamidated(N)@6 \\
\hline Cytochrome c oxidase subunit $6 \mathrm{~A} 2$ & GDHGGAGANTWR & Deamidated(N)@9 \\
\hline $\begin{array}{l}\text { NADH-ubiquinone oxidoreductase } 75 \\
\text { kDa subunit }\end{array}$ & GWNILTNSEK & Deamidated(N)@3 \\
\hline $\begin{array}{l}\text { NADH-ubiquinone oxidoreductase } 75 \\
\text { kDa subunit }\end{array}$ & SATYVNTEGR & Deamidated(N)@6 \\
\hline
\end{tabular}




\section{Table 3.2}

\begin{tabular}{|c|c|c|}
\hline Protein & Peptide sequence & Modification \\
\hline $\begin{array}{l}\text { NADH-ubiquinone oxidoreductase } 75 \\
\text { kDa subunit }\end{array}$ & LTEPMVRNEK & Deamidated(N)@8 \\
\hline $\begin{array}{l}\text { NADH dehydrogenase [ubiquinone] } 1 \\
\text { alpha subcomplex subunit } 7\end{array}$ & NWASGQDLQAK & Deamidated(N)@1 \\
\hline $\begin{array}{l}\text { NADH dehydrogenase [ubiquinone] } \\
\text { flavoprotein } 2\end{array}$ & QNGWLPISAMNK & Deamidated(N)@2 \\
\hline $\begin{array}{l}\text { NADH dehydrogenase [ubiquinone] } \\
\text { iron-sulfur protein } 2\end{array}$ & IDEVEEMLTNNR & Deamidated(N)@10 \\
\hline $\begin{array}{l}\text { NADH dehydrogenase [ubiquinone] } \\
\text { iron-sulfur protein } 2\end{array}$ & $\begin{array}{l}\text { LYTEGYQVPPGATYTAIEAP } \\
\mathrm{K}\end{array}$ & Deamidated(Q)@7 \\
\hline $\begin{array}{l}\text { NADH dehydrogenase [ubiquinone] } 1 \\
\text { alpha subcomplex subunit } 9 .\end{array}$ & FIHVSHLNASMK & Deamidated(N)@8 \\
\hline $\begin{array}{l}\text { NADH dehydrogenase [ubiquinone] } \\
\text { iron-sulfur protein } 4\end{array}$ & PKPKSKSYGANFSWNKR & Deamidated(N)@15 \\
\hline $\begin{array}{l}\text { NADH dehydrogenase [ubiquinone] } \\
\text { iron-sulfur protein } 4\end{array}$ & NGWSYDVEEK & Deamidated(N)@1 \\
\hline Camitine O-palmitoyltransferase 2 & $\begin{array}{l}\text { LEDTMKRYLSAQKPLLNDSQ } \\
\text { FR }\end{array}$ & Oxidation(M)@5 \\
\hline Creatine kinase S-type, mitochondrial & $\begin{array}{l}\text { ENLRLQKRGTGGVDTAAVA } \\
\text { DVYDISNIDR }\end{array}$ & $\begin{array}{l}\text { Deamidated(R)@8: } \\
\text { Oxidation(D)@14 }\end{array}$ \\
\hline Chaperone activity of bc1 complex-like & AAMLGDAIMVAK & $\begin{array}{l}\text { Protein Terminal Acetyl@N- } \\
\text { term }\end{array}$ \\
\hline \multicolumn{3}{|l|}{ Matrix-Associated Proteins } \\
\hline Aconitase Hydratase & KGEKNTIVTSYNR & Deamidated(N)@5 \\
\hline Aconitase Hydratase & LEAPDADELPR & Deamidated(N)@1 \\
\hline Aconitase Hydratase & LNRPLTLSEK & Deamidated(N)@1 \\
\hline $\begin{array}{l}\text { 2-oxoglutarate dehydrogenase E1 } \\
\text { component }\end{array}$ & HHVLHDQNVDKR & Deamidated(N)@8 \\
\hline $\begin{array}{l}\text { 2-oxoglutarate dehydrogenase E1 } \\
\text { component }\end{array}$ & NGHNEMDEPMFTQPLMYK & $\begin{array}{l}\text { Deamidated(N)@4: } \\
\text { Deamidated(Q)@13 }\end{array}$ \\
\hline $\begin{array}{l}\text { 2-oxoglutarate dehydrogenase E1 } \\
\text { component }\end{array}$ & $\begin{array}{l}\text { SWDIFFRNTNAGAPPGTAYQ } \\
\text { SPLSLSR }\end{array}$ & $\begin{array}{l}\text { Trioxidation }(W) @ 2: \\
\text { Deamidated }(N) @ 8\end{array}$ \\
\hline $\begin{array}{l}\text { 2-oxoglutarate dehydrogenase E1 } \\
\text { component }\end{array}$ & VIPENGPAAQDPHK & Deamidated(N)@5 \\
\hline $\begin{array}{l}\text { 2-oxoglutarate dehydrogenase E1 } \\
\text { component }\end{array}$ & VIPENGPAAQDPHKVK & Deamidated(N)@5 \\
\hline $\begin{array}{l}\text { 2-oxoglutarate dehydrogenase E1 } \\
\text { component }\end{array}$ & NMEEEVAITR & Deamidated(N)@1 \\
\hline Malate dehydrogenase & $\begin{array}{l}\text { TEWVAKAGAGSATLSMAYA } \\
\text { GAR }\end{array}$ & Dioxidation(K)@5 \\
\hline
\end{tabular}




\section{Table 3.2}

\begin{tabular}{|c|c|c|}
\hline Protein & Peptide sequence & Modification \\
\hline Malate dehydrogenase & NLGIGK & Deamidated(N)@1 \\
\hline $60 \mathrm{kDa}$ heat shock protein & $\begin{array}{l}\text { DKYKNIGAKLVQDVANNTNE } \\
\text { EAGDGTTTATVLAR }\end{array}$ & $\begin{array}{l}\text { Didehydroretinylidene(K)@9: } \\
\text { Deamidated }(\mathrm{N}) @ 19\end{array}$ \\
\hline $60 \mathrm{kDa}$ heat shock protein & TNEEAGDGTTTATVLAR & Deamidated(N)@2 \\
\hline Trifunctional enzyme subunit alpha & INSPNSKVNTLNK & Deamidated(N)@5 \\
\hline Trifunctional enzyme subunit alpha & $\begin{array}{l}\text { MGLVDQLVEPLGPGIKSPEE } \\
R\end{array}$ & Deamidated(Q)@6 \\
\hline Trifunctional enzyme subunit alpha & GQQQVFKGLNDKVK & Deamidated(Q)@4 \\
\hline $78 \mathrm{kDa}$ glucose-regulated protein & LGGKLSSEDKETMEK & Acetyl@N-term \\
\hline $78 \mathrm{kDa}$ glucose-regulated protein & NQLTSNPENTVFDAK & Deamidated(N)@1 \\
\hline Acetyl-CoA acetyltransferase & KMNISRQEQDTYALSSYTR & Deamidated(Q)@7 \\
\hline Acetyl-CoA acetyltransferase & $\begin{array}{l}\text { AGIPKEEVKEVYMGNVIQGG } \\
\text { EGQAPTR }\end{array}$ & Deamidated(N)@15 \\
\hline $\begin{array}{l}\text { Electron transfer } \\
\text { flavoprotein subunit } \\
\text { beta }\end{array}$ & $\begin{array}{l}\text { VKPDKSGVVTDGVKHSMNP } \\
\text { F }\end{array}$ & Deamidated(N)@18 \\
\hline $\begin{array}{l}\text { Very long-chain specific acyl-CoA } \\
\text { dehydrogenase }\end{array}$ & EATQAVLDKPETLSSDASTR & Deamidated(Q)@4 \\
\hline $\begin{array}{l}\text { Very long-chain specific acyl-CoA } \\
\text { dehydrogenase }\end{array}$ & LCDSWCIEAATR & $\begin{array}{l}\text { Carbamidomethyl(C)@2: } \\
\text { Oxidation(W)@5: } \\
\text { Carbamidomethyl(C)@6 }\end{array}$ \\
\hline $\begin{array}{l}\text { Long-chain specific acyl-CoA } \\
\text { dehydrogenase }\end{array}$ & KFFQEEVIPHHTEWEK & Deamidated(Q)@4 \\
\hline $\begin{array}{l}\text { Long-chain specific acyl-CoA } \\
\text { dehydrogenase }\end{array}$ & $\begin{array}{l}\text { FIPQMTAGKCIGAIAMTEPGA } \\
\text { GSDLQGVR }\end{array}$ & $\begin{array}{l}\text { Oxidation(P)@3: } \\
\text { Deamidated(Q)@4: } \\
\text { Dioxidation(M)@5: } \\
\text { Carbamidomethyl(C)@10 }\end{array}$ \\
\hline $\begin{array}{l}\text { Medium-chain specific acyl-CoA } \\
\text { dehydrogenase }\end{array}$ & MWITNGGK & Deamidated(N)@5 \\
\hline Grp75 & QAVTNPNNTFYATKR & Deamidated(N)@8 \\
\hline 3-ketoacyl-CoA thiolase & $\begin{array}{l}\text { DGTVTAGNASGVSDGAGAVI } \\
\text { IASEDAVKK }\end{array}$ & Deamidated(N)@8 \\
\hline Enoyl-CoA hydratase & GKNSSVGLIQLNRPK & Deamidated(N)@3 \\
\hline $\begin{array}{l}\text { Electron transfer flavoprotein subunit } \\
\text { alpha }\end{array}$ & $\begin{array}{l}\text { GQLRRAASLLRFQSTLVIAE } \\
\text { HANDSLAPITLNTITAAR }\end{array}$ & Deamidated(N)@23 \\
\hline 3.2-trans-enoyl-COA isomerase & EADIQNFTSFISK & Deamidated(N)@6 \\
\hline
\end{tabular}




\section{Table 3.2}

\begin{tabular}{|l|l|l|}
\hline Protein & Peptide sequence & Modification \\
\hline $\begin{array}{l}\text { Methylmalonate-semialdehyde } \\
\text { dehydrogenase [acylating] }\end{array}$ & $\begin{array}{l}\text { IVNDNPYGNGTAIFTTNGATA } \\
\text { R }\end{array}$ & $\begin{array}{l}\text { Deamidated(N)@9; } \\
\text { Deamidated(N)@17 }\end{array}$ \\
\hline Peroxiredoxin-5 & FSMVIDNGIVK & $\begin{array}{l}\text { Dethiomethyl(M)@3: } \\
\text { Deamidated(N)@7 }\end{array}$ \\
\hline Fatty acid-binding protein, heart & ADAFVGTWK & $\begin{array}{l}\text { Protein Terminal Acetyl@N- } \\
\text { term }\end{array}$ \\
\hline $\begin{array}{l}\text { Coiled-coil-helix-coiled-coil-helix } \\
\text { domain-containing protein 3 }\end{array}$ & RVTFEADENENITVKK & Deamidated(N)@9 \\
\hline $\begin{array}{l}\text { Delta-1-pyrroline-5-carboxylate } \\
\text { dehydrogenase }\end{array}$ & VANEPILAFSQGSPER & Deamidated(N)@3 \\
\hline 28S ribosomal protein S22 & LMTQAQLEEATR & Deamidated(Q)@4 \\
\hline
\end{tabular}


Table 3.2. Posttranslational modifications (PTM) present within diabetic IFM and reversed within mPHGPX diabetic IFM. Multidimensional protein identification technology (MudPIT) was used to identify PTMs of proteins from diabetic IFM that were reversed in mPHGPx diabetic IFM subpopulation. Peptides presented represent only those peptides that have PTMs in the diabetic IFM and not present in the mPHGPx diabetic group. 


\section{Chapter 4:}

\section{miRNA-141 is a Potential Regulator of Mitochondrial Phosphate Carrier (Slc25a3) in the Type 1 Diabetic Heart}

Walter A. Baseler, Dharendra Thapa, Rajaganapathi Jagannathan, Erinne R. Dabkowki, and John M. Hollander

West Virginia University School of Medicine, Division of Exercise Physiology; Center for Cardiovascular and Respiratory Sciences; Morgantown, WV 26506

Running Title: miRNA Regulation of Mitochondrial Proteins in the Diabetic Heart 


\begin{abstract}
Cardiac complications, such as diabetic cardiomyopathy are the leading cause of morbidity and mortality among diabetic patients. Dysfunctional mitochondria are central in the pathogenesis of diabetic cardiomyopathy. Mitochondrial proteomic alterations during diabetes mellitus have been reported however, the mechanisms responsible are unknown. The goal of this study was to determine whether miRNAs play a role in diabetes-induced mitochondrial proteomic dysregulation. RTQ-PCR miRNA screening in diabetic mice following multiple low-dose streptozotocin treatment revealed a significant increase in the expression of 26 miRNAs in the diabetic heart compared to control, including microRNA-141 (mir-141) $(\mathrm{P}<0.05)$. miRNA target predication analyses identified miR-141 as a potential regulator of the inner mitochondrial membrane phosphate transporter, solute carrier family 25 member 3 (Slc25a3), which provides inorganic phosphate to mitochondrial matrix and is essential for ATP production. Using a luciferase reporter construct with Slc25a3 3' UTR target sequence, overexpression of miR-141 down-regulated luciferase activity levels confirming miR-141/Slc25a3 3' UTR binding. miRNA-141 overexpression in HEK 293 cells elicited a decrease in Slc25a3 protein content similar to the diabetic phenotype $(\mathrm{P}<0.05)$. ATP synthase activity was decreased in miRNA-141 overexpressed HEK293 cells $(\mathrm{P}<0.05)$. Diabetic interfibrillar mitochondria (IFM) displayed decreased Slc25a3 protein content inversely correlating with increased miR-141 expression. Further, diabetic IFM ATP synthase activity was also decreased $(\mathrm{P}<0.05)$. Together these results indicate that miR-141 could be a potential regulator of slc $25 \mathrm{a} 3$ protein expression in the diabetic heart. Further, diabetes-induced miRNA modulation may influence mitochondrial proteomic make-up and alter functional processes such as mitochondrial ATP production.
\end{abstract}




\section{INTRODUCTION}

Cardiac complications, including diabetic cardiomyopathy, are the leading cause of morbidity and mortality among type 1 diabetic patients. Mitochondrial dysfunction has been shown to have a causal role in the role in cardiac abnormalities present during a type 1 diabetic insult $(9,13,30,34)$. Cardiac mitochondria are characterized as two spatially distinct mitochondrial subpopulations, located beneath the sarcolemma, termed subsarcolemmal mitochondria (SSM), and between myofibrils, termed interfibrillar mitochondria (IFM). Mounting evidence suggests that mitochondrial subpopulations are differentially affected in multiple pathologies $(4,9,10,18,19,27,32,40)$. Our laboratory has shown IFM to be dysfunctional in type 1 diabetes mellitus through mechanisms of enhanced oxidative stress, decreased oxidative phosphorylation, decreased cardiolipin content, and decreased nuclearencoded mitochondrial protein import $(4,9)$. Further, ourselves and others have shown dynamic alterations of the type 1 diabetic mitochondrial proteome, however the mechanism/mechanisms involved remain unclear $(6,14,34,35)$. A large proportion of the dysregulated proteins reside within the inner mitochondrial membrane (IMM) altering essential functions such as oxidative phosphorylation and fatty acid synthesis.

A specific protein that appears to be a target of interest is IMM phosphate carrier protein termed "Slc25a3", which has been shown to be decreased in abundance during a type 1 diabetic insult (4). This transmembrane protein is essential for ATP production as it acts a conduit for inorganic phosphate to pass from the inner membrane space into the matrix, providing phosphate to fuel the ATP synthase (16). Decrements to Slc25a3 have shown to have deleterious effects upon ATP production and cellular viability $(2,25,29)$. Clinically, patients with a homozygous mutation to Slc25a3 presented with exercise intolerance, proximal muscle weakness and 
cardiomyopathy (24). However, how Slc25a3 is regulated within type 1 diabetes mellitus has yet to be elucidated. One potential explanation for this phenomenon includes alterations to gene/protein expression by way of microRNA (miRNA) regulation.

miRNAs are 21-23 nucleotide non-coding RNA capable of post transcriptional regulation. Originally described in the nematode C. elegans, miRNAs are ubiquitous among many species including all vertebrates (38). Functionally, with the help of the RNA induced silencing complex, miRNAs will aid in the degradation of or inhibit the translational efficiency of the target mRNA (20). The mode of action is thought to largely depend on the binding efficiency of the miRNA to the target mRNA. miRNAs exist in all parts of the body and seem to be implicated in virtually all cellular processes currently known (33). miRNAs have been extensively studied in context to cancer, heart failure, and cellular homeostasis $(7,36)$. The miR-200 family (miR-200a, 200b, 200c, 141, 429) has been shown to modulate E-cadherin transcriptional repressors ZEB1 and SIP1, critical factors in epithelial to mesenchymal transition and tumor metastasis. Interestingly, miR-141 and miR-200c were shown to be up regulated in an acute hindlimb ischemic model of hypoxia, presumably through a mechanism of enhanced reactive oxygen species (ROS) production (21).

In this current study, we evaluated the impact type 1 diabetes mellitus has upon miRNA regulation within the heart. Further, we assessed how changes in this process may lead to specific mitochondrial proteomic detriments seen within a type 1 diabetic insult. Experimentally, we isolated total RNA from control and diabetic mouse hearts and performed broad scale quantitative real time polymerase chain reaction (RTQ-PCR) analyses on 375 of the most highly characterized mouse miRNAs within the groups. We found miR-141 was the most significantly increased miRNA within the diabetic heart. Further, through miRNA target 
prediction analyses (miRbase, TargetScan, PicTar), we were able to determine Slc25a3 as a likely target for regulation by miR-141. Therefore, we hypothesized that enhanced expression of miR-141 would negatively regulate Slc25a3 within cardiac mitochondria during a diabetic insult. Further, loss of Slc25a3 would lead to diminished mitochondrial ATP synthesis rates. 


\section{METHODS}

\section{Experimental Animals and Diabetes Induction}

The animal experiments in this study conformed to National Institutes of Health (NIH) Guidelines for the Care and Use of Laboratory Animals and were approved by the West Virginia University Animal Care and Use Committee. Male FVB mice (Charles River Laboratories, Wilmington, MA) were housed in the West Virginia University Health Sciences Center animal facility. Mice were given unlimited access to a rodent diet and water. Type 1 diabetes mellitus was induced in 8-wk-old mice following the protocol of the Animal Models of Diabetic Complications Consortium using multiple low-dose streptozotocin (STZ; Sigma, St. Louis, MO) injections. Injections of $50 \mathrm{mg} / \mathrm{kg}$ body weight STZ dissolved in sodium citrate buffer (pH 4.5) were performed daily for 5 consecutive days after 6 hours of fasting. Mice that served as vehicle controls were given the same volume per body weight of sodium citrate buffer. One week postinjections, hyperglycemia was confirmed by measuring fasting blood glucose levels using a commercially available kit (Bayer, Mishiwaka, IN). Blood glucose levers greater than 250 $\mathrm{mg} / \mathrm{dL}$ were considered diabetic. Five weeks post hyperglycemia onset, animals were sacrificed for further experimentation.

\section{Preparation of Individual Mitochondrial Subpopulations}

At 5 weeks post hyperglycemia onset, FVB mice and their littermate controls were sacrificed, and the hearts were excised. Hearts were rinsed in phosphate buffered saline (PBS, $\mathrm{pH}$ 7.4), then blotted dry. SSM and IFM were isolated as previously described following the methods of Palmer et al. (26) with minor modifications $(9,10,39)$. Mitochondrial subpopulation 
pellets were resuspended in sucrose based SEM buffer (250 mM Sucrose, $1 \mathrm{mM}$ EDTA, $10 \mathrm{mM}$ MOP-KOH, $\mathrm{pH}$ 7.2) or mitochondrial extraction buffer (Biovision, Mountain View, CA). Mitochondrial protein concentrations were determined using the Bradford method and bovine serum albumin as a standard (5).

\section{Western Blot Analyses}

SDS polyacrylamide gel electrophoresis (SDS-PAGE) was run on 4-12\% gradient gels as described (17), with equal amounts of protein loaded. Relative amounts of Slc25a3 were quantified in isolated mitochondrial subpopulations and HEK293 cells using anti-Slc25a3 goat antibody (Product \# sc-1661226, Santa Cruz Biotechnology, Santa Cruz, CA) and anti-Slc25a3 mouse antibody (Product \# ab67121, Abcam, Cambridge, MA) respectively. The secondary antibodies used in the analyses were donkey anti-goat IgG HRP conjugate (Product \# sc-2020) and goat-anti mouse conjugate (Product \# 31430, Pierce Biotechnology, Rockford, IL). Quantitation of chemiluminescent signals were detected using a G:BOX (Syngene, Frederick, MD), and data were expressed as arbitrary optical density units. Control for protein loading in isolated mitochondria was confirmed using Ponceau staining. Control for protein loading in HEK293 cells was confirmed using ant-GAPDH mouse antibody (Product \# ab8245, Abcam, Cambridge, MA) in conjunction with the secondary mouse antibody described above.

\section{RNA Isolation}


Hearts were rinsed in phosphate buffered saline (PBS, pH 7.4) then snap frozen with liquid nitrogen. Total RNA (small and large) was isolated from heart (25 mg) tissue using miRNeasy mini kit per manufacturer's protocol (Qiagen, Valencia, CA). Total RNA quantification and purity was assessed using a Nanodrop (ND-1000) and stored at $-80{ }^{\circ} \mathrm{C}$.

\section{miRNA RTQ-PCR Array}

For miRNA RTQ-PCR analyses, Enriched miRNA was converted to cDNA using the RT ${ }^{2}$ miRNA First Strand Kit. cDNA samples were then used in the SABiosciences RT $^{2}$ MicroRNA PCR Whole Genome Array system, which allowed for simultaneous detection of 378 mouse miRNAs, representing functional miRNAs, appropriate housekeeping genes (Rnu6, snoRNA, PPC), and RNA quality controls (SABiosciences, Frederick, MD). We performed the assay according to the manufacturer's protocol using a Taqman 7900HT system (Applied Biosystems, Foster City, CA) utilizing sequence detection systems software version 2.3 (SDS 2.3). Threshold cycles $\left(\mathrm{C}_{\mathrm{t}}\right)$ were used to determine miRNA copy number and levels of respective miRNAs. Relative qPCR expression was normalized to the expression of housekeeping genes using $\Delta \Delta \mathrm{C}_{\mathrm{t}}$ methodology.

\section{Cell Cultures, Transfections, and Plasmids}

HEK293 cells were grown at $37{ }^{\circ} \mathrm{C}$ in a humidified atmosphere of $5 \% \mathrm{CO}_{2}, 95 \%$ air. HEK293 cells were maintained in Dulbecco's Modified Eagle Medium (Cellgro, Manassas, VA) with $10 \%$ fetal bovine serum (Sigma, St. Louis, MO). miRNA Expression plasmids (pCMV- 
MIR) housing the mouse precursor sequence of miR-141 (5'GGGUCCAUCUUCCAGUGCAGUGUUGGAUGGUUGAAGUAUGAAGCUCCUAAC

ACUGUCUGGUAAAGAUGGCCC, mature sequence in black) and human miR-200c precursor sequence (5, CCCUCGUCUUACCCAGCAGUGUUUGGGUGCGGUUGGGAGUCUCU AAUACUGCCGGGUAAUGAUGGAGG, mature sequence in black ) were purchased from Origene and used for transfection studies (Origene, Rockville, MD). $2 \mu \mathrm{g}$ of plasmids was used per well for transfections, which were performed using FuGENE 6 transfection kit per manufacturer's protocol (Promega, Madison, WI) into 6-well culture plates. An Empty pCMVMIR plasmid was used as a negative control (Origene, Rockville, MD). 72 hours post transfection, cells were washed with phosphate-buffered saline (PBS) and harvested in either 1X RIPA Buffer (Sigma, St. Louis, MO) for protein based experimentation or RNA lysis buffer for RNA isolation.

miRNA Target Luciferase Assay

Mouse Slc25a3 3' UTR target region, 5'- TTTAAACTAGCGG CCGCTAGTCTTTATCTGCTTGTTGATCAgTGTTGTATATATTCTAGA (target sequence in black), was duplexed (Integrated DNA Technologies, Coralville, IA), cut by Pme1/Xba1 and ligated into pmirGLO Dual-Luciferase miRNA Target Expression Vector for miRNA binding analyses. $500 \mathrm{ng}$ of Slc25a3 PmirGLO vector was co-transfected as described above with $500 \mathrm{ng}$ of mouse miR-141, human miR-200c, or scrambled control vector in triplicate in 12-well culture plates. 24 hours post transfection, luciferase activities were assayed with the Dual-Luciferase Reporter Assay System (Promega, Madison, WI) per manufacturer's protocol using a Flexstation 
3 luminometer (Molecular Devices, Sunnyvale, CA). Luciferase activity was quantified as a ratio of firefly luciferase to renilla luciferase.

\section{RTQ-PCR Analyses}

Isolated total RNA from HEK293 cells was converted to cDNA using miRNA first strand cDNA synthesis kit (Origene, Rockville, MD) per manufacturer's protocol. 15ng of cDNA sample, $0.5 \mu \mathrm{M}$ human miR-141 primer pairs (Origene, Rockville, MD), and 2X SYBR Green I qPCR master mix (Origene, Rockville, MD) were used to perform RTQ-PCR analysis using a Taqman $7900 \mathrm{HT}$ system. RTQ-PCR was performed as follows: Activation $50^{\circ} \mathrm{C}$ for $2 \mathrm{~min}$, Pre-soak $95^{\circ} \mathrm{C}$ for $10 \mathrm{~min}$. Followed by 42 cycles: Denaturation $95^{\circ} \mathrm{C}$ for $15 \mathrm{sec}$, Annealing $55^{\circ} \mathrm{C}$ for $10 \mathrm{sec}$, Extension $72^{\circ} \mathrm{C}$ for $30 \mathrm{sec}$. Threshold cycles $\left(\mathrm{C}_{\mathrm{t}}\right)$ were used to determine miRNA copy number and levels of miR-141. Relative qPCR expression of miR-141 and Slc25a3 was normalized to the expression of RNU6 using $\Delta \Delta \mathrm{C}_{\mathrm{t}}$ method.

\section{Mitochondrial ATP Synthase Activity}

ATP synthase activity was measure in mitochondrial subpopulations and cellular lysate as oligomycin-sensitive ATPase activity using an assay coupled with pyruvate kinase which converts the ADP to ATP and produces pyruvate from phosphoenolpyruvate as previously described $(8,12,28,31)$. Protein content was assessed as described above (5) with final values expressed as nanomoles consumed per minute per milligram of protein, which was equal to the nanomoles of NADH oxidized per minute per milligram of protein. 


\section{Statistics}

Means and standard errors (SEM) were calculated for all data sets. Data were analyzed with a one-way analysis of variance (ANOVA) method to evaluate the main treatment effect, diabetes induction (GraphPad Software Inc., La Jolla, CA). Fisher's Least Significant Difference (LSD) post hoc tests were performed to determine the significant differences among means. When appropriate a Student's T-test was employed. $p<0.05$ was considered significant. 


\section{RESULTS}

\section{miRNA Dysregulation within the Diabetic Heart}

To give a better understanding of how type 1 diabetes mellitus affects miRNA regulation within the heart, we performed a broad scale RTQ-PCR analysis of 375 mouse miRNAs in STZ treated and control mice (Fig 4.1A). Interestingly, STZ treated hearts saw significant increases in 26 miRNAs and significant decreases in 3 miRNAs when compared to control (Fig 4.1A). miR family members miR-141 (5 fold) and miR-200c (2.9 fold) were among the most highly upregulated miRNA within the diabetic hearts (Fig 4.1B). Further, a significant increase in miR-208b, known to modulated cardiac hypertrophy, was also shown in the diabetic heart compared to control (Fig 4.1B).

\section{Slc25a3 is a Target of miR-141}

Because miR-141 elicited the highest fold change in STZ treated mice, we decided to analyze genes that were likely to be regulated by this specific miRNA. Through the utilization of known miRNA target predictor programs (MirBase, Target Scan, PicTar), we were able to identify mitochondrial phosphate carrier, Slc25a3, as a primary target of miR-141. Examination of Slc25a3 mRNA revealed two potential target sites of miR-141 within Slc25a3 3' UTR. Fig 4.2A highlights the putative recognition site of miR-141 and Slc25a3 3'UTR. Further, the binding site of the miR-141 seeding sequence to Slc25a3 3' UTR was highly conserved within multiple vertebrate species including mouse, rat, human, and guinea pig (Fig 4.2B). Multiple target sites and conserved vertebrate seeding regions are both positive indicators of potential miR-141 targeting and regulation of Slc25a3. 
In order to determine whether miR-141 was able to effectively bind the 3' UTR of Slc25a3, we performed a cell-based luciferase reporter assay in which Slc25a3 3' UTR binding region of miR-141 was cloned downstream of the Firefly luciferase gene in the pMIR-GLO plasmid. To determine specificity of miR-141, the luciferase reporter plasmid was co-transfected into HEK293 cells with miR-141, miR-200c, or pCMV-MIR control. miR-200c contains a slightly different seed region than miR-141 (Fig 4.3A), therefore was not expected to bind with the 3' UTR of Slc25a3. As shown in Fig 4.3B, miR-141 was able to significantly reduce luciferase activity by $30 \%$, whereas the control miR plasmid and miR-200c could not (Fig 4.3B). These results indicate that Slc25a3 is a potential target of miR-141. Further, miR-141 recognizes the putative recognition site in the 3' UTR of Slc25a3.

\section{Slc25a3 is Decreased in Type 1 Diabetic IFM}

We next analyzed Slc25a3 mRNA level and protein content within isolated mitochondrial subpopulations from control and diabetic mouse hearts to determine if miR-141 upregulation correlated with decreased in Slc25a3 content. Interestingly, mRNA levels of Slc25a3 were unchanged in control and diabetic groups (Fig 4.4A). Western blots analyses of mitochondrial subpopulations revealed a significant decrease of Slc25a3 within diabetic IFM compared to control (Fig 4.4C) with no significant change in the SSM subpopulations (Fig 4.4B). The results suggest that if miR-141 regulates Slc25a3, it is through a mechanism of translational repression, not transcriptional degradation.

We then examined whether loss of Slc25a3 would inhibit the mitochondria functionally through analysis of ATP synthase activity. The ATP synthase is able to create ATP by utilizing 
essential substrates ADP and phosphate, which are translocated into the mitochondrial matrix through adenine nucleotide transporter (ANT) and Slc25a3 respectively (Fig 4.5A). Correlating with decreased Slc25a3 levels, ATP synthase activity within the diabetic IFM was significantly decreased compared to control (Fig 4.5C). Diabetic SSM ATP synthase activity was not significantly changed when compared to control (Fig 4.5B).

\section{miR-141 Directly Regulates SIc25a3}

To determine whether miR-141 directly regulates Slc25a3 expression, we performed miR-141 overexpression studies within HEK293 cells. Lipofectamine based transient transfections increased miR-141 mRNA expression by 9 fold compared to control in HEK293 cells (Fig 4.6A). miR-141 overexpression did not change Slc25a3 mRNA expression levels when compared to control (Fig 4.6B). However, protein expression of Slc25a3 was significantly decreased (50\%) in miR-141 HEK293 cells 72 hours post transfection when compared to control (Fig 4.6C and D). These results recapitulate the findings within the diabetic heart that miR-141 action is through translational repression. Functionally, ATP synthase activity was also significantly decreased within miR-141 cells (Fig 4.7), indicating overexpression of miR-141 has

functional implications upon mitochondrial ATP production through a mechanism of decreased phosphate transport. 


\section{DISCUSSION}

Mitochondrial dysfunction is known to play an active role in the pathogenesis of diabetic cardiomyopathy. Specifically, mitochondrial proteomic dysregulation has been shown to be correlative with mitochondrial dysfunction and cardiac dysfunction seen type 1 diabetic models of diabetic cardiomyopathy $(9,40)$. However, the mechanisms involved in promoting diabetic induced mitochondrial dysfunction remain limited. miRNAs have the capability of transcriptional and translational repression, thus are an attractive potential mechanism for mitochondrial proteomic dysregulation. Therefore, the goal of this study was to determine the impact of miRNAs on the mitochondrial proteome in a diabetic setting. In order to accomplish this goal, we performed a broad scale RTQ-PCR miRNA analysis from the hearts of control and STZ-treated mice to evaluate miRNA dysregulation during a diabetic insult.

miRNAs have the ability to modulate physiological and pathological pathways through the regulation of specific target genes. Recently, studies have begun to elucidate how miRNAs regulate essential processes within the heart, including cardiomyocyte hypertrophy through a mechanism of miR133a dysregulation (11). However, no study to date has examined the ramifications of miRNA regulation of mitochondrial proteins in a type 1 diabetic model. RTQPCR analysis of 375 of the most abundant mouse miRNA revealed significant increases in 26 of the 29 dysregulated miRNAs in the diabetic group compared control (Fig 4.1). Specifically, four miRNAs displayed the highest fold change increases including miR-329, miR-208b, miR-200c, and miR-141. The miR-208 family has been identified as regulators of cardiac contractility through the regulation of $\beta$-MHC expression within the heart (37). Interestingly, cardiac myosin heavy chain (MHC) switching from $\alpha$ to $\beta$ has been shown in multiple type 1 and type 2 diabetic

models during times of oxidative stress, implicating miR-208b as a potential key regulator of 
heart function during diabetic cardiomyopathy (3). Further research into the impact of miR-208 expression on cardiac MHC switching could potentially be a mechanism as to why MHC switching occurs in diabetes mellitus.

miRNA family members miR-141 and miR-200c, located in mouse chromosome 6 , were significantly increased in the diabetic heart compared to control by 5 fold and 2.9 fold respectively. With miR-141 displaying the highest fold increase, we decided to identify nuclearencoded mitochondrial genes likely regulated by the miRNA. Through the use of multiple miRNA targeting databases (Microcosm, TargetScan, Pictar), IMM phosphate carrier Slc25a3 was identified as a likely target due to perfect seed region matching and high sequence homology between vertebrates (Fig 4.2). Further, luciferase inhibition after co-incubation of Slc25a3 3' UTR target region housed in a luciferase plasmid with miR-141 confirmed binding between the Slc25a3 target mRNA and miR-141 (Fig 4.3). Recently, miR-141 and miR-200c have been shown to be activated within oxidative stress settings $(21,22)$. Exposing both human umbilical vein endothelial cells and $\mathrm{C} 2 \mathrm{C} 12$ myoblasts to hydrogen peroxide, Magenta et. al. noted increases in both miR-141 and miR-200c expression (21). Further, acute hindlimb ischemia, known to foster a potent oxidative stress environment, also elevated both miR-141 and miR-200c (21). Our laboratory and others have shown the diabetic myocardium, specifically mitochondria, to display high levels of reactive oxygen species (ROS) production and ROS damage, potentially elucidating a plausible theory for the elevation of miR-141 during a diabetic insult $(9,14,30)$.

miR-141 overexpression studies were carried out within HEK293 cells to validate target gene (Slc25a3) repression. As expected, enhanced levels of miR-141 significantly decreased Slc25a3 protein content by 50\% (Fig 4.6) and decreased mitochondrial ATP synthesis rates (Fig 4.7). Multiple studies have linked detriments to Slc25a3 with decreased ATP synthesis within 
mitochondria, highlighting the critical role phosphate transport plays for proper mitochondrial energy production $(2,25,29)$. Most notably, patients with mitochondrial phosphate-carrier deficiency displayed decreased ATP synthesis in mitochondria isolated from muscle tissue which also correlated with hypertrophic cardiomyopathy and low cardiac output (23).

Cardiac and skeletal muscle contain two spatially distinct mitochondrial subpopulations that exist within the myocardium, the SSM, located beneath the sarcolemma, and IFM, situated between myofibrils that are suggested to produce ATP for subsarcolemmal metabolite transport and myofibrillar contraction respectively (26). Interestingly, miR-141 overexpression within the diabetic heart correlated with decreased protein content of Slc25a3 as well as decreased ATP synthase activity only within cardiac IFM (Figs 4.4C, 4.5C). These results were somewhat unexpected as we hypothesized Slc25a3 would be decreased within both mitochondrial subpopulations. However, mitochondrial dysfunction within cardiac and skeletal subpopulations has varied within many different physiological and pathological states including but not limited to obesity, diabetes, aging, and apoptotic initiation $(1,4,9,15,19)$. Further, other mechanisms of dysfunction can't currently be ruled out as contributors to mitochondrial proteomic dysregulation including altered nuclear-encoded mitochondrial protein import or enhanced post translational modifications as previously described (4). Nevertheless, future studies dedicated to elucidating the regulatory role of miRNAs in context to individual mitochondrial subpopulations is necessary and absolutely warranted.

In conclusion, these finding indicate that pathologies, such as diabetic cardiomyopathy, have the ability to alter mitochondrial specific proteins through differential expression of miRNAs. Specifically, we report for the first time that miR-141 is upregulated within the diabetic heart and is capable of regulating mitochondrial phosphate carrier Slc25a3. Perturbation 
of mitochondrial energy production via miR-141 could potentially be a mechanism for mitochondrial dysfunction leading to cardiac dysfunction present within diabetic cardiomyopathy. 


\section{REFERENCES}

1. Adhihetty PJ, Ljubicic V, Menzies KJ, and Hood DA. Differential susceptibility of subsarcolemmal and intermyofibrillar mitochondria to apoptotic stimuli. Am J Physiol Cell Physiol 289: C994-C1001, 2005.

2. Alcala S, Klee M, Fernandez J, Fleischer A, and Pimentel-Muinos FX. A high-throughput screening for mammalian cell death effectors identifies the mitochondrial phosphate carrier as a regulator of cytochrome c release. Oncogene 27: 44-54, 2008.

3. Aragno M, Mastrocola R, Medana C, Catalano MG, Vercellinatto I, Danni O, and Boccuzzi G. Oxidative stress-dependent impairment of cardiac-specific transcription factors in experimental diabetes. Endocrinology 147: 5967-5974, 2006.

4. Baseler WA, Dabkowski ER, Williamson CL, Croston TL, Thapa D, Powell MJ, Razunguzwa TT, and Hollander JM. Proteomic alterations of distinct mitochondrial subpopulations in the type 1 diabetic heart: contribution of protein import dysfunction. Am J Physiol Regul Integr Comp Physiol 300: R186200.

5. Bradford MM. A rapid and sensitive method for the quantitation of microgram quantities of protein utilizing the principle of protein-dye binding. Anal Biochem 72: 248-254, 1976.

6. Bugger H, Chen D, Riehle C, Soto J, Theobald HA, Hu XX, Ganesan B, Weimer BC, and Abel ED. Tissue-specific remodeling of the mitochondrial proteome in type 1 diabetic akita mice. Diabetes 58: 1986-1997, 2009.

7. Calin GA and Croce CM. MicroRNA signatures in human cancers. Nat Rev Cancer 6: 857-866, 2006.

8. Dabkowski ER, Baseler WA, Williamson CL, Powell M, Razunguzwa TT, Frisbee JC, and Hollander JM. Mitochondrial dysfunction in the type 2 diabetic heart is associated with alterations in spatially distinct mitochondrial proteomes. Am J Physiol Heart Circ Physiol 299: H529-540. 
9. Dabkowski ER, Williamson CL, Bukowski VC, Chapman RS, Leonard SS, Peer CJ, Callery PS, and

Hollander JM. Diabetic cardiomyopathy-associated dysfunction in spatially distinct mitochondrial subpopulations. Am J Physiol Heart Circ Physiol 296: H359-369, 2009.

10. Dabkowski ER, Williamson CL, and Hollander JM. Mitochondria-specific transgenic overexpression of phospholipid hydroperoxide glutathione peroxidase (GPx4) attenuates ischemia/reperfusion-associated cardiac dysfunction. Free Radic Biol Med 45: 855-865, 2008.

11. Feng B, Chen S, George B, Feng Q, and Chakrabarti S. miR133a regulates cardiomyocyte hypertrophy in diabetes. Diabetes Metab Res Rev 26: 40-49.

12. Feniouk BA, Suzuki T, and Yoshida M. Regulatory interplay between proton motive force, ADP, phosphate, and subunit epsilon in bacterial ATP synthase. J Biol Chem 282: 764-772, 2007.

13. Flarsheim CE, Grupp IL, and Matlib MA. Mitochondrial dysfunction accompanies diastolic dysfunction in diabetic rat heart. Am J Physiol 271: H192-202, 1996.

14. Hamblin M, Friedman DB, Hill S, Caprioli RM, Smith HM, and Hill MF. Alterations in the diabetic myocardial proteome coupled with increased myocardial oxidative stress underlies diabetic cardiomyopathy. J Mol Cell Cardiol 42: 884-895, 2007.

15. Kelley DE, He J, Menshikova EV, and Ritov VB. Dysfunction of mitochondria in human skeletal muscle in type 2 diabetes. Diabetes 51: 2944-2950, 2002.

16. Kramer R. Structural and functional aspects of the phosphate carrier from mitochondria. Kidney Int 49: 947-952, 1996.

17. Laemmli UK. Cleavage of structural proteins during the assembly of the head of bacteriophage T4. Nature 227: 680-685, 1970.

18. Lesnefsky EJ, Gudz TI, Moghaddas S, Migita CT, Ikeda-Saito M, Turkaly PJ, and Hoppel CL. Aging decreases electron transport complex III activity in heart interfibrillar mitochondria by alteration of the cytochrome c binding site. J Mol Cell Cardiol 33: 37-47, 2001. 
19. Lesnefsky EJ, Slabe TJ, Stoll MS, Minkler PE, and Hoppel CL. Myocardial ischemia selectively depletes cardiolipin in rabbit heart subsarcolemmal mitochondria. Am J Physiol Heart Circ Physiol 280: H2770-2778, 2001.

20. Lim LP, Lau NC, Garrett-Engele P, Grimson A, Schelter JM, Castle J, Bartel DP, Linsley PS, and Johnson JM. Microarray analysis shows that some microRNAs downregulate large numbers of target mRNAs. Nature 433: 769-773, 2005.

21. Magenta A, Cencioni C, Fasanaro P, Zaccagnini G, Greco S, Sarra-Ferraris G, Antonini A, Martelli F, and Capogrossi MC. miR-200c is upregulated by oxidative stress and induces endothelial cell apoptosis and senescence via ZEB1 inhibition. Cell Death Differ 18: 1628-1639.

22. Mateescu B, Batista L, Cardon M, Gruosso T, de Feraudy Y, Mariani O, Nicolas A, Meyniel JP, Cottu P, Sastre-Garau X, and Mechta-Grigoriou F. miR-141 and miR-200a act on ovarian tumorigenesis by controlling oxidative stress response. Nat Med 17: 1627-1635.

23. Mayr JA, Merkel O, Kohlwein SD, Gebhardt BR, Bohles H, Fotschl U, Koch J, Jaksch M, Lochmuller H, Horvath R, Freisinger P, and Sperl W. Mitochondrial phosphate-carrier deficiency: a novel disorder of oxidative phosphorylation. Am J Hum Genet 80: 478-484, 2007.

24. Mayr JA, Zimmermann FA, Horvath R, Schneider HC, Schoser B, Holinski-Feder E, Czermin B, Freisinger $\mathbf{P}$, and Sperl W. Deficiency of the mitochondrial phosphate carrier presenting as myopathy and cardiomyopathy in a family with three affected children. Neuromuscul Disord 21: 803-808.

25. Nishi Y, Fujimoto S, Sasaki M, Mukai E, Sato H, Sato Y, Tahara Y, Nakamura Y, and Inagaki N. Role of mitochondrial phosphate carrier in metabolism-secretion coupling in rat insulinoma cell line INS1. Biochem J 435: 421-430.

26. Palmer JW, Tandler B, and Hoppel CL. Biochemical properties of subsarcolemmal and interfibrillar mitochondria isolated from rat cardiac muscle. J Biol Chem 252: 8731-8739, 1977. 
27. Palmer JW, Tandler B, and Hoppel CL. Heterogeneous response of subsarcolemmal heart mitochondria to calcium. Am J Physiol 250: H741-748, 1986.

28. Paradies G, Ruggiero FM, Petrosillo G, and Quagliariello E. Enhanced cytochrome oxidase activity and modification of lipids in heart mitochondria from hyperthyroid rats. Biochim Biophys Acta 1225: 165-170, 1994.

29. Poncet D, Pauleau AL, Szabadkai G, Vozza A, Scholz SR, Le Bras M, Briere JJ, Jalil A, Le Moigne R, Brenner C, Hahn G, Wittig I, Schagger H, Lemaire C, Bianchi K, Souquere S, Pierron G, Rustin P, Goldmacher VS, Rizzuto R, Palmieri F, and Kroemer G. Cytopathic effects of the cytomegalovirusencoded apoptosis inhibitory protein vMIA. J Cell Biol 174: 985-996, 2006.

30. Rolo AP and Palmeira CM. Diabetes and mitochondrial function: role of hyperglycemia and oxidative stress. Toxicol Appl Pharmacol 212: 167-178, 2006.

31. Rosca MG, Okere IA, Sharma N, Stanley WC, Recchia FA, and Hoppel CL. Altered expression of the adenine nucleotide translocase isoforms and decreased ATP synthase activity in skeletal muscle mitochondria in heart failure. J Mol Cell Cardiol 46: 927-935, 2009.

32. Rosca MG, Vazquez EJ, Kerner J, Parland W, Chandler MP, Stanley W, Sabbah HN, and Hoppel CL. Cardiac mitochondria in heart failure: decrease in respirasomes and oxidative phosphorylation. Cardiovasc Res 80: 30-39, 2008.

33. Sen CK. MicroRNAs as new maestro conducting the expanding symphony orchestra of regenerative and reparative medicine. Physiol Genomics 43: 517-520.

34. Shen X, Zheng S, Thongboonkerd V, Xu M, Pierce WM, Jr., Klein JB, and Epstein PN. Cardiac mitochondrial damage and biogenesis in a chronic model of type 1 diabetes. Am J Physiol Endocrinol Metab 287: E896-905, 2004.

35. Turko IV and Murad F. Quantitative protein profiling in heart mitochondria from diabetic rats. $J$ Biol Chem 278: 35844-35849, 2003. 
36. van Rooij E and Olson EN. MicroRNAs: powerful new regulators of heart disease and provocative therapeutic targets. J Clin Invest 117: 2369-2376, 2007.

37. van Rooij E, Sutherland LB, Qi X, Richardson JA, Hill J, and Olson EN. Control of stressdependent cardiac growth and gene expression by a microRNA. Science 316: 575-579, 2007.

38. Walker MD. Role of MicroRNA in pancreatic beta-cells: where more is less. Diabetes 57: 2567$2568,2008$.

39. Williamson CL, Dabkowski ER, Baseler WA, Croston TL, Alway SE, and Hollander JM. Enhanced apoptotic propensity in diabetic cardiac mitochondria: influence of subcellular spatial location. Am J Physiol Heart Circ Physiol 298: H633-642, 2010.

40. Williamson CL, Dabkowski ER, Baseler WA, Croston TL, Alway SE, and Hollander JM. Enhanced apoptotic propensity in diabetic cardiac mitochondria: influence of subcellular spatial location. Am J Physiol Heart Circ Physiol 298: H633-642. 
Fig 4.1

A.

mou-miR-197 miu-miR-295 min-miR-329 minu-miR-185 mul-miR-208b minu-miR-134 mmu-miR-298 mim-miR-125b-3p mmu-miR-139-5p

mmu-miR-193b mmu-IniR-122 mul-miR-466g mmu-miR-10? mmu-miR-200c

mau-miR-346

mmu-miR-431

minu-IniR-541 mmu-miR-542-5p mou-miR-666-3p

mmu-miR-702

mau-miR-141

mmu-miR-770-3p

mmu-miR-221

mmu-miR-409-3p

mau-miR-222

mmu-miR-467a*

minu-miR-302a*

mul-miR-883a-5p

mmu-miR-882
B.

Diabetic Heart

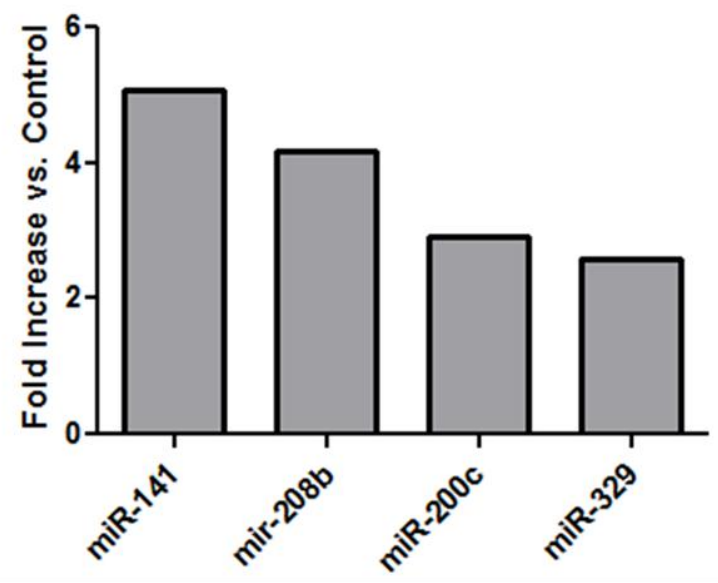


Figure 4.1. miRNA regulation in type 1 diabetic heart. (A) Heat map represents miRNA modulation in type 1 diabetic mouse hearts when compared with controls using RTQ-PCR analyses. Modulations are expressed using a $\log 2$ scale $(-\Delta \Delta \mathrm{Ct})$. Green indicates downregulation, red indicates up-regulation. (B) Graphical representation of highest miRNA fold increases in the diabetic heart miRNA compared to control. All values represented were statistically significant. Values are represented as mean $\pm \mathrm{SEM} ; \mathrm{N}=4$ per group. ${ }^{*} p<0.05$ for all miRNA presented. 


\section{Fig 4.2}

A.

$\begin{array}{rc}\text { Slc25a3 3' UTR } & \text { 5'- AUCUGCUUGUUGAUCAGUGUUU 3' } \\ \text { miR-141 } & \text { 3'- GGUAGAAAUGGUCUGUCACAAG } \\ \text { 5' }\end{array}$

B.
M. Musculus
5' - AUCUGCUUGUUGAUCAGUGUU - 3'
R. Norvegicus
5' - AUCUGCUUGUUGAUCAGUGUU - 3'
H. Sapiens
5' - AUCUGCUUGUUGAUCAGUGUU - 3'
C. Porcellus
5' - AUCUGCUUGUUGAUCAGUGUU - 3' 
Figure 4.2. miR-141 binding to Slc25a3. (A) Sequence homology between Slc25a3 3'-UTR (top) and miR-141 (bottom). Black lines represent perfect match, grey lines represent G-U wobbles. (B) miR-141 recognition sequence of Slc25a3 gene in Mus musculus, Rattus norvegicus, Homo sapien, and Cavia porcellus as indicted from TargetScan.org. Red characters represent the seed sequence for miR-141. 


\section{Fig 4.3}

A.

miR-141 3' - GGUAGAAAUGGUCUGUCACAA - 5'

miR-200c $\quad$ 3' - GGUAGUAAUGGGCCGUCAUAA - 5'

B.

Luciferase Activity

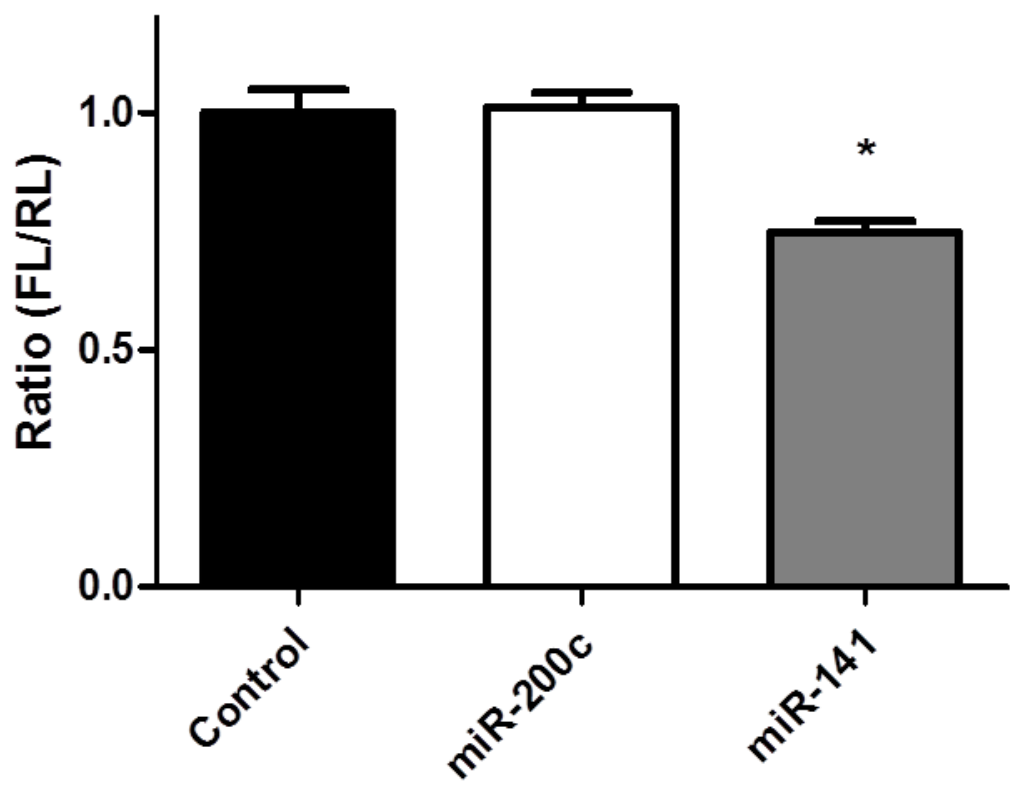


Figure 4.3. miR-141 specific binding to Slc25a3 3' UTR target sequence. (A) Sequence homology between miR-141 and family member miR-200c. Red characters indicate differences in miR-200c nucleotide sequence. (B) Relative luciferase activities of Slc25a3 3' reporter coexpressed with miR-141, miR-200c, or scrambled plasmid (PmirGlo) control in HEK293 cells 24 hours post transfection. Firefly luciferase activity was normalized to Renilla luciferase activity. Values are represented as mean $\pm \mathrm{SEM} ; \mathrm{N}=4$ per group. ${ }^{*} p<0.05$ for miR-141 vs. all other groups. 


\section{Fig 4.4}

A.



B.

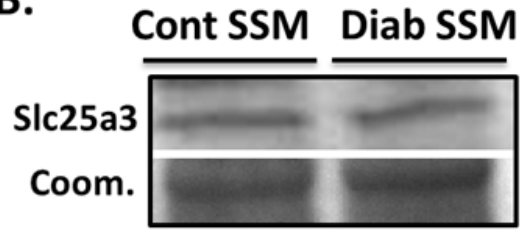

SIc25a3 SSM

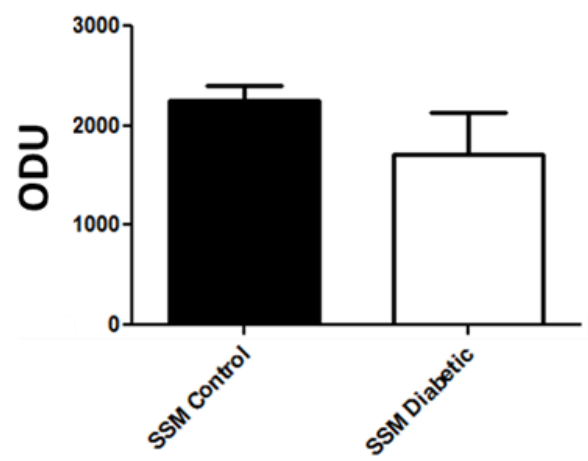

C.
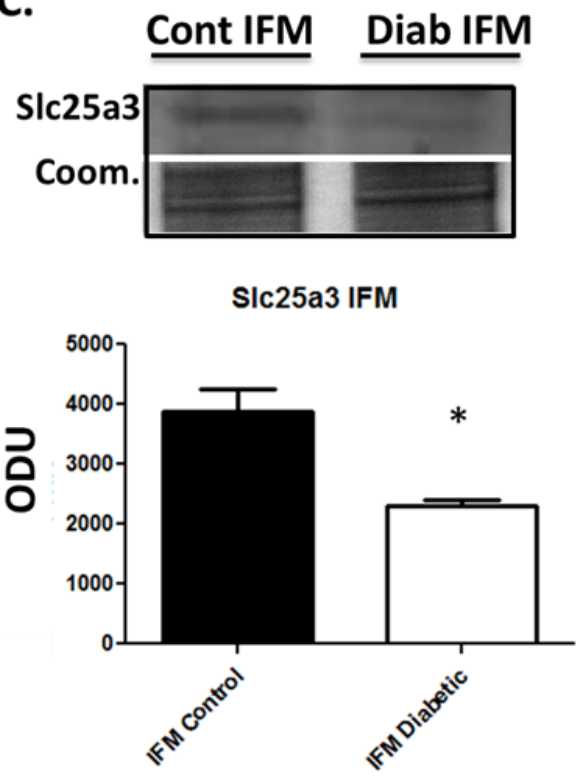
Figure 4.4. Slc25a3 expression levels. (A) Relative mRNA levels of Slc25a3 in control and diabetic heart tissue. RNU6 was used as an internal control. Western blots and densitometry analysis for Slc25a3 protein expression in (B) SSM, and (C) IFM from control and diabetic hearts $(\mathrm{N}=4)$. Control for protein loading was confirmed with Ponceau staining. Values are represented as mean $\pm \mathrm{SEM} ; \mathrm{N}=4$ per group. ${ }^{*} p<0.05$ for Diabetic IFM vs Control IFM. 


\section{Fig 4.5}

A.

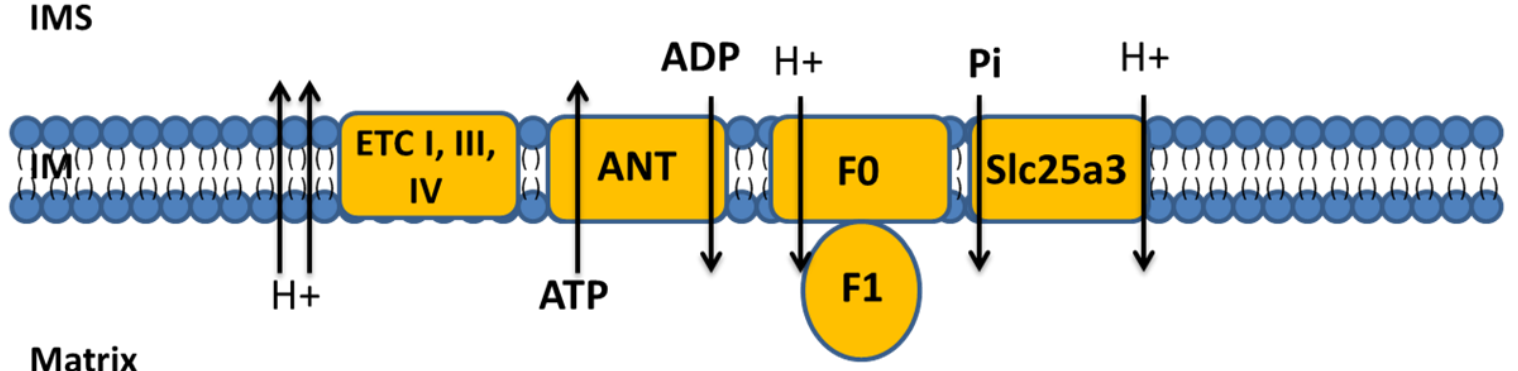

Matrix

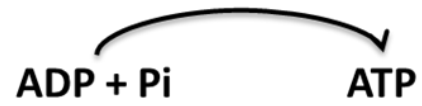

B.

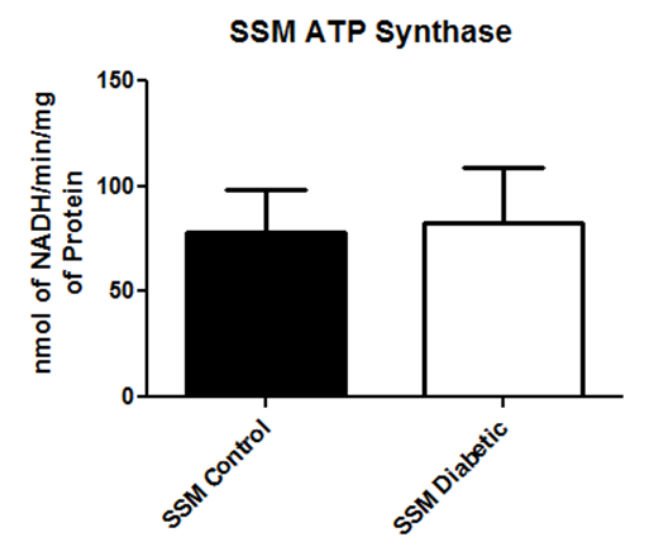

c.

IFM ATP Synthase

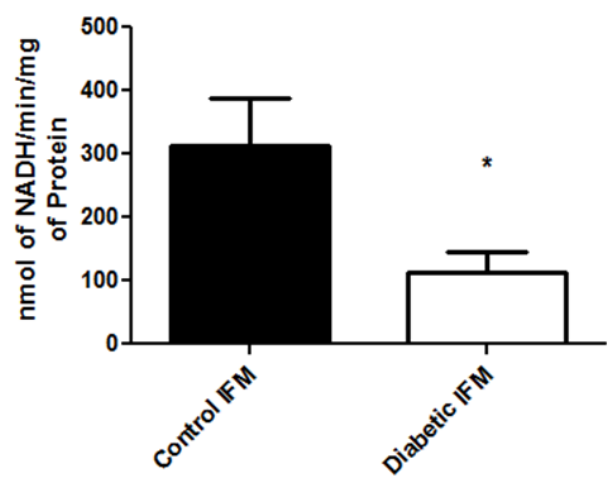


Figure 4.5. Mitochondrial subpopulation ATP synthase activity. (A) General schematic of how ATP synthase produces ATP with the aid of Slc25a3 (phosphate transport) and ANT (ADP transport) within the mitochondria. ATP synthase activity was assessed in SSM (B) and IFM (C) from hearts of control and diabetic animals using an assay coupled with pyruvate kinase which converts ADP to ATP and produces pyruvate from phosphoenolpyruvate. Final values are expressed as nanomoles/NADH/min/mg of protein $\pm \mathrm{SEM}$; $\mathrm{N}=4$ for each group. ${ }^{*} P<0.05$ for Diabetic IFM vs. Control IFM. 


\section{Fig 4.6}

A.
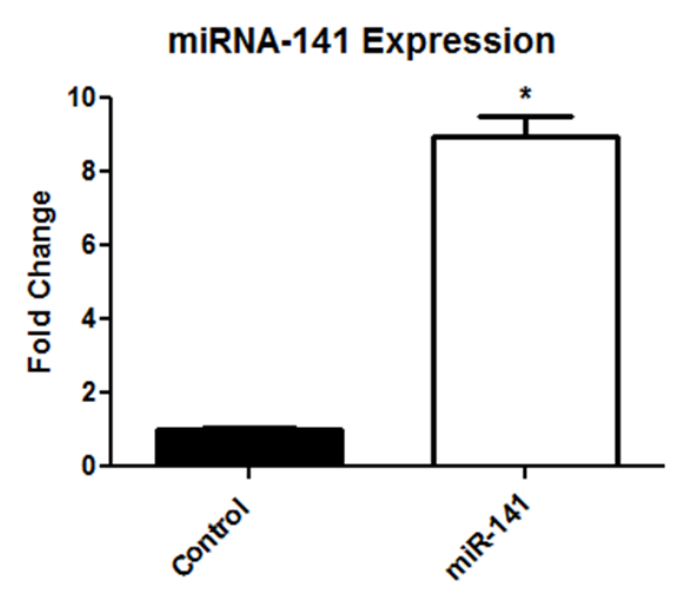

C.



B.

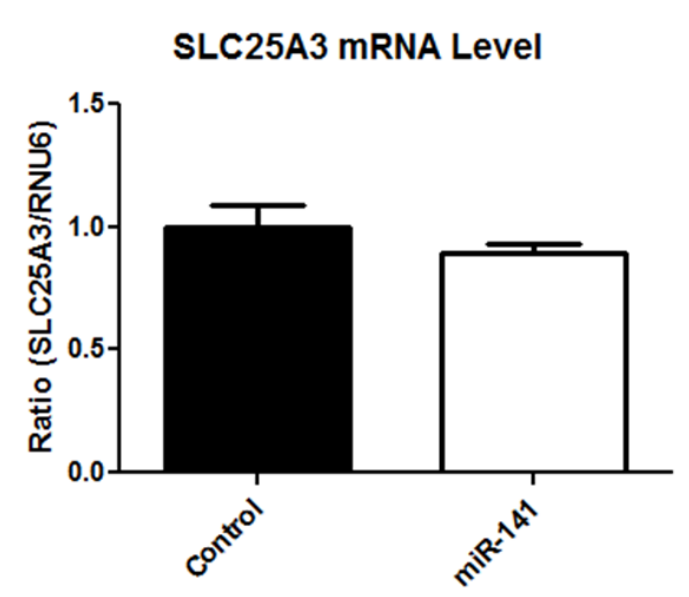

D.

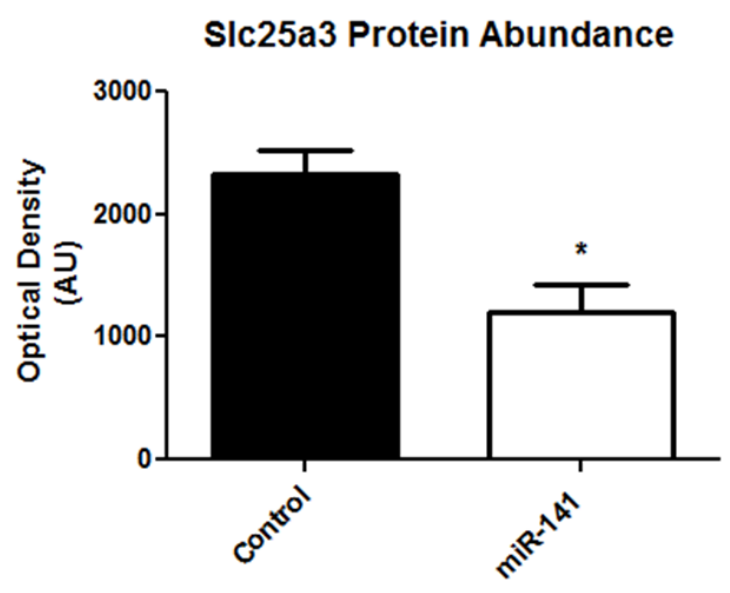


Figure 4.6. miR-141 overexpression. (A) Fold increase of miR-141 in HEK293 cells 72 hours post transfection with control or miR-141 expression plasmid. (B) Relative mRNA levels of Slc25a3 in HEK293 control and miR-141 cells. RNU6 was used as an internal control. Western blots and densitometry analysis for Slc25a3 protein expression in HEK293 control and miR-141 cells. GAPDH was used as an internal control. Values are represented as mean $\pm \mathrm{SEM}$; $\mathrm{N}=4$ per group. ${ }^{*} p<0.05$ where applicable. 


\section{Fig 4.7}

ATP Synthase Activity




Figure 4.7. miRNA-141 ATP synthase activity. ATP synthase activity was assessed in HEK293 control and miR-141 cells using an assay coupled with pyruvate kinase which converts ADP to ATP and produces pyruvate from phosphoenolpyruvate.. Final values are expressed as nanomoles $/ \mathrm{NADH} / \mathrm{min} / \mathrm{mg}$ of protein $\pm \mathrm{SEM} ; \mathrm{N}=4$ for each group. ${ }^{*} P<0.05$ for miR-141 vs Control groups. 


\section{Chapter 5:}

\section{General Discussion}




\section{GENERAL DISCUSSION}

The overall objective of this dissertation was to determine the mechanisms involved in mitochondrial proteomic dysregulation that occurs in the diabetic heart. Specifically, we sought to determine the effect of a diabetic insult on (1) nuclear-encoded mitochondrial protein import in mitochondrial subpopulations; (2) to test the therapeutic benefit of overexpressing mitochondrial specific antioxidant mPHGPx on protein translocation into individual mitochondrial subpopulations during a diabetic insult; (3) to evaluate the effect of diabetes induced miRNA modulation upon mitochondrial proteomic makeup. Our long term goal is to better understand the mechanisms involved in the pathogenesis of diabetic cardiomyopathy as a prerequisite to the development of therapeutic interventions designed to lessen cardiac complications associated with diabetes mellitus. The central hypothesis of this dissertation is that type 1 diabetic insult will cause dysfunction of the mitochondrial protein import process leading to a loss of key proteins required for adequate mitochondrial function and structure. These effects will be most pronounced in the IFM, influencing cardiac contractile processes. Our rationale for the proposed research is based upon the notion that the understanding of mitochondrial subpopulation response and identification of key factors that contribute to mitochondrial dysfunction will aid in the development of therapeutics that can address specific mitochondrial subpopulations at greatest risk from diabetes mellitus.

Cardiac complications are the leading cause of morbidity and mortality within diabetic patients. A significant amount of literature has linked mitochondrial dysfunction with cardiac abnormalities seen within the diabetic heart $(4,9,32,34,36,38)$. Specifically, abnormalities include, but are not limited to, altered substrate utilization, enhanced ROS production, increased apoptotic susceptibility, and altered mitochondrial structure during a diabetic insult $(4,9,47)$. 
Complicating cardiac mitochondrial studies, two spatially-distinct mitochondrial subpopulations exist within the myocardium and respond differently to various physiological and pathological stimuli $(1,20,21,33)$. I/R injury was shown to decrease SSM abundance, increase ROS production from ETC complexes I and III, and decrease IMM phospholipid cardiolipin (22). Likewise, Judge et al. reported increased oxidative damage in aged mice correlating with increased lipid peroxidations and enhanced antioxidant defense within the IFM subpopulation (17). Similar to the Judge study, previous research from our laboratory has highlighted IFM as the most dysfunctional subpopulation within the type 1 diabetic heart citing enhanced ROS production, enhanced ROS damage, and decreased size and internal complexity, whereas the diabetic SSM were relatively unaffected within these experimental parameters (9). Although it has been suggested IFM are the primary pathological loci of interest within a type 1 diabetic setting, the mechanisms driving such manifestations remain limited.

Cardiac and mitochondrial proteomic studies within type 1 diabetic models have shown the mitochondrial proteome to be dramatically altered in the presence of the pathology $(13,18$, 41). STZ-treated rats 4 weeks post diabetic induction displayed elevated levels of FAO proteins, decreases in ETC proteins from complex I, and a decrease in mitochondrial protein import constituent, MtHsp70 in cardiac tissue (41). Similarly, Hamblin et al. analyzed cardiac tissue from 8 week STZ-treated diabetic rats, which revealed similar results of enhanced FAO as well as decreases in antioxidant defense proteins (13). Using multiple proteomic approaches (2DDIGE and iTRAQ), we were able to identify IFM as the primary cardiac mitochondrial subpopulation most impacted by diabetes mellitus within STZ-treated mice (Chapter 2). Essentially all major processes occurring within IFM were significantly altered including those from the ETC (complex I, III, IV, V), FAO, the TCA cycle, and mitochondrial protein import 
(MtHsp70). Interestingly, we saw FAO proteins significantly decreased within the diabetic IFM, which was an unexpected finding. Because of the inability of the heart to utilize glucose in a diabetic setting, it is intuitive to think that $\beta$-oxidation would be increased to allow for proper mitochondrial ATP production. Although it is unclear as to why we see these discrepancies, it is important to point out that mitochondrial subpopulations were evaluated, there were differences in animal models, and different STZ protocols (high vs. low dose) were used. Nevertheless, the contradictory findings are certainly interesting and warrant future experimentation.

We next sought to understand mechanistically why the proteome of the IFM was severely impacted while the SSM subpopulation was not. MtHsp70, a key component to nuclear-encoded mitochondrial import and essential protein of the PAM complex, has been shown in multiple proteomic platforms to be decreased in a diabetic insult $(4,41)$. Temperature sensitive knockdown of MtHsp70 yeast homolog (ssc1) severely inhibited mitochondrial matrix import (8) and $\operatorname{ssc} 1$ knockout models have proven to be lethal (39). Interestingly, both proteomic analyses conducted from our laboratory highlighted decreased content of MtHsp70 within the diabetic IFM. Therefore, we decided to elucidate the impact of diabetes on nuclear-encoded mitochondrial import within cardiac mitochondrial subpopulations. Fluorometric and Western blot analyses both revealed decreased ability of mitochondrial matrix import protein (MitoGFP1) to translocate into diabetic IFM compared to control, with no change in the SSM. These results show for the first time that dysfunctional nuclear-encoded mitochondrial protein import is a potential mechanism for the proteomic dysregulation evident within diabetic IFM. Nuclearencoded mitochondrial protein import is a complicated process in which multiple proteins/protein complexes must work in uniform for successful protein translocation into the mitochondria $(19,31,46)$. Because of this, we attempted to clarify what part of the protein 
import process was dysfunctional within diabetic IFM. Western blot analyses of several of the most important OMM (Tom20, Tom40), IMM (Tim23), and matrix (Tim44, MtHsp70) translocases were analyzed. Interestingly, only MtHsp70 protein content was decreased within the diabetic IFM, which validated our proteomic data. Mitochondrial membrane potential has been shown not only to be a critical component for mitochondrial OXPHOS but also as a driving force for preprotein translocation from the IMS into the mitochondrial matrix (15). Interfibrillar mitochondria saw a modest $19 \%$ reduction in membrane potential during a diabetic insult, which may contribute to altered mitochondrial protein import. However, previous studies examining aged skeletal muscle elicited reductions in mitochondrial membrane potential by as much as $50 \%$, which had no impact on mitochondrial import dynamics (14). Therefore, it is possible slight reductions in membrane potential may not be able to reduce mitochondrial import mechanics alone.

There are other potential mechanisms that can account for mitochondrial proteomic dysregulation within the diabetic heart, including alterations to gene expression, detriments to cytoplasmic transport, and/or enhanced cytoplasmic proteasomal activity. In order to determine whether IFM proteomic dysfunction occurred due to upstream mechanisms prior to mitochondrial protein import, we examined multiple cytoplasmic chaperones directly involved in the transport of preproteins from the ribosomes to the mitochondria (Appendix 7.1). The most thoroughly characterized mitochondrial chaperones are constitutive heat shock protein 70 (Hsc70), inducible heat shock protein 70 (Hsp70i), and heat shock protein 90 (Hsp90). Mitochondrial transport chaperones hsc70, hsp70i, and hsp90 protein content were unaffected in diabetic IFM compared to control (Appendix 7.1). Dysregulation of mitochondrial transport specific chaperones have been shown in various pathologies, including significant increases of 
Hsp90 within skeletal muscle of aging rats (14). Further, although we did not see changes in Hsc70 within our diabetic model, it is important to note Chen et al. saw a significant decrease in Hsc70 abundance in the diabetic rat myocardium of singular high-dose STZ injected rats as late as 21 days post injection (6). The discrepancies between studies remain unclear; however, previously mentioned differences in experimental procedures may be the cause.

Another potential mechanism of proteomic dysregulation within mitochondria is enhanced cytoplasmic derived protein degradation due to elevated proteasomal abundance and/or activity. Therefore, we sought to determine if diabetes mellitus has an influence on this cytoplasmic process, leading to downstream effects upon mitochondrial proteomic makeup. Enhanced protein degradation has indeed been shown within the cytoplasm of senescent rat skeletal muscle (14). Further, the ubiquitin-proteasomal system has been implicated in multiple pathologies including cardiac hypertrophy, desmin-related cardiomyopathies, and numerous neurodegenerative diseases $(10,24,37)$. To determine whether ubiquitin-proteasomes have a detrimental role within the diabetic myocardium, we evaluated the activity level of its $20 \mathrm{~S}$ catalytic subunit. Interestingly, we saw no significant difference in activity level of the proteasomal 20S subunit in diabetic IFM compared to control IFM (Appendix 7.4). Further, we also quantified the abundance of the primary alpha and beta subunits of the proteasome and again, saw no significant increases in either group analyzed (Appendix 7.4). The results shown are in agreement with work presented from Liu et al. in which diabetic rat hearts displayed elevated levels of ubiquitin mRNA, but saw no change in free ubiquitin levels or proteasome chemotrypsin like peptidase activity (25). From these results we concluded that diabetic induced proteomic dysregulation within the diabetic IFM was not a consequence of alterations to protein degradation within the cytoplasm. 
Taken together, the data compiled from Chapter 2 indicates that diabetes-induced IFM proteomic dysregulation may be a consequence of altered nuclear-encoded mitochondrial protein import. Further, mitochondrial protein import decrements are directly impacted by decreased protein content of matrix chaperone MtHsp70.

Previous findings from our laboratory have suggested that the IMM of IFM may be particularly at risk within a type 1 diabetic setting (9). Further, although the IMM constitutes only $21 \%$ of the total protein content within mitochondria, our proteomics data revealed greater than $50 \%$ of proteins identified and dysregulated within the IFM were of IMM origin. Additionally, a significant amount of mitochondrial import proteins reside within or are directly in contact with the IMM. Therefore, we decided to employ the use of mPHGPx, an antioxidant potentially capable of preserving the IMM during a diabetic insult and analyze its effect upon diabetic IFM nuclear-encoded mitochondrial protein import. MPHGPx is the only antioxidant enzyme with the ability to reduce peroxidized acyl groups in phospholipids, fatty acid hydroperoxides and cholesterol peroxides in mitochondrial membranes (26). Residing within the mitochondrial IMS, this antioxidant has the ability to directly scavenge lipid hydroperoxides within mitochondrial membranes and has been implicated as the primary defense against mitochondrial membrane oxidations (40). Specifically, mPHGPx is known to protect essential IMM phospholipid, cardiolipin from oxidative damage. Cardiolipin is known to surround essential protein complexes within the IMM including the ETC complexes I, III and IV of the ETC as well as IMM import complex, TIM (23).

No study to date has evaluated the impact of antioxidant overexpression on the preservation of the mitochondrial proteome in a diabetic setting within any organelle, including the heart. Therefore, we decided to take mPHGPx transgenic mice, induce diabetes through STZ 
treatment, isolate cardiac IFM and evaluate how mPHGPx overexpression impacted the mitochondrial proteome and mitochondrial import process. Remarkably, mPHGPx overexpression was able to preserve a significant portion $(60 \%)$ of proteins originally decreased within the diabetic IFM (Chapter 3). Further, Ingenuity Pathway Analyses highlighted the preservation of proteins involved in processes such as OXPHOS, the TCA cycle, FAO, and mitochondrial protein import in mPHGPx diabetic IFM. A breakdown of the percentages of proteins preserved within the mPHGPx diabetic IFM revealed the vast majority of proteins resided within the IMM (61\%) and the mitochondrial matrix (36\%). Due to mPHGPx location within the IMS, we were surprised to see such a large preservation of mitochondrial matrix proteins. ETC complexes I and III, known sites for electron leakage, were also highly preserved within the mPHGPx diabetic IFM; therefore, mPHGPx overexpression may decrease total electron leakage and subsequent ROS generation (7). Given the matrix's proximal location to the IMM, decreased ROS generation may be mechanism of proteomic protection within the mPHGPx mouse. Indeed, our PTM data supports this notion by highlighting decreases in oxidations, acetylations, and deamidations within both the IMM and matrix of mPHGPx diabetic IFM compared to diabetic IFM (Chapter 3). Although to a lesser extent, mPHGPx is capable of scavenging hydrogen peroxide, which would also lessen the oxidative environment within the mitochondrial matrix (42).

Ingenuity pathway analyses were also conducted in an effort to identify key protein networks of interest within cardiac diabetic and mPHGPx diabetic IFM. Most interestingly, proteins involved with nuclear-encoded mitochondrial protein import formed a central network, which linked other protein networks such as ETC complexes I and II, a mitofilin-based structural network, and an ATP-sensitive potassium channel network. This gave us the impetus to study 
whether nuclear-encoded mitochondrial protein import was also preserved within mPHGPx diabetic IFM. As expected, mitochondrial protein import was restored within the mPHGPx diabetic IFM. Further, multiple mitochondrial translocases were preserved or increased in the mPHGPx diabetic IFM group including Tom20, Tim50, Tim23 and MtHsp70. In agreement, previous research in our laboratory has shown mPHGPx adenoviral overexpression also enhances Tom 20 protein content within cardiac rat neonatal cardiomyocytes (48). MPHGPx protection of such a large portion of protein import translocases would certainly bolster protein import dynamics, even in times of diabetic stress. Nevertheless, MtHsp70 was the only mitochondrial import protein shown to be significantly decreased within the diabetic IFM and therefore may act as the rate limiting step in matrix-associated mitochondrial protein import. This statement is supported by the fact that although Tom20, Tim50, and Tim23 were all increased in the mPHGPx diabetic IFM, MitoGFP1 import into the mitochondrial matrix was only restored, not enhanced. Further, BN-PAGE analysis of MtHsp70 complexing within the PAM complex was decreased within the diabetic IFM and subsequently restored within the mPHGPx diabetic IFM. These data proved conclusively that MtHsp70 protein content and functionality was preserved within the mPHGPx diabetic IFM. Of note, there are additional mitochondrial import translocases such as OMM Tom22 and Tom40, as well as IMM Tim21 and Tim17 that could all potentially play a role in mitochondrial import dysfunction or preservation within the mPHGPx transgenic mouse. Further, only the most highly abundant proteins, such as MtHsp70, were able to be identified and quantified through iTRAQ proteomic analyses, which is a known limitation for such experimentation. To circumvent such a problem, an interesting study would be to fractionate the mitochondrial subcompartments (OMM, IMS, IMM, matrix) and then perform proteomic analyses. This approach would allow for a much greater chance for 
less abundant proteins, such as the aforementioned translocases, to be identified and/or quantified. Scientific approaches such as this would certainly be warranted in the future.

Taken together, the results gathered from Chapter 3 highlight the unique ability of the antioxidant mPHGPx to protect cardiac IFM from proteomic decrements associated with type 1 diabetes mellitus. Further, restitution of the mitochondrial import processes, including essential protein import constituents, correlated with IFM proteomic preservation. Studies such as these give the impetus for the development of therapeutics targeting mitochondrial proteomic preservation and/or restitution of nuclear-encoded mitochondrial protein import, which may provide protection in the diabetic heart.

Regulation of nuclear gene transcription/translation is another potential mechanism of mitochondrial proteomic regulation within the diabetic heart. miRNAs are short (18-24nt) nucleotide molecules found within all vertebrate species that have the ability to cause gene silencing through mechanisms of mRNA degradation or translational repression $(3,5)$. Recently, a wealth of literature has shown miRNAs to be directly implicated in cardiac pathologies, most notably cardiac hypertrophy $(3,43-45)$. However, to date, research regarding miRNA modulation via diabetic insult remains limited. Further, no study has evaluated the impact of diabetes mellitus on miRNA regulation of the mitochondrial proteome. Therefore, using a broad scale RTQ-PCR approach, we evaluated 375 of the most prevalent mouse miRNAs in control and diabetic hearts to determine how miRNA are modulated within the pathology (Chapter 4). Interestingly, we saw upregulation of 26 miRNAs including miR-208b, miR-329, as well as family members miR-141 and miR-200c. These 4 miRNAs were the most highly upregulated with miR-141 being the highest at 5 fold. Interestingly, Van Rooij et al. has identified miR-208b as a primary regulator of $\mathrm{MHC}$ switching within the heart, which has the functional ability to 
repress $\alpha$-MHC and promote $\beta$-MHC expression (45). Given the context of this dissertation, we did not pursue whether miR-208b has similar effects within the diabetic heart. However, research does suggest MHC switching can occur during a diabetic insult, implicating miR-208b as a potential regulator of such a phenomenon, warranting future investigation (2).

miRNA targeting databases such as TargetScan.org, miRbase.org, and PicTar.org are becoming widely popular for their ability to predict miRNA binding partners within target genes 3' UTR's. Generally, the criteria for mRNA target prediction involves analyzing "seeding" region matches (nt 2-7), the number of miRNA target binding regions within the 3' UTR, and the sequence homology between vertebrates $(11,12)$. Remarkably, miR-141 was highly predicted to target mitochondrial inorganic phosphate carrier, Slc25a3, in all three of the aforementioned targeting databases. Previous proteomic analyses (Chapter 2 and 3) highlighted Slc25a3 to be significantly decreased within the diabetic IFM giving us the impetus to determine whether miR141 is capable of repressing Slc25a3 within a diabetic setting. Experiments were conducted in which the 3' UTR target region of Slc25a3 was transfected downstream of a firefly luciferase plasmid. Co-expression of this vector with miR-141 elicited a decrease in luciferase activity, confirming miR-141/Slc25a3 3' UTR binding. Further, overexpression studies (transient and stable transfections) of miR-141 within HEK293 cells caused a dramatic decrease in Slc25a3 protein content, further validating miR-141 regulation upon the mitochondrial inorganic phosphate carrier. Decrement to Slc25a3 has shown to cause significant decreases in ATP synthase activity and subsequent ATP production. Specifically, a human genetic mutation to Scl25a3 led to decreased ATP synthase activity correlating with hypertrophic cardiomyopathy and decreased cardiac output $(29,30)$. Similarly, overexpression of miR-141 also led to 
decreased ATP synthase production in HEK293 cells and diabetic IFM, confirming the downstream functional impact of matrix phosphate reduction within mitochondria.

Although the mechanism of miR-141 regulation upon Slc25a3 is clearly defined above, it is unclear why miR-141 is upregulated within a diabetic context. Recent literature has begun to identify oxidative stress, in particular hydrogen peroxide production, as a causative agent for miR-141 overexpression $(27,28)$. Our laboratory and others have shown significant elevations in ROS generation and damage within the diabetic myocardium; therefore, this scenario of enhanced miR-141 within diabetes mellitus is plausible $(9,34,35)$. Interestingly, Slc25a3 has been implicated as a primary member of the mPTP, which when formed, will induce mitochondrially-driven apoptosis through activation of a death-caspase cascade (16). Previously, we have shown the diabetic IFM to have increased susceptibility to MPTP opening and subsequent death-caspase activation (47). It could be speculated that increases in miR-141 in a diabetic setting is a protective mechanism aimed at decreasing mitochondrially-driven apotosis occurring within the diabetic IFM through inhibition of mPTP opening. Experimentation in this regard is necessary in the future to give a better understanding of why miR-141 is upregulated within the diabetic myocardium.

In summary, miRNAs are significantly altered within the diabetic heart and these modulations have the ability to influence nuclear-encoded mitochondrial proteins. Further, modulation of essential mitochondrial proteins, such as Slc25a3, may impact mitochondrial functionality in a diabetic setting. Therefore, experimentation examining miRNA regulation of other mitochondrial proteins of interest will allow for greater understanding of miRNAs and their effect upon the myocardium. 
Utilizing the supporting evidence from the studies, it is clearly evident that diabetesinduced mitochondrial proteomic dysregulation occurs through a multitude of coexisting mechanisms including decreased functionality of nuclear-encoded mitochondrial protein import (Chapter 2 and 3), enhanced PTM's (Chapter 2 and 3), and increased miRNA regulation (Chapter 4). We have also ruled out other potential mechanisms of mitochondrial proteomic dysregulation including detriments to mitochondrial transport chaperones (Appendix 7.3) and enhanced proteasomal degradation (Appendix 7.4). Further, mPHGPx overexpression was able to preserve a large portion of the mitochondrial proteome, protect the nuclear-encoded mitochondrial protein import process and reverse PTMs within diabetic IFM. Table 5.1 summarizes the mechanisms analyzed in this dissertation within our type 1 diabetic model as well as the effect mPHGPx had upon the mechanisms.

\begin{tabular}{|l|c|c|c|}
\hline $\begin{array}{l}\text { Mechanism of } \\
\text { Dysfunction }\end{array}$ & $\begin{array}{l}\text { Diabetic } \\
\text { Influence }\end{array}$ & $\begin{array}{l}\text { mPHGPx } \\
\text { Influence }\end{array}$ & Chapter Shown \\
\hline Protein Import & Decreased & Preserved & 2,3 \\
\hline PTM & Increased & Decreased & 2,3 \\
\hline miRNA Modulation & Increased & TBD & 4 \\
\hline $\begin{array}{l}\text { Cytoplasmic } \\
\text { Chaperones }\end{array}$ & No Change & N/A & 7 \\
\hline $\begin{array}{l}\text { Proteasomal } \\
\text { Degredation }\end{array}$ & No Change & N/A & 7 \\
\hline
\end{tabular}

Table 5.1. Mechanisms involved in IFM proteomic dysregulation in a diabetic setting 
The initial finding in Chapter 2 that nuclear-encoded mitochondrial import was dysfunctional in the diabetic IFM served as a springboard for the subsequent chapters of the dissertation. Because nearly all proteins must be imported into the mitochondrion, dysfunctional mitochondrial protein import seems to be the most logical explanation for the dysregulated mitochondrial proteome present in the diabetic IFM. This led us to examine mechanisms of proteomic restitution through overexpression of mPHGPx, which was analyzed in Chapter 3 of the dissertation. We had an inclination that mPHGPx would be able to restore mitochondrial protein import because of previous research in our laboratory in which mPHGPx overexpression in rat neonatal cardiomyocytes increased the protein content of OMM import protein Tim 20. Remarkably, mPHGPx overexpression in diabetic mice corrected not only nuclear-encoded mitochondrial protein import, but also preserved $60 \%$ of the IFM proteome originally decreased in the diabetic IFM. Therefore, the information accrued from both Chapter 2 and 3 strongly suggest alterations to nuclear-encoded mitochondrial protein import was a likely mechanism of mitochondrial proteomic dysregulation. The research conducted in Chapter 4 was performed to give a better overall prospective of gene regulation within the diabetic heart. With no supporting data to indicate miRNAs were modulated within the diabetic hearts, the preliminary results of 26 altered miRNAs came as a pleasant surprise. Interestingly, no mitochondrial import translocases were predicted to be regulated within the diabetic IFM, which was the original hypothesis to the aim. Nevertheless, alterations to Slc25a3 via miR-141 upregulation allowed us to identify a novel method of mitochondrial proteomic modulation within the diabetic heart completely independent from the results compiled in Chapters 2 and 3. Further, I believe it allowed for an overall broader prospective of how the mitochondrial proteome can be manipulated beyond acute mitochondrial specific mechanisms. 
In summary, the data presented suggests that multiple mechanisms must be taken into account when analyzing mitochondrial proteomic deficits that occur within the diabetic heart. In particular, nuclear-encoded mitochondrial import plays a critical role in maintaining proper protein content within mitochondria, specifically the IFM subpopulation during a diabetic insult. Further, enhanced miRNA regulation may also contribute to mitochondrial proteomic abnormalities present within diabetic IFM. Finally, therapeutics targeted at maintaining proper mitochondrial import function and/or miRNA regulation may be of clinical benefit in context to the type 1 diabetic heart. 


\section{REFERENCES}

1. Adhihetty PJ, Ljubicic V, Menzies KJ, and Hood DA. Differential susceptibility of subsarcolemmal and intermyofibrillar mitochondria to apoptotic stimuli. Am J Physiol Cell Physiol 289: C994-C1001, 2005.

2. Aragno M, Mastrocola R, Medana C, Catalano MG, Vercellinatto I, Danni O, and Boccuzzi G. Oxidative stress-dependent impairment of cardiac-specific transcription factors in experimental diabetes. Endocrinology 147: 5967-5974, 2006.

3. Barringhaus KG and Zamore PD. MicroRNAs: regulating a change of heart. Circulation 119: 2217-2224, 2009.

4. Baseler WA, Dabkowski ER, Williamson CL, Croston TL, Thapa D, Powell MJ, Razunguzwa TT, and Hollander JM. Proteomic alterations of distinct mitochondrial subpopulations in the type 1 diabetic heart: contribution of protein import dysfunction. Am J Physiol Regul Integr Comp Physiol 300: R186200.

5. Calin GA and Croce CM. MicroRNA signatures in human cancers. Nat Rev Cancer 6: 857-866, 2006.

6. Chen HS, Jia J, Su HF, Lin HD, Chen JW, Lin SJ, Yang JY, Lai HC, Mestril R, and Wang PH. Downregulation of the constitutively expressed $\mathrm{Hsc70}$ in diabetic myocardium is mediated by insulin deficiency. J Endocrinol 190: 433-440, 2006.

7. Chen Q, Vazquez EJ, Moghaddas S, Hoppel CL, and Lesnefsky EJ. Production of reactive oxygen species by mitochondria: central role of complex III. J Biol Chem 278: 36027-36031, 2003.

8. Craig EA, Kramer J, and Kosic-Smithers J. SSC1, a member of the 70-kDa heat shock protein multigene family of Saccharomyces cerevisiae, is essential for growth. Proc Natl Acad Sci U S A 84: 41564160, 1987. 
9. Dabkowski ER, Williamson CL, Bukowski VC, Chapman RS, Leonard SS, Peer CJ, Callery PS, and Hollander JM. Diabetic cardiomyopathy-associated dysfunction in spatially distinct mitochondrial subpopulations. Am J Physiol Heart Circ Physiol 296: H359-369, 2009.

10. Depre C, Wang Q, Yan L, Hedhli N, Peter P, Chen L, Hong C, Hittinger L, Ghaleh B, Sadoshima J, Vatner DE, Vatner SF, and Madura K. Activation of the cardiac proteasome during pressure overload promotes ventricular hypertrophy. Circulation 114: 1821-1828, 2006.

11. Griffiths-Jones S, Grocock RJ, van Dongen S, Bateman A, and Enright AJ. miRBase: microRNA sequences, targets and gene nomenclature. Nucleic Acids Res 34: D140-144, 2006.

12. Griffiths-Jones S, Saini HK, van Dongen S, and Enright AJ. miRBase: tools for microRNA genomics. Nucleic Acids Res 36: D154-158, 2008.

13. Hamblin M, Friedman DB, Hill S, Caprioli RM, Smith HM, and Hill MF. Alterations in the diabetic myocardial proteome coupled with increased myocardial oxidative stress underlies diabetic cardiomyopathy. J Mol Cell Cardiol 42: 884-895, 2007.

14. Huang JH, Joseph AM, Ljubicic V, Iqbal S, and Hood DA. Effect of age on the processing and import of matrix-destined mitochondrial proteins in skeletal muscle. J Gerontol A Biol Sci Med Sci 65: 138-146.

15. Huttemann M, Lee I, Pecinova A, Pecina P, Przyklenk K, and Doan JW. Regulation of oxidative phosphorylation, the mitochondrial membrane potential, and their role in human disease. J Bioenerg Biomembr 40: 445-456, 2008.

16. Javadov S, Karmazyn M, and Escobales N. Mitochondrial permeability transition pore opening as a promising therapeutic target in cardiac diseases. J Pharmacol Exp Ther 330: 670-678, 2009.

17. Judge S, Jang YM, Smith A, Hagen T, and Leeuwenburgh C. Age-associated increases in oxidative stress and antioxidant enzyme activities in cardiac interfibrillar mitochondria: implications for the mitochondrial theory of aging. FASEB J 19: 419-421, 2005. 
18. Jullig M, Hickey AJ, Middleditch MJ, Crossman DJ, Lee SC, and Cooper GJ. Characterization of proteomic changes in cardiac mitochondria in streptozotocin-diabetic rats using iTRAQ isobaric tags. Proteomics Clin Appl 1: 565-576, 2007.

19. Krayl M, Lim JH, Martin F, Guiard B, and Voos W. A cooperative action of the ATP-dependent import motor complex and the inner membrane potential drives mitochondrial preprotein import. Mol Cell Biol 27: 411-425, 2007.

20. Lesnefsky EJ, Chen Q, Slabe TJ, Stoll MS, Minkler PE, Hassan MO, Tandler B, and Hoppel CL. Ischemia, rather than reperfusion, inhibits respiration through cytochrome oxidase in the isolated, perfused rabbit heart: role of cardiolipin. Am J Physiol Heart Circ Physiol 287: H258-267, 2004.

21. Lesnefsky EJ, Gudz TI, Moghaddas S, Migita CT, Ikeda-Saito M, Turkaly PJ, and Hoppel CL. Aging decreases electron transport complex III activity in heart interfibrillar mitochondria by alteration of the cytochrome c binding site. J Mol Cell Cardiol 33: 37-47, 2001.

22. Lesnefsky EJ, Slabe TJ, Stoll MS, Minkler PE, and Hoppel CL. Myocardial ischemia selectively depletes cardiolipin in rabbit heart subsarcolemmal mitochondria. Am J Physiol Heart Circ Physiol 280: H2770-2778, 2001.

23. Li G, Chen S, Thompson MN, and Greenberg ML. New insights into the regulation of cardiolipin biosynthesis in yeast: implications for Barth syndrome. Biochim Biophys Acta 1771: 432-441, 2007.

24. Liu J, Tang $\mathbf{M}$, Mestril R, and Wang $\mathbf{X}$. Aberrant protein aggregation is essential for a mutant desmin to impair the proteolytic function of the ubiquitin-proteasome system in cardiomyocytes. $J \mathrm{Mol}$ Cell Cardiol 40: 451-454, 2006.

25. Liu Z, Miers WR, Wei L, and Barrett EJ. The ubiquitin-proteasome proteolytic pathway in heart vs skeletal muscle: effects of acute diabetes. Biochem Biophys Res Commun 276: 1255-1260, 2000.

26. Lu J and Holmgren A. Selenoproteins. J Biol Chem 284: 723-727, 2009. 
27. Magenta A, Cencioni C, Fasanaro P, Zaccagnini G, Greco S, Sarra-Ferraris G, Antonini A, Martelli F, and Capogrossi MC. miR-200c is upregulated by oxidative stress and induces endothelial cell apoptosis and senescence via ZEB1 inhibition. Cell Death Differ 18: 1628-1639.

28. Mateescu B, Batista L, Cardon M, Gruosso T, de Feraudy Y, Mariani O, Nicolas A, Meyniel JP, Cottu P, Sastre-Garau X, and Mechta-Grigoriou F. miR-141 and miR-200a act on ovarian tumorigenesis by controlling oxidative stress response. Nat Med 17: 1627-1635.

29. Mayr JA, Merkel O, Kohlwein SD, Gebhardt BR, Bohles H, Fotschl U, Koch J, Jaksch M, Lochmuller H, Horvath R, Freisinger P, and Sperl W. Mitochondrial phosphate-carrier deficiency: a novel disorder of oxidative phosphorylation. Am J Hum Genet 80: 478-484, 2007.

30. Mayr JA, Zimmermann FA, Horvath R, Schneider HC, Schoser B, Holinski-Feder E, Czermin B, Freisinger $\mathbf{P}$, and Sperl W. Deficiency of the mitochondrial phosphate carrier presenting as myopathy and cardiomyopathy in a family with three affected children. Neuromuscul Disord 21: 803-808.

31. Neupert W and Brunner M. The protein import motor of mitochondria. Nat Rev Mol Cell Biol 3: 555-565, 2002.

32. Pfanner $\mathbf{N}$ and Geissler A. Versatility of the mitochondrial protein import machinery. Nat Rev Mol Cell Biol 2: 339-349, 2001.

33. Ritov VB, Menshikova EV, He J, Ferrell RE, Goodpaster BH, and Kelley DE. Deficiency of subsarcolemmal mitochondria in obesity and type 2 diabetes. Diabetes 54: 8-14, 2005.

34. Rolo AP and Palmeira CM. Diabetes and mitochondrial function: role of hyperglycemia and oxidative stress. Toxicol Appl Pharmacol 212: 167-178, 2006.

35. Santos DL, Palmeira CM, Seica R, Dias J, Mesquita J, Moreno AJ, and Santos MS. Diabetes and mitochondrial oxidative stress: a study using heart mitochondria from the diabetic Goto-Kakizaki rat. Mol Cell Biochem 246: 163-170, 2003. 
36. Shen X, Zheng S, Thongboonkerd V, Xu M, Pierce WM, Jr., Klein JB, and Epstein PN. Cardiac mitochondrial damage and biogenesis in a chronic model of type 1 diabetes. Am J Physiol Endocrinol Metab 287: E896-905, 2004.

37. Shimura H, Hattori N, Kubo S, Mizuno Y, Asakawa S, Minoshima S, Shimizu N, Iwai K, Chiba T, Tanaka K, and Suzuki T. Familial Parkinson disease gene product, parkin, is a ubiquitin-protein ligase. Nat Genet 25: 302-305, 2000.

38. Stojanovski D, Johnston AJ, Streimann I, Hoogenraad NJ, and Ryan MT. Import of nuclearencoded proteins into mitochondria. Exp Physiol 88: 57-64, 2003.

39. Strub A, Rottgers K, and Voos W. The Hsp70 peptide-binding domain determines the interaction of the ATPase domain with Tim44 in mitochondria. EMBO J 21: 2626-2635, 2002.

40. Thomas JP, Maiorino M, Ursini F, and Girotti AW. Protective action of phospholipid hydroperoxide glutathione peroxidase against membrane-damaging lipid peroxidation. In situ reduction of phospholipid and cholesterol hydroperoxides. J Biol Chem 265: 454-461, 1990.

41. Turko IV and Murad F. Quantitative protein profiling in heart mitochondria from diabetic rats. J Biol Chem 278: 35844-35849, 2003.

42. Ursini F, Maiorino M, Brigelius-Flohe R, Aumann KD, Roveri A, Schomburg D, and Flohe L. Diversity of glutathione peroxidases. Methods Enzymol 252: 38-53, 1995.

43. van Rooij E, Marshall WS, and Olson EN. Toward microRNA-based therapeutics for heart disease: the sense in antisense. Circ Res 103: 919-928, 2008.

44. van Rooij E and Olson EN. MicroRNAs: powerful new regulators of heart disease and provocative therapeutic targets. J Clin Invest 117: 2369-2376, 2007.

45. van Rooij E, Sutherland LB, Qi X, Richardson JA, Hill J, and Olson EN. Control of stressdependent cardiac growth and gene expression by a microRNA. Science 316: 575-579, 2007. 
46. Voisine C, Craig EA, Zufall N, von Ahsen O, Pfanner N, and Voos W. The protein import motor of mitochondria: unfolding and trapping of preproteins are distinct and separable functions of matrix Hsp70. Cell 97: 565-574, 1999.

47. Williamson CL, Dabkowski ER, Baseler WA, Croston TL, Alway SE, and Hollander JM. Enhanced apoptotic propensity in diabetic cardiac mitochondria: influence of subcellular spatial location. Am J Physiol Heart Circ Physiol 298: H633-642.

48. Williamson CL, Dabkowski ER, Dillmann WH, and Hollander JM. Mitochondria protection from hypoxia/reoxygenation injury with mitochondria heat shock protein 70 overexpression. Am J Physiol Heart Circ Physiol 294: H249-256, 2008. 


\section{Chapter 6:}

\section{Future Directions}




\section{FUTURE DIRECTIONS}

Although much headway has been made concerning the evaluation of type 1 diabetes mellitus on the nuclear-encoded mitochondrial protein import processes within this dissertation, there are still many questions that remained to be answered. Most notably, our evaluation of the import process only analyzed matrix-associated mitochondrial protein import. Among the many reasons for this was because MtHsp70, shown to be deficient within diabetic IFM, is absolutely essential for matrix preprotein import into mitochondria. MtHsp70 is also known to influence IMM and IMS transport, albeit to a lesser extent. Though import into other areas of the mitochondria (IMM, IMS, and OMM) are seemingly more complicated and much less defined within the literature, we have created novel plasmid constructs designed specifically to allow us to analyze protein import efficiency into the other subcompartments of the mitochondria.

IMM protein import uses the TIM23 complex in a similar fashion to matrix import. However, these proteins contain a C-terminal hydrophobic region that locks the protein into the pore. Through a controversial mechanism, these proteins are then laterally sorted into the IMM (3). Similar to matrix preproteins, these proteins also contain N-terminal presequences, which are subsequently removed once properly inserted into the inner membrane. OMM proteins must enter through the TOM40 pore and with the help of small IMS translocases, reinsert themselves into the OMM using the sorting and assembly machinery (SAM) complex (3). It is important to note that OMM proteins do not contain N-terminal presequences. Experimentally, we cloned known proteins that reside within each submitochondrial location into an expression vector, expressed the protein using a reticulocyte lysate system and imported the proteins into their respective subcompartments. The specific proteins used for each subcompartment are described below: 
1. Matrix - TCA cycle enzyme, MDH2

2. IMM - Complex I protein, NDUFS3

3. OMM - OMM translocase, TOM22

As shown in Fig 6.1, we were able to successfully import each protein into isolated mitochondria. Within figure $6.1, \mathrm{~L}=$ protein lysate, $\mathrm{M}=$ isolated mitochondria, $\mathrm{L}+\mathrm{M}=$ protein lysate added to mitochondria. In order to confirm each specific protein reached their anticipated destinations, we imported the proteins into mitochondria, subfractioned the mitochondria, and then confirmed the protein resided in the correct subfraction through Western blot analyses. Mitochondrial IMS protein import was not analyzed because the exact mechanism of import has yet to be properly identified.

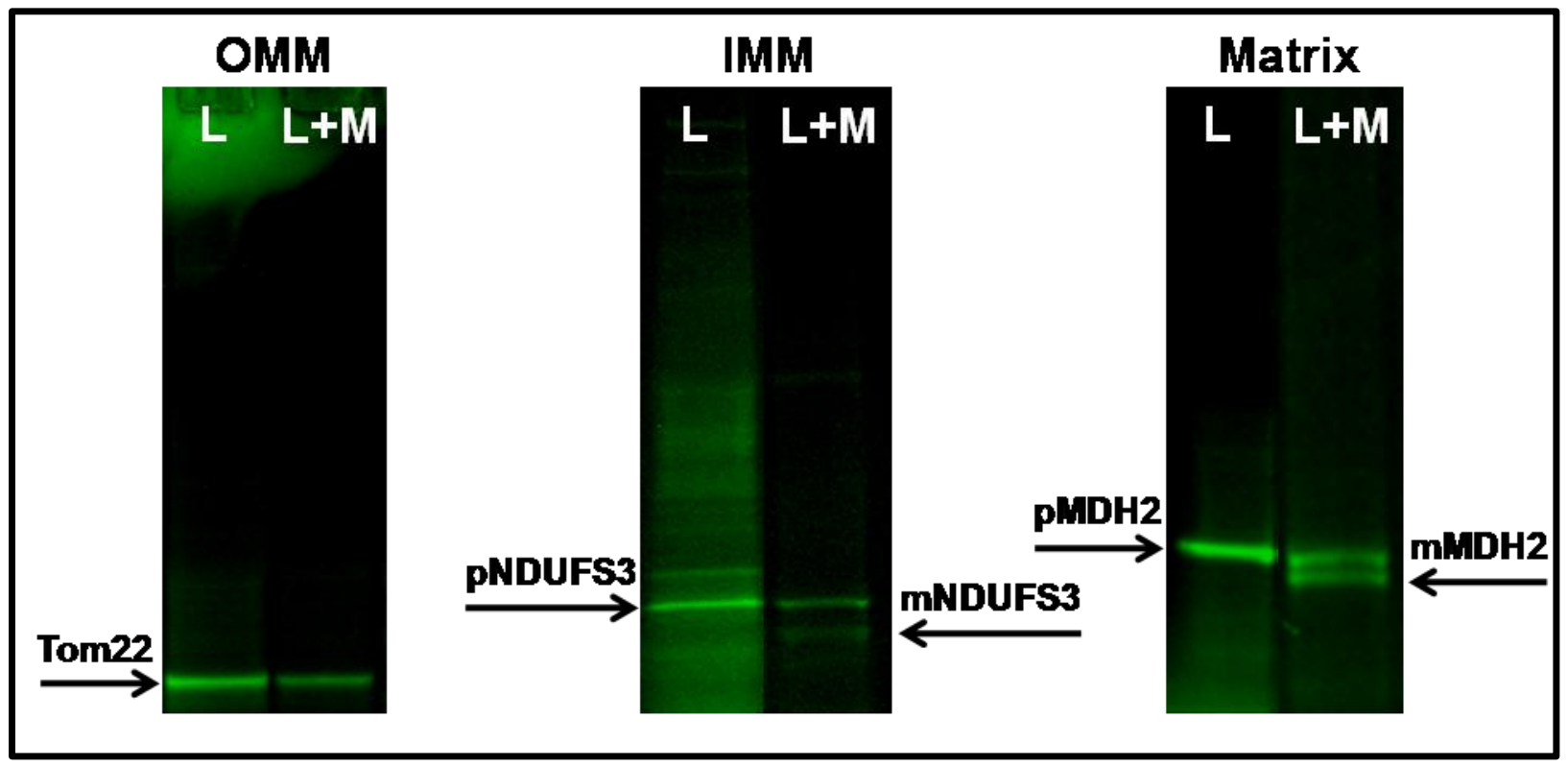

Figure 6.1. Mitochondrial protein import into the OMM, IMM, and Matrix.

Pertaining to future directions, the most obvious first step is to analyze the import of these proteins within type 1 diabetic mitochondrial subpopulations. Previous research from our laboratory has shown the IMM of IFM to be a primary site of dysfunction during a diabetic 
insult. Specifically, our results revealed decreased mitochondrial respiration correlating with decreased ETC complex activities (complex I, III, and IV) and decrements to ATP synthase activity. Further, proteomic analyses (Chapter 2 and 3) revealed that of all the dysregulated proteins within the diabetic IFM, over $50 \%$ were of IMM origin. Additionally, significant decreases in numerous ETC and ATP synthase proteins were evident, further validating the detrimental influence diabetes mellitus has upon the IMM of IFM. Examining the impact diabetes mellitus has upon IMM protein import may reveal a novel mechanism of dysfunction within this key submitochondrial region. Although we have not closely examined the influence diabetes mellitus has upon OMM proteins/protein complexes, many critical receptors (Tom20, Tom22) and channels (Tom40, VDAC) exist that are essential for proper mitochondrial functionality and viability. Insight into OMM protein import mechanics would be a critical first step in elucidating potential negative effects within this relatively understudied mitochondrial locale.

The research conducted in Chapter 3 highlighted the beneficial effect antioxidant mPHGPx had upon the mitochondrial proteome. Because we believe nuclear-encoded mitochondrial protein import efficiency is directly linked to mitochondrial proteomic homeostasis, we launched a full investigation to determine whether mPHGPx overexpression influenced protein import mechanics. Interestingly, much of the data presented highlighted the absolute impact MtHsp70 had upon matrix-associated protein import. Decrements or preservation of this critical protein directly correlated with the functionality of the mitochondrial import process (Chapter 2 and 3). Therefore one of the long term studies proposed within the laboratory is to determine the therapeutic effect of MtHsp70 transgenic overexpression on the diabetic heart. To accomplish this goal, I inserted human MTHSP70 into transgenic plasmid construct pCAGGS (Fig 6.2). We 
used this plasmid to create an MtHsp70 transgenic mouse line through pronuclear injection. Finally, genotypic (RTQ-PCR) and phenotypic (Western blot) experimentation was performed to confirm MtHsp70 overexpression within the mouse.

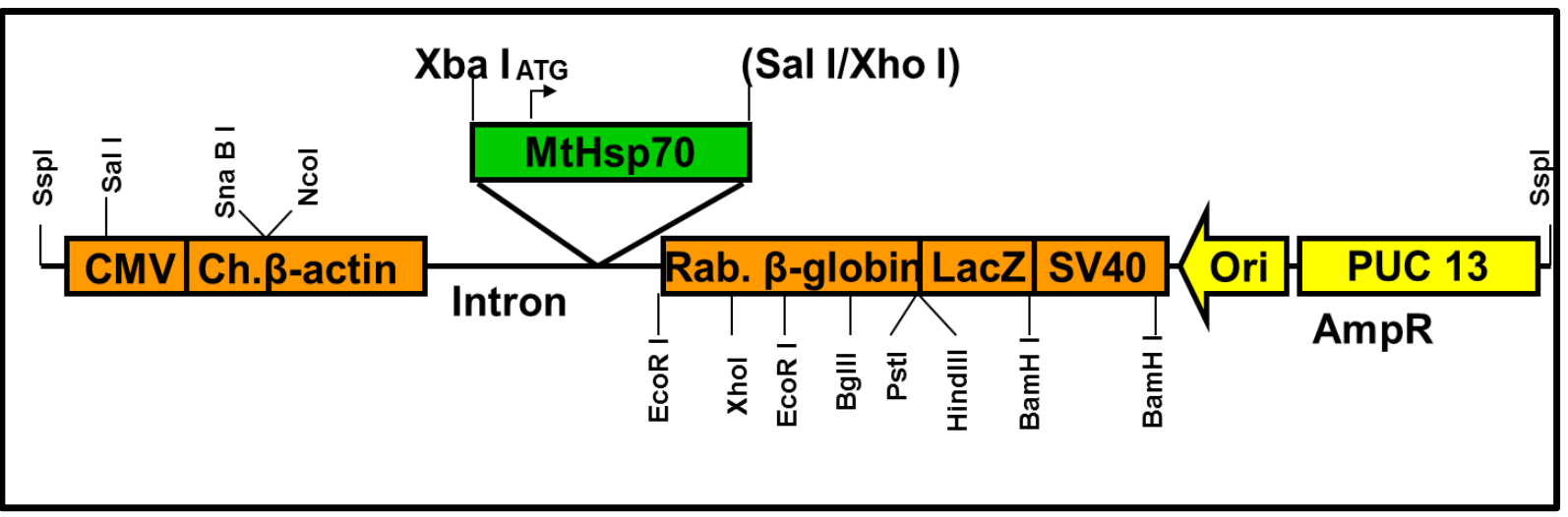

Figure 6.2. MtHsp70 transgenic construct

Through overexpression of MtHsp70, future researchers will be able to critically evaluate the role that both MtHsp70 and protein import has upon cardiac and mitochondrial functionality during a diabetic insult. Methodologies conducted in Chapter's 2 and 3 of this dissertation, as well as in this future directions section can serve as an experimental jumping point to begin to answer some of these critical questions. A topic currently being debated within the scientific community is the exact role MtHsp70 has pertaining to protein import into this key submitochondrial locale. Specifically, conflicting reports exist debating the extent MtHsp70 facilitates IMM protein import. Proteomic analyses evaluating IMM protein content derived from MtHsp70 overexpressing animals would help to elucidate whether MtHsp70 has a critical role in IMM protein import.

Interestingly, MtHsp70 has been shown to have additional functions within mitochondria beyond assisting with protein import into the matrix, which includes aiding in the folding of proteins into their mature form or helping in the degradation of dysfunctional proteins. Studies 
designed to analyze the impact pathologies, such as diabetes mellitus, have upon these lesser studied mitochondrial processes as well as the potential protective effects MtHsp70 overexpression elicits could all be explored in the immediate future.

Finally, the miRNA analyses within this dissertation were a definite step in the right direction in understanding how the mitochondrial proteome can be impacted by these small transcriptional/translational regulators. However, the results were compiled analyzing total heart tissue from control and diabetic mice. Most recently, literature has suggested that miRNAs potentially reside within the mitochondrion. From these manuscripts, it is clearly evident miRNAs are able to be isolated from liver mitochondria. However, why miRNA exist within the organelle is currently unknown $(1,2)$. The most logical explanation would be that these miRNAs modulate transcription/translation of the mitochondrial genome. Researchers have also speculated that mitochondria can potentially serve as reservoirs for miRNAs, expelling them under certain physiological or pathological conditions (1). Giving credence to such claims, use of bioinformatics approaches such as MiRanda and TargetScan algorithms determined mitochondrial miRNAs are likely involved in regulation of apoptosis, cell proliferation, and differentiation. However, solid evidence pertaining to mitochondrial miRNA functionality remains limited.

We have undertaken preliminary studies in which we examined miRNAs within cardiac mitochondrial subpopulations and analyzed the effect diabetes mellitus has upon mitochondrial miRNA modulation. As shown in Fig 6.3, not only was a distinct subpopulation of miRNA present within cardiac SSM and IFM, but diabetes had a completely opposite effect upon their miRNA makeup. Remarkably, in general, miRNAs were significantly reduced in the diabetic 
IFM whereas diabetic SSM had significant increases in miRNA content. Red indicates a significant increase in the miRNA, green indicates a significant decrease diabetic IFM.

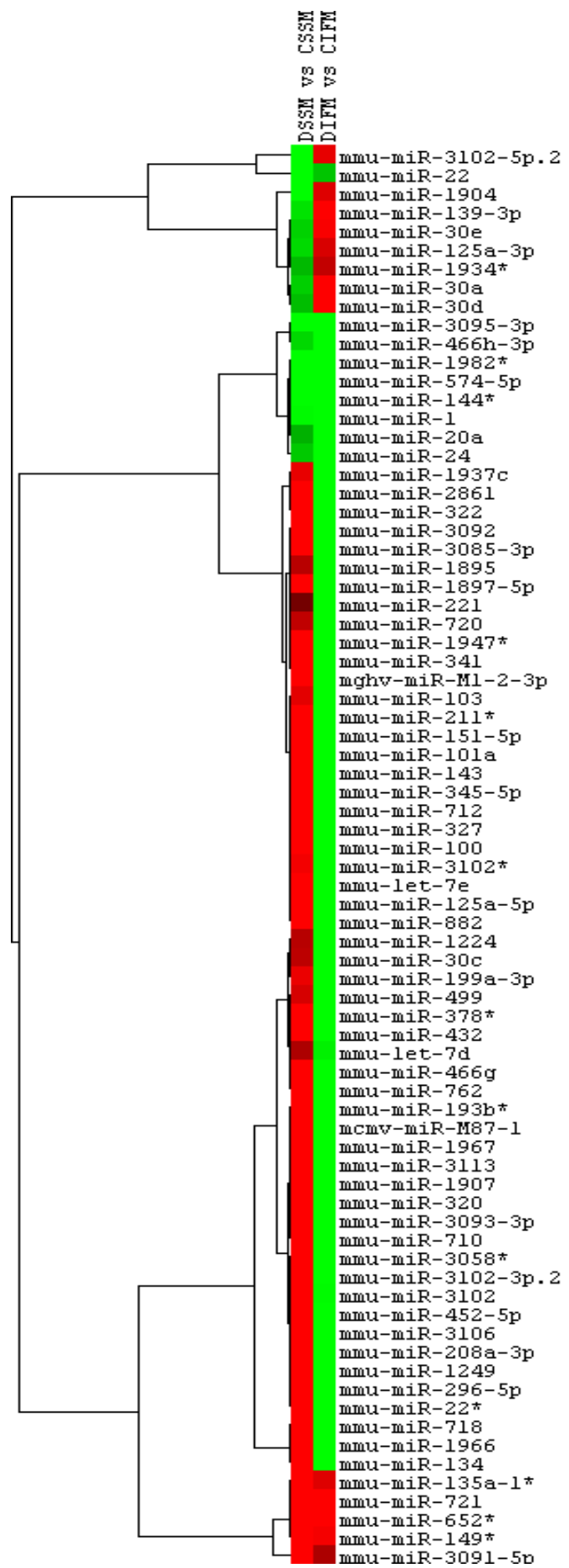

Figure 6.3 Mitochondrial miRNAs impacted by diabetes mellitus 
This preliminary data indicates for the first time that cardiac mitochondria possess a distinct mitochondrial subpopulation and miRNAs within mitochondrial subpopulations are differentially impacted by diabetes mellitus. Future directions within our laboratory would be to identify why miRNAs exist within cardiac mitochondria. Further, elucidating why miRNAs are dysregulated within the diabetic mitochondrial subpopulations is absolutely essential. We have begun to evaluate the impact of the mitochondrial miRNA subpopulation upon the mitochondrial genome and we believe this is a good start in understanding why these miRNA exist within mitochondria. Fig. 6.4 is a map of the mitochondrial genome and indicates potential miRNA binding partners within SSM and IFM subpopulations that may influence mitochondrial-encoded protein generation. A red line indicates a miRNA that is upregulated in diabetes mellitus and green lines indicates a miRNA that is downregulated in diabetes mellitus.



Figure 6.4. Mitochondrial miRNAs and their impact on the mitochondrial genome 
Future research in context to the preliminary miRNA data presented in this section could elucidate a novel mechanism of mitochondrial genomic regulation within the mitochondria. As stated above, it is also possible for mitochondria to act as holding chambers for cytoplasmic miRNAs. It could be speculated that opening or rupturing of the mitochondria would cause miRNA to efflux out of the damaged organelle. Interestingly, diabetic IFM have an increased propensity for mPTP opening, which coincides with decreased miRNA content as shown above. Therefore, increased mitochondrial pore opening may be a plausible mechanism as to why we see decreased miRNA within this select subpopulation. Experimentation concerning the influence of membrane stability on mitochondrial miRNA content should be examined in the future. In summary, findings derived from a study such as this has the potential to be highly impactful within scientific community and may lead to the identification of novel roles that both miRNA and mitochondria play in various physiological and pathological conditions. 


\section{REFERENCES}

1. Bian Z, Li LM, Tang R, Hou DX, Chen X, Zhang CY, and Zen K. Identification of mouse liver mitochondria-associated miRNAs and their potential biological functions. Cell Res 20: 1076-1078.

2. Kren BT, Wong PY, Sarver A, Zhang $\mathbf{X}$, Zeng $\mathrm{Y}$, and Steer CJ. MicroRNAs identified in highly purified liver-derived mitochondria may play a role in apoptosis. RNA Biol 6: 65-72, 2009.

3. Wiedemann N, Frazier AE, and Pfanner N. The protein import machinery of mitochondria. J Biol Chem 279: 14473-14476, 2004. 


\section{Chapter 7:}

Appendix 
Fig 7.1

A

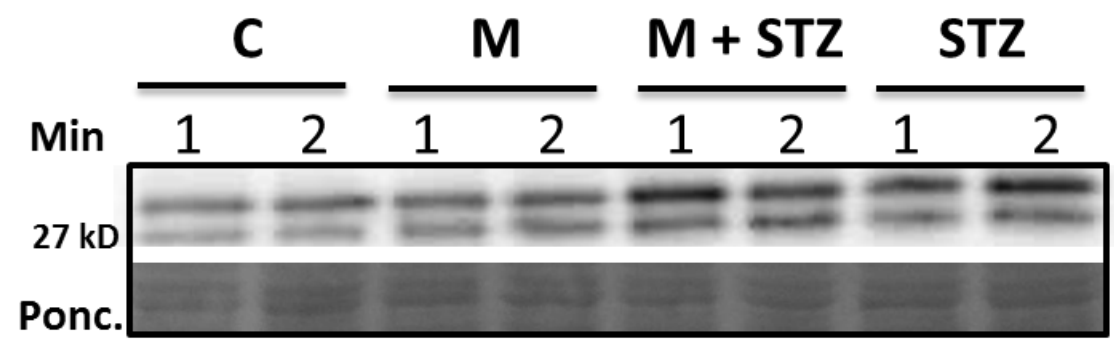

B

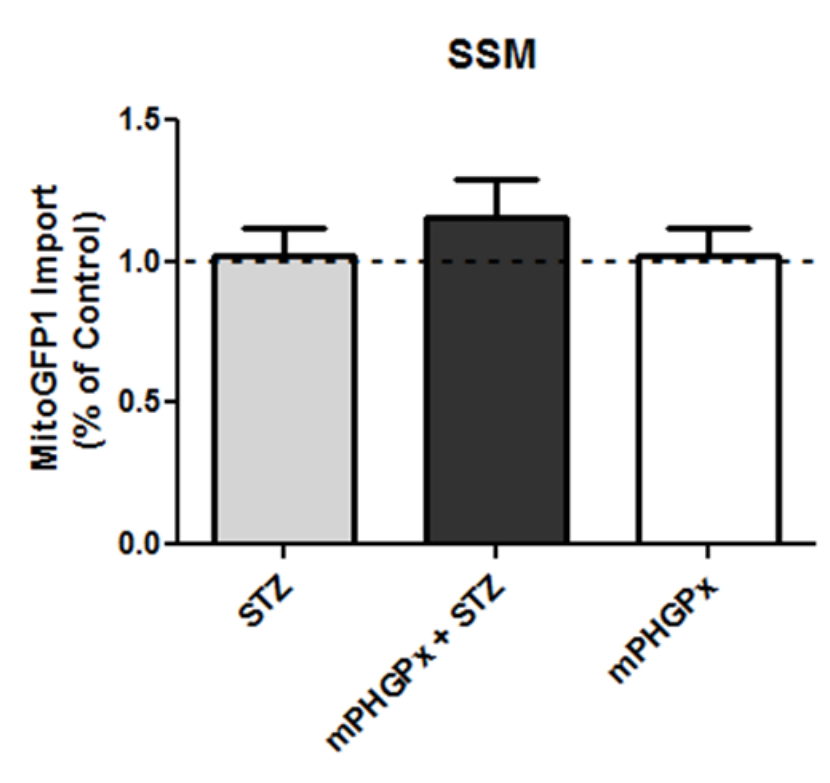


Figure 7.1. Mitochondrial protein import. Effect of type 1 diabetes mellitus and mPHGPx overexpression on MitoGFP1 import in SSM. Cardiac mitochondrial subpopulations from control, diabetic, mPHGPx, and diabetic mPHGPx mice were isolated and incubated with $2 \mu 1$ of MitoGFP1 protein lysate at 1 and 2 minute time points. Representative Western blots from SSM (A) protein import assay. Graphical representation of mitochondrial protein import performed in control (C), diabetic (STZ), mPHGPx (M), and diabetic mPHGPx IFM (M + STZ) (B). The relative amount of imported MitoGFP1 was determined by densitometry. Dashed line denotes control levels. Import efficiency was based off of percent control at the 1 and 2 minute time points. Both time point percentages were then averaged to show total import efficiency. Control for protein loading was confirmed by Ponceau staining. Values are presented as means $\pm \mathrm{SE}$. $\mathrm{N}=5$ per group. 


\section{Fig 7.2}
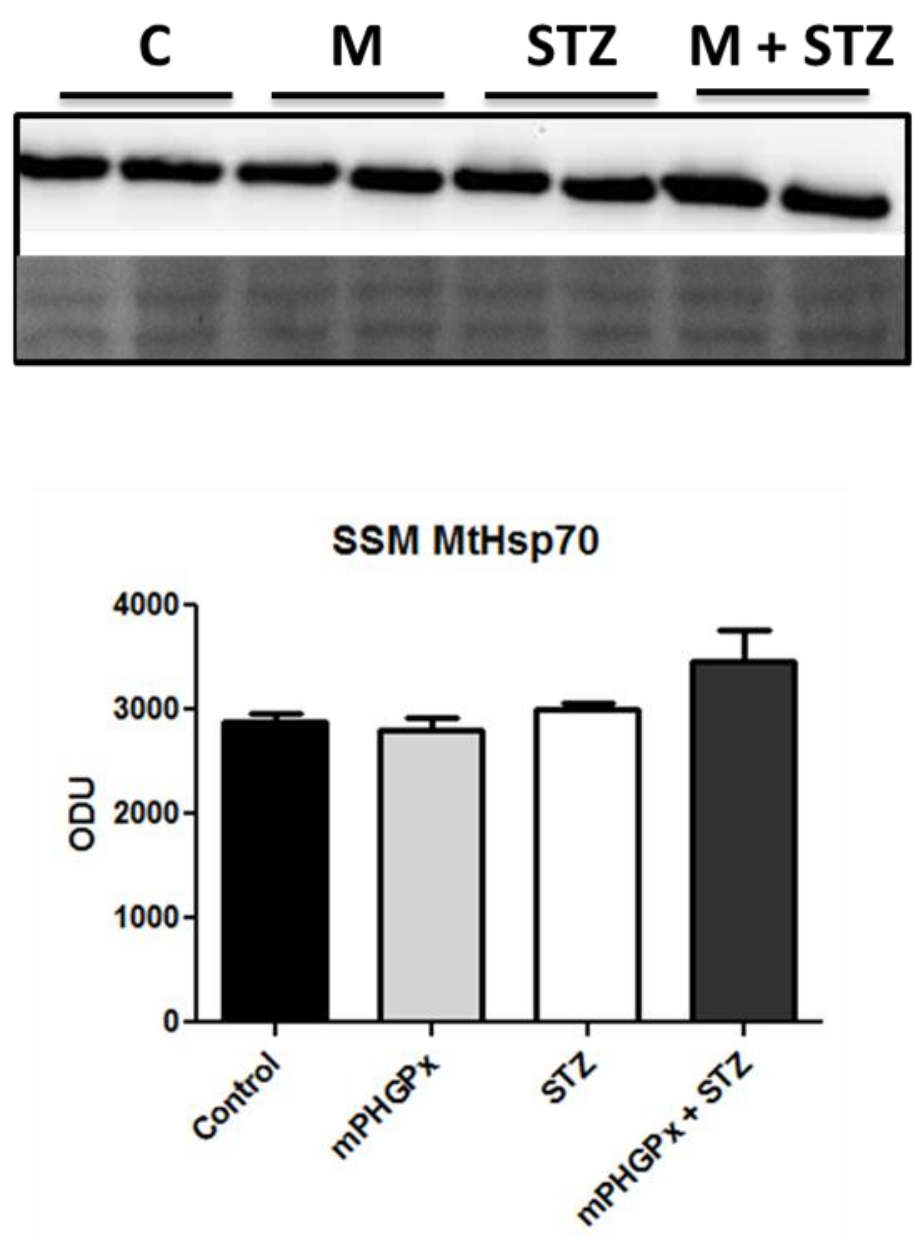
Figure 7.2. MtHsp70 content. Western blot analysis of protein import constituent MtHsp70 in control (C), mPHGPx (M), diabetic (STZ) and diabetic MPHGPx (M + STZ) SSM. Control for protein loading was confirmed by Ponceau staining. Values are presented as means $\pm \mathrm{SE}$; $\mathrm{P}<$ 0.07 for SSM mPHGPx + STZ vs. all groups; N=4 per group. 
Fig 7.3

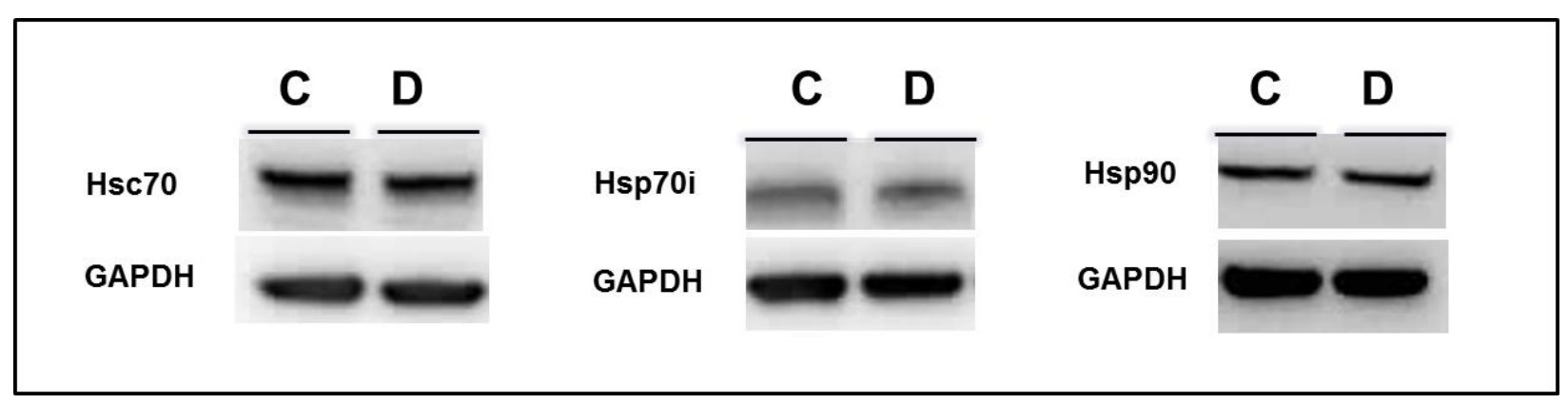


Figure 7.3. Cytoplasmic Chaperones. Western blot analysis of cytoplasmic chaperones involved mitochondrial preprotein translocation (Hsc70, Hsp70i, and Hsp90) from control and diabetic cytoplasm. Values are presented as means $\pm \mathrm{SE}$; Control for protein loading was confirmed with GAPDH. $\mathrm{N}=4$ per group. 


\section{Fig 7.4}

A

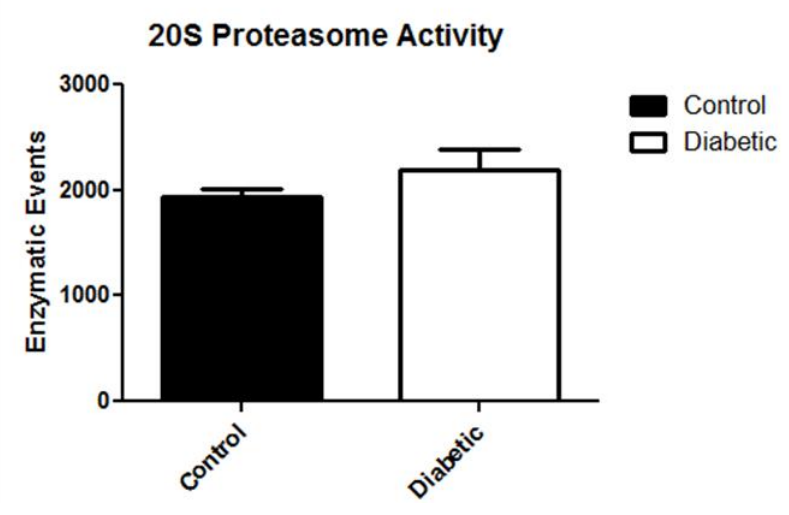

B

$\alpha$ and $\beta$ 20S Proteasome Subunits

$\begin{array}{lll}\alpha+\beta \text { 20S } & \text { Control Diabetic } \\ \text { GAPDH } & \\ & \end{array}$


Figure 7.4. Proteosomal analysis. Effect of type 1 diabetes mellitus on proteosomal abundance and activity within the cytoplasm. 20S proteosomal activity was measured fluorometrically in control and diabetic cytoplasm (A). Data was expressed as enzymatic events. Western blot analyses of $\alpha$ and $\beta$ subunits of the 20S proteasome in the cytoplasm of control and diabetic samples containing $30 \mu \mathrm{g}$ of protein (B). Control for protein loading was confirmed with GAPDH. Values are presented as means \pm SE. $N=4$ per group. 


\section{Permission to Reproduce Copyrighted}

Materials 


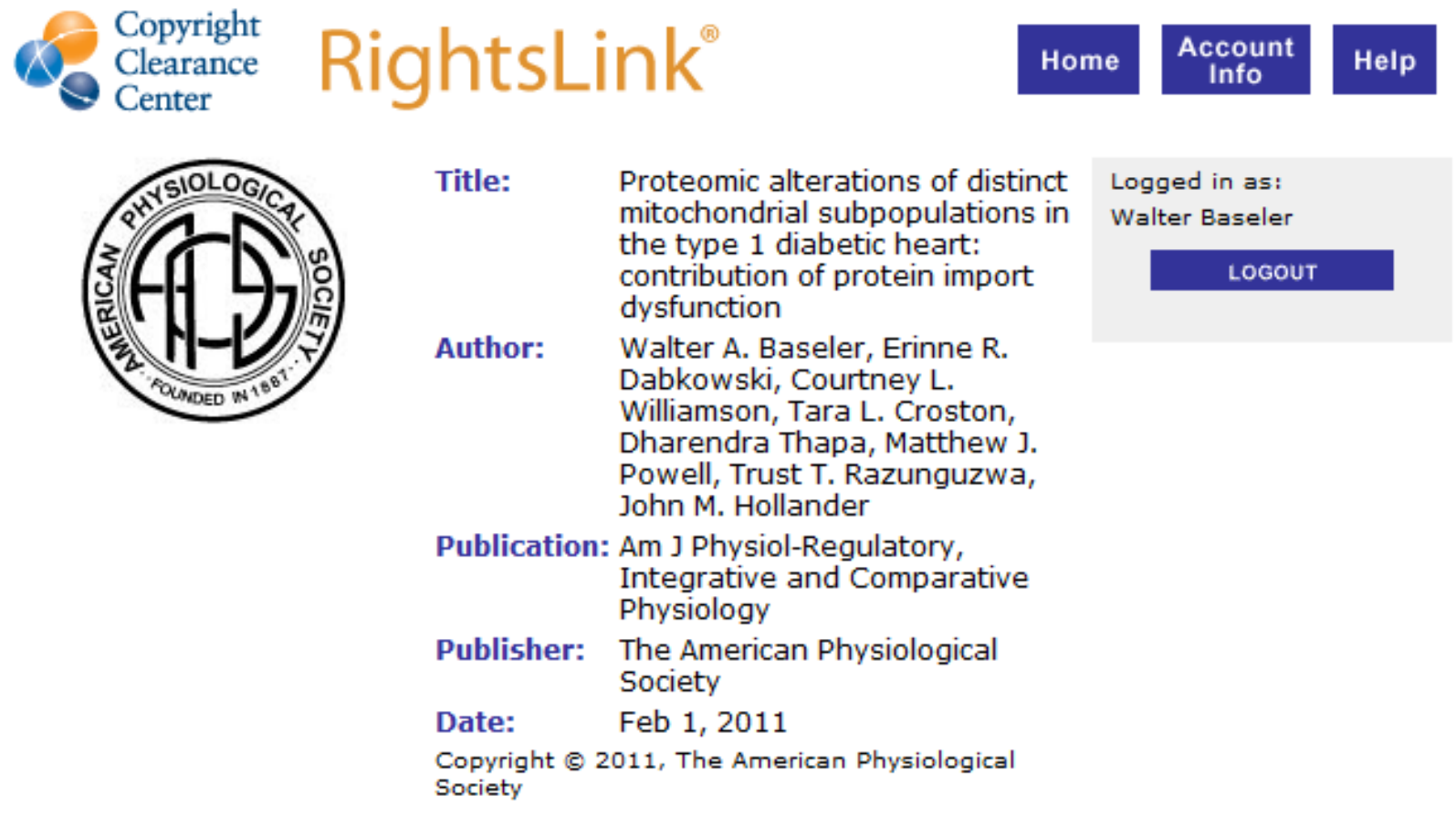

\section{Permission Not Required}

Permission is not required for this type of use.

\section{BACK}

CLOSE WINDOW

Copyright (9) 2012 Copyright Clearance Center, Inc, All Rights Reserved. Privacy statement.

Comments? We would like to hear from you. E-mail us at customercare@copyriqht.com 


\title{
CURRICULUM VITAE
}

\author{
Walter A. Baseler
}

\section{OFFICE ADDRESS}

Division of Exercise Physiology and

Center for Cardiovascular and

Respiratory Sciences

West Virginia School of Medicine

P.O. Box 9227

Morgantown, WV 26506

Tel: (304) 293-7311

Fax: (304) 293-7105

Email:wbaseler@hsc.wvu.edu

\section{$\underline{\text { EDUCATION }}$}

Feb 2012

Ph.D. Candidate, Exercise Physiology

Biomedical Sciences, Division of Exercise Physiology

West Virginia University School of Medicine

May 2005

Bachelor of Science, Microbiology

Department of Microbiology 


\section{University of Maryland, College Park}

\section{DISSERTATION}

Examination of Novel Cardiac Mechanisms Influencing Mitochondrial Proteomes during

Diabetes Mellitus

Director: John Hollander

Committee Members: Stephen Alway, Robert Brock, Kathy Brundage, Michael Morissette, Emidio Pistilli

\section{HONORS AND FELLOWSHIPS}

2010

2010

2009-2010

2009
American Heart Association Predoctoral Fellowship Recipient

$1^{\text {st }}$ Place Poster Presentation, Van Liere Convocation

West Virginia University

Selected Trainee on NIH Predoctoral Training

Grant in Cardiovascular and Pulmonary Diseases (T32)

West Virginia University School of Medicine

Biomedical Sciences Travel Award 


\section{POSITIONS HELD}

Search Committee Member for Assistant Director of Graduate

Education for West Virginia University Health Science Center

2010

Exercise Physiology Student Representative for Vice President of Graduate Studies Search at West Virginia University

2010

Van Liere Student Advisory Committee Member Responsible for Recruitment of Guest Speaker (Dr. Kenneth Chien)

\section{TEACHING EXPERIENCE}

2009-2011

Moderator. Cell Structure and Metabolism (BMS 705).

West Virginia University

2007

Teaching Assistant. Microbiology (MICB 323).

West Virginia University

2006

Teaching Assistant. Immunity, Infection, and

Disease (MICB 701). West Virginia University

\section{PROFESSIONAL SOCIETIES}


2009-Present

2009-Present

2007-2009
American College of Sports Medicine

American Physiological Society

American Gastroenterological Association

\section{PUBLICATIONS}

Articles

Baseler W.A., Thapa D, Jagannathan R., Dabkowski E.R., and Hollander J.M.. miRNA-141 is a Potential Regulator of Mitochondrial Phosphate Carrier (Slc25a3) in the Type 1 Diabetic Heart. In Preparation (2012)

Baseler W.A., Dabkowski E.R., Thapa D, Nichols C.E., Shepherd D.L., Croston T.L., Powell M.J., Razunguzwa T.T., Hollander J.M. Mitochondria-Specific Transgenic Overexpression of Phospholipid Hydroperoxide Glutathione Peroxidase (GPx4) Attenuates Cardiac Mitochondrial Proteomic Loss and Reverses Protein Import Detriments Observed in Type 1 Diabetes Mellitus. In Preparation (2012)

Dabkowski E.R., Baseler W.A. Shepherd D.L., Croston T.L., Williamson C.L., Thapa D., Nichols C.E., Hollander J.M. Mitochondrial Overexpression of Phospholipid Hydroperoxide 
Glutathione Peroxidase 4 (mPHGPx) Provides Cardioprotection from Type 1 Diabetes Mellitus Insult. Antioxidants and Redox Signaling. Submitted (2011)

Chen F., Lewis W., Hollander J.M., Baseler W.A., Finkel M.S. N-Acetylcysteine Reverses Cardiac Myocyte Dysfunction in HIV-Tat Proteinopathy. Am J Physiol Heart Circ Physiol. Submitted (2011)

Kekuda R., Manoharan P., Baseler W.A., Sundaram, U. Monocarboxylate 4 (Slc16a3) Rather than 1 (Slc16a1) is the Primary Butyrate Transporter in the Rat Intestinal Epithelial Cell Line IEC-18. Journal of Pharmacology and Experimental Therapeutics. Submitted (2011)

Baseler W.A., Croston T.L., Hollander J.M. Chapter 4; Functional Characteristics of Mortalin. In Kaul S. (Ed) Mortalin Biology- Stress, Life and Death. Springer Science. 2012 Apr. ISBN 978-94-007-3026-7

Hollander J.M, Baseler W.A., Dabkowski E.R. Proteomic Remodeling of Mitochondria in Heart Failure. Congestive Heart Failure. 2011 Oct; doi: 10.1111/j.1751-7133.2011.00254.x

Baseler W.A., Dabkowski E.R., Williamson C.L., Croston T.L., Thapa D., Powell M.J., Razunguzwa T.T., Hollander J.M.. Proteomic Alterations of Distinct Mitochondrial Subpopulations in the Type 1 Diabetic Heart: Contribution of Protein Import Dysfunction. Am J Physiol Regul Integr Comp Physiol. 2011 Feb;300(2):R186-200. 
Dabkowski E.R., Baseler W.A., Williamson C.L., Powell M., Razunguzwa T.T., Frisbee J.C., Hollander J.M.. Mitochondrial Dysfunction in the Type 2 Diabetic Heart is Associated with Alterations in Spatially Distinct Mitochondrial Proteomes. Am J Physiol Heart Circ Physiol. 2010 Aug;299(2):H529-40.

Williamson, C.L., Dabkowski, E.R., Baseler, W.A., Croston, T.L., Alway, S.E., Hollander, J.M. Enhanced Apoptotic Propensity in Diabetic Cardiac Mitochondria: Influence of Subcellular Spatial Location. Am J Physiol Heart Circ Physiol, 2010 Feb;298(2):H633-42.

\section{Editorial Review}

Davidson, S.M. A needle in a haystack: focus on "Proteomic alterations of distinct mitochondrial subpopulations in the type 1 diabetic heart". Am J Physiol Regul Integr Comp Physiol. 2011 Feb;300(2):R183-5.

Abstracts

Baseler W.A, Dabkowski E.R, Thapa D., Croston T.L., Williamson C.L, Hollander J.M. Proteomic Alterations of Distinct Mitochondrial Subpopulations in the Type 1 Diabetic Heart: Contribution of Protein Import Dysfunction. FASEB J. 2011 D229 
Dabkowski, E.R, Baseler W.A., Croston T.L, Thapa D., Hollander J.M. Mitochondrial phospholipid hydroperoxide glutathione peroxidase overexpression preserves the inner mitochondrial membrane in the diabetic heart. FASEB J. 2011 A171

Croston TL, Baseler W.A., Thapa D, Lewis SE, Nurkiewicz TR, Yi J, Hollander JM. Influence of Nanoparticle Inhalation on Cardiac Mitochondrial Function FASEB J. 2011 25:lb561

Thapa D, Baseler W.A., Croston TL, Lewis SE, Hollander JM. Examination of microRNA (miRNA) dysregulation in the type 1 diabetic heart and its functional implications $F A S E B J$. $201125: l b 464$

Baseler W.A, Williamson C.L, Dabkowski E.R, Croston T.L, Hollander J.M. MitochondriaSpecific Overexpression of Phospholipid Hydroperoxide Glutathione Peroxidase (GPx4) Attenuates Ischemia/Reperfusion (I/R) Associated Apoptosis. FASEB J. 2010 24:1b560

Croston TL, Dabkowski ER, Williamson CL, Baseler WA, Hollander JM. Mitochondrial subpopulation-specific proteomic alterations in the type 2 diabetic heart. FASEB J. 2010 24:1b573

Dabkowski E.R, Baseler W.A, Croston T.L, Courtney Williamson C.L, Hollander J.M. Mitochondrial Overexpression of Phospholipid Hydroperoxide Glutathione Peroxidase 4 (mPHGPx) Provides Cardioprotection From Type 1 Diabetes Mellitus Insult. FASEB J. 2010 $24: 789.2$ 
Baseler W.A, Dabkowski E.R, Williamson C.L, Hollander J.M. Examination of Protein Import in Mitochondria Influenced by Diabetes Mellitus in the Heart. Van Liere Convocation, West Virginia University. 2010

Baseler W.A, Dabkowski E.R, Williamson C.L, Hollander J.M. Skeletal Muscle Mitochondrial Subpopulation Response in a Type 2 Diabetic Mouse Model. Van Liere Convocation, West Virginia University. 2009

Baseler W.A, Dabkowski E.R, Williamson C.L, Hollander J.M. Skeletal Muscle Mitochondrial Subpopulation Response in a Type 2 Diabetic Mouse Model. FASEB J. 2009 23:LB93

Baseler W.A, Kekuda R, Sundaram U. Identification of the $\mathrm{SCFA} / \mathrm{HCO}_{3}$ and $\mathrm{Cl}-$ $/ \mathrm{HCO}_{3}$ Transporters Affected During Chronic Inflammation in the Rabbit Ileum. Van Liere Convocation, West Virginia University. 2008

Manoharan P.K, Saha P, Baseler W.A, Sundaram U. Prostaglandins Regulate Cl:HCO3 but not Butyrate:HCO3 Exchanger in the Chronically Inflamed Rabbit Intestine. DDW 2007 Washington D.C. 2007

\section{GRANTS RECEIVED}

American Heart Association Predoctoral Fellowship

American Heart Association (10PRE3420006) 
"Examination of Protein Import in Mitochondria Influenced by Diabetes Mellitus in the Heart" Role: PI

Status: Scored: 1.5

Funded: July 1, 2010 - Present

The goal of the study is to determine if mitochondrial protein import is a mechanism of dysfunction within diabetic cardiomyopathy.

NIH Predoctoral Training Grant in Cardiovascular and Pulmonary Diseases (T32)

National Institute of Health (5T32HL090610-03)

Role: Predoctoral Trainee

Funded: July 1, 2009 - July 1, 2010

\section{REFERENCES}

1. John M. Hollander, Ph.D. Mentor, Associate Professor, Director of Graduate Studies, Division of Exercise Physiology, West Virginia University. 1 Medical Center Drive, PO Box 9227, Morgantown, WV 26506. Phone: 304-293-3683

Email: jhollander@hsc.wvu.edu

2. Steven Alway, Ph.D. Professor and Chair of Exercise Physiology, West Virginia University. 1 Medical Center Drive, PO Box 9227, Morgantown, WV 26506. Phone: 304-293-0772 Email: salway@hsc.wvu.edu 
3. S. Jamal Mustafa, Ph.D. Assistant Vice President for Research, Robert C. Byrd Professor, Professor of Physiology and Pharmacology and Basic Pharmaceutical Sciences, West Virginia University. 1 Medical Center Drive, PO Box 9104, Morgantown, WV 26506. Phone: 304-293-5803.

Email: smustafa@hsc.wvu.edu 